\title{
MECANISMOS DE CONFINAMENTO E SUAS IMPLICAÇÕES NO REFORÇO DE PILARES DE CONCRETO POR ENCAMISAMENTO COM COMPÓSITO DE FIBRAS DE CARBONO
}

\author{
Ricardo Carrazedo
}

Dissertação apresentada à Escola de Engenharia de São Carlos da Universidade de São Paulo como parte dos requisitos para obtenção do título de Mestre em Engenharia de Estruturas.

ORIENTADOR: Prof. Titular João Bento de Hanai

São Carlos

2002 
FOLHA DE JULGAMENTO

Candidato: Engenheiro RICARDO CARRAZEDO

Dissertação defendida e julgada em 25-04-2002 perante a Comissão Julgadora:

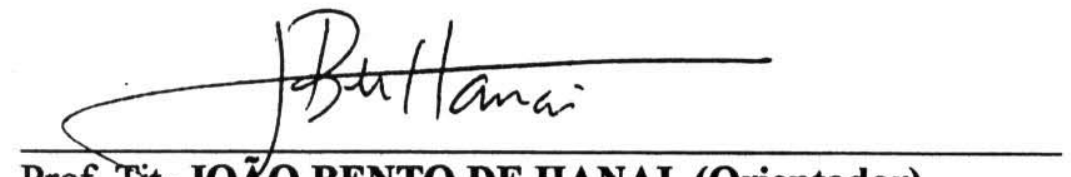

AprovapO

Prof. Tit: JOÃO BENTO DE HANAI (Orientador)

(Escola de Engenharia de São Carlos/USP)

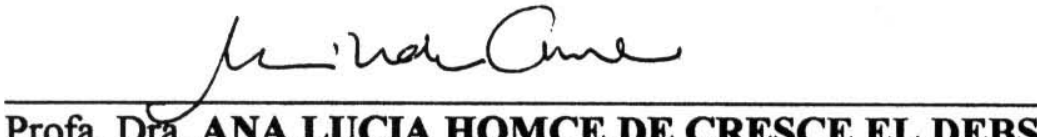

Aprovado

(Escola de Engenharia de São Carlos/USP)

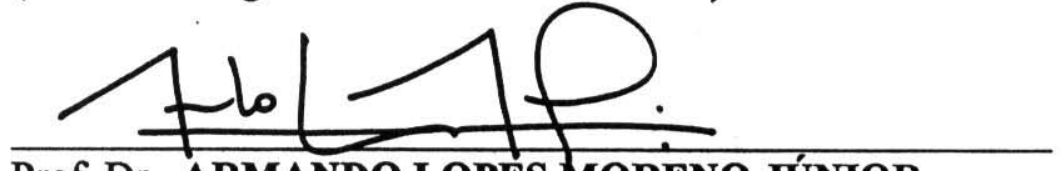

Prof. Dr. ARMANDO LOPES MORENO JÚNIOR

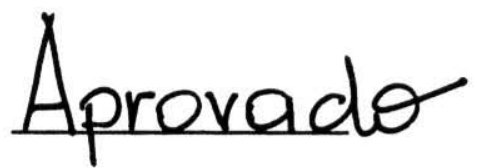

(Universidade Estadual de Campinas/UNICAMP)

$\frac{h .}{\text { Profa. Doutora ANA LÚCIA HOMCE DE CRESCE EL DEBS }}$

Coordenadora do Programa de Pós-Graduação em

Engenharia Civil (Engenharia de Estruturas)

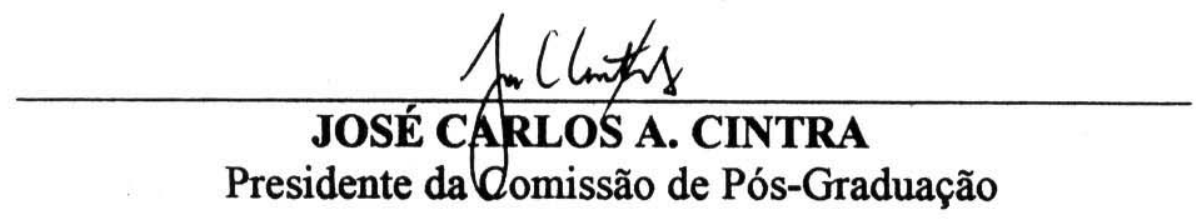


Aos meus pais e familiares. 


\section{AGRADECIMENTOS}

Ao Prof. João Bento de Hanai, pelo apoio e orientação no desenvolvimento deste trabalho.

Ao Eng $^{\circ}$ Adilson Roberto Takeuti pela inestimável colaboração na análise experimental e em outras etapas do trabalho.

Ao Prof. Humberto Correia Lima Jr. pelo incentivo desde o meu curso de graduação na Unioeste.

Aos funcionários do Laboratório de Estruturas pela dedicação e pela qualidade dos serviços prestados durante a análise experimental.

Aos colegas do Departamento de Engenharia de Estruturas pela amizade e companheirismo.

À CAPES (Fundação Coordenação de Aperfeiçoamento de Pessoal de Nível Superior) pela bolsa de estudo.

À FAPESP (Fundação de Amparo à Pesquisa do Estado de São Paulo) pelo apoio financeiro.

À SIKA S.A. pelo fornecimento dos materiais do sistema de reforço utilizados na análise experimental. 


\section{Sumário}

Lista de Figuras ......................................................................................

Lista de Tabelas ........................................................................................

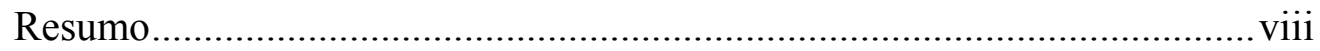

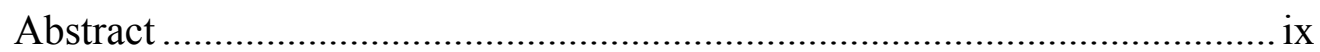

Capítulo 1 Introdução............................................................................. 1

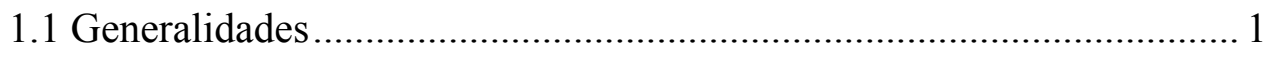

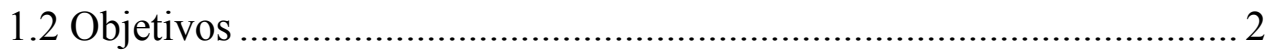

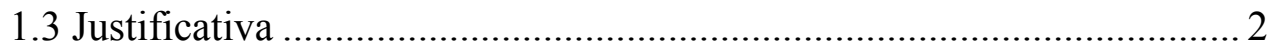

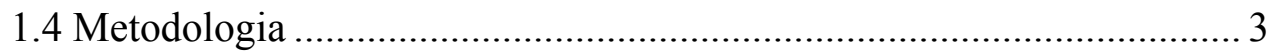

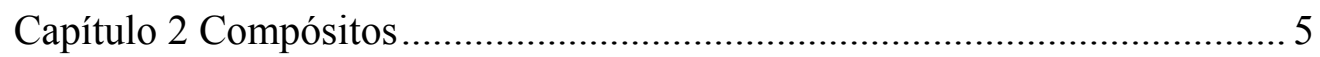

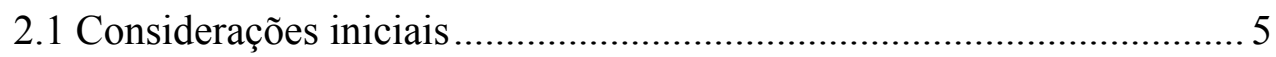

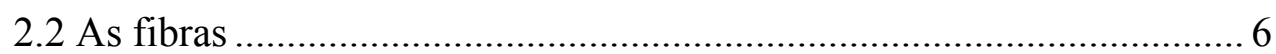

2.3 Materiais da matriz e do filler .......................................................... 8

2.4 Propriedades dos compósitos ............................................................

Capítulo 3 Resistência e deformabilidade do concreto ..................................... 12

3.1 Comportamento na compressão axial ................................................. 12

3.2 Comportamento do concreto em estados múltiplos de tensão ………... 14

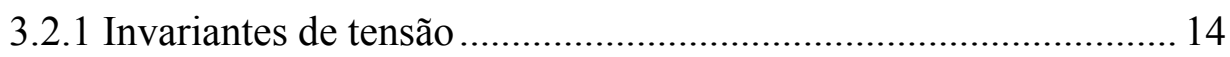

3.2.2 Intepretação física e geométrica dos invariantes............................. 16

3.2.3 Superfície de ruptura do concreto ................................................... 18

3.2.4 Critérios de ruptura do concreto...................................................... 21

3.2.4.1 Critério de MOHR-COULOMB ……………………............. 21

3.2.4.2 Critério de DRUCKER-PRAGER ………………………..... 24

3.2.4.3 Critérios de 3 parâmetros ......................................................... 25

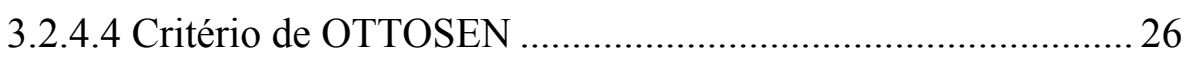

3.2.4.5 Critério de Willam \& Warnke................................................. 26

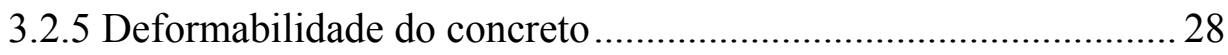




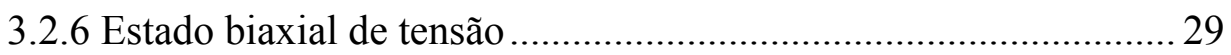

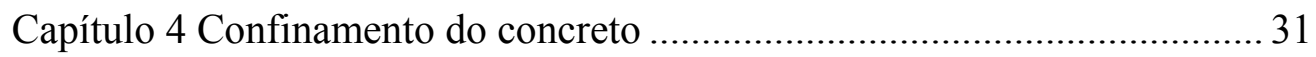

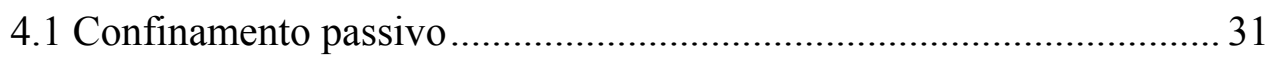

4.2 Efeito do confinamento sobre o concreto............................................ 33

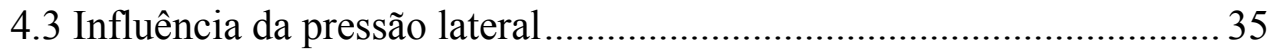

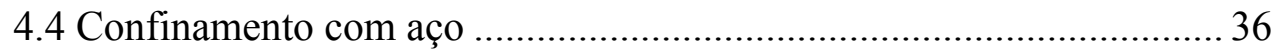

4.4.1 Cálculo da pressão lateral para pilares circulares ......................... 37

4.4.2 Outras variáveis influentes......................................................... 37

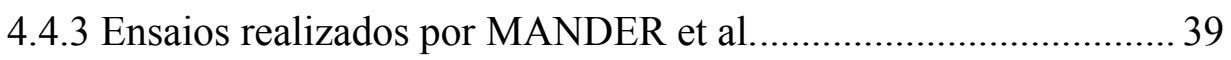

4.5 Confinamento com compósitos .................................................... 40

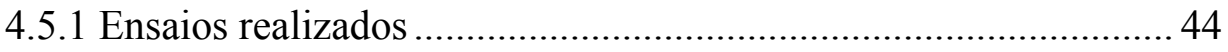

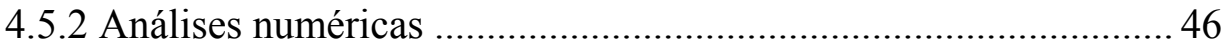

Capítulo 5 Modelos teóricos de confinamento............................................. 48

5.1 Modelos de confinamento com aço....................................................... 48

5.1.1 Modelo de Richart et al. (1929) .................................................... 48

5.1.2 Modelo de MANDER et al. (1988-b) ........................................... 49

5.1.3 Modelo de EL-DASH \& AHMAD (1995) .................................... 55

5.1.4 Modelo de CUSSON \& PAULTRE (1995) ................................... 56

5.1.5 Modelo de RAZVI \& SAATCIOGLU (1999-b).......................... 59

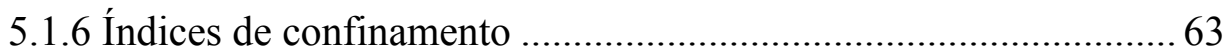

5.2 Modelos de confinamento com compósitos ........................................ 64

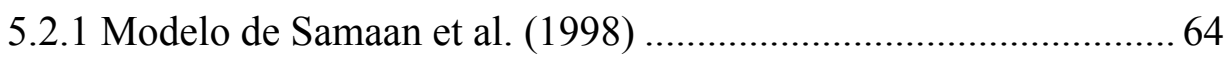

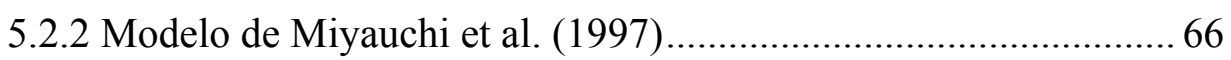

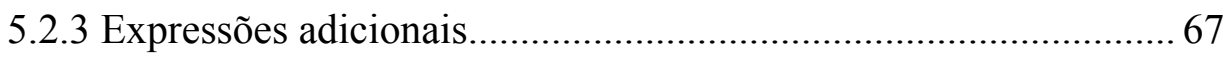

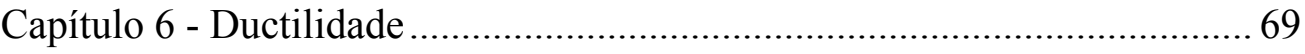

Capítulo 7 - Análise experimental................................................................ 73

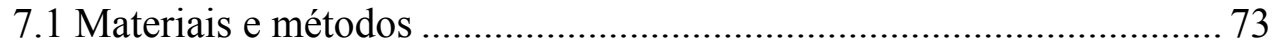

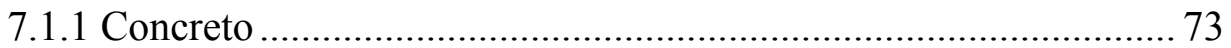

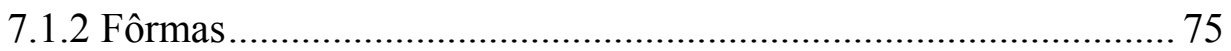

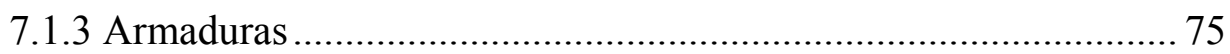

7.1.4 Sistema de reforço por encamisamento....................................... 77

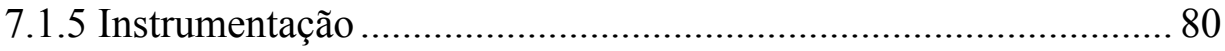




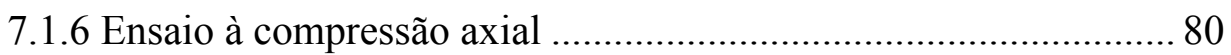

7.2 Ensaios de caracterização do compósito ............................................ 81

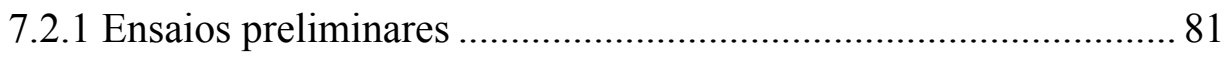

7.2.1.1 Frações volumétricas dos materiais constituintes .................. 81

7.2.1.2 Resistência à tração e módulo de elasticidade ...................... 82

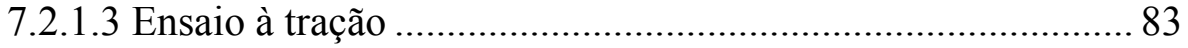

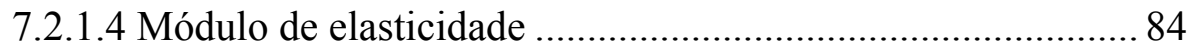

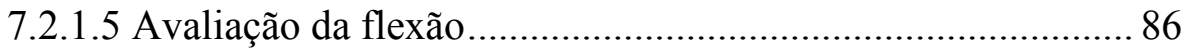

7.2.2 Ensaios definitivos de caracterização......................................... 87

7.2.3 Aplicabilidade dos resultados do compósito................................. 89

7.3 Ensaios de verificação do efeito da aderência....................................... 90

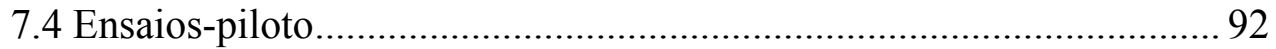

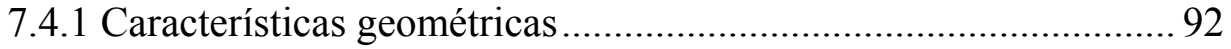

7.4.2 Preparação da superfície do concreto............................................ 93

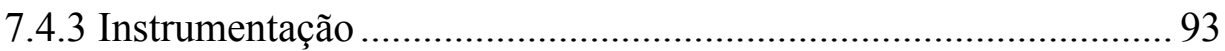

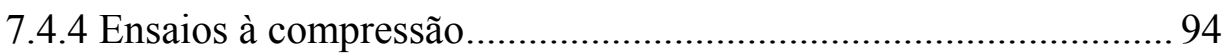

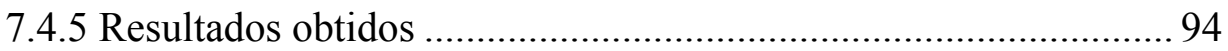

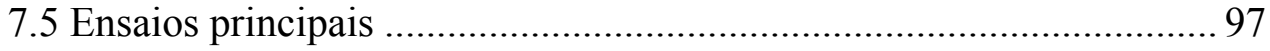

7.5.1 Características dos modelos e instrumentação ............................... 97

7.5.2 Cálculo das deformações axiais ................................................... 101

7.5.2.1 Justificativa do tratamento .................................................. 104

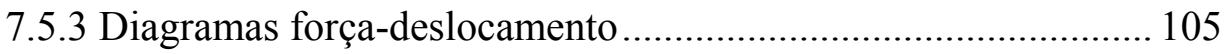

7.5.4 Deformações registradas pelos extensômetros............................. 110

7.5.5 Cálculo das tensões no concreto confinado ................................ 117

7.5.5.1 Influência do cobrimento ................................................... 118

7.5.6 Cálculo das tensões no concreto não confinado........................... 122

Capítulo 8 Análise dos resultados e simulações teóricas .............................. 123

8.1 Capacidade resistente dos pilares de seção circular............................ 123

8.2 Deformação última dos pilares de seção transversal circular ............ 124

8.3 Concreto confinado com PRFC ....................................................... 124

8.4 Concreto confinado com aço.............................................................. 128

8.5 Concreto confinado com aço e PRFC ............................................... 132 
8.5.1.1 Pilar C1S50

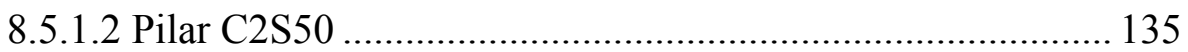

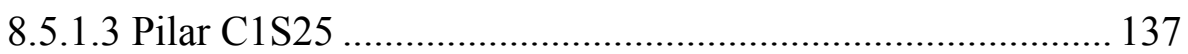

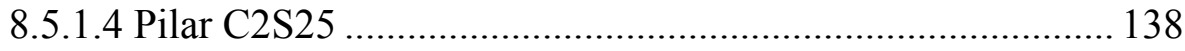

8.5.1.5 Observações gerais sobre as previsões.................................. 140

8.6 Pilares de seção transversal quadrada ................................................ 143

8.7 Distribuição de pressões confinantes nos modelos ............................ 146

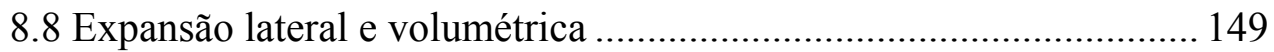

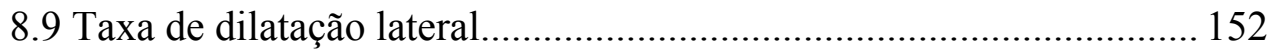

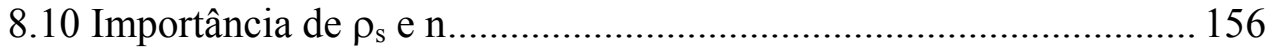

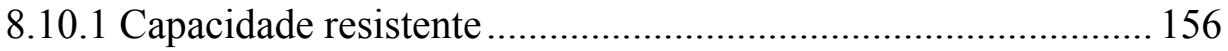

8.10.2 Deformação última no concreto confinado ................................ 157

8.10.3 Deformação de ruptura das fibras de carbono............................ 158

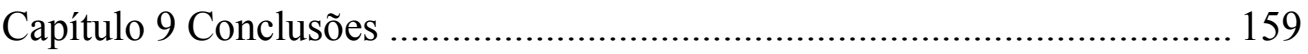

9.1 Propriedades do compósito ............................................................... 160

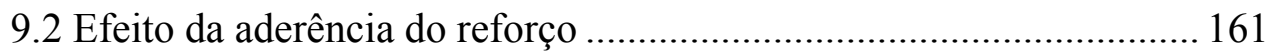

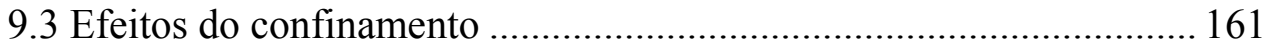

9.4 Concreto confinado com aço ou PRF .................................................. 163

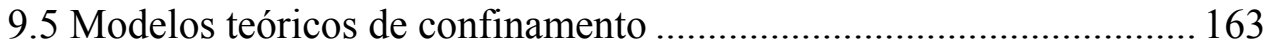

9.6 Pilares de seção transversal quadrada .............................................. 165

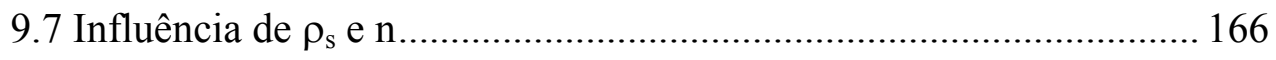

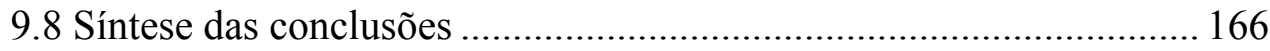

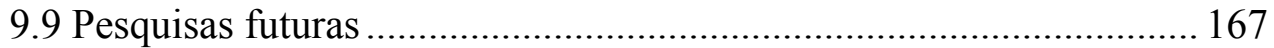

Referências Bibliográficas ................................................................... 169

Bibliografia Complementar...................................................................... 172

APÊNDICE I - Diagramas força-deslocamento.......................................... 1

APÊNDICE II - Fotos dos ensaios dos pilares.......................................... 7 


\section{Lista de Figuras}

Figura 2.1 - Variação das propriedades mecânicas com a direção do carregamento (GIBSON, 1994)

Figura 3.1 - Diagramas tensão x deformação para concretos de diferentes resistências (CHEN, 1982) 12

Figura 3.2 - Deformabilidade do concreto sob carregamento axial .......................... 14

Figura 3.3 - Espaço de tensões de Haigh-Westergaard (CHEN, 1982)..................... 17

Figura 3.4 - Projeção no plano deviatório (CHEN, 1982)....................................... 18

Figura 3.5 - Superfície de ruptura do concreto (FIB, 1999)..................................... 19

Figura 3.6 - Forma da seção transversal em diferentes níveis de $\xi$ (CHEN, 1982) .. 19

Figura 3.7 - Meridianos de compressão e tração (CHEN, 1982) ................................ 20

Figura 3.8 - Envoltória de MOHR-COULOMB …................................................ 22

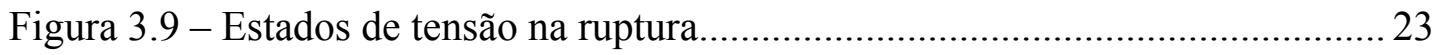

Figura 3.10 - Envoltória de MOHR-COULOMB (CHEN, 1982) ............................ 23

Figura 3.11 - Superfície de ruptura proposta por DRUCKER-PRAGER (CHEN, 1982) 24

Figura 3.12 - Envoltória do critério de Bresler \& Pister (CHEN, 1982)................... 25

Figura 3.13 - Critério de Willam \& Warnke (CHEN, 1982) .................................... 27

Figura 3.14 - Ensaios para definição dos parâmetros (CHEN, 1982) ...................... 27

Figura 3.15 - Ensaios de compressão axial de concreto em diferentes níveis de

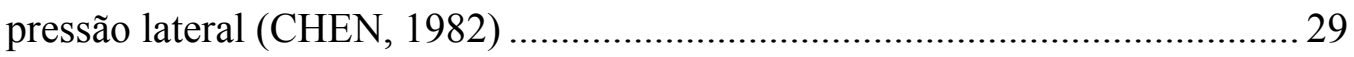

Figura 3.16 - Envoltória de ruptura em estados biaxiais (FIB, 1999)....................... 29

Figura 3.17 - Deformabilidade volumétrica do concreto em estados de compressão

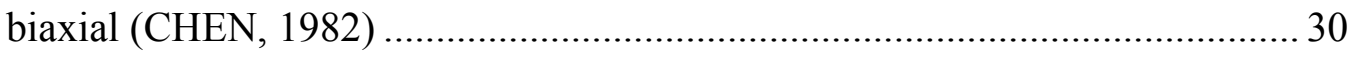

Figura 4.1 - Pilar de seção circular submetido à compressão axial ............................. 31

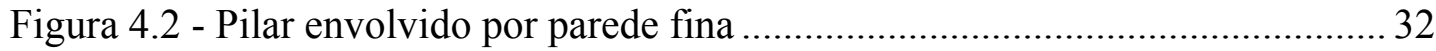

Figura 4.3 - Mecanismo de confinamento no concreto (FIB, 1990).......................... 34 
Figura 4.4 - Comportamento do concreto na compressão axial sob pressão lateral de fluidos (adaptado de CHEN, 1982). 36

Figura 4.5 - Diagramas tensão x deformação do concreto confinado com aço e com PRF (SAMAAN et al., 1998).

Figura 4.6 - Resposta volumétrica do confinamento com PRF e com aço SAMAAN et al., 1998) 42

Figura 4.7 - Taxa de dilatação lateral (SAMAAN et al., 1998)..... 43

Figura 5.1 - Variação de $\mathrm{k}_{1}$ com a pressão lateral, RICHART et al. 48

Figura 5.2 - Efeito do arqueamento em pilares na direção longitudinal 49

Figura 5.3 - Efeito do arqueamento em pilares com espirais 50

Figura 5.4 - Distribuição de áreas inefetivas na seção transversal de pilares de seção quadrada e retangular

Figura 5.5 - Determinação do ganho de resistência do concreto confinado para seções retangulares (MANDER et al., 1988-b)

Figura 5.6 - Diagrama tensão-deformação do concreto confinado com armaduras transversais (MANDER et al., 1988-b).....

Figura 5.7 - Modelo de confinamento bi-linear de SAMAAN (1998). ..................... 64

Figura 5.8 - Diagrama tensão-deformação - MIYAUCHI et al. (1997)..................... 67

Figura 7.1 - Fôrmas utilizadas para moldagem dos pilares .................................... 75

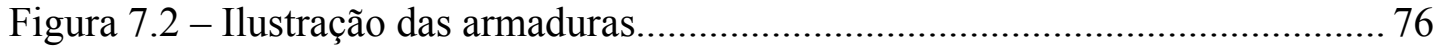

Figura 7.3 - Diagrama tensão-deformação das armaduras transversais .................... 76

Figura 7.4 - Modelo elasto-plástico x experimental ............................................... 77

Figura 7.5 - Diagrama tensão-deformação das armaduras longitudinais .................. 77

Figura 7.6 - Sistema de reforço estrutural SIKAWRAP ${ }^{\circledR}$....................................... 78

Figura 7.7 - Aplicação do sistema de reforço.......................................................... 79

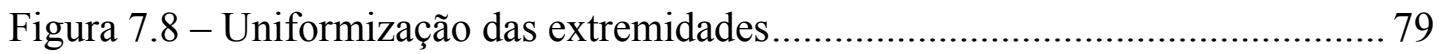

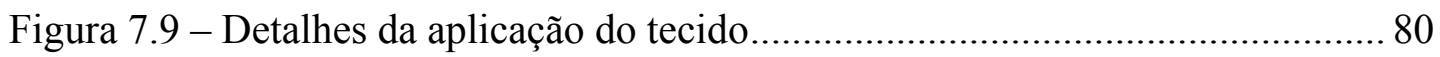

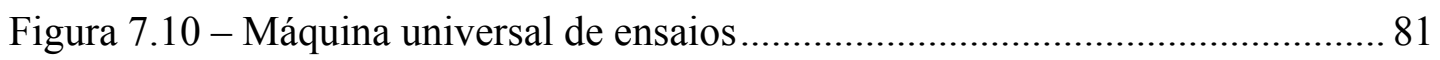

Figura 7.11 - Dimensões das amostras do ensaio à tração ........................................ 83

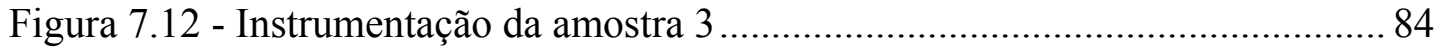

Figura 7.13 - Posições de ensaio da amostra 3 .......................................................... 84

Figura 7.14 - Diagrama tensão-deformação do compósito ...................................... 85 
Figura 7.15 - Diagramas tensão-deformação compósito x fibras 88

Figura 7.16 - Diagramas tensão-deformação - ensaios de tração definitivos............. 89

Figura 7.17 - Diagramas tensão-deformação com diferentes aderências.................... 91

Figura 7.18 - Seção transversal do pilar original ....................................................... 92

Figura 7.19 - Características geométricas dos modelos ............................................93

Figura 7.20 - Superfície obtida por lixamento........................................................ 93

Figura 7.21 - Pilares posicionados na máquina de ensaio.........................................94

Figura 7.22 - Diagrama força-deslocamento do modelos piloto................................ 95

Figura 7.23 - Leituras dos extensômetros do pilar P0 ............................................... 96

Figura 7.24 - Leituras dos extensômetros do pilar P2 …........................................... 96

Figura 7.25 - Diagramas força-deslocamento do pistão dos modelos-piloto.............. 97

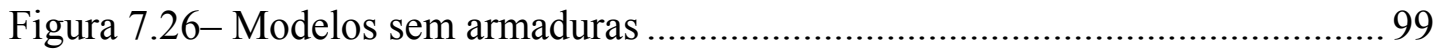

Figura 7.27- Modelos circulares com armaduras .................................................. 100

Figura 7.28- Modelos de seção transversal quadrada............................................ 101

Figura 7.29 - Diagramas força-deslocamento - Modelo C0 ................................... 102

Figura 7.30 - Diagramas força-deformação - Modelo C0 .................................... 103

Figura 7.31 - Diagramas força-deformação corrigidos - Modelo C0 ..................... 103

Figura 7.32 - Diagramas tensão-deformação do concreto não confinado ................ 104

Figura 7.33 - Comparação dos diagramas tensão-deformação do concreto confinado com a equação de POPOVICS...................................................................... 105

Figura 7.34 - Diagramas força-deslocamento dos modelos circulares sem armaduras 106

Figura 7.35 - Diagramas força-deslocamento - Modelo C1S25 ............................. 106

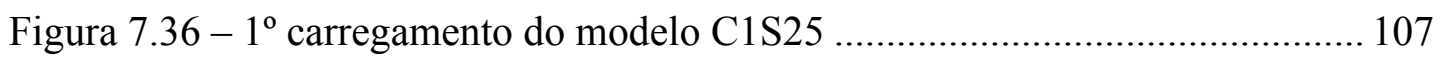

Figura 7.37 - Deslocamento plástico do $1^{\circ}$ carregamento ....................................... 108

Figura 7.38 - Força-deslocamento com o $2^{\circ}$ carregamento corrigido ..................... 108

Figura 7.39 - Diagramas força-deslocamento dos modelos com $\rho_{\mathrm{s}}=2 \%$............... 109

Figura 7.40- Diagramas força-deslocamento dos modelos com $\rho_{\mathrm{s}}=1 \%$................ 109

Figura 7.41 - Diagramas força-deslocamento - Modelos de seção quadrada ......... 110

Figura 7.42 - Leituras dos extensômetros - Modelo C0 ......................................... 111

Figura 7.43 - Leituras dos extensômetros - Modelo C1 …..................................... 111

Figura 7.44 - Leituras dos extensômetros - Modelo C2 …..................................... 112 
Figura 7.45 - Leituras dos extensômetros - C0S50 113

Figura 7.46 - Leituras dos extensômetros - C1S50 ................................................ 113

Figura 7.47 - Leituras dos extensômetros do pilar C2S50 ..................................... 114

Figura 7.48 - Leituras dos extensômetros do pilar C0S25 ...................................... 114

Figura 7.49 - Leituras dos extensômetros do pilar C1S25 - $1^{\circ}$ carregamento ......... 115

Figura 7.50 - Leituras dos extensômetros do pilar C1S25 - 2º carregamento ......... 115

Figura 7.51 - Leituras dos extensômetros do pilar C2S25 ..................................... 116

Figura 7.52 - Deformações dos extensômetros na camisa de reforço - Q2 ............ 117

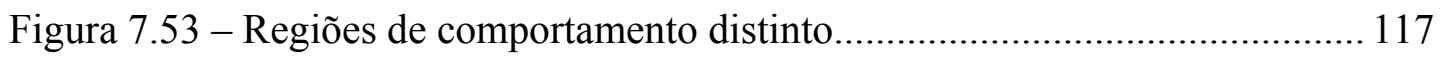

Figura 7.54 - Diagrama tensão-deformação do cobrimento adotado de acordo com

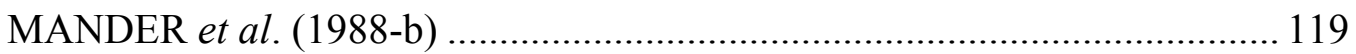

Figura 7.55 - Distribuição de forças no pilar C0S50 ............................................... 119

Figura 7.56 - Função polinomial adotada para o cobrimento.................................. 120

Figura 7.57 - Forças atuantes no modelo - C0S50.............................................. 121

Figura 7.58 - Forças atuantes no modelo - C0S25 ............................................. 121

Figura 8.1 - Diagramas tensão-deformação dos modelos sem armaduras ............... 127

Figura 8.2 - Diagrama tensão-deformação: teórico x experimental - Modelo C1 .. 128

Figura 8.3 - Diagrama tensão-deformação: teórico x experimental - Modelo C2 .. 128

Figura 8.4 - Diagramas tensão-deformação dos modelos confinados com aço ..... 131

Figura 8.5 - Diagrama tensão-deformação pilar C0S50 - experimental x modelos teóricos

Figura 8.6 - Diagrama tensão deformação pilar C0S25 - experimental x modelos teóricos

Figura 8.7 - Regiões 1 e 2

Figura 8.8 - Envoltórias de resistência do concreto confinado $\left(f_{\mathrm{co}}=26,16 \mathrm{MPa}\right)$.. 143

Figura 8.9 Diagramas tensão-deformação dos modelos de seção quadrada ............. 145

Figura 8.10 - Pressões laterais - Pilar C0 ................................................................ 146

Figura 8.11 - Pressões laterais - Pilar C1 …........................................................ 147

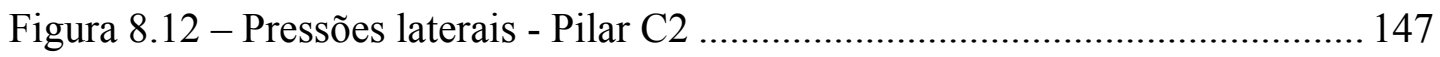

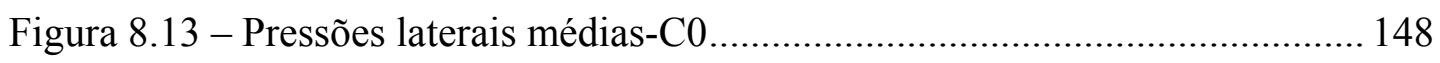

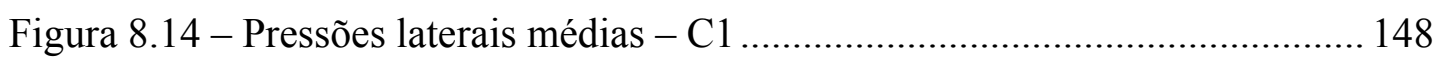

Figura 8.15 - Pressões laterais médias - C2 ……............................................. 148 
Figura 8.16 - Deformações axial, lateral e volumétrica - C0, C1 e C2.................. 149

Figura 8.17 - Deformação axial, lateral e volumétrica - C0, C0S50 e C0S25........ 150

Figura 8.18 - Deformações axial, lateral e volumétrica - C1S50 ........................... 151

Figura 8.19 - Deformações axial, lateral e volumétrica - C2S50 …....................... 151

Figura 8.20 - Deformações axial, lateral e volumétrica - C2S25 …....................... 152

Figura 8.21 - Taxa de dilatação - modelos C1 e C2 ….......................................... 153

Figura 8.22 - Taxa de dilatação - C0S50 e C0S25 ................................................ 154

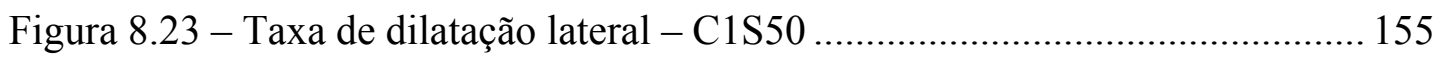

Figura 8.24 - Taxa de dilatação lateral - C2S50 ................................................... 155

Figura 8.25 - Taxa de dilatação lateral - C2S25 .................................................. 156 


\section{Lista de Tabelas}

Tabela 2.1 - Propriedades mecânicas médias das fibras (GIBSON, 1994)_................. 8

Tabela 2.2 - Propriedades mecânicas médias das matrizes (EDWARDS, 1998) ........ 9

Tabela 5.1 - Expressões de alguns modelos teóricos para $\mathrm{f}_{\mathrm{cc}}$ e $\varepsilon_{\mathrm{cc}} \ldots \ldots \ldots \ldots \ldots \ldots \ldots \ldots \ldots . . . . . . . . . . . . .68$

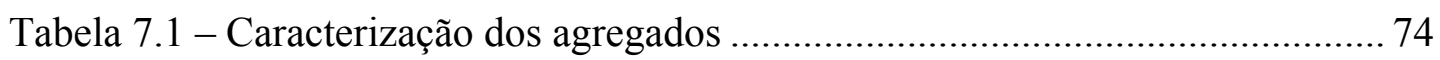

Tabela 7.2 - Traço unitário em massa do concreto................................................. 74

Tabela 7.3 - Resistência à compressão e módulo de elasticidade tangente................ 75

Tabela 7.4 - Propriedades dos tecidos de fibras de carbono...................................... 78

Tabela 7.5 - Propriedades da resina epóxi SIKADUR-330 _................................... 78

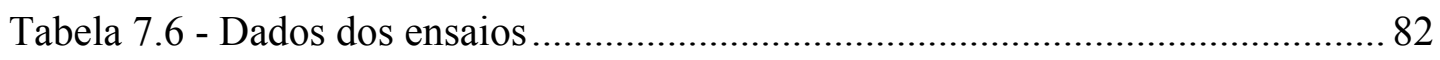

Tabela 7.7 - Resultados dos ensaios de tração ......................................................... 83

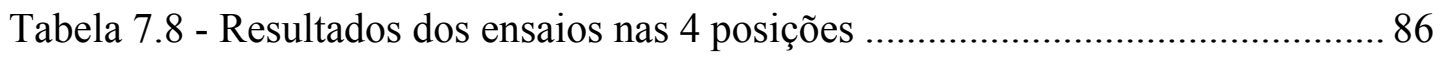

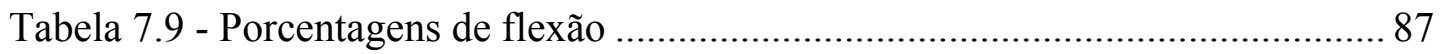

Tabela 7.10 - Resultados dos ensaios de tração ........................................................ 89

Tabela 7.11- Modelos circulares da análise experimental ........................................ 98

Tabela 8.1 - Capacidade resistente dos pilares de seção transversal circular.......... 123

Tabela 8.2 - Comparação da deformação última dos pilares de seção transversal

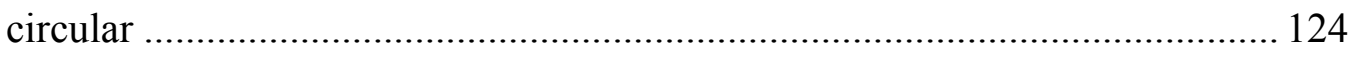

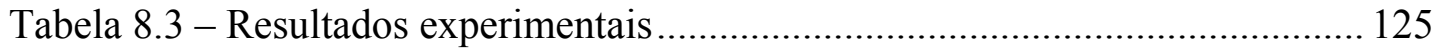

Tabela 8.4-Comparação dos resultados experimentais com os modelos teóricos ........... 125

Tabela 8.5 - Resultados experimentais dos modelos confinados com armadura

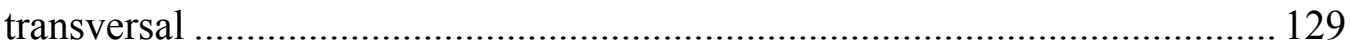

Tabela 8.6 - Pilar C0S50: resultados experimentais x teóricos................................ 129

Tabela 8.7 - Pilar C0S25: resultados experimentais x teóricos.................................. 130

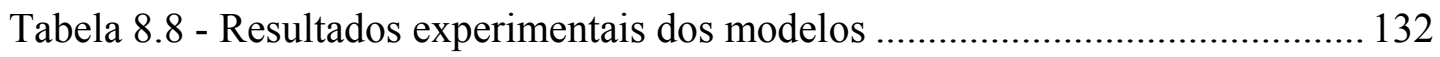

Tabela 8.9 - Hipóteses de cálculo nas simulações teóricas ...................................... 134

Tabela 8.10 - Pressões laterais - C1S50 ………................................................... 134

Tabela 8.11 - Previsão da resistência do concreto confinado - C1S50 .................... 134 
Tabela 8.12 - Erro percentual das simulações teóricas - C1S50 ............................ 135

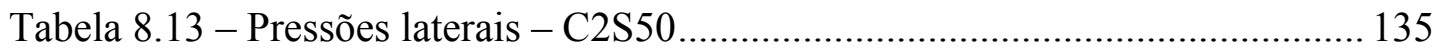

Tabela 8.14 - Previsão da resistência do concreto confinado - C2S50 .................... 136

Tabela 8.15 - Erro percentual das simulações teóricas - C2S50 ............................. 136

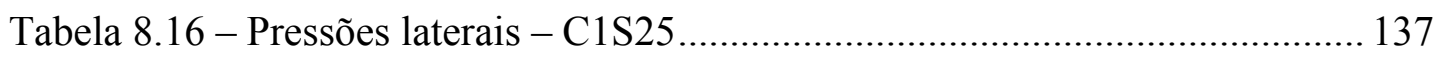

Tabela 8.17 - Previsão da resistência do concreto confinado - C1S25 ................... 137

Tabela 8.18 - Erro percentual das simulações teóricas - C1S25 ............................. 138

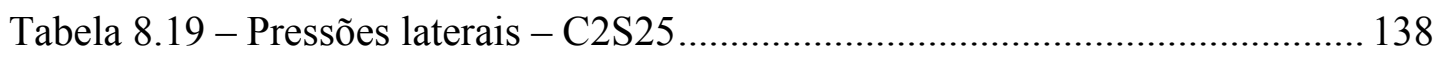

Tabela 8.20 - Previsão da resistência do concreto confinado - C2S25 ................... 139

Tabela 8.21 - Erro percentual das simulações teóricas - C2S25 ............................ 139

Tabela 8.22 - Previsões teóricas x experimental ................................................... 140

Tabela 8.23 - Previsões teóricas x experimental - média dos modelos teóricos..... 141

Tabela 8.24 - Previsões teóricas x experimental .................................................... 141

Tabela 8.25 - Previsões teóricas dos modelos teóricos .......................................... 142

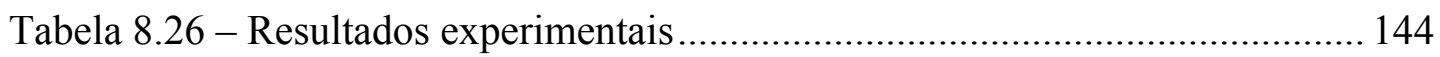

Tabela 8.27 - Resistência normalizada dos modelos.............................................. 156

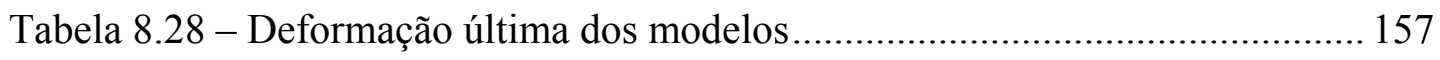

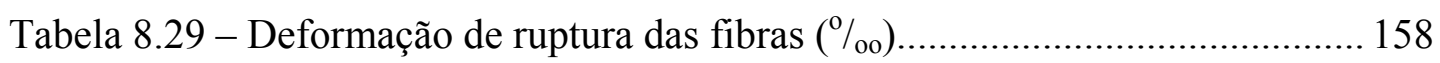




\section{Resumo}

CARRAZEDO, R. (2002). Mecanismos de confinamento e suas implicações no reforço de pilares de concreto por encamisamento com compósito de fibras de carbono. São Carlos, 2002. 173p. Dissertação (Mestrado) - Escola de Engenharia de São Carlos, Universidade de São Paulo.

Este trabalho aborda o efeito do confinamento desenvolvido em pilares de concreto armado reforçados com compósitos de fibras de carbono. Por meio do encamisamento é possível mobilizar o confinamento passivo do concreto, restringindo sua expansão lateral. Com o efeito do confinamento o concreto apresenta significativos ganhos de resistência e ductilidade. Efetuou-se uma análise experimental com pilares de seção transversal circular utilizando diferentes taxas de armadura transversal e variando-se o número de camadas do compósito. Observou-se a influência destas variáveis sobre a capacidade resistente e a deformabilidade destes pilares. Com o aumento do número de camadas de compósito ocorreram grandes acréscimos de capacidade resistente, mesmo com taxas de armadura transversal mais elevadas. $\mathrm{O}$ aumento da deformação última com o reforço foi grande no caso de pilares não armados. Em pilares com elevada taxa de armadura transversal não ocorreram ganhos significativos na deformação última. Verificou-se que em pilares de concreto armado reforçados com compósito de fibras de carbono, pode-se obter boas previsões do ganho de resistência utilizando-se modelos teóricos de confinamento adequados e a sobreposição de pressões laterais da camisa de reforço e da armadura transversal no núcleo. Foram ensaiados também pilares de seção transversal quadrada sem armaduras para verificar o efeito da forma da seção transversal. Observou-se que em seções quadradas a pressão lateral efetiva é menor se comparada com pilares de seção circular.

Palavras-chave: confinamento; compósitos; reforço; fibras de carbono; pilares; concreto armado. 


\section{Abstract}

CARRAZEDO, R. (2002). Confinement effects and their implication on the strengthening of concrete columns by wrapping with carbon fiber composites. São Carlos, 2002. 173p. Dissertação (Mestrado) - Escola de Engenharia de São Carlos, Universidade de São Paulo.

This work deals with the effect of confinement in reinforced concrete columns strengthened with carbon fiber composites. By wrapping, it is possible to mobilize the passive confinement of the concrete, restricting its lateral expansion. With the confinement, the concrete shows substantial gains in resistance and ductility. An experimental analysis of circular columns was carried out making use of different rates of transverse steel and numbers of composite layers. The influence of these variables over the load carrying capacity and deformability of these columns was observed. With an increased number of layers of the composite, there was a great increase in the load carrying capacity, even at high transverse steel rates. The increase in the ultimate strain given by the strengthening was great with unreinforced concrete columns. In columns with a high transverse steel rate there were no important gains in the ultimate strain. It was observed that in reinforced concrete columns strengthened with carbon fiber composites, one can very well foresee the gain in strength by using adequate analytical models of confinement and the overlaying of lateral pressures from the composite jacket and the transverse steel in the central core. Square columns without reinforcement bars were also subject to testing so as to investigate the effect of the shape of the cross-section. It was observable that in square sections the real lateral pressure is smaller when compared to circular columns.

Key-words: confinement; composites; strengthening; carbon fibers; columns; reinforced concrete. 


\section{Capitulo 1 Introdução}

\subsection{Generalidades}

As construções não são eternamente duráveis. Existem exemplos de obras antigas que resistiram à deterioração ao longo de muitos anos. No entanto é pouco provável que uma edificação ou uma obra de arte, mesmo construída com toda atenção e esmero permaneça intacta pela ação do tempo.

As estruturas têm o papel de manter a integridade da construção e um desempenho satisfatório deve ser assegurado para possibilitar a sua utilização durante a vida útil prevista. Muitas vezes podem ser necessárias intervenções durante a utilização das construções, de maneira a recuperar elementos estruturais danificados ou aumentar suas capacidades resistentes. O aumento da capacidade resistente é denominado reforço, que pode ser necessário também no caso de mudança de utilização ou ampliação da obra.

Este trabalho aborda o reforço de pilares de concreto armado. Entre as técnicas de reforço utilizadas nos últimos anos estão o reforço com perfís metálicos, aumento da seção ou encamisamento com concreto de baixa ou alta resistência e encamisamento com compósitos.

Entre as diversas técnicas de reforço de pilares nota-se algumas vantagens naquelas que mobilizam o efeito de confinamento do concreto. Por meio do confinamento torna-se possível contar com a colaboração do concreto do pilar préexistente, possibilitando grandes aumentos da capacidade resistente com pequeno aumento das dimensões dos elementos estruturais.

$\mathrm{O}$ efeito de confinamento se desenvolve com a presença de pressões transversais ao eixo longitudinal do pilar (pressões laterais), as quais possibilitam o aumento da capacidade resistente e da ductilidade. Pode ser obtido de forma ativa, pela aplicação de protensão transversal ou materiais expansivos confinados, ou de forma passiva, como ocorre com estribos, chapas de aço e camisas de compósitos coladas. 
No confinamento passivo, as pressões laterais se desenvolvem com a restrição da expansão lateral do concreto por meio das armaduras ou camisas projetadas para este fim. A aplicação de camisas de compósitos, como a obtida por colagem de fibras de carbono com resina epóxi possibilita o confinamento em toda seção do pilar.

\subsection{Objetivos}

Pretende-se neste trabalho analisar os efeitos de confinamento desenvolvidos pela aplicação de camisas de compósito de fibras de carbono em pilares de concreto armado. O trabalho envolve a análise experimental de modelos de pilares de concreto armado reforçados com esta técnica com ensaios de compressão axial centrada.

Procura-se observar a interação dos efeitos de confinamento desenvolvidos pela camisa de reforço com o confinamento desenvolvido pelas armaduras transversais existentes no pilar não reforçado. Outro aspecto avaliado é a influência da forma da seção transversal do pilar no efeito de confinamento.

As principais variáveis a serem analisadas são a capacidade resistente, a deformação última e o comportamento tensão-deformação dos modelos reforçados por encamisamento com PRFC.

A análise experimental se limita a ensaios de curta duração, não sendo verificado o comportamento ao longo do tempo, nem mesmo efeitos de précarregamento.

\subsection{Justificativa}

Sendo o concreto armado um material muito utilizado atualmente nas estruturas, pode-se imaginar a importância de desenvolver técnicas adequadas para sua reabilitação. A técnica de reforço com compósitos de polímeros reforçados com fibras (PRF) apresenta algumas vantagens sobre técnicas tradicionais de reforço para pilares, como a rapidez e facilidade de execução. No entanto, sendo esta técnica recente há necessidade de maior conhecimento dos parâmetros de dimensionamento e do comportamento das estruturas reabilitadas com esta técnica.

A utilização recente de compósitos na reabilitação de estruturas da Construção Civil requer estudos científicos apurados sobre seu comportamento estrutural. A falta de conhecimento dos profissionais a respeito do assunto e a 
inexistência de normatização dificultam o acesso dos profissionais a esta tecnologia, de maneira que se torna clara a necessidade de estudos que possibilitem dar parâmetros adequados sobre o comportamento estrutural destes materiais.

A durabilidade, os problemas patológicos e a recuperação das estruturas interessam à comunidade mundial. Os problemas patológicos e a necessidade de reabilitação de construções de concreto são conhecidos e aparecem com freqüência em diversos lugares. O Brasil, por exemplo, emprega em grande escala produtos à base de cimento em estruturas de edifícios. A pesquisa e a formação de recursos humanos nesta área são importantes e provocam reflexos significativos na economia.

O domínio completo dos métodos e técnicas de reabilitação de estruturas de concreto é de interesse nacional e mundial. Apesar dos rápidos avanços na área de reabilitação de estruturas, os profissionais contam apenas com sua experiência empírica acumulada. Isto porque os processos de reabilitação têm um caráter artesanal e particular, já que cada problema tem suas características próprias. Não há uma única metodologia específica para a análise do comportamento estrutural da peça reabilitada e nem diretrizes para orientar o projetista durante o redimensionamento e reprojeto.

Apesar de várias obras terem sido reabilitadas com sucesso, muitos fatores ainda devem ser investigados para avaliar melhor o comportamento da estrutura reabilitada.

O melhor desenvolvimento e a exploração de novas possibilidades de uma técnica já aplicada com sucesso em alguns casos específicos também contribuirá ao domínio completo deste campo de atividade.

\subsection{Metodologia}

A avaliação dos mecanismos de confinamento foi realizada por meio de análise experimental e simulações teóricas com modelos de confinamento.

A análise experimental consistiu do ensaio de pilares curtos de seção transversal circular e quadrada submetidos à compressão axial, devidamente preparados e instrumentados para observação da capacidade resistente, ductilidade e efeitos de confinamento. O programa experimental envolveu modelos de referência (não reforçados) e modelos reforçados pela aplicação de camisas de compósito de 
fibras de carbono. Variou-se o número de camadas de compósito aplicadas e as taxas de armadura transversal empregadas tanto nos modelos reforçados, como nos de referência.

Foram executados ensaios piloto para melhor definir os procedimentos de ensaio e os objetivos mais detalhados da análise. Os ensaios foram realizados no Laboratório de Estruturas, empregando-se, dentre outros equipamentos e instalações, a Máquina Universal Servo-Hidráulica, para ensaios com deformação controlada e observação do comportamento pós-pico de resistência. Maiores detalhes da análise experimental são dados na seqüência deste trabalho.

Com a análise dos resultados investigou-se a adequação de alguns modelos de confinamento existentes para avaliação da capacidade resistente e deformação última dos pilares encamisados com compósitos. Verificou-se a validade da superposição dos efeitos de confinamento passivo desenvolvidos pela armadura transversal e pela camisa de PRFC, por meio da observação experimental dos mecanismos resistentes e pela simulação teórica com modelos teóricos de confinamento.

Ao final do desenvolvimento da pesquisa, no estabelecimento das conclusões, foram avaliados os resultados efetivamente alcançados, comparando-os com os objetivos estabelecidos inicialmente. 


\section{Capitulo 2 Compósitos}

\subsection{Considerações iniciais}

Segundo GIBSON (1994), os materiais estruturais podem ser divididos em quatro grandes classes: os metais, os polímeros, as cerâmicas e os compósitos. Os compósitos são os materiais formados pela combinação dos anteriores em duas ou mais fases distintas formando um arranjo estrutural macroscópico. Estas fases são a matriz, as fibras e eventualmente o filler.

O homem conhece há muito tempo a utilidade dos compósitos, quando empregava fibras naturais em seus blocos cerâmicos para reduzir a retração. Podem ser encontrados exemplos de compósitos mesmo na natureza. A madeira, por exemplo, é um compósito formado por uma matriz de lignina com fibras de celulose.

Com o avanço da tecnologia foram sendo desenvolvidos novos tipos de compósitos, como o concreto, polímeros reforçados com fibras (PRF), e até mesmo compósitos de matrizes cerâmicas e metálicas com fibras de "silicon carbide" (SiC). As boas propriedades mecânicas obtidas com os PRF viabilizaram sua utilização em equipamentos de alta tecnologia da indústria aeronáutica e aeroespacial (GIBSON, 1994). A primeira aplicação de compósitos de fibras de vidro na indústria aeronáutica ocorreu em 1944. A partir daí os PRF encontraram muitas aplicações na construção de navios, no processamento químico e nos setores médico e automotivo.

Segundo SAADATMANESH \& EHSANI (1994) a motivação para o grande crescimento no uso dos compósitos nos últimos anos se deve principalmente às altas resistência e módulo de elasticidade em relação ao peso próprio destes materiais e à sua durabilidade em ambientes corrosivos. Possuem ainda um comportamento à fadiga melhor que o dos metais estruturais.

Dentre os diversos tipos de compósitos existentes, neste trabalho é dada uma maior ênfase aos PRF. Estes são compósitos formados por uma matriz polimérica como poliéster, epóxi ou fenol e fibras de alta resistência como a de vidro, carbono, aramida ou boro. 


\subsection{As fibras}

Atualmente sabe-se que muitos materiais apresentam sua mais alta resistência quando se encontram na forma de fibras. Este fato pode ter entre outras causas um melhor alinhamento das cadeias moleculares. Isto acontece com alguns polímeros e com o grafite. No entanto a utilização direta das fibras nas estruturas é inviável, já que elas não podem resistir isoladamente à compressão longitudinal e nem mesmo a esforços transversais. Desta maneira seu emprego torna-se possível apenas com a utilização de matrizes (GIBSON, 1994).

GIBSON (1994) classifica as fibras como básicas e avançadas. As básicas possuem alta resistência à tração, baixo módulo de elasticidade e em geral um menor custo. Dentre estas a fibra de vidro é a mais importante, a mais antiga em aplicações estruturais e há muito tempo a mais utilizada comercialmente. É obtida com a mistura de óxidos, dentre os quais a sílica é a mais utilizada, além de óxidos de cálcio, alumínio, boro e ferro em menor quantidade (EDWARDS, 1998). Apesar de atingir resistências à tração maiores que muitas fibras avançadas (próxima a 3500 $\mathrm{MPa}$ ), seu módulo de elasticidade é considerado baixo, da ordem de $70 \mathrm{GPa}$. SAADATMANESH \& EHSANI (1994) cita como suas principais vantagens o baixo custo, as altas resistências química e à tração, e como desvantagens, um baixo módulo de elasticidade e baixa resistência à fadiga.

As fibras avançadas possuem maior módulo de elasticidade, no entanto apresentam um custo mais elevado. Sua aplicação é mais restrita a casos onde o elevado desempenho justifica o custo, como ocorre na indústria aeroespacial.

São fibras avançadas as de carbono, aramida, boro e "silicon carbide". As fibras de carbono são as mais utilizadas entre as avançadas. São produzidas por tratamento térmico de fibras precursoras orgânicas como poliacrilonitrila (PAN), piche e "rayon" que se transformam em carbono por pirólise controlada. O grafite é obtido em temperatura mais elevada e possui aproximadamente $99 \%$ de carbono em sua composição. As chamadas fibras de carbono possuem cerca de 95\% de carbono.

Pode-se variar significativamente o módulo de elasticidade e a resistência das fibras de carbono controlando a temperatura no processo de obtenção. Em geral aumentando-se o módulo de elasticidade ocorre uma redução na resistência e na deformação de ruptura. 
SAADATMANESH \& EHSANI (1994) classificam as fibras de carbono em quatro tipos: módulo de elasticidade normal, módulo intermediário, alto módulo e fibras de piche. Apesar das fibras de carbono serem caras, o preço caiu muito e a utilização cresceu nos últimos anos. O desenvolvimento de fibras de grafite e carbono tem crescido rapidamente. Por exemplo, com um precursor de piche pode-se obter fibras com módulo de elasticidade de $690 \mathrm{GPa}$, três vezes maior que o do aço (GIBSON, 1994).

As fibras de aramida, produzidas pela DuPont com o nome comercial de Kevlar foram inicialmente desenvolvidas para utilização em pneus radiais (Kevlar 29). Depois foram desenvolvidas fibras de maior módulo, como a Kevlar 49, utilizada para fins estruturais. A densidade é de metade da que possui a fibra de vidro e a resistência específica está entre as mais altas. Possuem excelente tenacidade, ductilidade e resistência ao impacto, diferentemente do vidro ou carbono (GIBSON, 1994). No entanto, por sua natureza anisotrópica, apresentam pobres propriedades na compressão (EDWARDS, 1998).

As fibras de boro são compósitos produzidos pelo cobrimento com boro de um substrato de carbono ou tungstênio. O diâmetro é o maior entre as fibras avançadas, (0,05-0,2 mm). Possuem resistência e módulo de elasticidade maiores que as fibras de carbono, mas sua densidade e custo também são maiores (GIBSON, 1994). As propriedades mecânicas médias das fibras são dadas na Tabela 2.1. 
Tabela 2.1 - Propriedades mecânicas médias das fibras (GIBSON, 1994)

\begin{tabular}{|c|c|c|c|}
\hline Tipo & $\begin{array}{l}\text { Resistência à } \\
\text { Tração (MPa) }\end{array}$ & $\begin{array}{c}\text { Módulo de } \\
\text { Elasticidade (MPa) }\end{array}$ & $\begin{array}{c}\text { Densidade } \\
\left(\mathrm{g} / \mathrm{cm}^{3}\right)\end{array}$ \\
\hline \multicolumn{4}{|c|}{ Vidro } \\
\hline E & 3448 & 72 & 2,54 \\
\hline $\mathrm{S}$ & 4482 & 86 & 2,49 \\
\hline \multicolumn{4}{|c|}{ Carbono (precursor PAN) } \\
\hline AS-4 & 4000 & 228 & 1,80 \\
\hline IM-7 & 5413 & 276 & 1,77 \\
\hline $\mathrm{T}-300$ & 3654 & 231 & 1,77 \\
\hline $\mathrm{T}-650 / 42$ & 5033 & 290 & 1,77 \\
\hline \multicolumn{4}{|c|}{ Carbono (precursor piche) } \\
\hline $\mathrm{P}-55$ & 1724 & 379 & 1,99 \\
\hline P-75 & 2068 & 517 & 1,99 \\
\hline $\mathrm{P}-100$ & 2241 & 690 & 2,16 \\
\hline \multicolumn{4}{|c|}{ Fibras de aramida } \\
\hline Kevlar $^{\circledR} 29$ & 3792 & 62 & 1,44 \\
\hline Kevlar $^{\circledR} 49$ & 3792 & 131 & 1,47 \\
\hline \multicolumn{4}{|c|}{ Boro } \\
\hline $0,10 \mathrm{~mm}$ & 3516 & 400 & 2,57 \\
\hline $0,14 \mathrm{~mm}$ & 3516 & 400 & 2,49 \\
\hline
\end{tabular}

\subsection{Materiais da matriz e do filler}

As matrizes podem ser constituídas por metais, polímeros ou cerâmicas. Sua função é manter as fibras posicionadas na unidade estrutural e protegê-las de danos externos. Transferem e distribuem as cargas aplicadas às fibras. Em alguns casos precisam de ductilidade, tenacidade ou isolação elétrica. Devem ter boa aderência às fibras. A matriz e as fibras devem ser compatíveis, ou seja, não podem ocorrer reações entre estas. A matriz também deve ter bom desempenho na temperatura de serviço (GIBSON, 1994).

Os polímeros são as matrizes mais utilizadas. Podem ser resinas termofixas, como a epóxi, o poliéster e o fenol, ou termoplásticas. Após a cura as termofixas produzem uma estrutura molecular tridimensional de ligações cruzadas fortes que não se fundem a altas temperaturas. As cadeias moleculares das resinas termoplásticas não se cruzam, logo amolecem e se fundem a altas temperaturas. As epóxis e poliésteres têm sido as resinas mais utilizadas nos últimos anos (GIBSON, 1994). Pode-se adicionar "filler" à matriz no processo de fabricação. Estes geralmente são utilizados não para melhorar as propriedades mecânicas, mas sim para redução de peso ou custo. $\mathrm{Na}$ Tabela 2.2 estão apresentadas algumas propriedades médias das matrizes: 
Tabela 2.2 - Propriedades mecânicas médias das matrizes (EDWARDS, 1998)

\begin{tabular}{ccccc}
\hline Material & $\begin{array}{c}\text { Densidade } \\
\left(\mathrm{g} / \mathrm{cm}^{3}\right)\end{array}$ & $\begin{array}{c}\text { Resistência } \\
\text { à tração } \\
(\mathrm{MPa})\end{array}$ & $\begin{array}{c}\text { Módulo de } \\
\text { elasticidade } \\
(\mathrm{GPa})\end{array}$ & $\begin{array}{c}\text { Deformação } \\
\text { de ruptura } \\
(\%)\end{array}$ \\
\hline Poliéster & $1,1-1,46$ & $42-91$ & $2-4,5$ & 1,25 \\
Vinil-éster & 1,15 & 73 & 3,5 & - \\
Epóxi & $1,11-1,4$ & $28-91$ & 2,4 & $4-7$ \\
\hline
\end{tabular}

\subsection{Propriedades dos compósitos}

As variáveis de maior importância sobre as propriedades dos compósitos são o tipo, alinhamento e distribuição das fibras, interface entre matriz e fibras, tamanho e forma da fibra e a direção do carregamento.

Os laminados são a combinação de lâminas de compósitos de fibras contínuas orientadas nas direções apropriadas e coladas. A separação interlaminar pode ser um problema, pois a resistência interlaminar é regida pela matriz. Compósitos entrelaçados não têm este problema, porém apresentam menores resistência e módulo de elasticidade longitudinais em comparação com os compósitos de fibras longitudinais unidirecionais (GIBSON, 1994).

Segundo EDWARDS (1998), devido às baixas deformações de ruptura e à falta de um patamar de escoamento os compósitos são muitos sensíveis a concentrações de tensões. Por isso recomenda-se evitar quinas no reforço com compósitos.

As propriedades mecânicas são muito afetadas pela quantidade e disposição das fibras. Para mesmas quantidades de fibras o arranjo aleatório resulta nas mais baixas propriedades mecânicas longitudinais e o unidirecional nas mais altas.

No caso do arranjo unidirecional, com qualquer desvio de direção das tensões atuantes nas fibras as propriedades mecânicas reduzem-se bruscamente. As propriedades transversais do compósito são próximas às das resinas. Na Figura 2.1 pode-se observar o efeito da variação do ângulo $(\theta)$ entre as fibras e a direção de carregamento sobre as propriedades do compósito. Pode-se notar que com uma pequena desorientação em relação às fibras ocorre uma grande mudança no módulo de elasticidade longitudinal $\left(E_{\mathrm{x}}\right)$. Podem ser observadas ainda as variações do coeficiente de Poisson $\left(v_{\mathrm{xy}}\right)$, do módulo de elasticidade de cisalhamento $\left(\mathrm{G}_{\mathrm{xy}}\right)$ e do efeito de "shear coupling" $\left(\eta_{\mathrm{xy}}\right)$. 

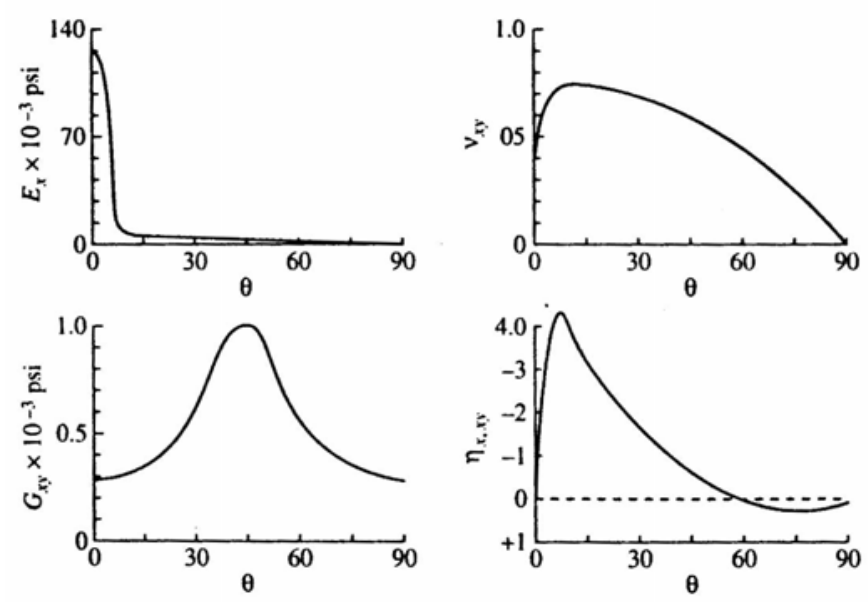

Figura 2.1 - Variação das propriedades mecânicas com a direção do carregamento (GIBSON, 1994)

EDWARDS (1998) sugere que as propriedades dos compósitos são aproximadamente representadas pela Lei das Misturas. Por ela podem ser obtidos o módulo de elasticidade, a densidade e o coeficiente de Poisson. Conhecidas as densidades das fibras, da matriz e do compósito, pode-se obter a fração volumétrica de vazios em função das frações em massa do compósito através da relação a seguir:

$$
v_{v}=1-\frac{\left(W_{f} / d_{f}\right)+\left(W_{m} / d_{m}\right)}{W_{c} / d_{c}}
$$

onde:

- $\mathrm{d}_{\mathrm{f}}, \mathrm{d}_{\mathrm{m}}$ e $\mathrm{d}_{\mathrm{c}}$ são as densidades das fibras, da matriz e do compósito, respectivamente;

- $\mathrm{W}_{\mathrm{f}}, \mathrm{W}_{\mathrm{c}}$ e $\mathrm{W}_{\mathrm{m}}$ são as frações em massa de fibras, compósito e matriz respectivamente.

As frações volumétricas da matriz e das fibras podem ser obtidas pelas equações:

$$
\begin{aligned}
& v_{f}+v_{m}+v_{v}=1 \\
& d_{c}=d_{f} \cdot v_{f}+d_{m} \cdot v_{m}
\end{aligned}
$$

onde $v_{f}$ e $v_{m}$ são as frações volumétricas das fibras e da matriz respectivamente.

Assumindo-se perfeita aderência entre as fibras e a matriz, o módulo de elasticidade longitudinal à tração é dado por: 


$$
E_{l}=E_{f} \cdot v_{f}+E_{m} \cdot v_{m}
$$

onde:

- $\mathrm{E}_{\mathrm{l}}, \mathrm{E}_{\mathrm{f}}$ e $\mathrm{E}_{\mathrm{m}}$ são os módulos de elasticidade longitudinais do compósito, das fibras e da matriz respectivamente;

- $\quad v_{\mathrm{f}}$ e $\mathrm{v}_{\mathrm{m}}$ são as frações volumétricas das fibras e da matriz respectivamente.

EDWARDS (1998) propõe um fator de eficiência das fibras (A) com valores para os diferentes arranjos, sendo 1 para o unidirecional, 0,5 para bidirecional e 0,375 para aleatório. O módulo de elasticidade longitudinal à tração é então dado por:

$$
E_{l}=E_{f} \cdot v_{f} \cdot A+E_{m} \cdot v_{m}
$$

A previsão da resistência à tração longitudinal pela Lei das Misturas dá resultados imprecisos já que a matriz se comporta de uma maneira não linear e rompe num nível de tensão diferente das fibras. No entanto o modelo fornece um valor máximo para a resistência à tração (EDWARDS, 1998):

$$
\sigma_{1}=\sigma_{f} \cdot v_{f}+\sigma_{m} \cdot v_{m}
$$

onde $\sigma_{\mathrm{f}}$ e $\sigma_{\mathrm{m}}$ são as resistências à tração longitudinal das fibras e matriz, respectivamente. 


\section{Capitulo 3 Resistência e deformabilidade do concreto}

\subsection{Comportamento na compressão axial}

Sob carregamento uniaxial o concreto apresenta um comportamento tensãodeformação não-linear altamente influenciado pela microfissuração. Concretos de resistência normal (da ordem de $30 \mathrm{MPa}$ ) apresentam considerável microfissuração, tendo conseqüentemente diagramas tensão-deformação com notável diminuição da rigidez com o crescimento da tensão. Concretos de alta resistência (acima de 50 $\mathrm{MPa})$ têm diferenças significativas na microestrutura interna, apresentando menor microfissuração, de forma que o diagrama se aproxima do linear até próximo à ruptura como indica a Figura $3.1\left(f_{c}{ }^{\prime}\right.$ é a resistência à compressão uniaxial do concreto).

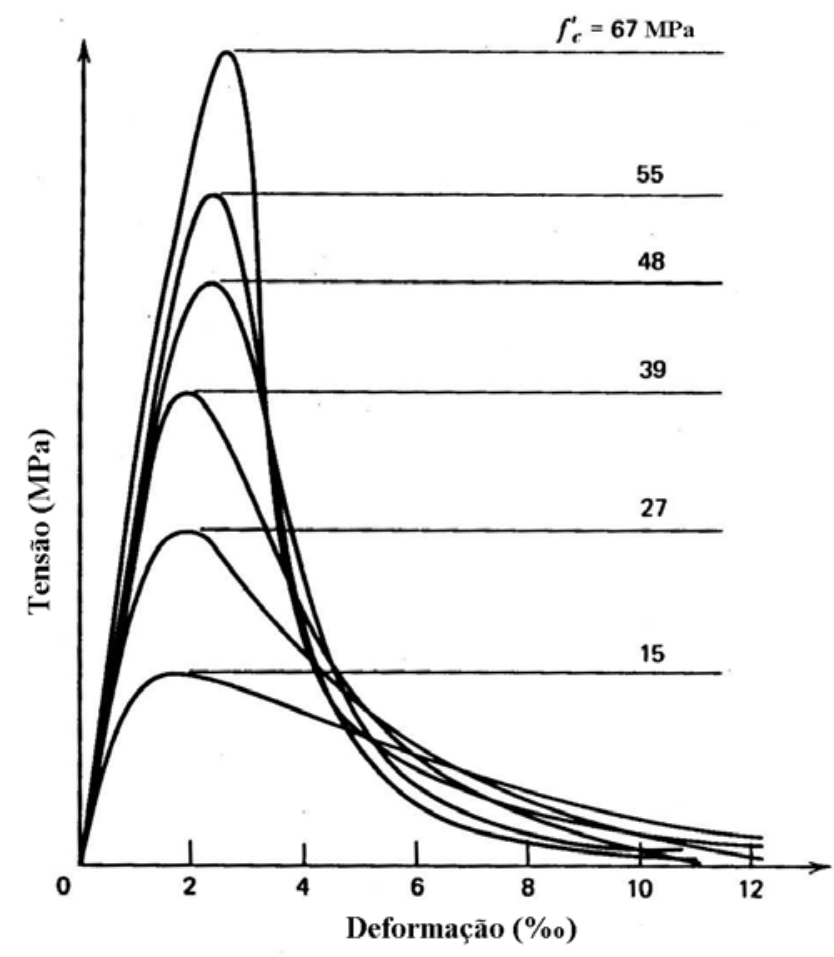

Figura 3.1 - Diagramas tensão x deformação para concretos de diferentes resistências (CHEN, 1982) 
Em concretos de resistência normal a chamada zona de transição entre pasta e agregado tem uma influência considerável no mecanismo de ruptura. Antes da aplicação da carga a zona de transição possui falhas decorrentes do processo de adensamento, onde a água em excesso se acumula ao redor dos agregados, prejudicando localmente a aderência e a resistência mecânica. A retração e as deformações diferenciais durante o processo de cura também são fatores de microfissuração. Com isto, mesmo antes da aplicação da carga existem microfissuras.

A deformabilidade do concreto ao longo do carregamento uniaxial de compressão pode ser compreendida por meio da explanação de CHEN (1982) e da Figura 3.2. Iniciando-se o carregamento as fissuras existentes permanecem estáveis até cerca de $30 \%$ da resistência à compressão do concreto não confinado $\left(f_{c o}\right)$ e a relação entre tensão e deformação é linear. A tensão de $0,30 \cdot f_{\mathrm{co}}$ é denominada limite de proporcionalidade.

Entre 0,30 e $0,50 \cdot f_{\text {co }}$ o diagrama tensão-deformação do concreto começa a apresentar uma curvatura. No entanto, existe um sistema estável de microfissuras na zona de transição e a fissuração na matriz é desprezível.

As fissuras na matriz começam a surgir entre 0,50 e $0,60 \cdot f_{\text {co }}$. Aproximadamente a $0,75 \cdot f_{\text {co }}$ o sistema de fissuras na zona de transição fica instável e a proliferação de fissuras na matriz aumenta. Neste momento o diagrama tensãodeformação se inclina consideravelmente e ocorrem deformações muito grandes, indicando a rápida propagação de fissuras tanto na matriz como na zona de transição.

Entre 0,75 e $0,80 \cdot f_{\text {co }}$ o sistema de fissuras fica instável, de forma que pode ocorrer ruptura com carga constante. Este nível de tensão é denominado tensão crítica (CHEN, 1982).

Na Figura 3.2 pode-se observar também que o concreto sofre uma contração volumétrica praticamente linear até atingir a tensão crítica. Neste ponto a microfissuração fica instável e provoca um aumento assintótico da deformação lateral. Este aumento da deformação lateral causa a expansão volumétrica. A deformabilidade lateral do concreto merece especial atenção, pois é o principal mobilizador do confinamento passivo. Segundo CUSSON \& PAULTRE (1995) o coeficiente de Poisson do concreto pode ultrapassar 0,5 próximo à ruptura. 


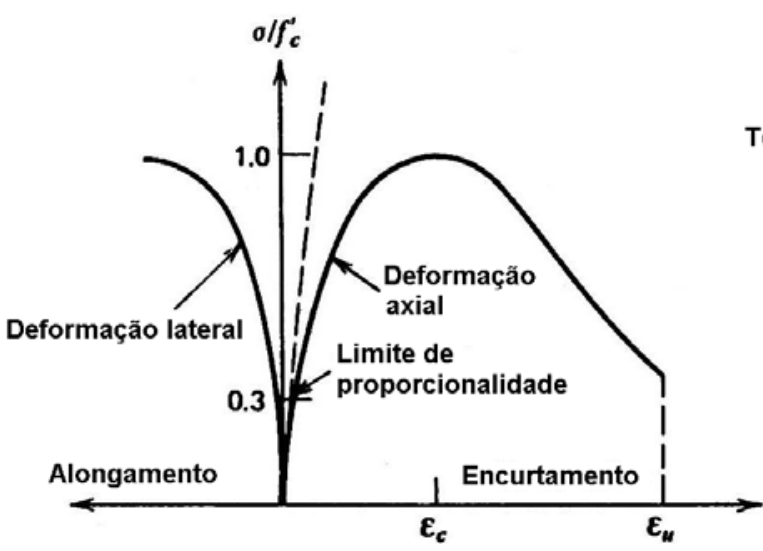

(a)

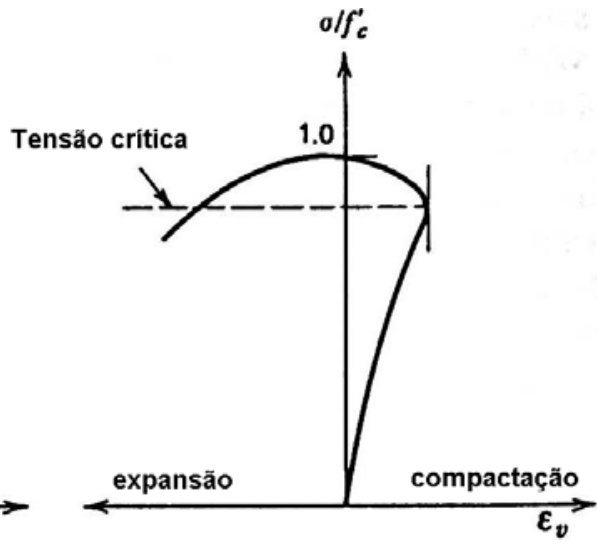

(b)

Figura 3.2 - Deformabilidade do concreto sob carregamento axial

(a) Deformabilidade axial e lateral (b) Deformabilidade volumétrica (CHEN, 1982)

\subsection{Comportamento do concreto em estados múltiplos de tensão}

\subsubsection{Invariantes de tensão}

A ruptura do concreto em estados multiaxiais de carregamento pode ser representada por critérios em função das tensões principais. Estes critérios normalmente envolvem os invariantes de tensão para caracterizar a situação de determinado estado de tensão quanto à ruptura. Aqui adota-se como ruptura a capacidade de carregamento última do material.

Seja um estado de tensões qualquer em um ponto representado pelo tensor:

$$
\sigma_{i j}=\left[\begin{array}{ccc}
\sigma_{x} & \tau_{x y} & \tau_{x z} \\
\tau_{y x} & \sigma_{y} & \tau_{y z} \\
\tau_{z x} & \tau_{z y} & \sigma_{z}
\end{array}\right]
$$

As tensões de cisalhamento associadas com os eixos principais são nulas, logo pode-se escrever:

$$
\left|\begin{array}{ccc}
\sigma_{x}-\sigma_{p} & \tau_{x y} & \tau_{x z} \\
\tau_{y x} & \sigma_{y}-\sigma_{p} & \tau_{y z} \\
\tau_{z x} & \tau_{z y} & \sigma_{z}-\sigma_{p}
\end{array}\right| \cdot\left\{\begin{array}{l}
n_{x} \\
n_{y} \\
n_{z}
\end{array}\right\}=\left\{\begin{array}{l}
0 \\
0 \\
0
\end{array}\right\}
$$

onde: 
- $\sigma_{\mathrm{p}}$ é uma tensão principal;

- $\left\{\mathrm{n}_{\mathrm{x}} \mathrm{n}_{\mathrm{y}} \mathrm{n}_{\mathrm{z}}\right\}$ é o vetor que dá a direção principal.

Para a resolução deste sistema é necessário que o determinante indicado na expressão (3.2) seja nulo. Logo, as tensões principais $\left(\sigma_{\mathrm{p}}\right)$ são obtidas com a resolução do polinômio do terceiro grau mostrado a seguir:

$$
\sigma_{p}{ }^{3}-I_{1} \cdot \sigma_{p}{ }^{2}+I_{2} \cdot \sigma_{p}-I_{3}=0
$$

onde $\mathrm{I}_{1}, \mathrm{I}_{2}$ e $\mathrm{I}_{3}$ são os invariantes de tensão, dados por:

$$
\begin{aligned}
& I_{1}=\left|\sigma_{x}\right|+\left|\sigma_{y}\right|+\left|\sigma_{z}\right| \\
& I_{2}=\left|\begin{array}{ll}
\sigma_{x} & \tau_{x y} \\
\tau_{y x} & \sigma_{y}
\end{array}\right|+\left|\begin{array}{ll}
\sigma_{x} & \tau_{x z} \\
\tau_{z x} & \sigma_{z}
\end{array}\right|+\left|\begin{array}{ll}
\sigma_{y} & \tau_{y z} \\
\tau_{z y} & \sigma_{z}
\end{array}\right| \\
& I_{3}=\left|\begin{array}{lll}
\sigma_{x} & \tau_{x y} & \tau_{x z} \\
\tau_{y x} & \sigma_{y} & \tau_{y z} \\
\tau_{z x} & \tau_{z y} & \sigma_{z}
\end{array}\right|
\end{aligned}
$$

Os invariantes de tensão são independentes do sistema de coordenadas adotado.

Uma maneira alternativa de representar o estado de tensões em um ponto é pela soma de dois tensores, um com tensões puramente hidrostáticas $\left(\sigma_{\mathrm{m}} . \delta_{\mathrm{ij}}\right)$ e um com tensões desviatórias $\left(\mathrm{s}_{\mathrm{ij}}\right)$, ou seja:

$$
\sigma_{i j}=s_{i j}+\sigma_{m} \cdot \delta_{i j}
$$

onde:

- $\sigma_{m}=\frac{1}{3} \cdot\left(\sigma_{x}+\sigma_{y}+\sigma_{z}\right)$ é a tensão média ou hidrostática;

- $\delta$ ij é o delta de Kronecker, que assume os valores 1 para $\mathrm{i}=\mathrm{j}$ e 0 para $\mathrm{i} \neq \mathrm{j}$.

Logo, as tensões desviatórias são obtidas retirando-se do estado de tensões as componentes hidrostáticas:

$$
s_{i j}=\left[\begin{array}{ccc}
\sigma_{x}-\sigma_{m} & \tau_{x y} & \tau_{x z} \\
\tau_{y z} & \sigma_{y}-\sigma_{m} & \tau_{y z} \\
\tau_{z x} & \tau_{z y} & \sigma_{z}-\sigma_{m}
\end{array}\right]=\left[\begin{array}{ccc}
s_{x} & \tau_{x y} & \tau_{x z} \\
\tau_{y x} & s_{y} & \tau_{y z} \\
\tau_{z x} & \tau_{z y} & s_{z}
\end{array}\right]
$$

Os invariantes das tensões desviatórias são:

$$
J_{1}=\left|s_{x}\right|+\left|s_{y}\right|+\left|s_{z}\right|=0
$$




$$
\begin{aligned}
J_{2} & =\frac{1}{6} \cdot\left[\left(\sigma_{x}-\sigma_{y}\right)^{2}+\left(\sigma_{y}-\sigma_{z}\right)^{2}\left(\sigma_{z}-\sigma_{x}\right)^{2}\right]+\tau_{x y}{ }^{2}+\tau_{y z}{ }^{2}+\tau_{x z}{ }^{2} \\
J_{3} & =\left|\begin{array}{lll}
s_{x} & \tau_{x y} & \tau_{x z} \\
\tau_{x y} & s_{y} & \tau_{y z} \\
\tau_{x z} & \tau_{y z} & s_{z}
\end{array}\right|
\end{aligned}
$$

\subsubsection{Intepretação física e geométrica dos invariantes}

O critério de ruptura deve ser independente do sistema de coordenadas adotado para representar o estado de tensão. Uma possibilidade seria utilizar as tensões principais $\sigma_{1} \geq \sigma_{2} \geq \sigma_{3}$, obtidas por meio da expressão (3.3). O critério de ruptura seria função destas tensões principais:

$$
f\left(\sigma_{1}, \sigma_{2}, \sigma_{3}\right)=0
$$

Porém esta forma de análise fica complexa e de difícil interpretação física. Uma maneira mais simples de representar o critério de ruptura é através dos invariantes de tensão $I_{1}, J_{2}$ e $J_{3} . I_{1}$ representa um estado hidrostático puro e $J_{2}$ e $J_{3}$ representam estados de cisalhamento puro.

A interpretação física destes invariantes pode ser dada por meio das tensões octaédricas. Estas são as tensões atuantes em um plano cuja normal faz ângulos iguais com as direções principais (plano octaédrico). Pode-se demonstrar que as componentes normal e de cisalhamento das tensões octaédricas respectivamente são dadas por:

$$
\begin{aligned}
& \sigma_{\text {oct }}=\frac{1}{3} \cdot l_{1}=\sigma_{m} \\
& \tau_{\text {oct }}=\sqrt{\frac{2}{3} \cdot J_{2}}
\end{aligned}
$$

A direção da componente de cisalhamento é definida por

$$
\cos (3 \theta)=\frac{3 \sqrt{3}}{2} \cdot \frac{J_{3}}{J_{2^{\frac{3}{2}}}}
$$

onde $\theta$ é o ângulo de similaridade, que varia entre 0 e $60^{\circ}$.

Assim obtém-se a representação dos invariantes $I_{1}, J_{2}$ e $J_{3}$ por $\sigma_{\text {oct }} \tau_{\text {oct }}$ e $\theta$. Outra interpretação é dada pelas tensões médias. Considerando-se um elemento de volume esférico em que a cada ponto de sua superfície atuam uma tensão normal $\left(\sigma_{\mathrm{s}}\right)$ 
e uma de cisalhamento $\left(\tau_{\mathrm{s}}\right)$, pode-se obter tensões médias sobre a superfície da esfera (S). A tensão normal média é dada por:

$$
\begin{aligned}
& \sigma_{m}=\lim _{S \rightarrow 0}\left[\frac{1}{S} \int_{S} \sigma_{S} d S\right] \\
& \sigma_{m}=\frac{1}{3}\left(\sigma_{1}+\sigma_{2}+\sigma_{3}\right)=\frac{1}{3} \cdot l_{1}
\end{aligned}
$$

As tensões cisalhantes são dadas por um valor quadrático médio:

$$
\begin{aligned}
& \tau_{m}=\lim _{S \rightarrow 0}\left[\frac{1}{S} \int_{S} \tau_{S}{ }^{2} d S\right]^{\frac{1}{2}} \\
& \tau_{m}{ }^{2}=\frac{2}{5} J_{2}
\end{aligned}
$$

A interpretação geométrica pode ser dada em um espaço tri-dimensional em que as coordenadas são as tensões principais. Suponhamos que $\sigma_{1} \geq \sigma_{2} \geq \sigma_{3}$ sejam as tensões principais de um determinado estado de tensões em um ponto. Nesta representação não importa a direção dos eixos principais, ou o sistema de coordenadas adotado para representar o estado de tensão, apenas a magnitude das tensões principais é que determina um ponto neste espaço. Assim um estado de tensão pode ser representado pelo vetor que une o ponto $\mathrm{O}$ (origem) ao ponto $\mathrm{P}\left(\sigma_{1}\right.$, $\left.\sigma_{2}, \sigma_{3}\right)$. Na Figura 3.3 é apresentado este espaço, que é denominado Espaço de Tensões de Haigh-Westergaard.

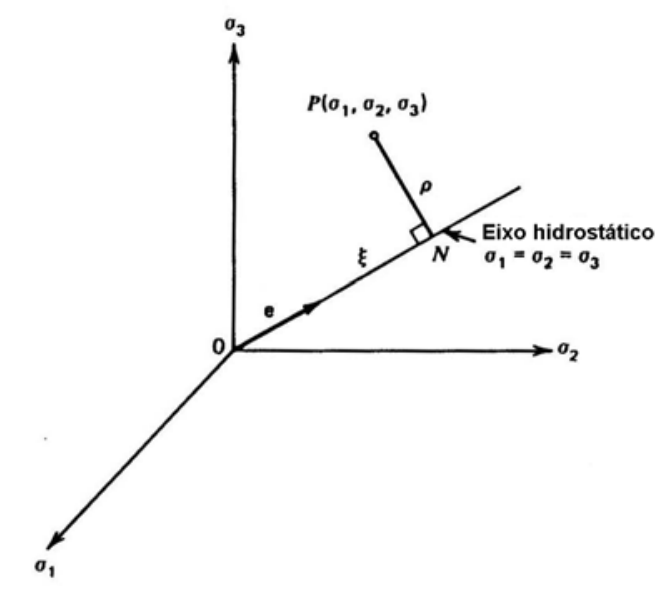

Figura 3.3 - Espaço de tensões de Haigh-Westergaard (CHEN, 1982)

O eixo hidrostático corresponde a estados de tensão hidrostáticos, em que as tensões principais são todas iguais. Os planos perpendiculares ao eixo hidrostático 
são os planos desviatórios. O plano desviatório que passa pela origem $\left(\sigma_{1}+\sigma_{2}+\sigma_{3}=0\right)$ é denominado plano $\pi$.

$\mathrm{O}$ estado de tensão, representado pelo vetor $\overline{\mathrm{OP}}$ pode ser decomposto em duas componentes $\xi$ e $\rho$, hidrostática e desviatória respectivamente. Estas podem ser calculadas por:

$$
\begin{aligned}
& \xi=\frac{1}{\sqrt{3}} I_{1}=\sqrt{3} \cdot \sigma_{o c t}=\sqrt{3} \cdot \sigma_{m} \\
& \rho=\sqrt{2 \cdot J_{2}}=\sqrt{3} \cdot \tau_{o c t}=\sqrt{3} \cdot \tau_{m}
\end{aligned}
$$

Na Figura 3.4 é apresentada a projeção do estado de tensões e os eixos do espaço de Haigh-Westergaard em um plano desviatório qualquer. Nesta Figura apresenta-se também o ângulo de similaridade, que é contido no plano desviatório e é medido da direção positiva do eixo $\sigma_{1}$.

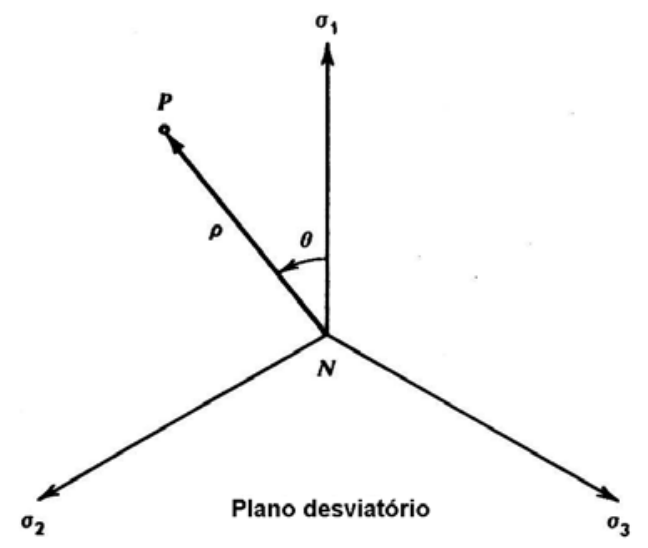

Figura 3.4 - Projeção no plano deviatório (CHEN, 1982)

Pode-se demonstrar que o ângulo de similaridade é dado por:

$$
\cos \theta=\frac{\sqrt{3}}{2} \cdot \frac{s_{1}}{\sqrt{J_{2}}}=\frac{2 \sigma_{1}-\sigma_{2}-\sigma_{3}}{2 \sqrt{3} \sqrt{J_{2}}}
$$

\subsubsection{Superfície de ruptura do concreto}

A envoltória de ruptura do concreto pode ser dada como uma superfície no espaço de Haigh-Westergaard em função dos invariantes $\xi, \rho$ e $\theta$. A forma desta superfície está indicada na Figura 3.5. 


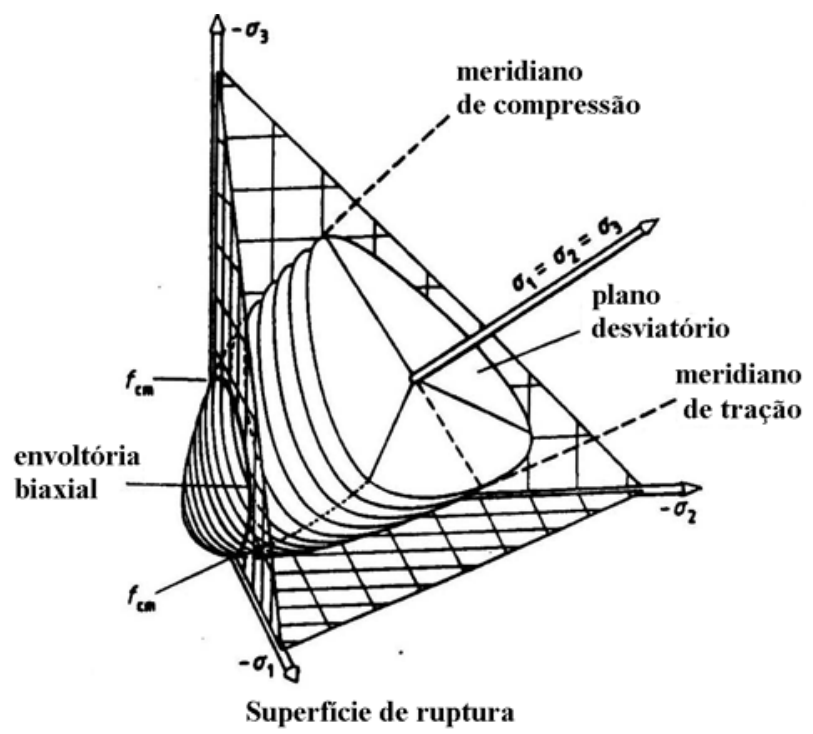

Figura 3.5 - Superfície de ruptura do concreto (FIB, 1999)

Uma maneira mais fácil de visualizar esta superfície é por meio de seções transversais e meridianos. As seções transversais são obtidas na interseção da superfície de ruptura com os planos desviatórios em que $\xi=$ constante e apresentam uma forma semelhante à indicada na Figura 3.6.

Pode-se observar que a seção transversal da envoltória se modifica com o nível de tensão hidrostática, dado por $\mathrm{I}_{1}$. A forma da curva na seção transversal varia na direção do eixo hidrostático, sendo aproximadamente triangular para tensões de tração e pequenas tensões de compressão e se aproxima da forma circular para maiores tensões de compressão (maiores tensões hidrostáticas). A curva da seção transversal é suave, convexa e simétrica em relação à projeção dos três eixos de coordenadas. Logo basta conhecer o comportamento para $\theta$ entre 0 e $60^{\circ}$ para determinar a curva em um determinado plano desviatório.

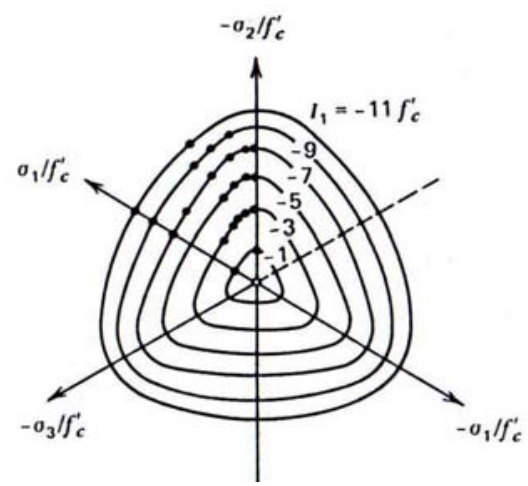

Figura 3.6 - Forma da seção transversal em diferentes níveis de $\xi(C H E N, 1982)$ 
Os meridianos são formados pela interseção da superfície de ruptura e planos contendo o eixo hidrostático, $\operatorname{com} \theta$ constante. Por condições de simetria do ângulo $\theta$ torna-se necessário variá-lo apenas de 0 a $60^{\circ}$. Existem dois meridianos em particular que merecem especial atenção: o de 0 e o de $60^{\circ}$. O meridiano de $60^{\circ}$ é o meridiano de compressão. Este representa uma tensão de compressão uniaxial sobreposta a uma pressão hidrostática. Segundo CHEN (1982) a maior parte dos dados experimentais foi obtida neste meridiano. São exemplos o estado de compressão uniaxial (pressão hidrostática nula), de tração biaxial igual e os casos de confinamento (passivo ou ativo) com pressão radial uniforme.

$\mathrm{O}$ meridiano de $0^{\circ}$ é o de tração. Corresponde a uma tensão de tração uniaxial somada a uma pressão hidrostática. São poucos os dados de ensaios, entre estes o ensaio de tração uniaxial. A forma destes meridianos foi obtida por meio de ensaios com pressão lateral aplicada por fluidos, e é apresentada na Figura 3.7. Os meridianos de 0 e $60^{\circ}$ são importantes para a determinação da superfície de ruptura. A curva dos meridianos também é suave e convexa (CHEN, 1982).

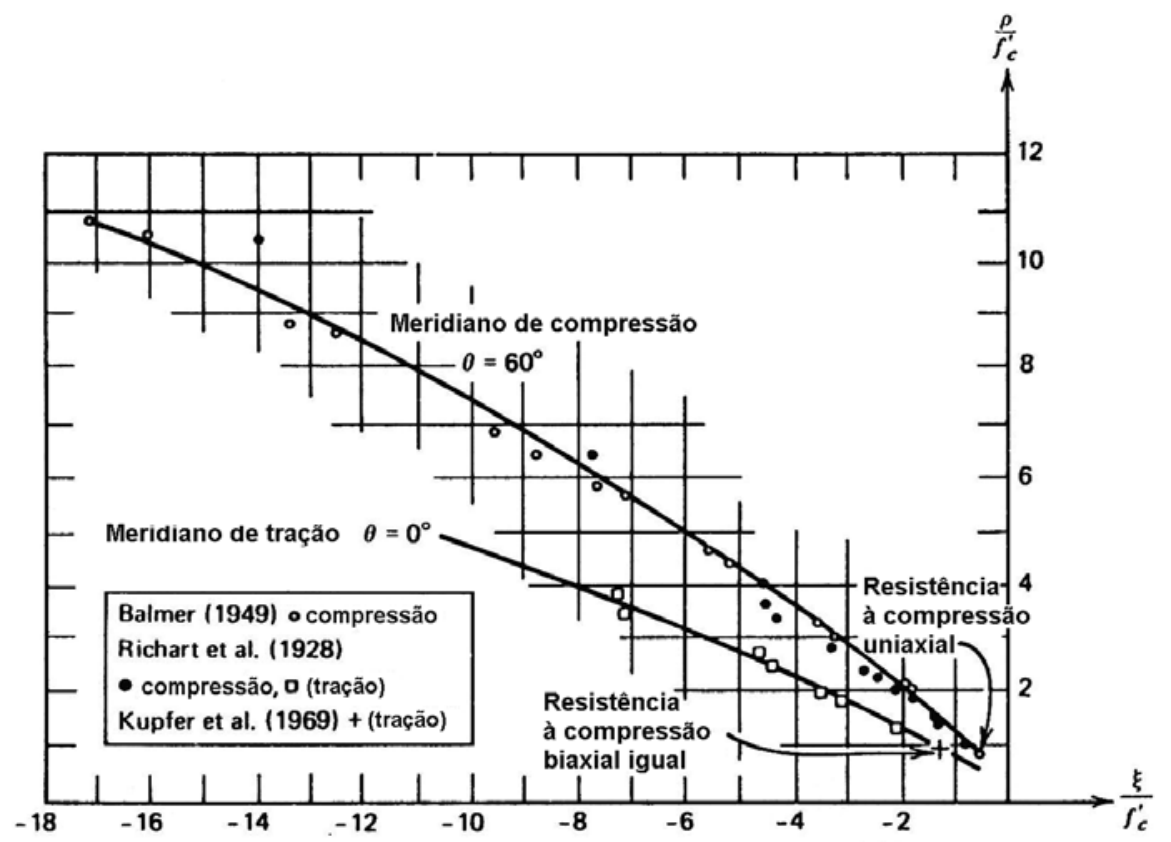

Figura 3.7 - Meridianos de compressão e tração (CHEN, 1982) 
Segundo CHEN (1982) um carregamento puramente hidrostático não pode levar o material à ruptura. CHIN e ZIMERMAN ${ }^{1}$ apud CHEN (1982) determinaram uma curva de ruptura ao longo do meridiano de compressão até uma tensão hidrostática em que $I_{1}=-79 \cdot f_{c o}$, sem verificar uma tendência de aproximação da curva com o eixo hidrostático. Porém atingindo-se tensões de compressão hidrostática muito altas ocorrem danos significativos na estrutura do concreto, devido à sua heterogeneidade.

\subsubsection{Critérios de ruptura do concreto}

O comportamento real do concreto em diferentes estados de tensão depende de suas propriedades físicas e mecânicas, bem como da natureza do carregamento. Os modelos de ruptura mais comuns são definidos no espaço de tensões por um número de variáveis independentes entre 1 e 5 . Os critérios iniciais eram mais simples, com 1 ou 2 parâmetros, possibilitando cálculos manuais. Com o avanço da computação e disponibilidade de mais dados experimentais foi possível refinar estes critérios iniciais e desenvolver alguns mais complexos, com três, quatro ou cinco parâmetros (CHEN, 1982).

Neste trabalho são apresentados alguns dos critérios de ruptura de maior aplicação ao concreto. Abordou-se aqui apenas critérios dependentes da pressão hidrostática, fator essencial na análise do concreto confinado.

\subsubsection{Critério de MOHR-COULOMB}

Parte-se do princípio que a resistência do material depende do ângulo de atrito interno de suas partículas $\phi$ e da coesão c (2 parâmetros). De uma maneira simplificada pode-se dizer que:

$$
|\tau|=c-\sigma \cdot \tan \phi
$$

onde $\tau$ é a tensão de cisalhamento e $\sigma$ é a tensão normal atuantes em um plano qualquer do material. Na Figura 3.8 o critério é apresentado em função de $\tau$ e $\sigma$. Qualquer estado de tensão contido entre as linhas da envoltória é seguro.

\footnotetext{
${ }^{1}$ CHIN, J.; ZIMMERMAN, R. M. (1965). Behaviour of Plain Concrete Under Various High Triaxial Compression Loadings Conditions.Techical Report No. WL TR 64-163 (AD 468460), Air Force Weapons Laboratory, New Mexico, August, 1965.
} 


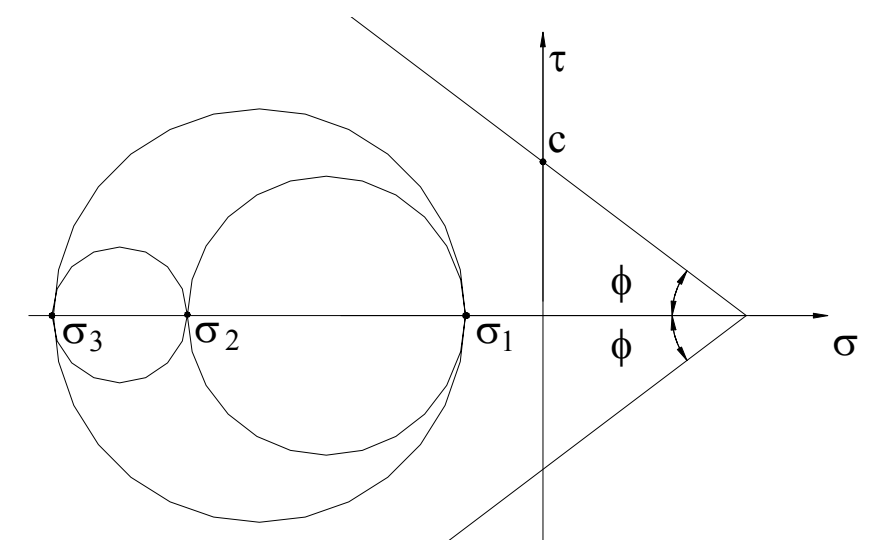

Figura 3.8 - Envoltória de MOHR-COULOMB

Outra maneira de se expressar o critério é em função das tensões principais:

$$
\sigma_{1} \cdot \frac{(1+\operatorname{sen} \phi)}{2 \cdot c \cdot \cos \phi}-\sigma_{3} \cdot \frac{(1-\operatorname{sen} \phi)}{2 \cdot c \cdot \cos \phi}=1
$$

Pode-se notar que o critério foi formulado sem considerar o efeito da tensão intermediária. Isto é uma fonte de erro, já que no próprio estado biaxial de compressão despreza-se um aumento de até $25 \%$ da resistência do concreto. No confinamento em pilares cuja pressão lateral é uniforme isto não causa maiores problemas, pois duas das tensões principais são iguais (pressão lateral) e a outra é menor (compressão axial).

Em termos dos invariantes escreve-se

$$
\begin{aligned}
& f\left(l_{1}, J_{2}, \theta\right)=\frac{1}{3} \cdot l_{1} \cdot \operatorname{sen} \phi+\sqrt{J_{2}} \cdot \operatorname{sen}\left(\theta+\frac{1}{3} \pi\right)+\frac{\sqrt{J_{2}}}{\sqrt{3}} \cdot \cos \left(\theta+\frac{\pi}{3}\right) \cdot \operatorname{sen} \phi-c \cdot \cos \phi=0 \\
& f(\xi, \rho, \theta)=\sqrt{2} \cdot \xi \cdot \operatorname{sen} \phi+\sqrt{3} \cdot \rho \cdot \operatorname{sen}\left(\theta+\frac{1}{3} \pi\right)+\rho \cdot \cos \left(\theta+\frac{\pi}{3}\right) \cdot \operatorname{sen} \phi-\sqrt{6} \cdot c \cdot \cos \phi=0
\end{aligned}
$$

No caso de pressão lateral uniforme pode-se equacionar a envoltória em termos da pressão lateral $\left(f_{1}\right)$, da resistência do concreto confinado $\left(f_{c c}\right)$ e da resistência do concreto não confinado $\left(f_{c o}\right)$. Na Figura 3.9 são representados dois estados de tensão de ruptura. Um deles é a ruptura do concreto sob compressão axial simples (representado pelo círculo menor). O outro é o concreto confinado por uma pressão lateral $f_{1}$. Para dado valor de $f_{1}$ a ruptura ocorre quando a tensão axial supera o valor $\mathrm{f}_{\mathrm{cc}}$. Neste ponto o círculo correspondente ao estado de tensão tangencia a envoltória. 


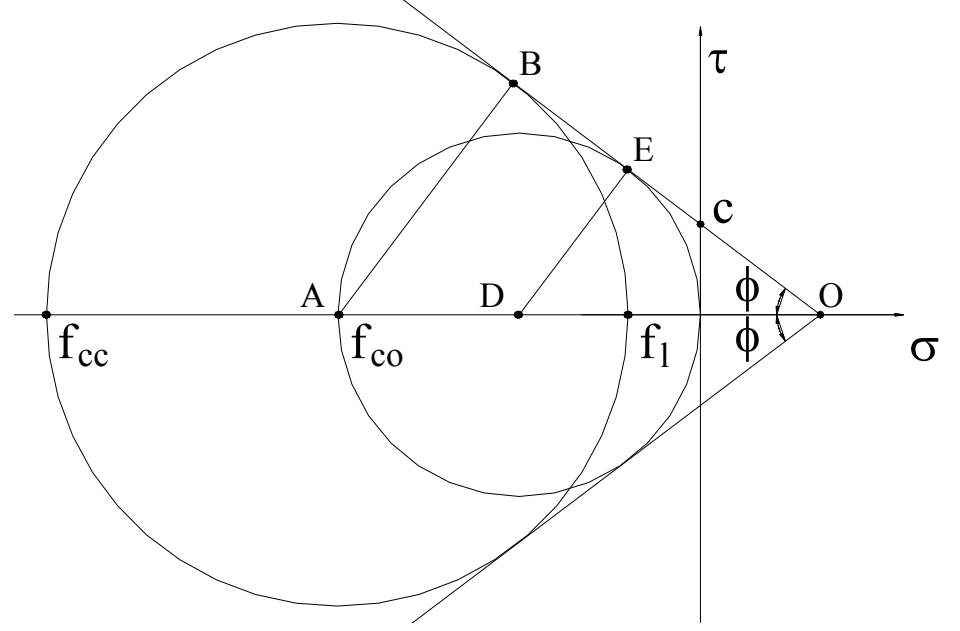

Figura 3.9 - Estados de tensão na ruptura

Utilizando-se a semelhança dos triângulos $\overline{A B O}$ e $\overline{D E O}$ e a relação dada por $c=\frac{1-\operatorname{sen}(\phi)}{2 \cdot \cos (\phi)} \cdot f_{c o}$

Pode-se expressar o critério de MOHR-COULOMB em termos de $f_{c o}, f_{l}, f_{c c}$ e $\phi$, por meio de:

$$
f_{c c}=f_{c o}+\frac{1+\operatorname{sen}(\phi)}{1-\operatorname{sen}(\phi)} \cdot f_{l}
$$

Assumindo-se para $\phi$ o valor de $37^{\circ}$ (conforme recomendações de SHEHATA et al., 2001) obtém-se uma envoltória dada por:

$$
f_{c c}=f_{c o}+4,02 \cdot f_{l}
$$

$\mathrm{Na}$ Figura 3.10 pode-se observar a forma da superfície de ruptura do critério de MOHR-COULOMB, por meio dos meridianos e seções transversais.
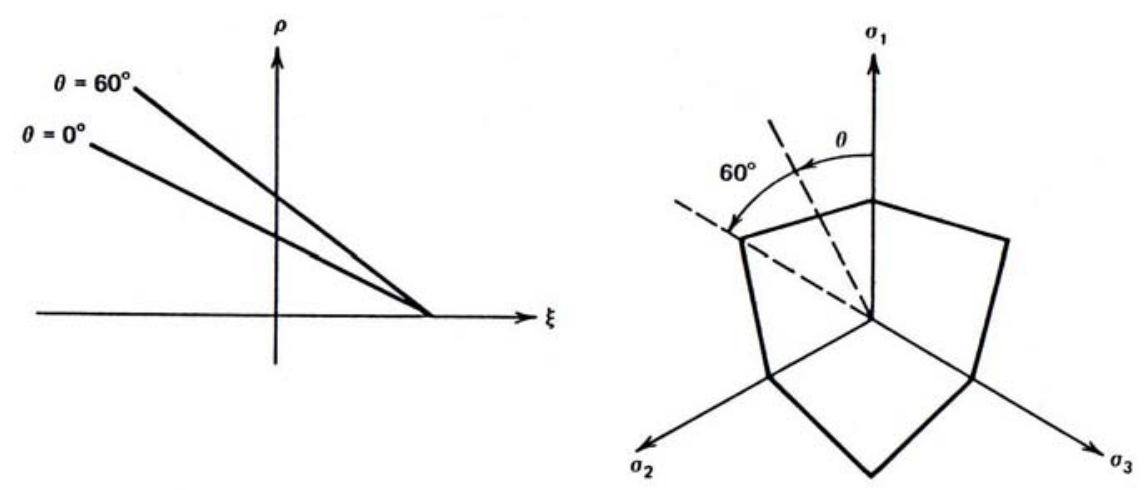

Figura 3.10 - Envoltória de MOHR-COULOMB (CHEN, 1982) 
Para melhor aproximação, no caso de tensões de tração pode-se utilizar um critério de corte para a tensão máxima de tração. Assim o modelo fica com três parâmetros.

Por simplicidade, os primeiros critérios, como o de MOHR-COULOMB, assumiam que as seções desviatórias eram similares na forma em todos níveis de pressão hidrostática. O único ajuste da pressão lateral era sobre o tamanho da seção transversal.

\subsubsection{Critério de DRUCKER-PRAGER}

Segundo CHEN (1982), a superfície de ruptura do critério de MOHRCOULOMB tem cantos que causam dificuldades na obtenção de soluções numéricas. DRUCKER E PRAGER ${ }^{2}$ apud CHEN (1982) sugeriram então uma suavização do critério de MOHR COULOMB por meio de uma modificação no critério de von Mises. O critério de Drucker Prager $^{2}$ é expresso por:

$$
\begin{aligned}
& f\left(I_{1}, J_{2}\right)=\alpha \cdot I_{1}+\sqrt{J_{2}}-k=0 \\
& f(\xi, \rho)=\sqrt{6} \cdot \alpha \cdot \xi+\rho-\sqrt{2} \cdot k=0
\end{aligned}
$$

onde os dois parâmetros são $\alpha$ e k.

O critério de Drucker-Prager ${ }^{2}$ é mais utilizado para solos. Porém encontra aplicações na modelagem numérica, inclusive do confinamento, utilizando o método dos elementos finitos, como relata MIRMIRAN et al. (2000). Na Figura 3.11 é apresentada a envoltória de ruptura.
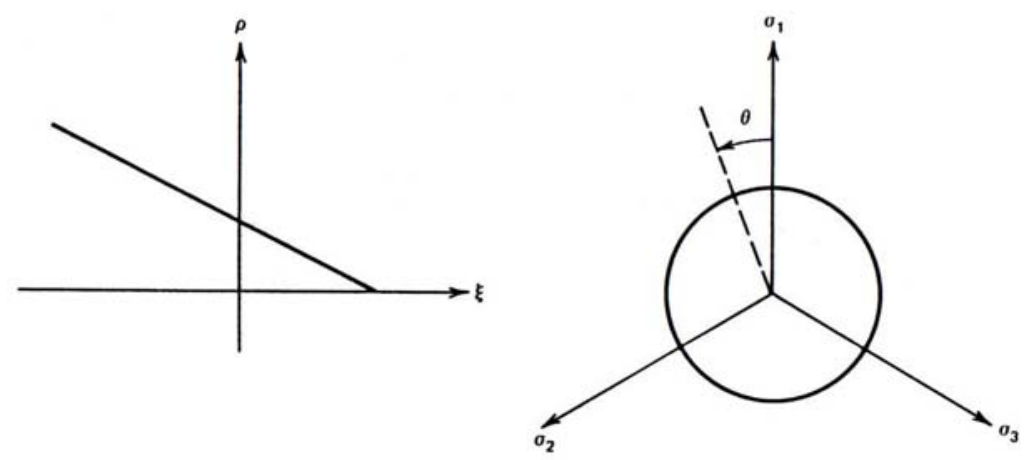

Figura 3.11 - Superfície de ruptura proposta por DRUCKER-PRAGER (CHEN, 1982)

${ }^{2}$ DRUCKER, D. C.; PRAGER, W. (1952). Soil Mechanics and Plastic Analysis or Limit Design, Quarterly of Applied Mathematics, Vol. X., No. 2, 1952, pp. 157-165. 
As limitações do critério de Drucker-Prager ${ }^{2}$ são a relação linear entre $\xi$ e $\rho$ e a independência do ângulo de similaridade.

\subsubsection{Critérios de 3 parâmetros}

Nos critérios de 3 parâmetros procurou-se refinar a envoltória de ruptura em relação aos anteriormente apresentados. Pode-se utilizar uma relação parabólica entre $\xi$ e $\rho$ mantendo-se a independência do ângulo de similaridade. Outra alternativa é manter a relação linear entre $\xi$ e $\rho$ utilizando seções desviatórias dependentes do ângulo de similaridade.

BRESLER \& PISTER $^{3}$ apud CHEN (1982) propuseram um modelo com relação parabólica entre $\xi$ e $\rho$, e com seções desviatórias circulares. A relação em termos de tensões octaédricas é dada por:

$$
\frac{\tau_{o c t}}{f_{c o}}=a-b \cdot\left(\frac{\sigma_{o c t}}{f_{c o}}\right)+c \cdot\left(\frac{\sigma_{o c t}}{f_{c o}}\right)^{2}
$$

onde os parâmetros a, b e c são obtidos com dados experimentais. A Figura 3.12 mostra a envoltória.
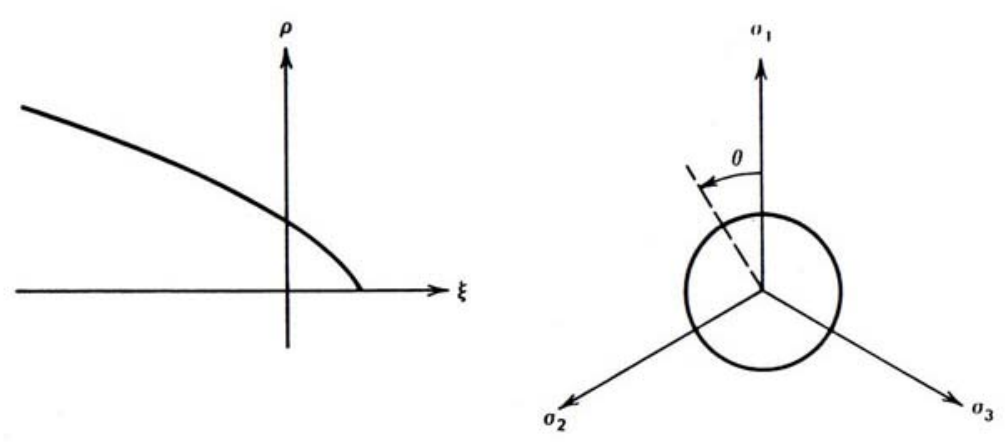

\section{Figura 3.12 - Envoltória do critério de Bresler \& Pister (CHEN, 1982)}

Argyris et al. ${ }^{4}$ apud CHEN (1982) sugeriu um modelo de três parâmetros em função dos invariantes, dado pela expressão (3.33).

\footnotetext{
${ }^{3}$ BRESLER, G. G.; PISTER, K. S. (1958). Strength of Concrete Under Combined Stresses. Journal of American Concrete Institute, September, 1958, pp. 321-345.

4 ARGYRIS, J. H.; FAUST, G.; WILLAN, K. J. (1976). Limit Load Analyis of Thick-walled Concrete Structures - A Finite Element Approach to Fracture. Computer Methods in Applied Mechanics and Engineering. Vol. 8, North-Holland Co., 1976, pp. 215-243.
} 


$$
f\left(I_{1}, J_{2}, \theta\right)=d \frac{I_{1}}{f_{c o}}+(e-f \cdot \cos 3 \theta) \frac{\sqrt{J_{2}}}{f_{c o}}-1=0
$$

onde os parâmetros d, e e f são obtidos dos dados experimentais. Este critério mantém os meridianos com relações lineares e seções desviatórias não circulares.

\subsubsection{Critério de OTTOSEN}

O critério de OTTOSEN ${ }^{5}$ apud CHEN (1982) é expresso em função de $\mathrm{I}_{1}, \mathrm{~J}_{2} \mathrm{e}$ $\theta$, conforme equação a seguir:

$$
f\left(I_{1}, J_{2}, \cos 3 \theta\right)=\gamma \frac{J_{2}}{f_{c o}}+\lambda \frac{\sqrt{J_{2}}}{f_{c o}}+\beta \frac{I_{1}}{f_{c o}}-1=0
$$

onde:

$$
\begin{aligned}
& \lambda=\eta_{1} \cdot \cos \left[\frac{1}{3} \cdot \cos ^{-1}\left(\eta_{2} \cdot \cos 3 \theta\right)\right] \quad \text { para } \quad \cos 3 \theta \geq 0 \\
& \lambda=\eta_{1} \cdot \cos \left[\frac{\pi}{3}-\frac{1}{3} \cdot \cos ^{-1}\left(-\eta_{2} \cdot \cos 3 \theta\right)\right] \quad \text { para } \quad \cos 3 \theta \leq 0
\end{aligned}
$$

As variáveis $\gamma, \beta, \eta_{1}$ e $\eta_{2}$ são constantes (4 parâmetros) determinadas experimentalmente, com ensaios de compressão e tração uniaxial, compressão biaxial e algum ensaio triaxial no meridiano de compressão.

Os meridianos são parabólicos e as seções desviatórias não circulares. A forma da seção desviatória varia de aproximadamente triangular para pequenas tensões e aproximadamente circular para grandes tensões de compressão. Este critério é adotado pelo FIB (2000) para estados múltiplos de tensão. A superfície de ruptura obtida foi apresentada na Figura 3.5.

\subsubsection{Critério de Willam \& Warnke}

No critério de WILLAM \& WARNKE ${ }^{6}$ apud CHEN (1982) os meridianos são representados por parábolas enquanto as seções transversais são representadas

\footnotetext{
${ }^{5}$ OTTOSEN, N. S. (1977). A Failure Criterion for Concrete. Journal of the Engineering Mechanics Division, ASCE, Vol. 103, No. EM 4, August 1977, pp. 527-535.

${ }^{6}$ WILlAN, K. J.; WARNKE, E. P. (1974). Constitutive Models for the Triaxial Behaviour of Concrete. International Association of Bridge and Structural Engineers Seminar on Concrete Structures Subjected to Triaxial Stresses, Paper III-1, Bergamo, Italy, May 17-19, 1974, pp. 1-30.
} 
por curvas elípticas. Na Figura 3.13 podem ser observadas as características destas curvas.
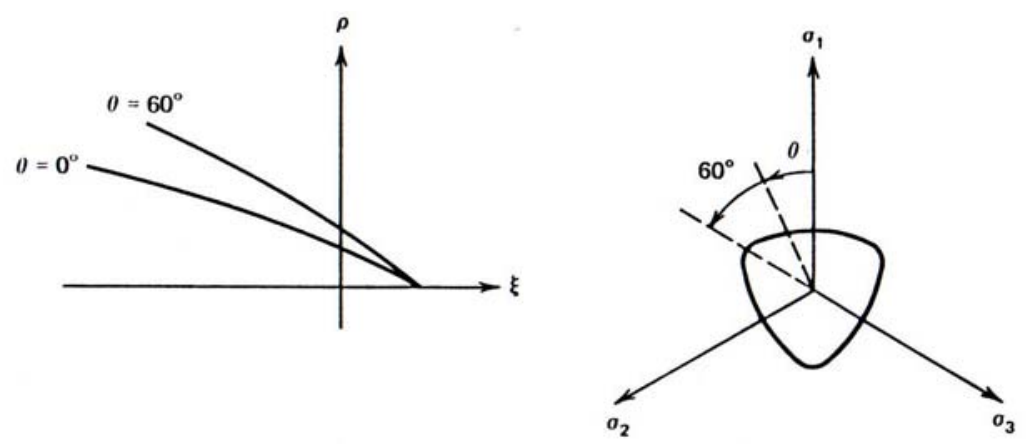

Figura 3.13 - Critério de Willam \& Warnke (CHEN, 1982)

A envoltória é definida com cinco parâmetros obtidos experimentalmente por meio de ensaios de compressão e tração uniaxial, compressão biaxial igual, ensaios triaxiais a altos valores de compressão nos meridianos de compressão e tração. Estes pontos são indicados na Figura 3.14.

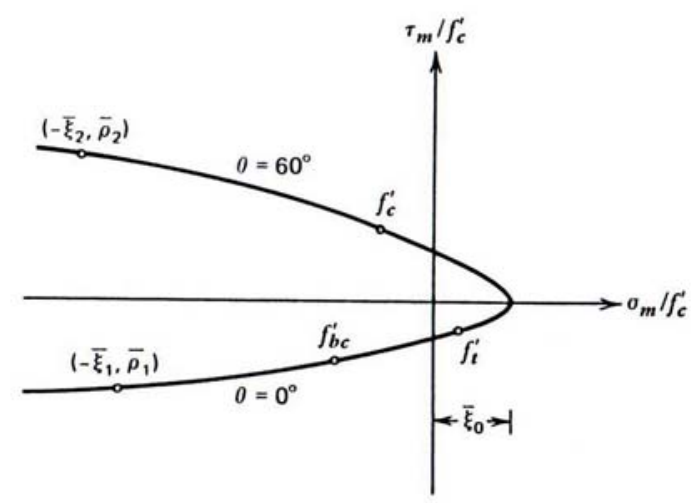

\section{Figura 3.14 - Ensaios para definição dos parâmetros (CHEN, 1982)}

Os pontos apresentados na Figura 3.14 definem as curvas dos meridianos, que são obtidas em função das tensões médias no meridiano de tração e compressão, ou dos invariantes $\rho_{\mathrm{c}}$ e $\rho_{\mathrm{t}}$ :

$$
\begin{aligned}
& \frac{\tau_{m t}}{f_{c o}}=\frac{\rho_{t}}{\sqrt{5} \cdot f_{c o}}=a_{o}+a_{1}\left(\frac{\sigma_{m}}{f_{c o}}\right)+a_{2}\left(\frac{\sigma_{m}}{f_{c o}}\right)^{2} \quad \theta=0^{\circ} \\
& \frac{\tau_{m c}}{f_{c o}}=\frac{\rho_{c}}{\sqrt{5} \cdot f_{c o}} b_{o}+b_{1}\left(\frac{\sigma_{m}}{f_{c o}}\right)+b_{2}\left(\frac{\sigma_{m}}{f_{c o}}\right)^{2} \theta=60^{\circ}
\end{aligned}
$$

Fazendo-se com que as curvas dos meridianos se encontrem com o eixo hidrostático no mesmo ponto elimina-se dois parâmetros, sendo necessários então apenas cinco. 
O critério possui meridianos muito convexos, prejudicando a previsão da resistência a pressões hidrostáticas muito altas. As seções transversais representam bem o comportamento do concreto, sendo mais próximas de triangulares para pequenas tensões de compressão e aproximando-se da forma circular para grandes tensões de compressão.

As seções transversais são obtidas por meio da equação (3.39), em função de $\theta$ :

$$
\rho(\theta)=\frac{2 \rho_{c} \cdot\left(\rho_{c}{ }^{2}-\rho_{c}{ }^{2}\right) \cos (\theta)+\rho_{c} \cdot\left(2 \rho_{t}-\rho_{c}\right) \cdot\left[4\left(\rho_{c}{ }^{2}-\rho_{t}{ }^{2}\right) \cdot \cos ^{2} \theta+5 \rho_{t}{ }^{2}-4 \rho_{t} \rho_{c}\right]^{\frac{1}{2}}}{4\left(\rho_{c}{ }^{2}-\rho_{t}{ }^{2}\right) \cdot \cos ^{2} \theta+\left(\rho_{c}-2 \rho_{c}\right)^{2}}
$$

A superfície de ruptura é dada por:

$$
f\left(\sigma_{m}, \tau_{m}, \theta\right)=\sqrt{5} \cdot \frac{\tau_{m}}{\rho\left(\sigma_{m}, \theta\right)}
$$

\subsubsection{Deformabilidade do concreto}

Ensaios experimentais apresentados por BALMER ${ }^{7}$ apud CHEN (1982) mostraram que com diferentes níveis de confinamento o comportamento do concreto pode ser quase-frágil, plástico com amolecimento ou plástico com endurecimento (ver Figura 3.15). Nestes ensaios o concreto foi submetido a determinados níveis de pressão hidrostática (por meio de pressão de fluidos) e então carregado à compressão axial até a ruptura. Segundo CHEN (1982) o aumento da pressão hidrostática diminui a possibilidade de fissuras de aderência e o modo de ruptura passa de segmentação a esmagamento da pasta de cimento.

\footnotetext{
${ }^{7}$ BALMER, G. G., (1949). Shearing Strentgh of Concrete Under High Triaxial Stress-Computation of Mohr's Envelope as a Curve. Structural Research Laboratory Report No. SP-23, Bureau of Reclamations, United States Department of the Interior.
} 


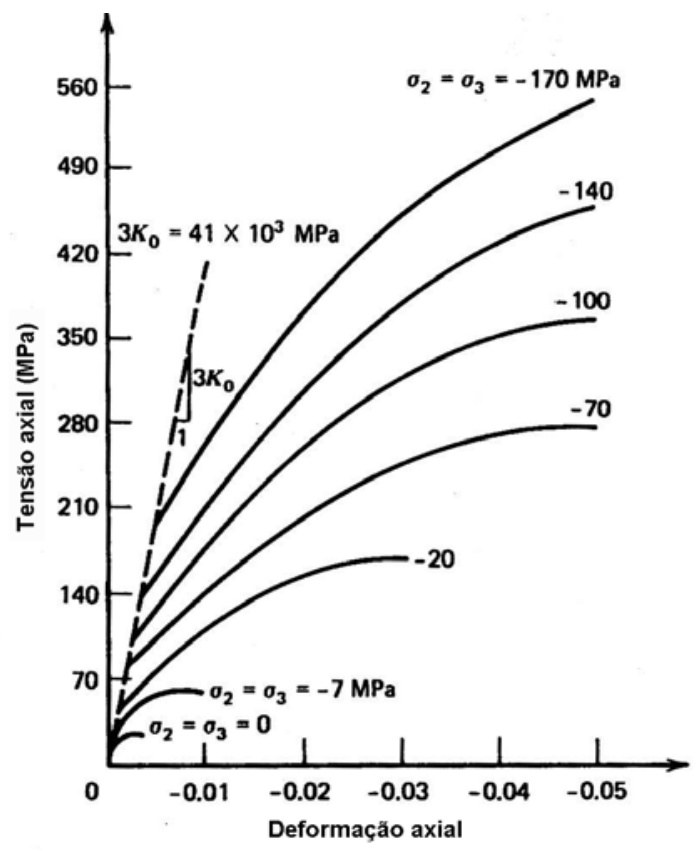

Figura 3.15 - Ensaios de compressão axial de concreto em diferentes níveis de pressão lateral (CHEN, 1982)

\subsubsection{Estado biaxial de tensão}

Resultados experimentais indicam que o concreto submetido à compressão biaxial apresenta um ganho de resistência. $\mathrm{O}$ aumento máximo de resistência ocorre quando $\sigma 2 / \sigma 1$ está próximo de 0,5 e pode representar um acréscimo superior a $25 \%$ sobre a resistência uniaxial. Num estado de compressão biaxial em que $\sigma 2 / \sigma 1=1$ a resistência apresenta um aumento da ordem de 16\% (CHEN, 1982). O ganho de resistência pode ser observado na Figura 3.16.

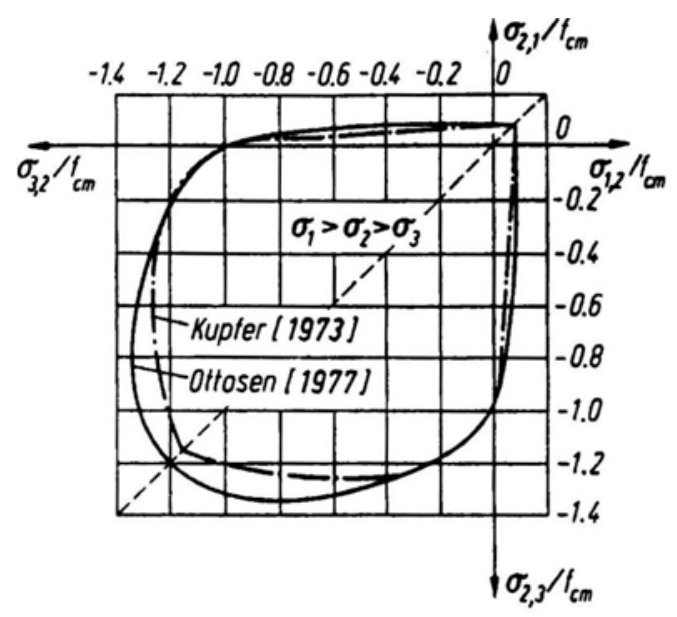

Figura 3.16 - Envoltória de ruptura em estados biaxiais (FIB, 1999) 
$\mathrm{Na}$ compressão biaxial ocorre uma inversão da expansão volumétrica semelhante à observada na compressão uniaxial (verificar na Figura 3.17). Ocorre uma redução de volume aproximadamente linear até uma tensão próxima à de ruptura, onde o comportamento se altera caminhando em direção a uma expansão volumétrica. Este aumento de volume é denominado "dilatancy" em CHEN (1982).

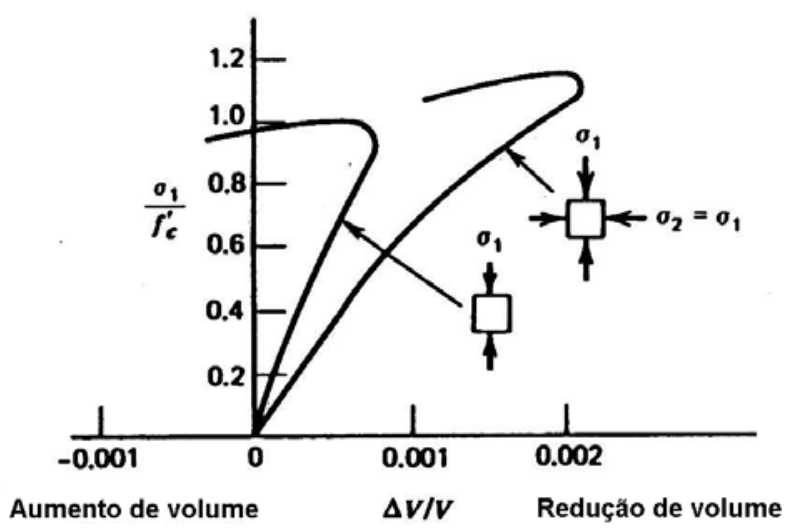

Figura 3.17 - Deformabilidade volumétrica do concreto em estados de compressão biaxial (CHEN, 1982) 


\section{Capitulo 4 Confinamento do concreto}

Pôde-se verificar na seção anterior que apenas o aumento das tensões hidrostáticas não provoca a ruptura do material. Isto é válido até certos limites, já que para tensões hidrostáticas muito altas a heterogeneidade do concreto pode causar a ruptura. Já que a ruptura é governada pelas tensões desviatórias, com o aumento da pressão confinante (pressão lateral) deve-se aplicar uma tensão axial maior para atingir a ruptura. A pressão lateral pode ser aplicada de forma ativa, através de um líquido confinante, ou de forma passiva.

\subsection{Confinamento passivo}

O confinamento passivo pode ser facilmente entendido analisando-se um pilar de seção circular envolvido por um tubo de parede fina. Imagine-se inicialmente que o pilar seja constituído de um material de comportamento elástico-linear e esteja livre de qualquer restrição lateral (Figura 4.1). Sabe-se que com a aplicação de um esforço axial (P) ocorre um encurtamento axial proporcional ao módulo de elasticidade deste material (E) e uma expansão radial proporcional a $v \cdot E$ (onde $v$ é o coeficiente de Poisson).

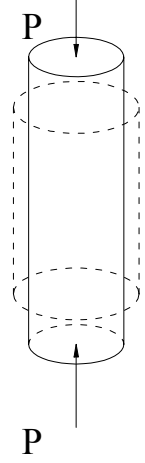

Figura 4.1 - Pilar de seção circular submetido à compressão axial

Suponha-se agora que o pilar da Figura 4.1 esteja envolvido por um tubo de parede fina antes da aplicação da carga, como indica a Figura 4.2. Aplicada a carga P o tubo restringe a deformação lateral, desenvolvendo-se no interior do tubo uma 
pressão $\mathrm{f}_{1}$. A magnitude desta pressão depende da carga axial aplicada, dos materiais constituintes do pilar e do tubo e das características geométricas envolvidas. No entanto, considerando que o tubo tenha uma parede fina, a relação entre a pressão interna e o esforço de tração na parede do tubo pode ser obtida através de um simples equilíbrio de esforços da seção transversal indicados na Figura 4.2.

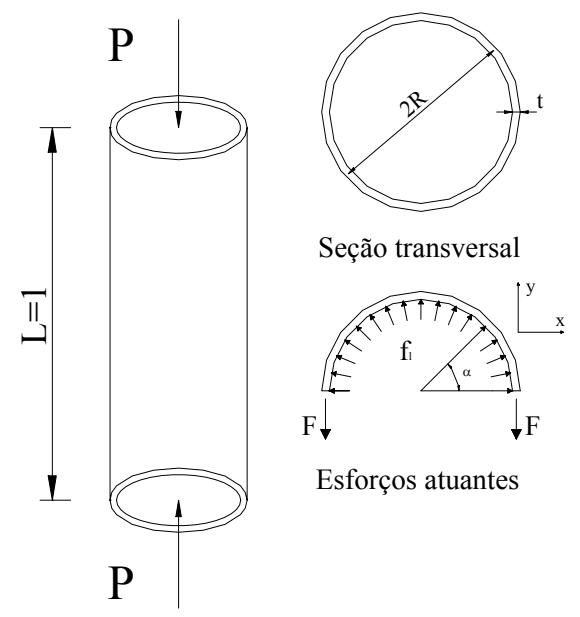

Figura 4.2 - Pilar envolvido por parede fina

Considerando-se o equilíbrio de forças na direção y:

$$
-2 \cdot F+\int_{0}^{\pi} f_{l} \cdot R \cdot \operatorname{sen} \alpha \cdot d \alpha=0
$$

onde:

- F é a resultante de tração por unidade de comprimento do tubo;

- R é o raio médio do tubo e $\alpha$ o ângulo central do pilar.

Por meio da expressão (4.1) chega-se à relação entre a pressão lateral $\left(\mathrm{f}_{1}\right)$ e o esforço no tubo $(\mathrm{F})$ :

$$
F=f_{l} \cdot R
$$

Como a parede é fina pode-se admitir que a tensão é constante ao longo da espessura ( $\mathrm{t}$ ) e é dada por:

$$
f_{p}=\frac{F}{t}
$$

onde $f_{p}$ é a tensão atuante no tubo na direção circunferencial (como a força $F$ da Figura 4.2).

Substituindo-se a expressão (4.2) na expressão (4.3) obtém-se a relação entre a pressão lateral e a tensão no tubo: 


$$
f_{p}=\frac{f_{l} \cdot R}{t}
$$

Sendo as áreas das seções transversais do pilar e do tubo envolvente dadas pelas equações (4.5) e (4.6) respectivamente

$$
\begin{aligned}
& A_{c}=\pi \cdot R^{2} \\
& A_{p}=2 \cdot \pi \cdot R \cdot t
\end{aligned}
$$

a taxa volumétrica do material do tubo pode ser expressa por:

$$
\rho_{p}=\frac{A_{p}}{A_{c}}
$$

Pode-se então relacionar a pressão lateral, a tensão no tubo e a taxa volumétrica do material do tubo:

$$
f_{l}=\frac{\rho_{p}}{2} \cdot f_{p}
$$

Deve-se salientar que a relação (4.8) independe do material existente no interior do tubo, que pode ser até mesmo um fluido, um material elástico ou o concreto. Considerando-se que este material é elástico, a relação entre a tensão longitudinal aplicada $\mathrm{f}_{\mathrm{cc}}$ e a pressão lateral $\mathrm{f}_{1}$ depende, entre outros fatores do módulo de elasticidade do material e do seu coeficiente de Poisson. Porém como o material em questão é o concreto outros fatores devem ser considerados, sobretudo aqueles que influenciam a expansão lateral, como a microfissuração.

\subsection{Efeito do confinamento sobre o concreto}

Para entender o efeito do confinamento no que se refere ao material concreto, FIB (1999) explica o seu mecanismo de ruptura sob carregamento uniaxial de uma maneira simplificada. Concretos correntes possuem cerca de $75 \%$ de agregados de vários tamanhos. Os agregados são os componentes rígidos do concreto e as forças de compressão caminham através deles (ver Figura 4.3-a). Para o equilíbrio são necessárias componentes laterais, que no concreto não confinado são provenientes da coesão da pasta de cimento ( Figura 4.3-b). Quando se supera esta coesão surgem as primeiras microfissuras entre agregados e a pasta de cimento ( Figura 4.3-c). As microfissuras crescem com o aumento da carga e o concreto rompe com fissuração 
paralela à aplicação da carga. O confinamento aumenta a coesão, resultando em uma maior resistência (ver Figura 4.3-d).

Quando o confinamento é obtido por meio de armaduras transversais são necessárias grandes deformações laterais para mobilizá-lo e conseqüentemente ocorre um aumento da ductilidade. O confinamento é portanto muito importante para aplicações em regiões com abalos sísmicos que necessitam de elevada ductilidade (FIB, 1990).

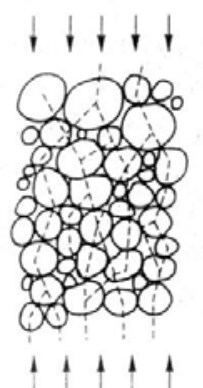

(a)

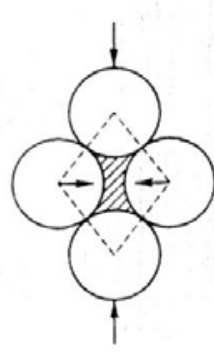

(b)

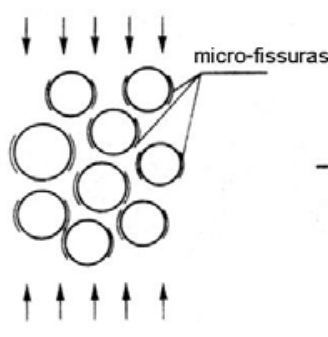

(c)

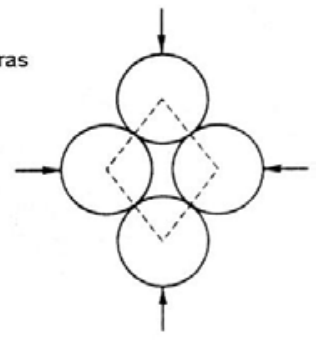

(d)

Figura 4.3 - Mecanismo de confinamento no concreto (FIB, 1990)

A resposta do concreto é diferente quanto ao confinamento passivo e ativo. Segundo EL-DASH \& AHMAD (1995) o confinamento obtido com armaduras transversais (passivo) torna-se importante em tensões da ordem da resistência uniaxial do concreto. A deformação lateral do concreto é muito pequena antes do início da microfissuração. Com o desenvolvimento da microfissuração a um nível de tensão mais elevado a expansão lateral cresce consideravelmente solicitando as armaduras transversais.

As propriedades do material confinante também influenciam a resposta do concreto. Existe uma grande diferença na pressão lateral desenvolvida por estribos de aço e por compósitos. $\mathrm{O}$ aço, após atingir o escoamento, proporciona uma pressão constante, enquanto o compósito possibilita uma pressão crescente até sua ruptura. Logo os modelos de confinamento são diferentes para os dois materiais confinantes, principalmente em relação à deformabilidade do concreto confinado. As duas formas de confinamento serão abordadas neste trabalho em separado. 


\subsection{Influência da pressão lateral}

Os primeiros estudos sobre concreto confinado datam do início do século XX. RICHART et $a l^{8}$ apud RAZVI \& SAATCIOGLU (1999-b) realizaram alguns dos primeiros ensaios de compressão axial do concreto confinado. Verificaram o comportamento do concreto submetido à pressão hidrostática de fluidos e de armaduras transversais. Nos ensaios com fluidos aplicava-se ao concreto uma pressão hidrostática sobrepondo-se um esforço de compressão axial por meio de um pistão até a ruptura do material. Foram ensaiados também cilindros com armadura em espiral.

RICHART et $a l^{8}$ verificaram que a resistência à compressão axial e a deformação última do concreto crescem na presença de pressões confinantes. Propuseram então equações lineares para relacionar a resistência $\left(f_{c c}\right)$ e a deformação última $\left(\varepsilon_{\mathrm{cc}}\right)$ do concreto confinado com a pressão lateral:

$$
\begin{aligned}
& f_{c c}=f_{c o}+k_{1} \cdot f_{l} \\
& \varepsilon_{c c}=\varepsilon_{c o}+k_{2} \cdot \frac{f_{l}}{f_{c o}}
\end{aligned}
$$

onde:

- $\mathrm{f}_{\mathrm{co}}$ é a resistência do concreto não confinado;

- $\mathrm{f}_{1}$ é a pressão lateral;

- $\mathrm{k}_{1}$ e $\mathrm{k}_{2}$ são coeficientes que assumem diferentes valores nos diversos modelos teóricos existentes. RICHART et $a l^{3}$ verificaram que $\mathrm{k}_{1}$ variava com a pressão lateral tendendo a 4,1 para maiores pressões laterais. Propuseram então coeficientes $\mathrm{k}_{1}=4,1$ e $\mathrm{k}_{2}=5 \cdot \mathrm{k}_{1}$.

BALMER $^{7}$ apud MANDER et al. (1988-b), em ensaios com fluidos confinantes, verificou para $\mathrm{k}_{1}$ valores entre 4,5 e 7 (em média 5,6), sendo os valores

\footnotetext{
${ }^{8}$ RICHART, F. E.; BRADTZAEG, A.;BROWN, R. L. (1928). A study of the failure of concrete under combined compressive stresses. Bull. No. 185, University of Illinois, Engineering Experimental Station, Urbana, III., 104.
} 
mais altos para menores pressões laterais. CONSIDÈRE $^{9}$ apud DE LORENZIS \& TEPFERS (2001), também havia encontrado valores para $\mathrm{k}_{1}$ inicialmente de 4,8 e depois revisados para 4,2. Na Figura 4.4 são apresentados os resultados experimentais obtidos por RICHART et al. ${ }^{8}$ e BALMER ${ }^{7}$ apud CHEN (1982) e a aproximação linear adotada por RICHART et al. ${ }^{10}$ apud MANDER (1988-b).

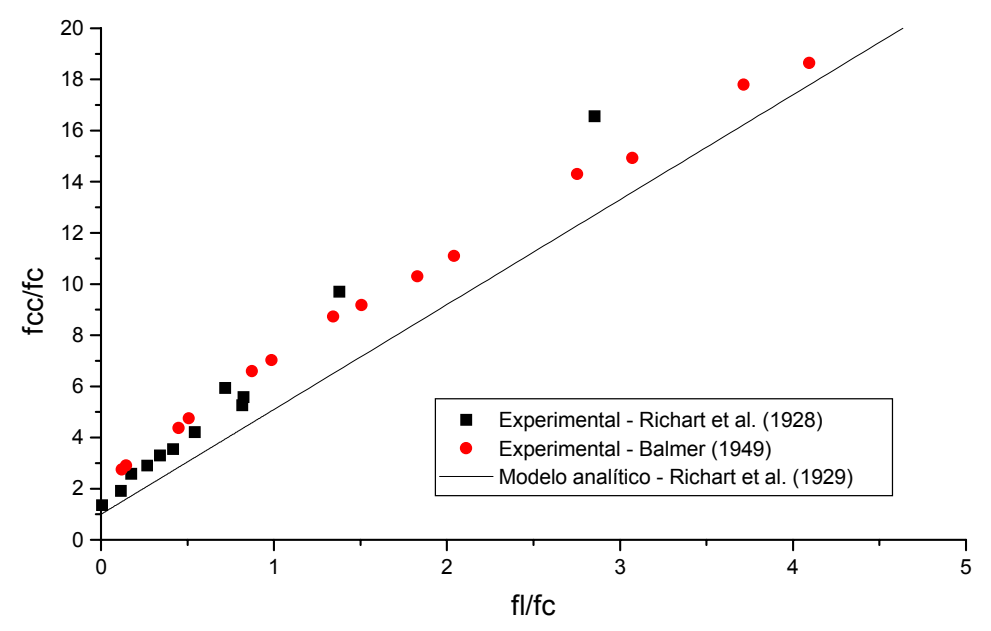

Figura 4.4 - Comportamento do concreto na compressão axial sob pressão lateral de fluidos (adaptado de CHEN, 1982).

Deve-se observar a semelhança entre a equação (4.9) proposta por RICHART et $a l .{ }^{10}$ e a envoltória obtida com o critério de MOHR-COULOMB na expressão (3.29).

\subsection{Confinamento com aço}

Pode-se confinar o concreto no interior de tubos de aço ou por meio de armaduras transversais como espirais ou estribos. $\mathrm{O}$ confinamento do concreto por meio de espirais é uma forma muito antiga de aumentar a capacidade resistente e a deformabilidade de pilares de concreto armado. Segundo AHMAD et al. (1991) seu efeito já é conhecido desde o início do século e despertou o interesse em pesquisa,

${ }^{9}$ CONSIDÈRE, A. (1906). Résistance à la compression du beton armé et du beton freté, Experimental researches on reinforced concrete, translated by L.S. Moisseif, McGraw Publishing Co., New York, $188 \mathrm{p}$.

${ }^{10}$ RICHART, F. E.; BRADTZAEG, A.;BROWN, R. L. (1929). The failure of plain and spirally reinforced concrete in compression. Bull. No. 190, University of Illinois, Engineering Experimental Station, Urbana, III., 74 
sendo nos anos 30 realizado um intenso trabalho de pesquisa no American Concrete Institute (ACI).

O confinamento por meio de armaduras transversais de aço é influenciado pelas seguintes variáveis: taxa volumétrica, disposição, distribuição, espaçamento e resistência da armadura transversal, distribuição da armadura longitudinal na seção, forma da seção transversal e resistência do concreto.

\subsubsection{Cálculo da pressão lateral para pilares circulares}

A taxa volumétrica da armadura transversal é o fator mais importante sobre o confinamento. A pressão lateral, calculada pelo equilíbrio de forças, depende diretamente da taxa volumétrica de armadura transversal:

$$
f_{l}=\frac{\rho_{s}}{2} \cdot f_{s}
$$

onde:

- $\mathrm{f}_{\mathrm{s}}$ é a tensão na armadura transversal;

- $\rho_{\mathrm{s}}$ é a taxa volumétrica da armadura transversal, que para pilares de seções circulares com armaduras em espiral ou estribos circulares é dada por:

$$
\rho_{s}=\frac{4 \cdot A_{s \phi}}{D_{c} \cdot s}
$$

sendo:

- $\mathrm{A}_{s ø}$ a área da seção transversal de uma barra da armadura transversal;

- $\quad \mathrm{D}_{\mathrm{c}}$ o diâmetro do núcleo confinado (de centro a centro das barras transversais);

- s o espaçamento da armadura transversal (de centro a centro das barras transversais).

\subsubsection{Outras variáveis influentes}

Geralmente pode-se considerar para a tensão no aço $\left(f_{s}\right)$ a tensão de escoamento $\left(f_{y}\right)$. Segundo CUSSON \& PAULTRE (1995) esta consideração é válida para pilares de concreto e armaduras de resistência normal. Para concretos de alta resistência com armaduras de alta resistência deve-se calcular a tensão real na armadura, já que esta pode vir a não escoar. CUSSON \& PAULTRE (1995) verificaram que neste caso a tensão de escoamento foi atingida apenas em pilares 
com altos índices de confinamento. Sugerem ainda que a tensão na armadura transversal para a tensão de pico do concreto confinado é diretamente relacionada ao grau de confinamento do pilar.

O comportamento do concreto confinado varia significativamente com a resistência do concreto não confinado. Concretos de menor resistência apresentam uma maior microfissuração, resultando numa maior expansão lateral. Desta maneira mobilizam mais facilmente a armadura transversal, de modo que para armaduras de resistência normal pode-se considerar o seu escoamento. Segundo EL-DASH \& AHMAD (1995) o aumento relativo de resistência devido ao confinamento e a ductilidade decrescem com o aumento da resistência do concreto não confinado.

O espaçamento entre armaduras transversais influencia a pressão efetiva de confinamento. Alguns autores consideram este efeito através da redução da área confinada efetiva como MANDER et al. (1988-b), enquanto outros consideram a variação da pressão lateral entre estribos, como RAZVI \& SAATCIOGLU (1999-b). Aplicam então fatores redutores da pressão lateral $\left(\mathrm{f}_{\mathrm{l}}\right)$.

Segundo FARDIS \& KHALILI (1981) pilares encamisados com tubos de aço mostram pouca interação entre o aço e o concreto. Existe uma folga entre o tubo de aço e o concreto devido a dois fatores: o coeficiente de Poisson do concreto no nível de tensões elásticas é menor que o do aço e o efeito da retração do concreto. A ruptura pode ocorrer por escoamento à compressão do aço ou por esmagamento do concreto.

Uma das aplicações do confinamento é melhorar a ductilidade de pilares de concreto de alta resistência, por meio de elevadas taxas de armadura transversal. Nestes pilares, após uma certa carga, o cobrimento desprende-se. Segundo RAZVI \& SAATCIOGLU (1999-b), a queda do cobrimento ocorre devido a uma instabilidade. Forma-se um plano de separação entre o cobrimento e o núcleo na região da armadura transversal, e com o acréscimo de carga o cobrimento desprende-se. Com a perda do cobrimento ocorre uma queda na resistência. Caso o pilar tenha um confinamento suficiente, este pode recuperar a capacidade portante pelo aumento da resistência do concreto do núcleo.

O aumento da resistência do aço aumenta a pressão lateral se a efetividade da armadura for tal que o concreto consiga se expandir lateralmente o suficiente para 
mobilizá-la. RAZVI \& SAATCIOGLU (1999-b) sugerem uma troca entre as variáveis taxa de armadura transversal e resistência do aço, desde que utilizada uma quantidade mínima de armadura.

Em pilares de seções transversais diferentes da circular os estribos retilíneos apresentam tensões não uniformes, com concentrações de tensão nos pontos de encontro com a armadura longitudinal. $\mathrm{O}$ arqueamento destes estribos, que possuem pequena rigidez, provoca considerável redução da pressão lateral. Porém com arranjos adequados das barras transversais e longitudinais pode-se atingir níveis de confinamento semelhantes aos de pilares circulares. Da mesma maneira que ocorre no espaço entre armaduras transversais a diminuição de $\mathrm{f}_{1}$ é feita por coeficientes redutores. Pilares de seções transversais circulares apresentam a mesma deformabilidade que pilares de seção quadrada com taxas de armadura mais elevadas.

Segundo FARDIS \& KHALILI (1981) para pilares retangulares com armadura transversal o confinamento resulta em baixo aumento na resistência e grande aumento na ductilidade. No caso de espirais consegue-se grande aumento em ambos.

\subsubsection{Ensaios realizados por MANDER et al.}

MANDER et al. (1988-a) apresentam resultados de ensaios em pilares de seção circular com $500 \mathrm{~mm}$ de diâmetro e $1500 \mathrm{~mm}$ de altura (relação diâmetro/altura $=1 / 3)$. Estes foram carregados numa taxa de deformação rápida $(0,015 / \mathrm{s})$ para simular o efeito de carregamento sísmico.

Variou-se a taxa volumétrica da armadura transversal, taxas volumétricas e diâmetros da armadura longitudinal. Os pilares com baixas taxas de armadura transversal $\left(\rho_{\mathrm{s}}=0,006\right)$ apresentaram uma superfície de ruptura inclinada atravessando a seção transversal.

Pilares com moderada taxa de armadura transversal $\left(\rho_{\mathrm{s}}=0,02\right)$ apresentaram espirais rompidas, barras longitudinais flambadas e não apresentaram um plano de ruptura definido. A variável de maior importância foi a taxa volumétrica de armadura transversal. A influência do espaçamento entre estribos para mesmas taxas volumétricas foi pequena. 
A taxa de armadura longitudinal demonstrou não ter qualquer influência. Aços de maior resistência apresentaram menor deformação de ruptura. No entanto a energia acumulada até a ruptura foi aproximadamente a mesma para os diferentes tipos de aço.

A taxa volumétrica de armadura transversal $\rho_{\mathrm{s}}$ pode ser reduzida com o aumento de $f_{y}$ sem que ocorra uma queda da resistência do concreto confinado e mantendo uma ductilidade ainda alta.

Com um menor volume de aço de alta resistência obtém-se uma menor energia na fratura e por conseqüência uma menor deformação última do concreto na ruptura da armadura transversal.

O coeficiente de efetividade da armadura transversal para pilares de seções circulares ficou entre 0,89 e 1 . Em pilares retangulares verificou-se baixos coeficientes de efetividade, entre 0,4 e 0,7, devido principalmente ao grande espaçamento da armadura transversal se comparado com as dimensões da seção.

Os pesquisadores propõem para o cálculo da tensão no concreto confinado retirar-se da carga total a parcela do cobrimento, a parcela da armadura longitudinal e dividir o valor restante pela área do núcleo.

\subsection{Confinamento com compósitos}

Durante muito tempo utilizou-se modelos de confinamento de concreto armado para o projeto de reforços com polímeros reforçados com fibras (PRF). Estes modelos no entanto mostraram-se contra a segurança (SAMAAN et al., 1998).

Ocorrem diferenças muito grandes no comportamento entre o concreto confinado por aço e o confinado por PRF. Segundo SAMAAN et al. (1998) e MIRMIRAN (2000) os modelos para aço em geral superestimam a resistência do reforço com PRF, de maneira que são necessários grandes coeficientes de segurança no projeto. Com mesmos níveis de pressão lateral e com concretos semelhantes o desempenho observado não é o mesmo.

Segundo SAMAAN et al. (1998) o concreto é um material mais sensível à contenção do que à pressão. Segundo o pesquisador isto explica as diferenças encontradas entre confinamento passivo e ativo, e a grande diferença no confinamento com PRF e com aço. 
Experiências sobre concreto confinado com aço mostraram uma pequena suavização do diagrama tensão-deformação quando o concreto atinge sua resistência máxima $\mathrm{f}_{\mathrm{cc}}$. $\mathrm{O}$ diagrama segue em um trecho descendente e a tensão do concreto na ruptura da espiral é menor que $\mathrm{f}_{\mathrm{cc}}$. A resistência de pico do concreto $\mathrm{f}_{\mathrm{cc}}$ é atingida logo que o aço escoa.

No caso pilares de seção transversal circular encamisados com PRF ocorre uma resposta tensão-deformação bi-linear, com uma forte suavização e uma zona de transição ao nível da resistência do concreto não confinado. Após esta transição a rigidez tangencial se estabiliza em um certo valor e continua fixa até a ruptura (ver Figura 4.5). Pode-se observar pelas áreas sob os diagramas da Figura 4.5 que o concreto confinado com aço pode absorver mais energia que o PRF. Para uma mesma pressão lateral, o grau de restrição lateral não é o mesmo. O tubo de PRF aplica uma pressão de crescimento constante até a ruptura, enquanto o de aço mantém uma pressão fixa após o escoamento.

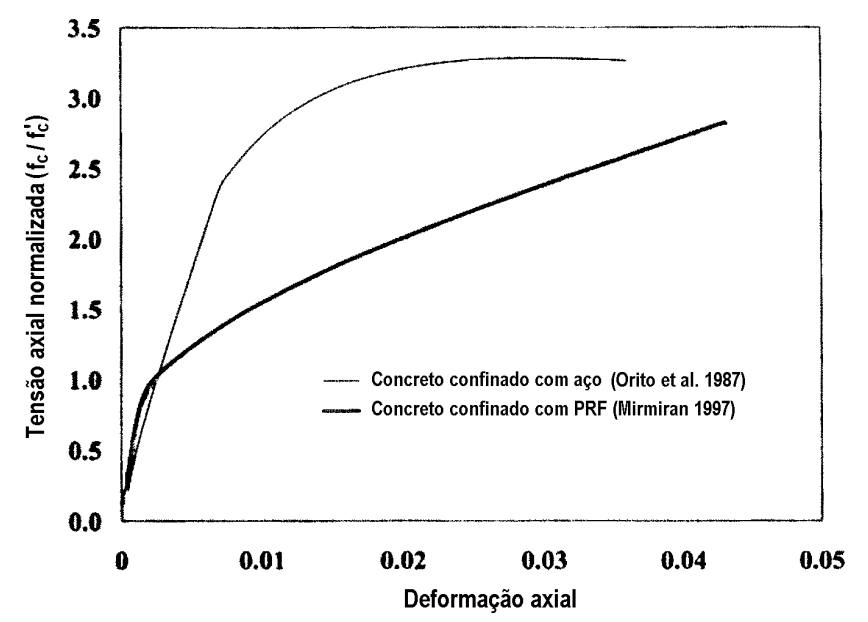

Figura 4.5 - Diagramas tensão $x$ deformação do concreto confinado com aço e com PRF (SAMAAN et al., 1998)

A expansão volumétrica do concreto tem comportamentos diferentes para os dois tipos de confinamento, conforme indica Figura 4.6. No caso do confinamento com aço esta fica instável quando o aço escoa, e caminha no sentido de uma expansão volumétrica. No confinamento com PRF este impede a expansão lateral do concreto desde o momento em que a tensão crítica foi alcançada, até a ruptura do tubo. Há uma inversão da deformação volumétrica no momento em que o compósito 
começa a atuar e o concreto rompe com grande contração de volume (SAMAAN et al., 1998).

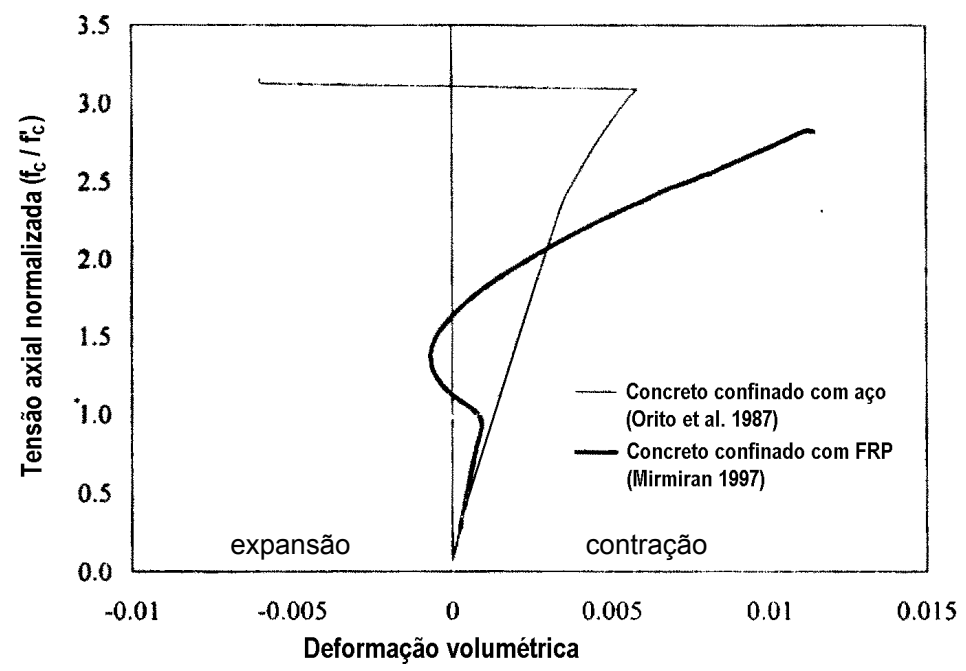

\section{Figura 4.6 - Resposta volumétrica do confinamento com PRF e com aço}

\section{SAMAAN et al., 1998)}

Segundo SAMAAN et al. (1998) a taxa de dilatação lateral $(\mu)$, definida como a taxa de mudança da deformação lateral em relação à deformação axial tem grande importância sobre o confinamento. Na Figura 4.7 apresenta-se o comportamento de $\mu$ para o concreto não confinado, concreto confinado com aço e com PRF.

Nas três curvas, $\mu$ começa acompanhando o coeficiente de Poisson do concreto. No concreto não confinado, $\mu$ cresce indefinidamente com a fissuração. No confinamento com aço há um atraso no crescimento de $\mu$ até que o aço escoe, a partir de onde o comportamento é similar ao do concreto não confinado. No confinamento com PRF a resposta é totalmente diferente. Não apenas ocorre uma retenção da taxa de dilatação lateral como esta se reduz a um valor assintótico. Conclui-se então que é necessário considerar o efeito da rigidez da camisa. Logo, um modelo que atenda o confinamento com diferentes materiais deve incluir o mecanismo de contenção e a tendência de dilatação do concreto. 


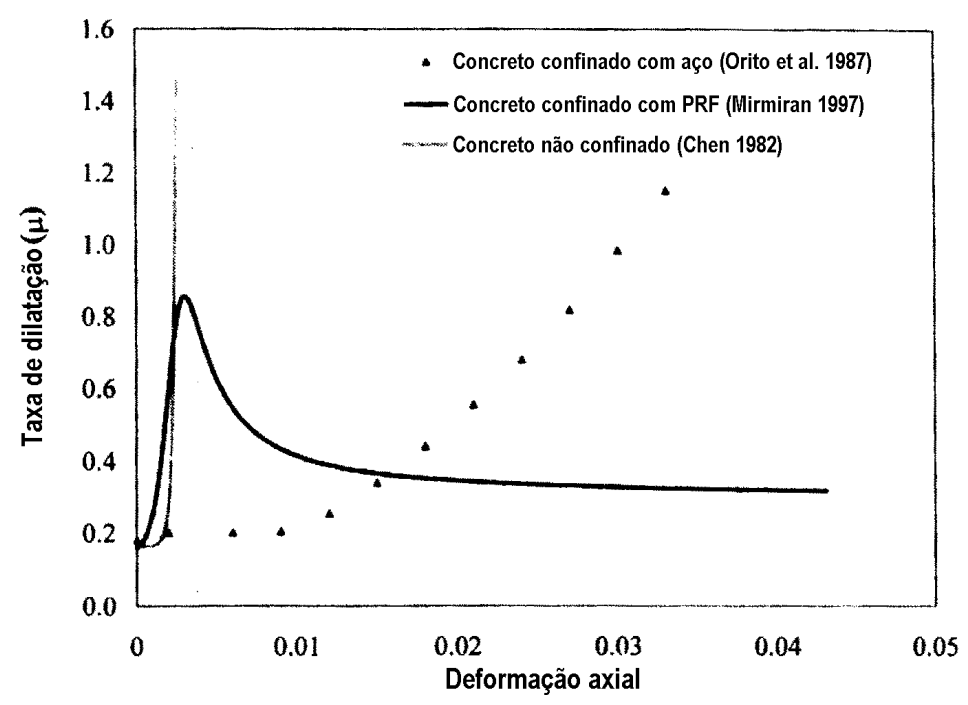

Figura 4.7 - Taxa de dilatação lateral (SAMAAN et al., 1998)

Segundo MIRMIRAN (2000) há três abordagens distintas para o confinamento com compósitos:

- Utilizar modelos para confinamento com aço - como o de MANDER et al. (1988-b), que utiliza um balanço energético para prever as deformações axiais no concreto e a primeira fratura no aço. Segundo MIRMIRAN (2000) este modelo superestima a resistência para o confinamento com PRF.

- Modelos para PRF - são os modelos mais recomendados, já que utilizam um diagrama tensão-deformação bi-linear para o caso de pilares circulares e consideram a rigidez da camisa de PRF no cálculo das deformações laterais.

- Modelagem em elementos finitos com consideração da plasticidade ROCHETTE E LABOSSIERE ${ }^{11}$ apud MIRMIRAN (2000) utilizaram uma técnica incremental pelo Método dos Elementos Finitos. Modelaram o concreto como um material elasto-plástico perfeito e adotaram o critério de ruptura associativo de Drucker-Prager ${ }^{2}$. O modelo se comportou bem para cargas axiais. Entretanto é necessária uma formulação mais complexa para seções de diferentes formas, orientação das fibras e combinações de carga.

${ }^{11}$ ROCHETTE, P.; LABOSSIÈRE, P. (1996). A plasticity aproach for concrete columns confined with composite materials. In: M. M. EL-BARY (ED.), PROCEEDINGS ADVANCED COMPOSITE MATERIALS IN BRIDGES AND STRUCTURES, CSCE, 1996, pp. 359-366. 


\subsubsection{Ensaios realizados}

Segundo FARDIS \& KHALILI (1981), tubos plásticos (PVC ou ABS) confinam o concreto de maneira mais eficiente que tubos de aço. Para um índice de esbeltez menor que 20 a ruptura ocorre por cisalhamento a $45^{\circ}$, resultante da compressão axial combinada com a tração horizontal no tubo. Com plásticos que não são nem rígidos nem resistentes observou-se pequenos ganhos de resistência.

FARDIS \& KHALILI (1981) ensaiaram então pilares curtos de seções circulares encamisados com fibras de vidro. As camisas possuíam fibras orientadas nas direções transversal e longitudinal. As fibras orientadas na direção horizontal possibilitaram o confinamento do concreto, enquanto as fibras na direção longitudinal resistiram aos esforços de flexão e aumentaram a rigidez do elemento.

Considerou-se seu comportamento independente, sendo a resistência circunferencial das fibras pouco afetada pela compressão na direção axial. Com a compressão axial introduz-se pequeno alongamento na direção circunferencial das fibras. Quando o núcleo de concreto e a camisa têm a mesma deformação axial, a interface está sob compressão desde o início do carregamento. A rigidez circunferencial da camisa impede as deformações laterais e a micro-fissuração do concreto. A resistência é governada pela ruptura das fibras na direção circunferencial.

Os ensaios de FARDIS \& KHALILI (1981) foram feitos em corpos-de-prova cilíndricos de 7,5 x $15 \mathrm{~cm}$ e 10 × $20 \mathrm{~cm}$. Utilizaram 4 tipos de reforço com compósito de fibras de vidro, sendo que um destes compósitos possuía o mesmo número de fibras nas duas direções principais (balanceado) com $339 \mathrm{~g} / \mathrm{m}^{2}$ de fibras, e os demais foram desbalanceados, com densidades de 814,441 e $508 \mathrm{~g} / \mathrm{cm}^{2}$. O tecido era préimpregnado e possuía uma taxa volumétrica de resina / fibras de 50\%: 50\%.

Em alguns modelos as fibras foram aplicadas com enrolamento mecânico, atingindo uma quantidade de fibras de $80 \%$. As amostras foram moldadas em formas desmontáveis e encamisadas após a cura do concreto. A resistência à compressão do concreto não confinado ficou entre 30 e $35 \mathrm{MPa}$. A ruptura ocorreu quando o compósito atingiu sua deformação de ruptura. Os autores citados admitem que a ruptura do compósito e o esmagamento do concreto ocorrem simultaneamente. 
AHMAD et al. (1991) ensaiaram 27 corpos-de-prova cilíndricos de concreto de 10 × $20 \mathrm{~cm}$ encamisados com compósito de fibras de vidro. A camisa possuía $80 \%$ de fibras de vidro e $20 \%$ de matriz de resina de poliéster, atingindo $2070 \mathrm{MPa}$ de resistência à tração e 48,3 GPa de módulo de elasticidade. Para um concreto não confinado de $40 \mathrm{MPa}$ de resistência o aumento da resistência ficou entre 32 e 196\%.

O ganho de resistência relativo decresceu com o aumento da classe de resistência do concreto. Observou-se um grande aumento na deformação última e de ruptura. Amostras com grande confinamento apresentaram trechos descendentes do diagrama tensão-deformação longos indicando aumento de ductilidade. O efeito do confinamento não foi percebido até $80-90 \%$ da resistência a compressão do concreto não confinado.

As amostras confinadas continuaram a sofrer deformações a maiores tensões de compressão além do pico, até que as fibras começaram a romper gradualmente. A ruptura das fibras foi se dando parcialmente e gradualmente, com um pequeno número de fibras rompendo simultaneamente. Este comportamento resultou em uma curva suave até o final do ensaio.

Nas amostras sem espaçamento entre tiras a superfície de concreto rompeu na direção perpendicular à carga, ou seja a fissura foi horizontal. Com tiras espaçadas as fissuras ficaram inclinadas. Devido à fragilidade da fibra de vidro a deformação máxima foi da ordem de 0,01 , quando esta rompeu. Deformações muito mais altas são obtidas com espirais de aço.

No caso do confinamento contínuo (sem espaçamento) a pressão lateral média, o aumento na resistência e o aumento da deformabilidade em todos os casos foram superiores aos do aço. Isto é possível pelo desenvolvimento de maiores pressões laterais já que o compósito apresentou uma resistência à tração da ordem de 5 vezes a do aço.

KATSUMATA et al ${ }^{12}$ (1988) apud SAADATMANESH \& EHSANI (1994) realizaram ensaios com pilares de seção quadrada de 20 × $20 \mathrm{~cm}$ reforçados com

12 KATSUMATA, H.; KOBATAKE, Y.; TAKEDA, T. (1988). Study With Carbon Fiber for Earthquake-Resistant Capacity of Existing Reinforced Concrete Columns, PROCEEDINGS OF NINTH WORLD CONFERENCE ON EARTHQUAKE ENGINEERING, Aug. 2-9, 1988, Tokyo, V.7, pp. 517,522. 
compósito de fibras de carbono. Os ensaios consistiam em cargas laterais cíclicas e com carga axial constante. Concluíram que o deslocamento último e a dissipação de energia aumentam linearmente com a quantidade de compósito, que a capacidade resistente a sismos pode ser aproximadamente relacionada à de pilares com espirais de aço e que a quantidade de armadura transversal de fibra de carbono e de aço podem ser convertidos mutuamente por meio da taxa relativa de resistência.

MYIAUCHI et al. (1997) ensaiaram corpos-de-prova cilíndricos de concreto de 30 e $50 \mathrm{MPa}$ de resistência, encamisados com 1, 2 e 3 camadas de fibras de carbono e não encamisados como referência. As fibras apresentavam $3481 \mathrm{MPa}$ de resistência à tração e 230,5 GPa de módulo de elasticidade. Os ganhos de resistência à compressão axial ficaram entre 31,5 e 225,9\%. Observaram que o aumento da deformação última do concreto confinado é menor para concretos de maior resistência.

MIRMIRAN e SHAHAWY ${ }^{13}$ apud SAMAAN et al.(1998) ensaiaram 30 corpos-de-prova cilíndricos de $15 \times 30 \mathrm{~cm}$ com três diferentes espessuras de um compósito de resina de poliéster e fibras de vidro aplicadas em ângulos de $\pm 75^{\circ}$. Vinte e dois destes foram testados sob carregamento axial monotônico. O ganho de resistência do concreto ficou entre 74 e $287 \%$.

\subsubsection{Análises numéricas}

SAADATMANESH \& EHSANI (1994) utilizaram o modelo analítico de MANDER et al.(1988-b) para modelar o efeito do confinamento em análise numérica de pilares de seção circular e retangular reforçados com espirais de compósitos. Neste estudo variou-se a resistência do concreto não confinado, a espessura das cintas de compósitos, o espaçamento livre entre cintas, e o tipo de fibras: carbono ou vidro.

Os modelos foram submetidos à flexo-compressão, obtendo-se os diagramas de iteração e o fator de ductilidade $\phi_{\mathrm{u}} / \phi_{\mathrm{y}}$, onde $\phi_{\mathrm{u}}$ é a rotação última e $\phi_{\mathrm{y}}$ é a rotação de escoamento, em função carga axial relativa $\mathrm{P} / \mathrm{P}_{\mathrm{o}}$, onde $\mathrm{P}$ é a carga axial do pilar confinado e $\mathrm{P}_{\mathrm{o}}$ é a carga axial do pilar não confinado. $\mathrm{O}$ ganho de resistência

${ }^{13}$ MIRMIRAN, A.; SHAHAWY, M. (1997-a). Behavior of Concrete Columns Confined by Fiber Composites, J. Struct. Engrg., ASCE, 123(5), 583-590. 
observado foi maior para concretos de menores resistências, mas a ductilidade ficou inalterada. Observou-se que o aumento na resistência à flexão é menor que o aumento da resistência axial.

O aumento do espaçamento causou redução na ductilidade e na resistência. No entanto, aumentando-se a espessura da camada de compósito observou-se aumento tanto na resistência quanto na ductilidade. Os mesmos efeitos foram observados para os pilares de seção retangular.

Para comparar a eficiência do confinamento com diferentes materiais da camisa foram simulados pilares com a mesma força de confinamento. O reforço com fibras de vidro necessitou de uma espessura de $25 \mathrm{~mm}$ para mobilizar a mesma força que $10 \mathrm{~mm}$ de fibras de carbono.

Porém, neste caso a ductilidade e a resistência do elemento obtidas com a fibra de vidro foram maiores que as obtidas com fibra de carbono. Considerando ainda o menor custo das fibras de vidro, SAADATMANESH \& EHSANI (1994) sugere que estas são mais promissoras que as fibras de carbono.

Apesar de as fibras de vidro permitirem maior alongamento de ruptura, as de carbono têm maior capacidade de absorção de energia, resultando em maior ganho de resistência e ductilidade para as mesmas taxas volumétricas.

O menor aumento na resistência à flexão comparado à carga axial é desejável em regiões sujeitas a sismos, já que a ruptura por flexão é mais dúctil que a ruptura por compressão. A ductilidade aumenta com a espessura do compósito, porém a taxa de aumento é menor quando o espaçamento entre cintas cresce. 


\section{Capitulo 5 Modelos teóricos de confinamento}

\subsection{Modelos de confinamento com aço}

\subsubsection{Modelo de Richart et al. (1929)}

O modelo de RICHART et al. (1929) ${ }^{10}$ foi desenvolvido com base em resultados de uma análise experimental do concreto confinado em ensaios com pressão hidrostática de fluidos e pilares com armaduras em espirais. Os pesquisadores propuseram a seguinte expressão para uma envoltória de ruptura linear:

$$
f_{c c}=f_{c o}+k_{1} \cdot f_{l}
$$

Observou-se experimentalmente que o coeficiente $\mathrm{k}_{1}$ da Equação (5.1) varia com a pressão lateral, como indica a Figura 5.1. Porém RICHART et al. $(1929)^{10}$ adotaram $\mathrm{k}_{1}$ constante e igual a 4,1 .

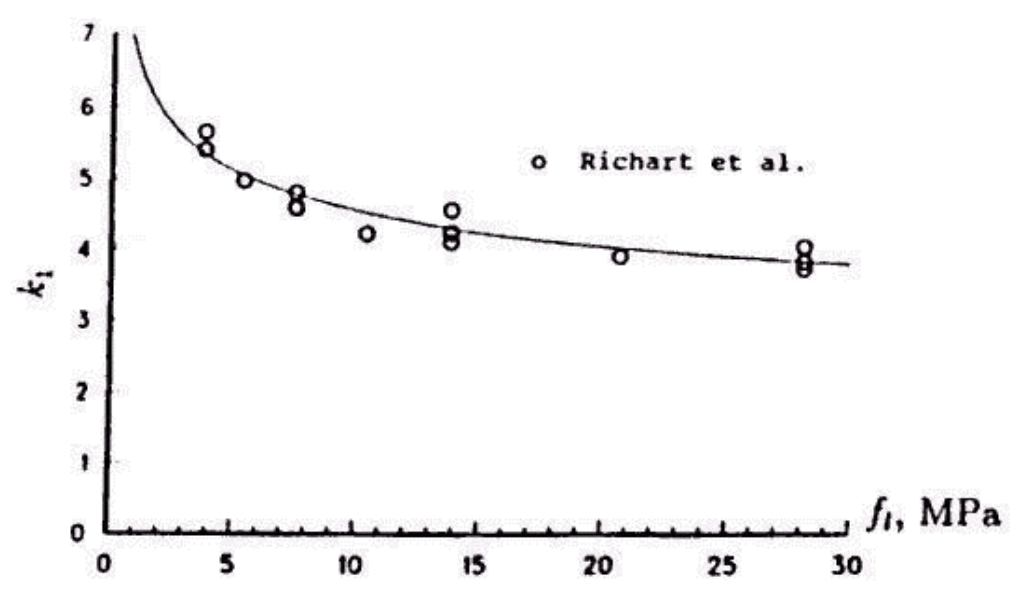

Figura 5.1 - Variação de $k_{1}$ com a pressão lateral, RICHART et al. ${ }^{10}$

Foi proposta também uma equação para prever a deformação última do concreto confinado:

$$
\varepsilon_{c c}=\varepsilon_{c o}\left(1+k_{2} \cdot \frac{f_{1}}{f_{c o}}\right)
$$

onde adotou-se $\mathrm{k}_{2}=5 \mathrm{k}_{1}$. 
No modelo de RICHART et al. (1929) ${ }^{10}$ não foram consideradas reduções da pressão lateral com o espaçamento de armaduras transversais, já que o espaçamento era bem reduzido.

\subsubsection{Modelo de MANDER et al. (1988-b)}

O modelo de MANDER et al. (1988-b) atualmente é um dos modelos de confinamento mais utilizados. Considera a área efetivamente confinada do núcleo, obtida pela eliminação das áreas decorrentes do efeito de arqueamento. $\mathrm{O}$ arqueamento ocorre tanto no sentido longitudinal como transversal em pilares de seção quadrada ou retangular. Em pilares de seção circular, com armadura em espirais ou estribos circulares, o arqueamento ocorre apenas no sentido longitudinal, na região entre barras transversais (ver Figura 5.2).

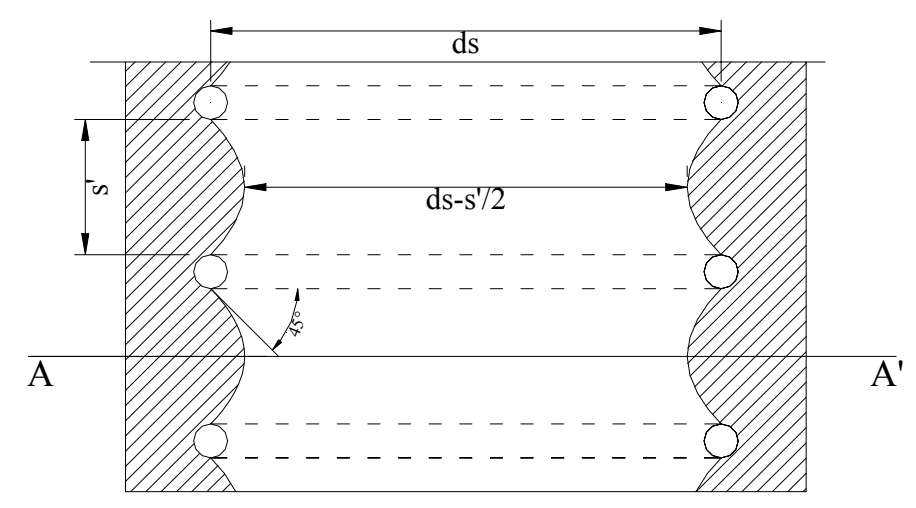

\section{Figura 5.2 - Efeito do arqueamento em pilares na direção longitudinal}

A consideração da perda de efetividade é feita por um coeficiente de efetividade $\left(\mathrm{k}_{\mathrm{e}}\right)$ que multiplica a pressão lateral $\left(\mathrm{f}_{\mathrm{l}}\right)$, de maneira semelhante à proposta por SHEIKH \& UZUMERI (1982). A pressão efetiva é dada por:

$$
f_{l e}=f_{l} \cdot k_{e}
$$

O coeficiente de efetividade é obtido pela expressão:

$$
k_{e}=\frac{A_{e}}{A_{c c}}
$$

onde:

- $\mathrm{Ae}=$ área efetivamente confinada;

- $A_{c c}=A_{c} \cdot\left(1-\rho_{l}\right)$;

- $\mathrm{A}_{\mathrm{c}}$ é a área do núcleo delimitada pelas linhas centrais das barras da armadura de espiral ou circular; 
- $\rho_{1}$ é a taxa de armadura longitudinal do núcleo.

$\mathrm{O}$ arqueamento se desenvolve na forma de uma parábola de segundo grau com inclinação inicial de $45^{\circ}$ como pode-se observar na Figura 5.2.

Para pilares com estribos circulares a área de concreto efetivamente confinada é a área do núcleo cortada pelo plano A-A' (Figura 5.2), dada por:

$$
A_{e}=\frac{\pi}{4} \cdot d_{s}^{2} \cdot\left(1-\frac{s^{\prime}}{2 \cdot d_{s}}\right)^{2} \text { para estribos circulares }
$$

onde:

- $d_{s}$ é o diâmetro entre os centros das barras da espiral;

- s' é o espaçamento interno de estribos. Para espirais a área efetiva indicada em A-A' é diferente do caso de estribos circulares, como pode-se observar na Figura 5.3 .

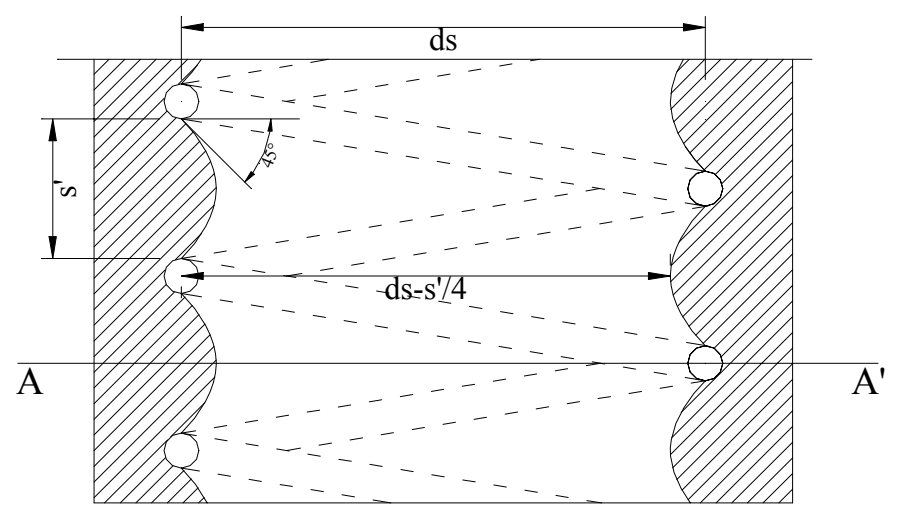

Figura 5.3 - Efeito do arqueamento em pilares com espirais

A área efetivamente confinada para espirais é dada por

$$
A_{e}=\frac{\pi}{4} \cdot d_{s}^{2} \cdot\left(1-\frac{s^{\prime}}{2 \cdot d_{s}}\right)
$$

Logo o coeficiente de efetividade $k_{e}=\frac{A_{e}}{A_{c c}}$ é dado por

$$
k_{e}=\frac{\left(1-\frac{s^{\prime}}{2 \cdot d_{s}}\right)^{2}}{1-\rho_{c c}} \text { para estribos circulares }
$$




$$
k_{e}=\frac{\left(1-\frac{s^{\prime}}{2 \cdot d_{s}}\right)}{1-\rho_{c c}} \text { para espirais }
$$

Seções quadradas ou retangulares sofrem redução no nível de confinamento tanto na direção longitudinal como transversal. A redução na direção longitudinal é análoga à de seções circulares e pode ser obtida por meio das equações (5.7) e (5.8).

A redução dentro da seção transversal é devida à flexão das armaduras transversais, que possuem baixa rigidez. Novamente delimita-se a região confinada com uma parábola de declividade inicial de $45^{\circ}$. O efeito é considerado subtraindo as parábolas de concreto não confinado entre nós rígidos (encontro com as barras longitudinais). Pode-se mostrar facilmente que a área inefetiva entre dois nós rígidos (barras longitudinais impedidas de deslocar-se lateralmente) com distância interna de $\mathrm{W}_{\mathrm{i}}$ é dada por $\left(\mathrm{w}_{\mathrm{i}}\right)^{2} / 6$ ( ver Figura 5.4).

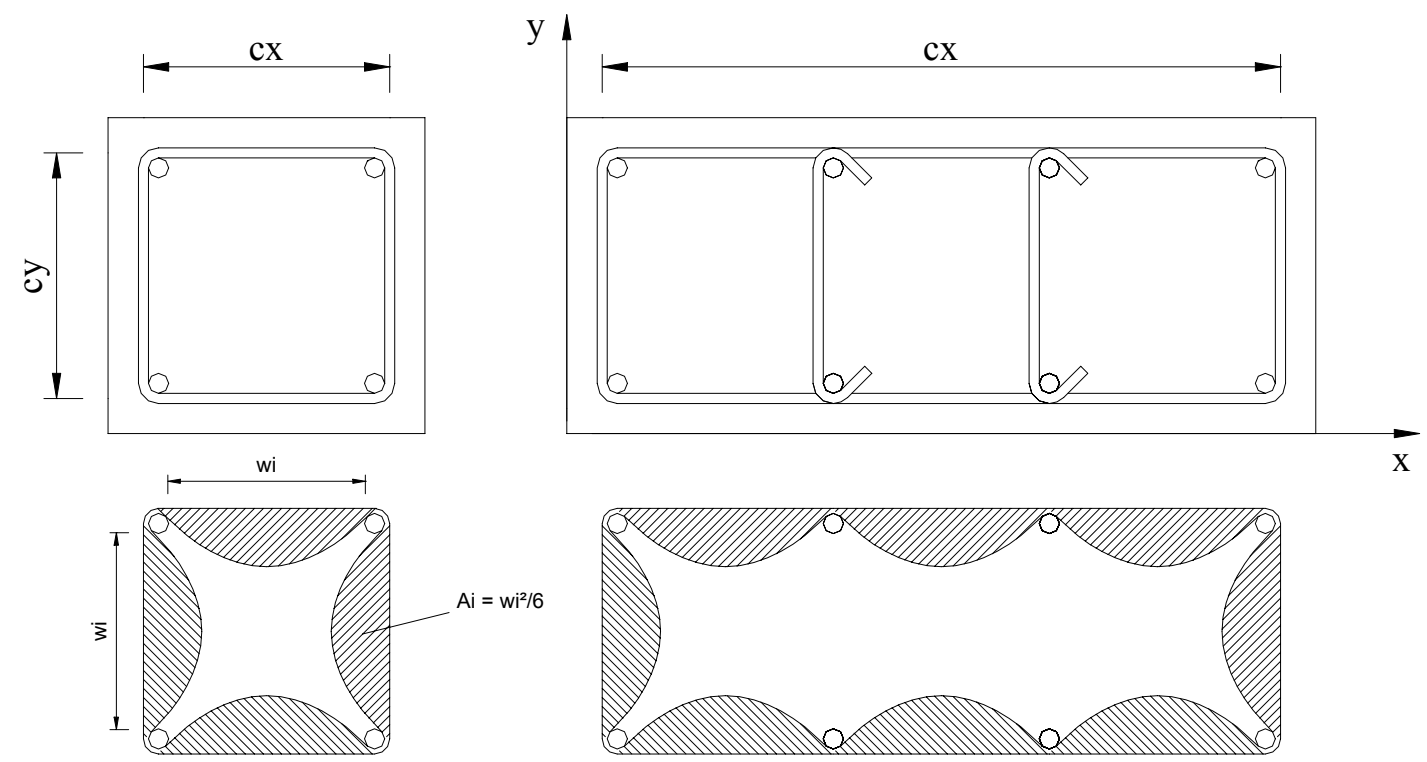

Figura 5.4 - Distribuição de áreas inefetivas na seção transversal de pilares de seção quadrada e retangular

A soma das áreas inefetivas é dada por:

$$
A_{i}=\sum_{i=1}^{n} \frac{\left(w_{i}\right)^{2}}{6}
$$

Considerando-se a redução em conjunto das áreas inefetivas longitudinais e transversais, obtém-se para pilares com estribos retangulares uma área efetiva dada por: 


$$
A_{e}=\left(c_{x} \cdot c_{y}-\sum_{1=1}^{n} \frac{\left(w_{i}\right)^{2}}{6}\right) \cdot\left(1-\frac{s^{\prime}}{2 \cdot c_{x}}\right) \cdot\left(1-\frac{s^{\prime}}{2 \cdot c_{y}}\right)
$$

onde $c_{\mathrm{x}}$ e $\mathrm{c}_{\mathrm{y}}$ são as dimensões do pilar.

Logo o coeficiente de efetividade considerando todos os fatores é:

$$
k_{e}=\frac{\left(1-\sum_{1=1}^{n} \frac{\left(w_{i}\right)^{2}}{6 \cdot c_{x} \cdot c_{y}}\right) \cdot\left(1-\frac{s^{\prime}}{2 \cdot c_{x}}\right) \cdot\left(1-\frac{s^{\prime}}{2 \cdot c_{y}}\right)}{\left(1-\rho_{l}\right)}
$$

Para pilares com taxas de armadura transversal diferentes nas direções x e y:

$$
\begin{gathered}
\rho_{x}=\frac{A_{s x}}{s \cdot c_{y}} \\
\rho_{y}=\frac{A_{s y}}{s \cdot C_{x}}
\end{gathered}
$$

onde $\mathrm{A}_{\mathrm{sx}}$ e $\mathrm{A}_{\mathrm{sy}}$ são as áreas das armaduras transversais orientadas nas direções x e y respectivamente.

As pressões nas direções x e y são respectivamente dadas por:

$$
\begin{aligned}
& f_{l x}=k_{e} \cdot \rho_{x} \cdot f_{y} \\
& f_{l y}=k_{e} \cdot \rho_{y} \cdot f_{y}
\end{aligned}
$$

MANDER et al. (1988-b) consideram em separado os efeitos das duas pressões $\left(\mathrm{f}_{\mathrm{lx}}\right.$ e $\left.\mathrm{f}_{\mathrm{ly}}\right)$ pelo ábaco da Figura 5.5. Entra-se com as pressões laterais nas direções x e y obtendo-se o acréscimo de resistência do concreto confinado. Para o caso de espirais ou estribos circulares em que a pressão lateral é constante nas direções radiais, MANDER et al. (1988-b) sugerem uma solução baseada na superfície de ruptura multiaxial de cinco parâmetros (semelhante à indicada na Figura 3.5) dada por WILLIAN \& WARNKE 6 apud MANDER et al. (1988-b):

$$
f_{c c}=f_{c o} \cdot\left(-1,254+2,254 \cdot \sqrt{1+\frac{7,94 \cdot f_{l e}}{f_{c o}}}-2 \cdot \frac{f_{l e}}{f_{c o}}\right)
$$




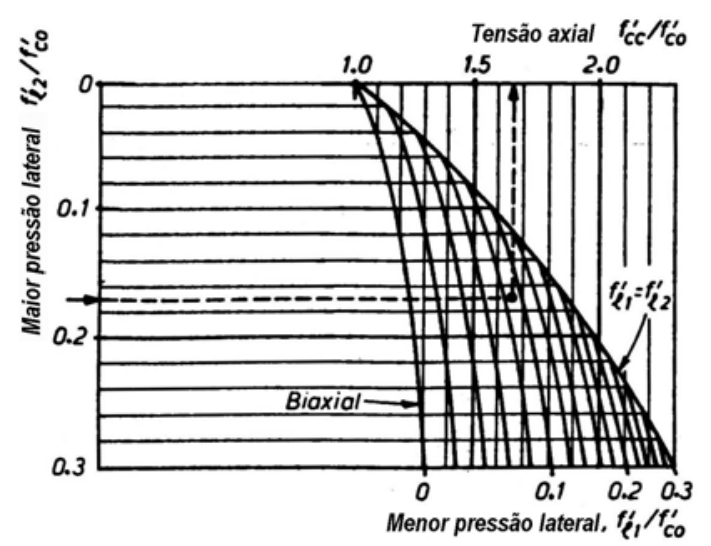

Figura 5.5 - Determinação do ganho de resistência do concreto confinado para seções retangulares (MANDER et al., 1988-b)

MANDER et al. (1988-b) propõem o diagrama tensão-deformação indicado na Figura 5.6, aplicável a seções circulares e retangulares.

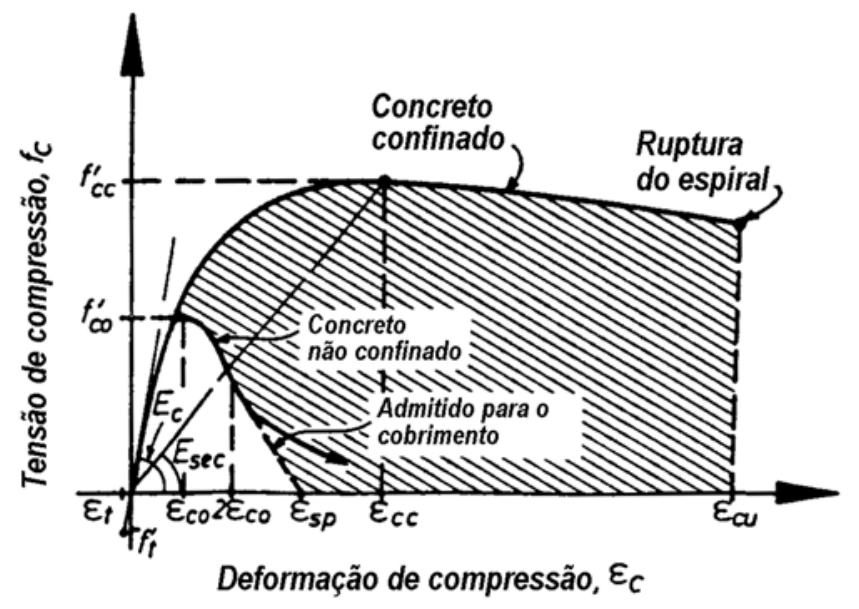

Figura 5.6 - Diagrama tensão-deformação do concreto confinado com armaduras transversais (MANDER et al., 1988-b)

A curva é determinada pela equação de POPOVICS ${ }^{14}$ apud MANDER et al.:

$$
f_{c}=\frac{f_{c c} \cdot x \cdot r}{r-1+x^{r}}
$$

onde $\mathrm{x}$ é dado por:

$$
x=\frac{\varepsilon_{c}}{\varepsilon_{c c}}
$$

sendo:

${ }^{14}$ POPOVICS, S. (1973). A numerical approach to the complete stress-strain curves for concrete. Cement and concrete research, 3 (5), 583 - 599. 
- $\varepsilon_{\mathrm{c}}$ a deformação do concreto;

- $\varepsilon_{\mathrm{cc}}$ a deformação correspondente à tensão de pico do concreto confinado, dada por:

$$
\varepsilon_{c c}=\varepsilon_{c o} \cdot\left[1+5 \cdot\left(\frac{f_{c c}}{f_{c o}}-1\right)\right]
$$

onde:

- $\mathrm{f}_{\mathrm{co}}$ e $\varepsilon_{\mathrm{co}}$ são respectivamente a resistência e deformação última do concreto confinado;

$$
r=\frac{E_{c}}{E_{c}-E_{\mathrm{sec}}}
$$

sendo:

- $\mathrm{E}_{\mathrm{c}}$ e $\mathrm{E}_{\mathrm{sec}}$ respectivamente o módulo de elasticidade tangente à origem e secante do concreto confinado, dados pelas expressões:

$$
\begin{aligned}
& E_{c}=5000 \cdot \sqrt{f_{c o}} \quad(\mathrm{em} \mathrm{MPa}) \\
& E_{\mathrm{sec}}=\frac{f_{c c}}{\varepsilon_{c c}}
\end{aligned}
$$

MANDER et al. (1988-b) consideram como deformação última do concreto aquela em que a espiral rompe, pois a carga cai abruptamente e o comprimento de flambagem da armadura longitudinal aumenta. Utilizam um balanço energético para calcular a deformação última do concreto confinado $\left(\varepsilon_{\mathrm{cu}}\right)$, igualando a energia adicional devida ao confinamento à energia acumulada no estribo. O balanço energético é dado pela relação:

$$
U_{s h}=U_{c c}-U_{c o}+U_{s c}
$$

onde as energias por unidade de volume são:

- $\mathrm{U}_{\mathrm{sh}}$ - energia de deformação última da armadura transversal;

- $\mathrm{U}_{\mathrm{cc}}$ - área sob o diagrama tensão-deformação do concreto confinado;

- $\mathrm{U}_{\mathrm{co}}$ - área sob o diagrama tensão-deformação do concreto não confinado;

- $\mathrm{U}_{\mathrm{sc}}$ - energia para manter as armaduras longitudinais em escoamento.

MANDER et al. (1988-b) sugerem algumas simplificações que possibilitam calcular a deformação última do concreto confinado por meio da equação a seguir: 


$$
110 \cdot \rho_{s}=\int_{0}^{\varepsilon_{c u}} f_{c} \cdot d \varepsilon_{c}-0,017 \cdot \sqrt{f_{c o}}+\int_{0}^{\varepsilon_{c u}} f_{s l} \cdot d \varepsilon_{c}
$$

onde $\mathrm{f}_{\mathrm{sl}}$ é a tensão na armadura longitudinal.

\subsubsection{Modelo de EL-DASH \& AHMAD (1995)}

O modelo proposto é aplicável a concretos de alta resistência e resistência normal. Assume-se que a pressão lateral é distribuída uniformemente no núcleo de concreto confinado e permanece constante após o escoamento da armadura transversal.

Utiliza-se o equilíbrio de forças, as propriedades dos materiais e a geometria da seção para calcular a pressão lateral. Os parâmetros considerados são a resistência e o comportamento tensão-deformação do concreto não confinado, a taxa volumétrica, o espaçamento, o diâmetro e a tensão de escoamento da armadura transversal. Apesar dos pesquisadores admitirem uma pequena influência da taxa de armadura longitudinal, o efeito desta é desprezado. Utiliza-se uma equação fracional para representar a relação tensão-deformação do concreto confinado:

$$
y=\frac{A \cdot x+(B-1) \cdot x^{2}}{1+(A-2) \cdot x+B \cdot x^{2}}
$$

onde $y=\frac{f_{C}}{f_{C C}}, x=\frac{\varepsilon_{c}}{\varepsilon_{c C}}, A=\frac{E_{c C}}{E_{p}}$ e $E_{p}=\frac{f_{c C}}{\varepsilon_{c C}}$, sendo:

- $\mathrm{f}_{\mathrm{c}}$ a tensão no concreto;

- $\mathrm{f}_{\mathrm{cc}}$ a resistência do concreto confinado;

- $\varepsilon_{\mathrm{c}}$ a deformação do concreto;

- $\varepsilon_{\mathrm{cc}}$ a deformação correspondente a $\mathrm{f}_{\mathrm{cc}}$. Deve-se observar que quando $\mathrm{x}>1$, y deve ser maior que 0,2 .

Para o cálculo de um suposto módulo de elasticidade do concreto confinado recomendam:

$$
E_{c c}=0,043 \cdot w_{c}^{1,5} \cdot f_{c o}^{0,5} \cdot\left(1+0,62 \cdot \frac{f_{l}}{f_{c o}}\right)
$$

onde $\mathrm{w}_{\mathrm{c}}$ é a massa unitária do concreto $\mathrm{em} \mathrm{kg} / \mathrm{m}^{3}$.

São necessários cinco parâmetros para obter o diagrama tensão-deformação: a resistência do concreto confinado, a deformação correspondente, a pressão lateral 
máxima, e os coeficientes A e B. Recomenda-se as equações (5.1) e (5.2) para calcular a resistência do concreto confinado e a deformação correspondente ao ponto de máximo. Os coeficientes $\mathrm{k}_{1}$ e $\mathrm{k}_{2}$ são propostos como:

$$
\begin{aligned}
& k_{1}=5,1 \cdot\left(\frac{f_{c o}}{f_{y}}\right)^{0,5} \cdot\left(\frac{A_{s \phi}}{\rho_{s}}\right)^{0,25} \\
& k_{2}=\frac{66}{\left(\frac{s}{A_{s \phi}}\right) \cdot f_{c o}^{1,7}}
\end{aligned}
$$

Sugere-se para o cálculo da deformação de pico do concreto não confinado:

$$
\varepsilon_{c o}=0,001648+0,000016 \cdot f_{c o}
$$

O parâmetro B controla a forma do diagrama tensão-deformação no trecho descendente, e é baseado em resultados de ensaios.

$$
B=\frac{16,5}{\sqrt{f_{c o}}} \cdot\left(\frac{f_{l} \cdot A_{s \phi}}{s}\right)^{0,33}
$$

A pressão lateral máxima é obtida por

$$
f_{l}=0,5 \cdot \rho_{s} \cdot f_{y} \cdot\left(1-\sqrt{\frac{s}{1,25 \cdot D_{c}}}\right)
$$

\subsubsection{Modelo de CUSSON \& PAULTRE (1995)}

O modelo, desenvolvido para concreto de alta resistência, foi calibrado com resultados de 50 pilares em escala real ensaiados sob carga de compressão axial centrada. Utiliza a mesma definição do modelo de MANDER et al. (1988-b) para pressões efetivas de confinamento, descontando as áreas inefetivas tanto na seção transversal como na longitudinal. A diferença no cálculo das pressões é que neste modelo calcula-se uma pressão equivalente para taxas de armadura diferentes nas duas direções. A pressão idealizada neste caso é dada por

$$
f_{l}=\frac{f_{s}}{s} \cdot\left(\frac{A_{s x}+A_{s y}}{c_{x}+c_{y}}\right)
$$

onde $\mathrm{f}_{\mathrm{s}}$ é a tensão na armadura transversal.

A pressão efetiva é obtida multiplicando-se a pressão lateral ideal pelos coeficientes de efetividade $\left(\mathrm{k}_{\mathrm{e}}\right)$, análogos aos propostos por MANDER et al. (1988- 
b). Por meio dos métodos dos mínimos quadrados e dos desvios absolutos elaborouse uma relação entre o ganho de resistência e a pressão lateral semelhante à equação (4.9) proposta por RICHART et $a l^{\mathbf{1 0}}$ :

$$
\frac{f_{c c}}{f_{c o}}=1,0+2,1 \cdot\left(\frac{f_{l e}}{f_{c o}}\right)^{0,7}
$$

A diferença nas formulações está no coeficiente $\mathrm{k}_{1}$ e no coeficiente de potência, sendo o último utilizado para incluir o efeito da não linearidade da envoltória. A deformação no ponto da resistência de pico também é dada por:

$$
\varepsilon_{c c}=\varepsilon_{c o}+0,21 \cdot\left(\frac{f_{l e}}{f_{c o}}\right)^{1,7}
$$

O ganho de ductilidade é definido como a diferença entre as deformações correspondentes a $50 \%$ da resistência de pico do concreto confinado no trecho descendente do diagrama tensão-deformação $\left(\varepsilon_{c 50 c}\right)$ e do concreto não confinado neste mesmo ponto da curva $\left(\varepsilon_{\mathrm{c} 50 \mathrm{u}}\right)$. A relação é dada por:

$$
\varepsilon_{c 50 c}-\varepsilon_{c 50 u}=0,15 \cdot\left(\frac{f_{l e}}{f_{c o}}\right)^{1,1}
$$

$\mathrm{Na}$ falta de dados experimentais para $\varepsilon_{\mathrm{c} 50 \mathrm{c}}$, CUSSON \& PAULTRE (1995) recomendam 0,004 .

Em pilares de concreto de resistência normal com armaduras de resistência normal, a tensão de escoamento do aço tem sido utilizada freqüentemente para o cálculo da pressão lateral. Para pilares de concreto de alta resistência com armaduras de alta resistência a tensão real na armadura transversal deve ser calculada.

CUSSON \& PAULTRE (1995) observaram que no caso de pilares de concreto de alta resistência com armaduras de alta resistência, o escoamento foi atingido apenas em amostras com alto índice de confinamento. Tensões muito menores foram registradas em pilares com baixo índice de confinamento. Isto ocorre porque em pilares bem confinados a deformação axial de pico $\varepsilon_{\mathrm{cc}}$ é grande o suficiente para permitir que a armadura transversal se deforme até atingir o escoamento. As tensões na armadura transversal ao nível da resistência de pico do concreto são diretamente proporcionais ao índice de confinamento. 
Para o cálculo da tensão na armadura transversal ao nível da resistência de pico do concreto confinado $\mathrm{f}_{\mathrm{s}}$ a deformação radial $\left(\varepsilon_{\mathrm{r}}\right)$ deve ser calculada. Adota-se uma aproximação baseada na Teoria da Elasticidade.

$$
\varepsilon_{r}=v \cdot \varepsilon_{c c}-\frac{(1-v) \cdot f_{l e}}{E_{\mathrm{sec}}}
$$

onde $v$ é o coeficiente de Poisson do concreto confinado a nível da resistência de pico. O coeficiente de Poisson pode atingir valores próximos de 0,5.

Esta equação pode ser aplicada para pilares de concreto de alta resistência com leve confinamento, desde que o trecho ascendente do diagrama tensãodeformação seja aproximadamente linear até a ruptura. Para altos índices de confinamento podem ocorrer erros, mas provavelmente a tensão será maior que a de escoamento, indicando que as barras escoaram. Simplificando a expressão com $\nu=0,5$ obtém-se

$$
\varepsilon_{r}=0,5 \cdot \varepsilon_{c c}\left[1-\left(f_{l e} / f_{c c}\right)\right]
$$

A expressão (5.37) possui do lado direito da igualdade três variáveis desconhecidas: $\varepsilon_{c c}, f_{l e}$ e $f_{c c}$. Todas são dependentes de $f_{s}$. Logo a deformação $\varepsilon_{r}$ e $f_{s}$ podem ser determinados por processo iterativo:

1. calcula-se $\mathrm{f}_{\mathrm{le}}$ supondo-se $\mathrm{f}_{\mathrm{s}}=\mathrm{f}_{\mathrm{y}}$;

2. estima-se $\mathrm{f}_{\mathrm{cc}}$ e a correspondente $\varepsilon_{\mathrm{cc}}$;

3. estima-se $\varepsilon_{\mathrm{r}}$;

4. encontra-se $\mathrm{f}_{\mathrm{s}}$ por meio do diagrama tensão-deformação das barras;

5. recalcula-se a pressão efetiva $f_{l e}$ com a nova tensão $f_{s}$ somente se $f_{s}<$ $\mathrm{f}_{\mathrm{y}}$

6. repete-se os passos 2 a 5 até a convergência.

Para o diagrama tensão-deformação adaptou-se ao trecho ascendente a formulação proposta por POPOVICS ${ }^{14}$ apud CUSSON \& PAULTRE (1995) para concreto não confinado:

$$
f_{c}=\frac{f_{c c} \cdot x \cdot r}{r-1+x^{r}}
$$


Para concreto de alta resistência $\mathrm{r}$ é maior e expressa o fato que o diagrama tensão-deformação é quase linear com alto módulo de elasticidade. O trecho descendente é dado por:

$$
\begin{aligned}
& f_{c}=f_{c c} \cdot \exp \left[k_{3} \cdot\left(\varepsilon_{c}-\varepsilon_{c c}\right)^{k_{4}}\right] \text { para } \varepsilon_{c} \geq \varepsilon_{c c} \\
& k_{3}=\frac{\ln 0,5}{\left(\varepsilon_{c 50 c}-\varepsilon_{c c}\right)^{k_{4}}} \\
& k_{4}=0,58+16 \cdot\left(\frac{f_{l e}}{f_{c o}}\right)^{1,4}
\end{aligned}
$$

onde:

- $\mathrm{k}_{3}$ controla a inclinação do trecho descendente do diagrama tensão-deformação e o força a passar pelo ponto $\left(\varepsilon_{\mathrm{c} 50 \mathrm{c}}, 0,5 . \mathrm{f}_{\mathrm{cc}}\right)$. Para concreto bem confinado $\mathrm{k}_{3}$ é grande e produz um trecho descendente suave. Para confinamento leve $\mathrm{k}_{3}$ é pequeno e produz um trecho descendente bem inclinado;

- $\mathrm{k}_{4}$ controla a curvatura. Os valores experimentais de $\mathrm{k}_{4}$ foram encontrados para cada amostra com o seguinte processo iterativo. As incógnitas são substituídas pelos valores experimentais para cada amostra e $\mathrm{k}_{4}$ minimiza as áreas sob a curva experimental e analítica. Para concreto não confinado pode-se utilizar $\mathrm{k}_{4}=1,5$.

\subsubsection{Modelo de RAZVI \& SAATCIOGLU (1999-b)}

O modelo utiliza o conceito de pressão uniforme equivalente. Através da Lei de Hooke se estabelece uma relação entre a deformação axial e transversal.

$$
-\frac{v \cdot f_{c c}}{E_{c o}}=\frac{f_{l}-v \cdot\left(f_{c o}+f_{l}\right)}{E_{c o}}
$$

onde $\mathrm{E}_{\mathrm{co}}$ é o módulo de elasticidade do concreto não confinado.

A partir desta relação chega-se a:

$$
f_{c c}=f_{c o}+k_{1}^{\prime} \cdot f_{l}
$$

onde, para um material elástico-linear:

$$
k_{1}^{\prime}=\frac{(1-v)}{v}
$$

Observou-se que devido à envoltória altamente não linear do concreto, k' ${ }_{1}$ deve ser substituído por $\mathrm{k}_{1}$, que varia com a pressão lateral. RICHART et al. ${ }^{10}$ apud 
RAZVI \& SAATCIOGLU (1999-b) mostraram que k k $_{1}$ varia com a pressão lateral. Adotou-se uma expressão em função da pressão lateral:

$$
k_{1}=6,7 \cdot f_{l e}^{-0,17}
$$

onde $f_{l e}$ é a pressão lateral, obtida multiplicando-se a pressão lateral ( $f_{l}$ ) pelo coeficiente $k_{5}$. Para pilares de seção transversal retangular calcula-se em separado as pressões laterais nas duas direções x e y:

$$
\begin{aligned}
f_{l x}= & \frac{\sum A_{s \phi} \cdot f_{s} \cdot \operatorname{sen}\left(\alpha_{1}\right)}{s \cdot c_{y}} \\
f_{l y} & =\frac{\sum A_{s \phi} \cdot f_{s} \cdot \operatorname{sen}\left(\alpha_{1}\right)}{s \cdot c_{x}}
\end{aligned}
$$

onde

- $\quad \alpha_{1}$ é o ângulo entre a armadura e plano em que atua a pressão;

- $\mathrm{f}_{\mathrm{s}}$ é a tensão no aço da armadura transversal, que pode ser diferente da de escoamento.

No caso de concreto de resistência normal com armadura de resistência normal pode-se assumir que a armadura escoa sem maiores problemas. No caso de concreto de alta resistência, com armaduras de alta resistência a tensão no aço fica abaixo do limite de escoamento.

A tensão na armadura pode então ser obtida por:

$$
f_{s}=E_{s} \cdot\left(0,0025+0,04 \cdot \sqrt[3]{\frac{k_{5} \cdot \rho_{c}}{f_{c o}}}\right) \leq f_{y}
$$

onde $\mathrm{E}_{\mathrm{s}}$ é o módulo de elasticidade do aço da armadura transversal.

A perda de efetividade da armadura pode ser considerada multiplicando-se a pressão lateral ideal $f_{1}$ pelo coeficiente $k_{5}$. Não é considerada a perda de efetividade em pilares circulares, que tem um coeficiente $\mathrm{k}_{5}=1$. Para pilares de seção quadrada ou retangular utiliza-se um coeficiente de efetividade dado por:

$$
k_{5}=0,15 \cdot \sqrt{\left(\frac{b_{c}}{s}\right) \cdot\left(\frac{b_{c}}{s_{I}}\right)}
$$

onde:

- $\quad b_{c}$ é a dimensão do núcleo;

- $\quad$ s é o espaçamento da armadura transversal; 
- $\mathrm{S}_{1}$ é o espaçamento das armaduras longitudinais de nós fixos (amarradas a estribos que atravessam a seção transversal).

No coeficiente $\mathrm{k}_{5}$ são consideradas as variações da pressão lateral ao longo das barras da armadura transversal. A pressão é maior nas regiões dos nós, e depende da resistência da barra que cruza a seção. Na região entre os nós a pressão relacionase com a rigidez elástica das armaduras transversais até o escoamento. Após o escoamento a pressão permanece constante, até que o aço apresente endurecimento. A rigidez do estribo e a ação de restrição são muito pequenas se comparadas à ação dos nós. A pressão nos nós é muito maior.

Portanto a distribuição de pressões é função do arranjo de armaduras. A pressão permanece praticamente constante nas barras longitudinais, mas no concreto entre barras longitudinais ocorre considerável variação da pressão lateral ao longo do comprimento do pilar. A barra longitudinal mantém sua capacidade de restrição até sua flambagem. Observou-se no caso de diferentes pressões laterais que seus efeitos são proporcionais às dimensões da seção (SAATCIOGLU \& RAZVI, 1992). No caso de armaduras diferentes nas duas direções as pressões laterais efetivas são calculadas em separado e seu efeito então é considerado em conjunto pela equação

$$
f_{l e}=\frac{f_{l e x} \cdot c_{x}+f_{l e y} \cdot c_{y}}{c_{x}+c_{y}}
$$

Segundo RAZVI \& SAATCIOGLU (1999-b) o ganho absoluto de resistência devido ao confinamento independe da resistência do concreto não confinado. A ductilidade é definida pela deformação de pico $\varepsilon_{\mathrm{cc}}$ e pela inclinação do trecho descendente. $O$ trecho descendente do diagrama tensão-deformação é assumido como uma reta que passa pelos pontos $\left(\varepsilon_{\mathrm{cc}}, \mathrm{f}_{\mathrm{cc}}\right)$ e $\left(\varepsilon_{85}, 0,85 \cdot \mathrm{f}_{\mathrm{cc}}\right)$ A formulação é semelhante à desenvolvida por SAATCIOGLU \& RAZVI (1992), no entanto considera fatores $\mathrm{k}_{6}$ e $\mathrm{k}_{7}$ para incluir o comportamento de concretos de alta resistência. A deformação de pico do concreto confinado é dada por:

$$
\varepsilon_{c c}=\varepsilon_{c o} \cdot\left(1+5 \cdot k_{6} \cdot k_{7}\right)
$$

onde:

$$
k_{6}=\frac{40}{f_{c o}} \leq 1,0
$$




$$
k_{7}=\frac{k_{1} \cdot f_{l e}}{f_{c o}}
$$

A deformação no trecho descendente correspondente a $85 \%$ da resistência do concreto confinado é obtida por

$$
\varepsilon_{85}=260 \cdot \varepsilon_{c o} \cdot k_{3} \cdot \rho_{s} \cdot\left[1+0,5 \cdot k_{5} \cdot\left(k_{8}-1\right)\right]+\varepsilon_{085}
$$

onde

$$
k_{8}=\frac{f_{y}}{500} \geq 1,0
$$

e

$$
\rho_{s}=\frac{\sum_{i=1}^{n}\left(A_{s x}\right)_{i}+\sum_{j=1}^{m}\left(A_{s y}\right)_{j}}{s \cdot\left(c_{x}+c_{y}\right)}
$$

onde $\rho_{\mathrm{s}}$ é a taxa volumétrica de armadura, com limites de aplicabilidade entre 0,03 e $0,01 \cdot \mathrm{k}_{6}$.

$\mathrm{Na}$ falta de dados experimentais, para as propriedades do concreto não confinado podem ser assumidos os seguintes valores:

$$
\varepsilon_{c o}=0,0028-0,0008 \cdot k_{6}
$$

onde $\varepsilon_{\mathrm{co}}$ é a deformação de pico do concreto não confinado e

$$
\varepsilon_{085}=\varepsilon_{c o}+0,0018 \cdot k_{6}{ }^{2}
$$

sendo $\varepsilon_{085}$ a deformação do trecho descendente correspondente a $85 \%$ da resistência do concreto não confinado. Estes valores devem ser encarados como limites máximos para valores experimentais.

Para o trecho ascendente do diagrama tensão-deformação utiliza-se a equação de POPOVICS ${ }^{14}$ apud RAZVI \& SAATCIOGLU (1999-b).

Para $E_{c}$ propõe-se a equação:

$$
E_{c}=3,320 \cdot \sqrt{f_{c o}}+6,9 \text { com } E_{c} \geq E_{\mathrm{sec}}
$$

Propõe-se a superposição de efeitos de diferentes arranjos de confinamento. As pressões em áreas iguais devem ser sobrepostas. As pressões são determinadas separadamente e independentemente. Não é considerada a interação de pressões. 


\subsection{6 Índices de confinamento}

RAZVI \& SAATCIOGLU (1999-b) e outros autores recomendam o índice de confinamento dado por:

$$
I C_{1}=\rho_{s} \cdot f_{y} / f_{c o}
$$

Segundo RAZVI \& SAATCIOGLU (1999-b) IC I $_{1}$ é um bom parâmetro de projeto independentemente da resistência do concreto não confinado. $\mathrm{O}$ índice $\mathrm{IC}_{1}$ cresce linearmente com o ganho de resistência. Recomenda-se para ganhos de resistência de 25 e $40 \%, \mathrm{IC}_{1}=0,09$ e 0,14 , respectivamente. Deve-se tomar cuidado com aços de tensão de escoamento muito alta (1000 MPa) em pilares com confinamento ineficiente. RAZVI \& SAATCIOGLU (1999-b) afirmam que há relações lineares de $\mathrm{IC}_{1}$ com a ductilidade e com a resistência de pilares circulares.

CUSSON \& PAULTRE (1995) afirmam que para diferentes configurações da armadura transversal em pilares quadrados ou retangulares, ocorreram respostas muito diferentes com o índice $\mathrm{IC}_{1}$. Se a tensão de escoamento da armadura transversal não é atingida o índice de confinamento superestima o ganho de resistência. CUSSON \& PAULTRE (1995) recomendam o índice de confinamento dado por:

$$
I C_{2}=f_{l e} / f_{c o}
$$

$\mathrm{O}$ índice $\mathrm{IC}_{2}$ permite a consideração do arqueamento (perda de efetividade). Existem três classes de confinamento segundo este índice: nível 1, com baixo confinamento $\left(\mathrm{IC}_{2}\right.$ entre 0 e $5 \%$ ); nível 2, com médio confinamento $\left(\mathrm{IC}_{2}\right.$ entre 5 e $20 \%$ ) e nível 3, com alto confinamento ( $\mathrm{IC}_{2}$ acima de $20 \%$ ). Segundo CUSSON \& PAULTRE (1995), o confinamento de nível 1 não deve ser utilizado para fins sísmicos. O confinamento de nível 2 atinge ganhos moderados de resistência e comportamento pós-pico dúctil. $\mathrm{O}$ de nível 3 apresenta elevados ganhos de resistência e comportamento pós-pico dúctil. Os dois últimos níveis são apropriados para regiões sísmicas. Notar que pilares quadrados com arranjos de apenas quatro barras longitudinais dispostas nos cantos resultaram em confinamento de nível 1. 


\subsection{Modelos de confinamento com compósitos}

\subsubsection{Modelo de Samaan et al. (1998)}

SAMAAN et al. (1998) propõem uma resposta tensão-deformação bi-linear do concreto confinado com PRF em pilares de seção circular, com um trecho de transição (ver Figura 5.7) através da seguinte equação:

$$
f_{c}=\frac{\left(E_{1}-E_{2}\right) \cdot \varepsilon_{c}}{\left[1+\left(\frac{\left(E_{1}-E_{2}\right) \cdot \varepsilon_{c}}{f_{0}}\right)^{n_{1}}\right]^{\frac{1}{n_{1}}}}+E_{2} \cdot \varepsilon_{c}
$$

onde $\mathrm{n}_{1}$ é o parâmetro de forma da curva, que define o trecho de transição.

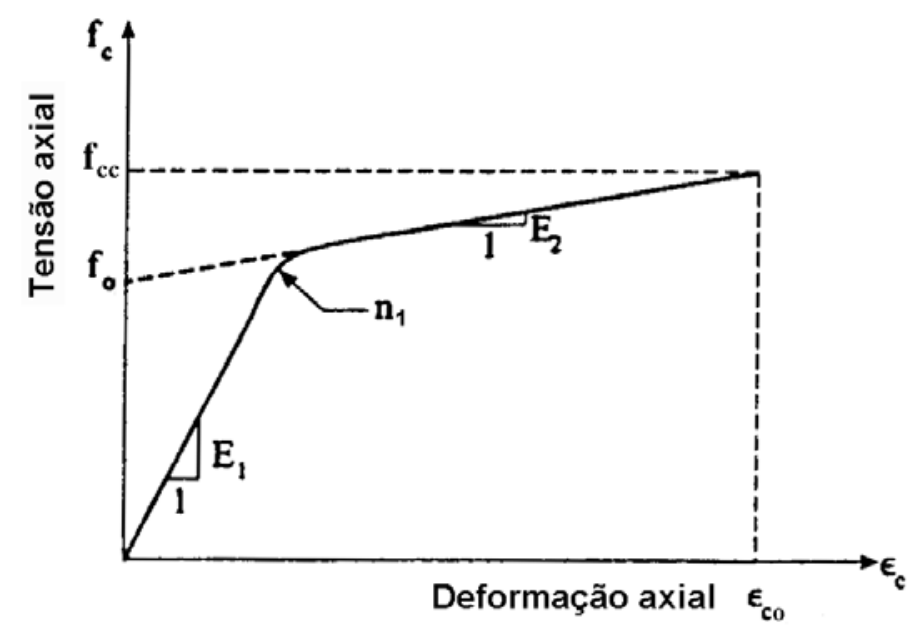

Figura 5.7 - Modelo de confinamento bi-linear de SAMAAN (1998).

Neste modelo utiliza-se a formulação da equação (5.1), proposta por RICHART et al. ${ }^{\mathbf{1 0}}$, com modificações no parâmetro $\mathrm{k}_{1}$. Baseando-se em resultados experimentais, SAMAAN et al. (1998) relacionaram $\mathrm{k}_{1}$ com a pressão lateral pela seguinte expressão:

$$
k_{1}=6,0 \cdot f_{l}^{-0,3}
$$

Substituindo-se a equação (5.63) na (5.1) obtém-se a relação entre a resistência do concreto confinado e a pressão lateral:

$$
f_{c c}=f_{c o}+6,0 \cdot f_{l}^{0,7}
$$

Para o primeiro trecho SAMAAN et al. (1998) adotaram para o módulo de elasticidade secante a equação:

$$
E_{1}=3950 \cdot \sqrt{f_{c o}}
$$


A inclinação do segundo trecho é função da rigidez do tubo e da resistência do concreto não confinado dada por

$$
E_{2}=245,61 \cdot f_{c o}^{0,2}+1,3456 \cdot \frac{E_{f} \cdot t_{f} \cdot n}{D_{c}}
$$

onde:

- $\mathrm{E}_{\mathrm{f}}$ é o módulo de elasticidade das fibras;

- $t_{\mathrm{f}}$ é a espessura da camada de fibras;

- n é o número de camadas de fibras.

A intersecção $f_{0}$ é função da resistência do concreto não confinado e da pressão de confinamento, dada por:

$$
f_{0}=0,872 \cdot f_{c o}+0,371 \cdot f_{l}+6,258
$$

e a deformação última do concreto confinado é dada por

$$
\varepsilon_{c c}=\frac{f_{c c}-f_{0}}{E_{2}}
$$

As relações válidas para deformações axiais podem ser estendidas para as deformações laterais:

$$
f_{c}=\frac{\left(E_{1 r}-E_{2 r}\right) \cdot \varepsilon_{r}}{\left[1+\left(\frac{\left(E_{1 r}-E_{2 r}\right) \cdot \varepsilon_{r}}{f_{0}}\right)^{n_{r}}\right]^{\frac{1}{n_{r}}}}+E_{2 r} \cdot \varepsilon_{r}
$$

onde o índice $r$ indica a direção radial.

A inclinação do primeiro trecho linear é dada por:

$$
E_{1 r}=\frac{E_{1}}{v}
$$

onde $v$ é o coeficiente de Poisson do concreto não confinado, (entre 0,15 e 0,22).

Os demais parâmetros são obtidos com as taxas de dilatação $\mu_{\max }$ e com $\mu_{\mathrm{u}}$ que são relacionadas à resistência do tubo.

$$
\begin{aligned}
& \mu_{\max }=-0,977 \cdot \ln \left(\frac{2 \cdot E_{f} \cdot t_{f} \cdot n}{f_{c o} \cdot D_{c}}\right)+3,938 \\
& \mu_{u}=-0,187 \cdot \ln \left(\frac{2 \cdot E_{f} \cdot t_{f}}{f_{c o} \cdot D_{c}}\right)+0,881
\end{aligned}
$$

O módulo de elasticidade radial do segundo trecho é dado por 


$$
E_{2 r}=\frac{E_{2}}{\mu_{u}}
$$

O parâmetro de forma da curva é dado por

$$
n_{r}=\frac{n_{1}}{\mu_{\max }}
$$

O intercepto é:

$$
f_{\text {or }}=0,636 \cdot f_{c o}+0,233 \cdot f_{l}+4,651
$$

A deformação radial última é dada por

$$
\varepsilon_{r u}=\frac{f_{c c}-f_{o r}}{E_{2 r}}
$$

onde $\mathrm{f}_{\mathrm{cc}}$ é a tensão última do concreto confinado.

\subsubsection{Modelo de Miyauchi et al. (1997)}

Baseados em resultados de ensaios com corpos de prova cilíndricos de concreto encamisados com PRFC propuseram para a previsão da resistência do concreto confinado uma equação semelhante à de Richart et al. (1929). Introduziram um coeficiente de efetividade $\mathrm{k}_{\mathrm{e}}$ de 0,85 , resultando em:

$$
\frac{f_{c c}}{f_{c o}}=1+3,50 \cdot \frac{f_{l}}{f_{c o}}
$$

Propuseram para previsão da deformação última do concreto confinado expressões com funções exponenciais para os dois níveis de resistência ensaiados, de 30 e $50 \mathrm{MPa}$. Utilizaram o método dos mínimos quadrados para o ajuste das curvas.

$$
\begin{aligned}
& \frac{\varepsilon_{c c}}{\varepsilon_{c o}}=1,0+10,6 \cdot\left(\frac{f_{I}}{f_{c o}}\right)^{0,373} \quad \text { para } f_{c o}=30 \mathrm{MPa} \\
& \frac{\varepsilon_{c c}}{\varepsilon_{c o}}=1,0+10,5 \cdot\left(\frac{f_{I}}{f_{c o}}\right)^{0,525} \quad \text { para } f_{c o}=50 \mathrm{MPa}
\end{aligned}
$$

O diagrama tensão-deformação é dividido em dois trechos. O primeiro é parabólico, seguindo o comportamento do concreto não confinado e o segundo é linear, tangenciando a parábola em um determinado ponto de intersecção $\left(\varepsilon_{\text {tan }}\right)$. O equacionamento é dado a seguir: 


$$
\begin{aligned}
& f_{c}=f_{c o} \cdot\left[2 \cdot \frac{\varepsilon_{c}}{\varepsilon_{c o}}-\left(\frac{\varepsilon_{c}}{\varepsilon_{c o}}\right)^{2}\right] \text { para } 0 \leq \varepsilon_{c} \leq \varepsilon_{\tan } \\
& f_{c}=f_{c c}-\lambda \cdot\left(\varepsilon_{c c}-\varepsilon_{c}\right) \text { para } \varepsilon_{\tan } \leq \varepsilon_{c} \leq \varepsilon_{c c}
\end{aligned}
$$

onde

$$
\varepsilon_{\tan }=\varepsilon_{c o}-\frac{\lambda \cdot \varepsilon_{c o}^{2}}{2 \cdot f_{c o}}
$$

e

$$
\left.\lambda=\frac{1}{\varepsilon_{c o}{ }^{2}} \cdot\left\{-2 \cdot f_{c o} \cdot\left(\varepsilon_{c c}-\varepsilon_{c o}\right)+\sqrt{4 \cdot f_{c o} \cdot\left(f_{c o} \cdot \varepsilon_{c c}{ }^{2}-2 \cdot f_{c o} \cdot \varepsilon_{c o} \cdot \varepsilon_{c c}+f_{c o} \cdot \varepsilon_{c o}{ }^{2}\right.}\right)\right\}
$$

Na Figura 5.8 é apresentado o diagrama tensão-deformação sugerido por MIYAUCHI et al. (1997).

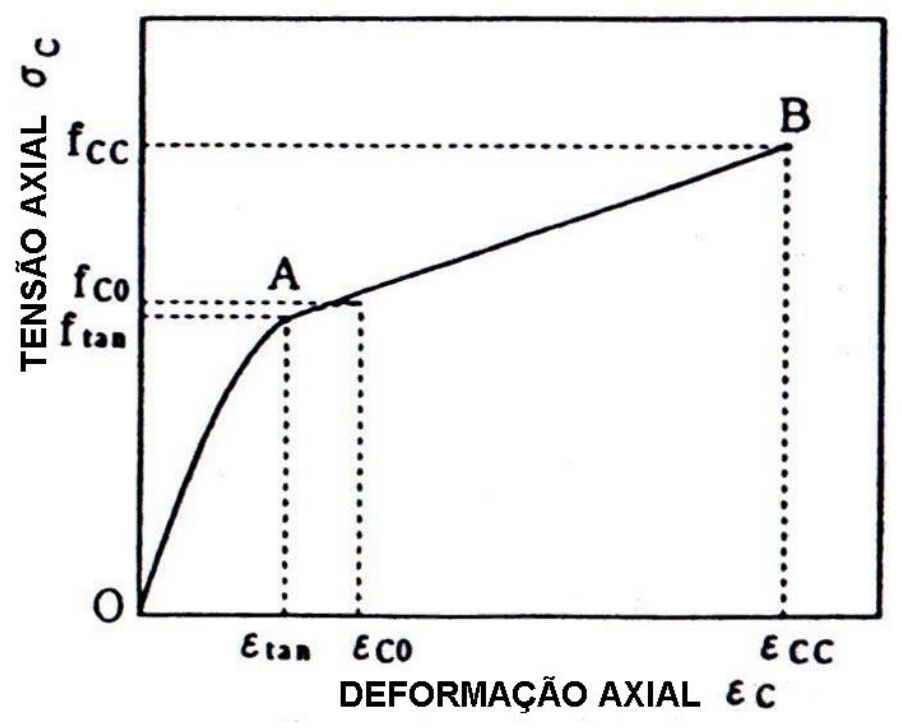

Figura 5.8 - Diagrama tensão-deformação - MIYAUCHI et al. (1997)

\subsubsection{Expressões adicionais}

Alguns textos de modelos teóricos não foram obtidos na íntegra, porém DE LORENZIS \& TEPFERS (2001) trazem um resumo das principais equações dos modelos teóricos aqui apresentados e algumas adicionais. Aqui serão apresentadas as formulações destes modelos teóricos para o ganho de resistência e de deformação última do concreto confinado. 
Tabela 5.1 - Expressões de alguns modelos teóricos para $\mathbf{f}_{\mathrm{cc}} \mathbf{e} \varepsilon_{\mathrm{cc}}$

\begin{tabular}{ccc}
\hline Modelo analítico & $\mathrm{f}_{c c}$ & $\varepsilon_{c c}$ \\
\hline Kono et al. $(1998)^{15}$ & $\frac{f_{c c}}{f_{c o}}=1+0,0572 \cdot f_{l}$ & $\frac{\varepsilon_{c c}}{\varepsilon_{c o}}=1+0,280 \cdot f_{l}$ \\
Toutanji $(1999)^{16}$ & $\frac{f_{c c}}{f_{c o}}=1+3,5 \cdot\left(\frac{f_{l}}{f_{c o}}\right)^{0,85}$ & $\frac{\varepsilon_{c c}}{\varepsilon_{c o}}=1+\left(310,57 \cdot \varepsilon_{f u}+1,90\right) \cdot\left(\frac{f_{c c}}{f_{c o}}-1\right)$ \\
Saafi et al. $(1999)^{17}$ & $\frac{f_{c c}}{f_{c o}}=1+2,2 \cdot\left(\frac{f_{l}}{f_{c o}}\right)^{0,84}$ & $\frac{\varepsilon_{c c}}{\varepsilon_{c o}}=1+\left(537 \cdot \varepsilon_{f u}+2,6\right) \cdot\left(\frac{f_{c c}}{f_{c o}}-1\right)$ \\
Spoelstra \& Monti (1999) & $\frac{f_{c c}}{f_{c o}}=0,2+3 \cdot\left(\frac{f_{l}}{f_{c o}}\right)^{0,5}$ & $\frac{\varepsilon_{c c}}{\varepsilon_{c o}}=2+1,25 \cdot \frac{E_{c o}}{f_{c o}} \cdot \varepsilon_{f u} \cdot \sqrt{\frac{f_{l}}{f_{c o}}}$ \\
\hline
\end{tabular}

${ }^{15}$ KONO, S.; INAZUMI, M.; KAKU, T. (1998). Evaluation of Confining Effects of CFRP Sheets on Reinforced Concrete Members. Proceedings of the $2^{\text {nd }}$ International Conference on Composites in Infraestructure ICC'I 98, 5-7 January 1998. Tucson, Arizona. Pp. 343-355

${ }^{16}$ TOUTANJI, H. (1999). Stress-Strain Characteristics of Concrete Columns Externally Confined with Advanced Fiber Composite Sheets. ACI Materials Journal, v. 96, No. 3, May-June 1999. pp. 397-404.

${ }^{17}$ SAAFI, M.; TOUTANJI, H. A.; LI, Z. (1999). Behaviour of Concrete Columns Confined with Fiber Reinforced Polymer Tubes. ACI Materials Journal, v. 96, No. 4, July-August 1999, pp. 500-509.

${ }^{18}$ SPOELSTRA, M. R.; MONTI, G. (1999). FRP-Confined Concrete Model. Journal of Composites for Construction, ASCE, v. 3, No. 3, August 1999. pp. 143-150. 


\section{Capitulo 6 - Ductilidade}

Segundo MENDES (1993), a ductilidade pode ser abordada em três aspectos: o do material; o do elemento estrutural e o da estrutura. Quanto ao material pensa-se em diagramas tensão-deformação de corpos-de-prova, e a ductilidade pode ser encarada como uma propriedade intrínseca do material. Em um elemento estrutural devem ser acrescentados outros fatores como tipo de solicitação, geometria, condições de contorno e interações entre os materiais constituintes. A ductilidade neste aspecto é avaliada por meio de curvas ação-deformação seccionais ou do elemento. Em termos de estrutura a quantidade de variáveis é grande e o estudo torna-se complexo.

Define-se aqui ductilidade, segundo MENDES (1993), como "a capacidade de um material, seção, elemento ou sistema estrutural deformar-se inelasticamente sem perder de maneira brusca sua capacidade resistente". A ductilidade possibilita à estrutura maior segurança, apresentando fissuras e grandes deformações, evitando o colapso progressivo e absorvendo energia em solicitações dinâmicas. Desta maneira torna-se muito importante no dimensionamento de elementos em regiões sísmicas.

A ductilidade do concreto como material é avaliada pelo do diagrama tensãodeformação de ensaios de compressão de corpos-de-prova. Geralmente utiliza-se o trecho descendente do diagrama para a quantificação da ductilidade. $\mathrm{AHMAD}^{19}$ apud MENDES (1993) define a ductilidade do concreto pela relação:

$$
I D_{1}=\frac{\varepsilon_{0,50}}{\varepsilon_{c o}}
$$

onde $\varepsilon_{0,5}$ é a deformação do trecho descendente do diagrama tensão-deformação correspondente a $0,5 \cdot f_{\mathrm{co}}$.

${ }^{19}$ AHMAD, S. H. (1992). Notas de aula do curso de Concreto de Alta Resistência e Durabilidade II. COPPE/UFRJ, Ago. 1992. 
Pode-se analisar a ductilidade por meio do trecho ascendente, utilizando a relação:

$$
I D_{2}=\frac{\varepsilon_{c o}}{\varepsilon_{e}}
$$

onde $\varepsilon_{\mathrm{e}}$ é a deformação elástica equivalente à tensão máxima obtida com o módulo tangente à origem. Em ambas formulações a ductilidade do concreto reduz-se com o aumento da resistência.

A ductilidade do aço é obtida de ensaios de tração em corpos-de-prova. Há basicamente dois tipos de aço: com e sem patamar de escoamento. Pode-se quantificar a ductilidade pela deformação última $\left(\varepsilon_{\mathrm{u}}\right)$ e pela relação:

$$
I D_{s}=\frac{f_{u}}{f_{y}}
$$

onde:

- $\mathrm{f}_{\mathrm{u}}$ é a tensão última;

- $f_{y}$ é a tensão de escoamento.

No aspecto de elemento estrutural será abordada a ductilidade de pilares de concreto armado. Os pilares são muito sensíveis ao tipo de concreto e a seu diagrama tensão-deformação. Em grande parte dos trabalhos tenta-se quantificar a ductilidade com corpos-de-prova de pequenas dimensões submetidos à compressão axial. Em MENDES (1993) apresenta-se o seguinte índice para concreto confinado:

$$
I D_{P 1}=\frac{\varepsilon_{0,85}}{\varepsilon_{c o}}
$$

onde $\varepsilon_{0,85 \mathrm{c}}$ é a deformação correspondente a $0,85 \cdot \mathrm{f}_{\mathrm{cc}}$ no trecho descendente do diagrama tensão-deformação do concreto confinado.

MARTINEZ, NILSON e SLATE ${ }^{20}$ (1984) utilizaram definição semelhante, porém no lugar de $\varepsilon_{\mathrm{co}}$ utilizaram $\varepsilon_{\mathrm{cc}}$ (do concreto confinado). Estas definições de ductilidade são parecidas com as utilizadas para concreto não confinado e o valor de $0,85 \cdot f_{\mathrm{cc}}$ é definido arbitrariamente por estar num intervalo em que pode ser obtido no ensaio (MENDES, 1993).

${ }^{20}$ MARTINEZ, S.; NILSON, A. H.; SLATE, F. C. (1984). Spirally Reinforced High Strength Concrete Columns. ACI Journal, V. 81, n. 5, p. 431-442, sep./oct. 1984. 
AHMAD E SHAH ${ }^{21}$ apud MENDES (1993) utilizaram a inclinação do trecho descendente como indicador da ductilidade. Utilizou-se o ângulo $\theta$, medido entre a horizontal e a reta dos pontos do diagrama tensão-deformação correspondentes a $\varepsilon_{\mathrm{co}}$ e $2 \cdot \varepsilon_{\mathrm{co}}$. Quanto menor este ângulo, mais dúctil é o comportamento.

Segundo MENDES (1993) influem na ductilidade de um pilar a resistência do concreto e seu comportamento tensão-deformação; a taxa de armadura transversal; o tipo de armadura, tensão de escoamento e espaçamento da armadura transversal; a forma da seção transversal e a disposição das barras transversais e longitudinais; a taxa de armadura longitudinal, número de barras e diâmetro; o tipo de agregado; a espessura do cobrimento; a presença de cisalhamento; a taxa de compressão axial relativa; o tipo de ensaio e fatores dependentes do tempo.

Nota-se que, entre outros fatores, o confinamento passivo obtido com armaduras transversais é significativo sobre a ductilidade de pilares de concreto armado. Segundo AHMAD E $\mathrm{SHAH}^{21}$ sendo conhecidos o comportamento do concreto no confinamento ativo e a relação tensão-deformação do aço da armadura de confinamento pode-se determinar o comportamento no confinamento passivo impondo a compatibilidade entre a deformação lateral do concreto e a do aço. O confinamento lateral pode diminuir a inclinação do trecho descendente do diagrama tensão-deformação. Porém certas vezes a taxa de armadura necessária é muito alta, tornando-se antieconômica.

Normalmente o estribo não é tão efetivo quanto a espiral, que sendo continua, distribui melhor as tensões ao longo do pilar. Quanto à resistência do concreto podese dizer que o concreto de alta resistência desenvolve menores pressões de confinamento para um mesmo nível de compressão. Isto ocorre devido a uma menor micro-fissuração e por conseqüência uma menor deformação lateral. A microfissuração depende da relação resistência agregado/resistência da pasta. No concreto de alta resistência em que a pasta é bastante resistente as fissuras atravessam diretamente o agregado. Nos concretos comuns estas contornam os agregados, aumentando a micro-fissuração e a expansão lateral. Para obter maior ductilidade do

21 AHMAD, S. H.; SHAH, S. P. (1982). Stress-Strain Curves of Concrete Confined by Spiral Reinforcement. ACI Journal, Procedings v. 79, n. 6, p. 484-490, Nov./Dec. 1982. 
concreto de alta resistência pode-se utilizar agregados com maior resistência, como os agregados de alta densidade (MENDES, 1993).

AHMAD E SHAH ${ }^{21}$, utilizando a inclinação do trecho descendente para quantificar a ductilidade, observaram que para uma mesma taxa de armadura lateral a ductilidade é menor em concretos de alta resistência. No entanto observaram que a melhoria relativa com a adição de uma certa taxa de armadura transversal independe da resistência e tipo do concreto. Ou seja, a relação dada pela equação (6.5) independe da resistência do concreto.

$$
I D_{P 2}=\frac{\theta_{c c}-\theta_{c o}}{\theta_{c o}}
$$

onde:

- $\theta_{\text {cc }}$ é o ângulo do trecho descendente do diagrama tensão-deformação para o concreto confinado;

- $\theta_{\text {co }}$ é o ângulo do trecho descendente do diagrama tensão-deformação para o concreto não confinado.

RAZVI \& SAATCIOGLU (1999-b) recomendam a utilização do índice de ductilidade ID $\mathrm{P} 2_{\text {. }}$ 


\section{Capitulo 7 - Análise experimental}

A análise experimental teve como objetivo observar o comportamento de pilares de concreto armado reforçados por encamisamento com compósitos de fibras de carbono. Os ensaios foram de compressão axial centrada. Procurou-se analisar experimentalmente a influência da taxa de armadura transversal e do número de camadas de reforço em pilares de seção transversal circular. Foram ensaiados também pilares de seção transversal quadrada reforçados com a mesma técnica, a fim de verificar a influência da forma da seção transversal.

Fizeram parte também da análise experimental os ensaios realizados para caracterização dos materiais, ensaios de verificação do efeito da aderência e ensaios piloto. Os ensaios-piloto foram realizados em uma fase inicial da pesquisa, com o objetivo de verificar a adequação dos procedimentos adotados para o ensaio.

Neste capítulo são apresentados os materiais utilizados, os procedimentos de preparo e os resultados obtidos dos ensaios de caracterização, dos ensaios-piloto e dos ensaios principais. Os resultados são apresentados neste capítulo em uma forma bruta, sendo que as análises e tratamentos dos resultados encontram-se no Capítulo 8 . Inicialmente são abordados os materiais utilizados, discriminando suas propriedades mecânicas e os procedimentos de preparo dos modelos. A caracterização do compósito é apresentada em separado, devido à importância de tais dados. Em seguida são apresentadas as características dos modelos ensaiados e os resultados obtidos.

\subsection{Materiais e métodos}

São apresentadas aqui as características dos materiais e os métodos utilizados para a confecção dos modelos ensaiados na análise experimental.

\subsubsection{Concreto}

Utilizou-se areia natural como agregado miúdo e brita $\mathrm{n}^{\circ} 1$ de origem basáltica como agregado graúdo. A caracterização dos agregados foi realizada no 
laboratório das Centrais Elétricas de Furnas, em Aparecida de Goiânia-GO, e seus resultados são apresentados na Tabela 7.1.

Tabela 7.1 - Caracterização dos agregados

\begin{tabular}{ccccc}
\hline \multicolumn{2}{c}{$\begin{array}{c}\text { Método de ensaio } \\
\text { Norma }\end{array}$} & Procedimento & Ensaio & \multicolumn{2}{c}{ Material } \\
Areia Natural & Brita 1 \\
\hline NBR-9777/87 & 1.02 .04 & Absorção (\%) & 0,48 & - \\
NBR-7217/87 & 1.02 .44 & Granulometria (M.F.) & 2,40 & - \\
NBR-9776/87 & 1.02 .02 & Massa específica $\left(\mathrm{g} / \mathrm{cm}^{3}\right)$ & 2,62 & - \\
NBR-7220/87 & 1.02 .11 & Teor de matéria orgânica & + Clara & - \\
NBR-6465/84 & 1.02 .16 & Abrasão Los Angeles $(\%)$ & - & $13(\mathrm{~B})$ \\
NBR-9937/87 & 1.02 .03 & Absorção (\%) & - & 1,0 \\
NBR-7217/87 & 1.02 .09 & Granulometria & - & 6,67 \\
NBR-9937/87 & 1.02 .03 & Massa específica S.S.S. $\left(\mathrm{g} / \mathrm{cm}^{3}\right)$ & - & 2,88 \\
NBR-7251/82 & 1.02 .05 & Massa unitária - estado solto $\left(\mathrm{kg} / \mathrm{dm}{ }^{3}\right)$ & 1,54 & 1,49 \\
NBR-7218/87 & 1.02 .13 & Teor de argila em torrões e materiais friáveis & 0,10 & - \\
NBR-7219/87 & 1.02 .12 & Teor de material pulverulento $(\%)$ & 1,12 & - \\
\hline
\end{tabular}

Utilizou-se cimento Portland do tipo CP II E 32, da marca Itaú. O traço unitário em massa do concreto utilizado está indicado na Tabela 7.2.

Tabela 7.2 - Traço unitário em massa do concreto

\begin{tabular}{cc}
\hline Material & Traço unitário em massa \\
\hline Cimento CP II E - Itaú & 1,000 \\
Areia natural & 2,762 \\
Brita 1 & 3,238 \\
Água & 0,610 \\
\hline
\end{tabular}

A mistura foi realizada em uma betoneira de eixo vertical com capacidade de 200 litros. O concreto foi então lançado, sendo que nos pilares circulares o sentido de lançamento e adensamento coincidiu com o eixo dos pilares. Nos pilares de seção quadrada, no entanto, o sentido de lançamento e adensamento foi perpendicular ao eixo dos mesmos. Isto pode ter acarretado uma diminuição da resistência à compressão destes modelos na direção axial.

A cura foi realizada em câmara úmida por 7 dias. Os ensaios foram realizados aos 21 dias de idade. Na Tabela 7.3 são apresentados a resistência e o módulo de elasticidade obtidos com corpos de prova cilíndricos de 10 x $20 \mathrm{~cm}$. 
Tabela 7.3 - Resistência à compressão e módulo de elasticidade tangente

\begin{tabular}{ccc}
\hline Série & $\begin{array}{c}\text { Resistência (MPa) } \\
\text { Média 3 C.P.s }\end{array}$ & $\begin{array}{c}\text { Módulo de elasticidade } \\
\text { GPa }\end{array}$ \\
\hline 1 & 32,0 & 28,55 \\
2 & 35,3 & 26,32 \\
\hline
\end{tabular}

\subsubsection{Fôrmas}

Para a moldagem dos pilares de seção transversal circular utilizou-se fôrmas cilíndricas confeccionadas com tubos de PVC e fundo de madeira. Presilhas metálicas foram utilizadas para garantir sua fixação e estanqueidade. Os pilares de seção transversal quadrada foram moldados em formas metálicas para prismas de concreto de $15 \times 15 \times 50 \mathrm{~cm}$. Os cantos foram arredondados com moldes em massa plástica utilizando-se um raio de $3 \mathrm{~cm}$. O comprimento foi reduzido de 50 para 45 $\mathrm{cm}$, para manter a proporção entre largura e comprimento de 1:3. Na Figura 7.1 apresenta-se as fôrmas utilizadas e a direção do lançamento do concreto.

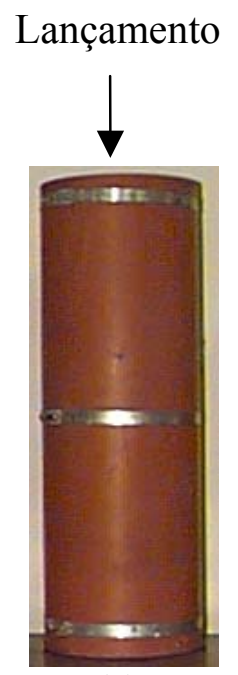

(a)

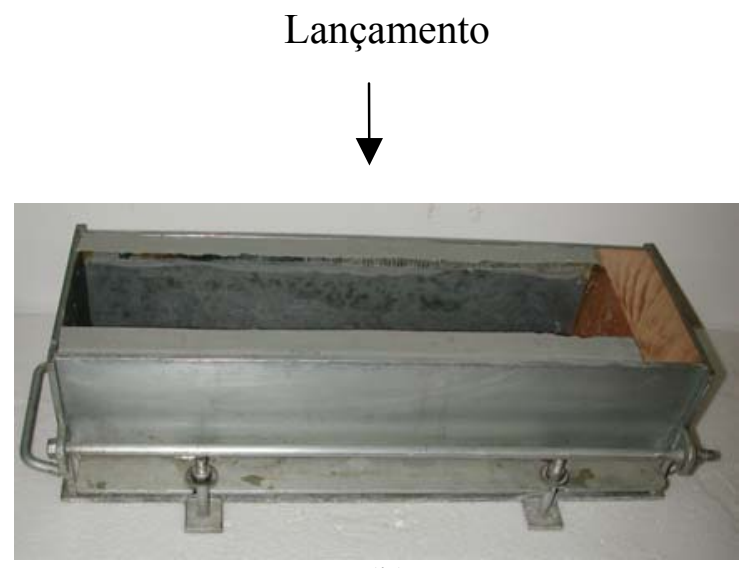

(b)

Figura 7.1 - Fôrmas utilizadas para moldagem dos pilares

(a) Seção transversal circular (b) Seção transversal quadrada

\subsubsection{Armaduras}

Em 6 pilares de seção transversal circular utilizou-se armaduras nas direções longitudinal e transversal. O diâmetro das armaduras transversais foi de $5 \mathrm{~mm}$ enquanto o das longitudinais foi de $8 \mathrm{~mm}$. Utilizou-se diferentes espaçamentos de armaduras transversais para obter as taxas volumétricas necessárias. Na Figura 7.2 
apresenta-se uma ilustração das armaduras. Pode-se notar que a armadura transversal utilizada tem a forma de espiral.

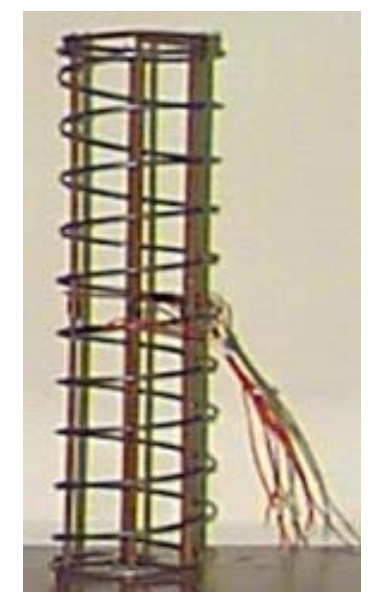

Figura 7.2 - Ilustração das armaduras

O aço da armadura transversal não apresenta patamar de escoamento. Assim a tensão de escoamento convencional é obtida com uma deformação residual de 0,2\%. A tensão de escoamento foi de $756 \mathrm{MPa}$ e o módulo de elasticidade de 204,7 GPa.

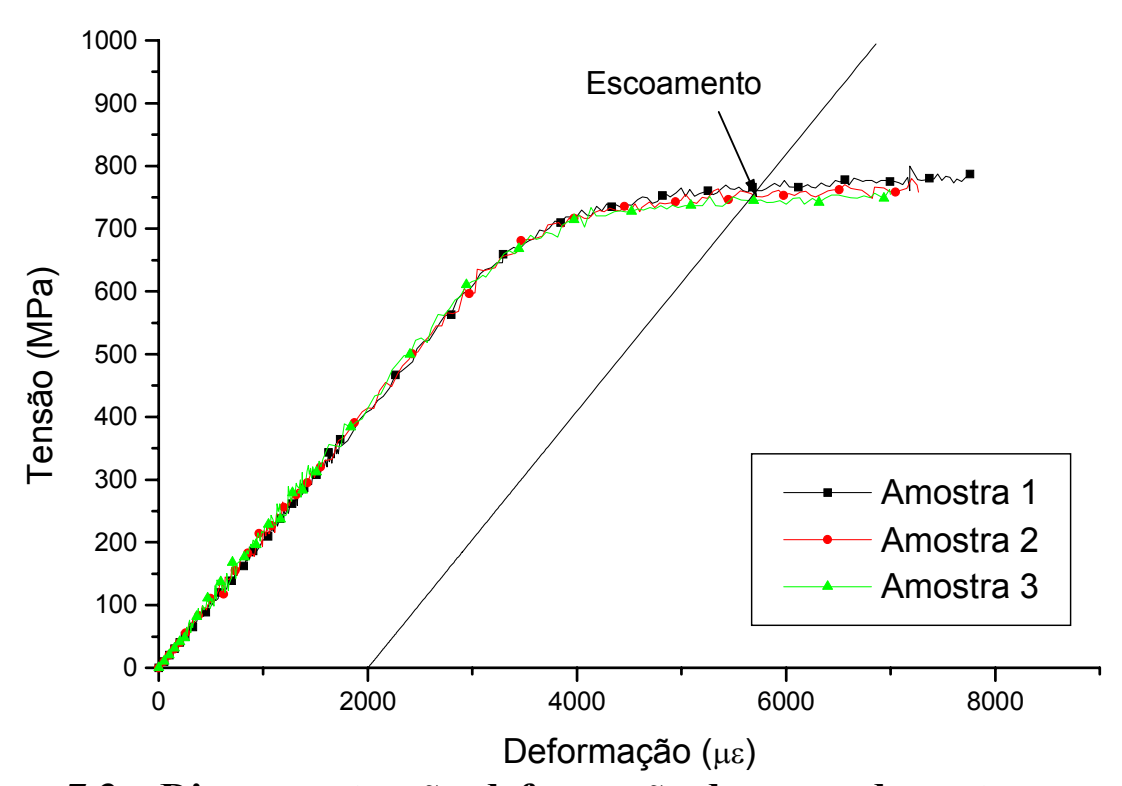

Figura 7.3 - Diagrama tensão-deformação das armaduras transversais

Para simplificação da análise dos resultados foi adotado um comportamento elasto-plástico perfeito para o aço da armadura transversal, com o módulo de elasticidade e tensão de escoamento obtidas dos ensaios. Na Figura 7.4 apresenta-se o modelo utilizado e a média dos dados experimentais. 


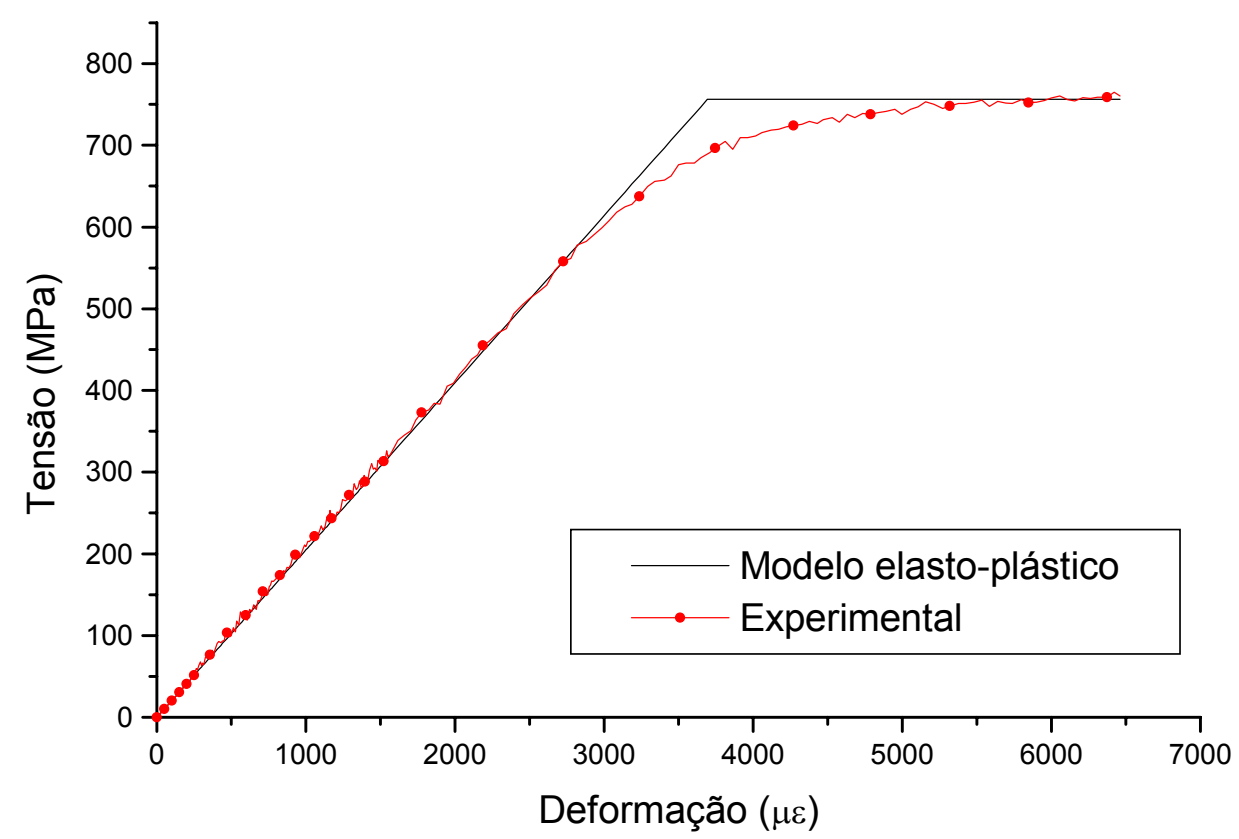

Figura 7.4 - Modelo elasto-plástico x experimental

A armadura longitudinal apresentou um comportamento elasto-plástico quase perfeito, com uma tensão de escoamento de 554,8 MPa e módulo de elasticidade de 201,5 GPa.

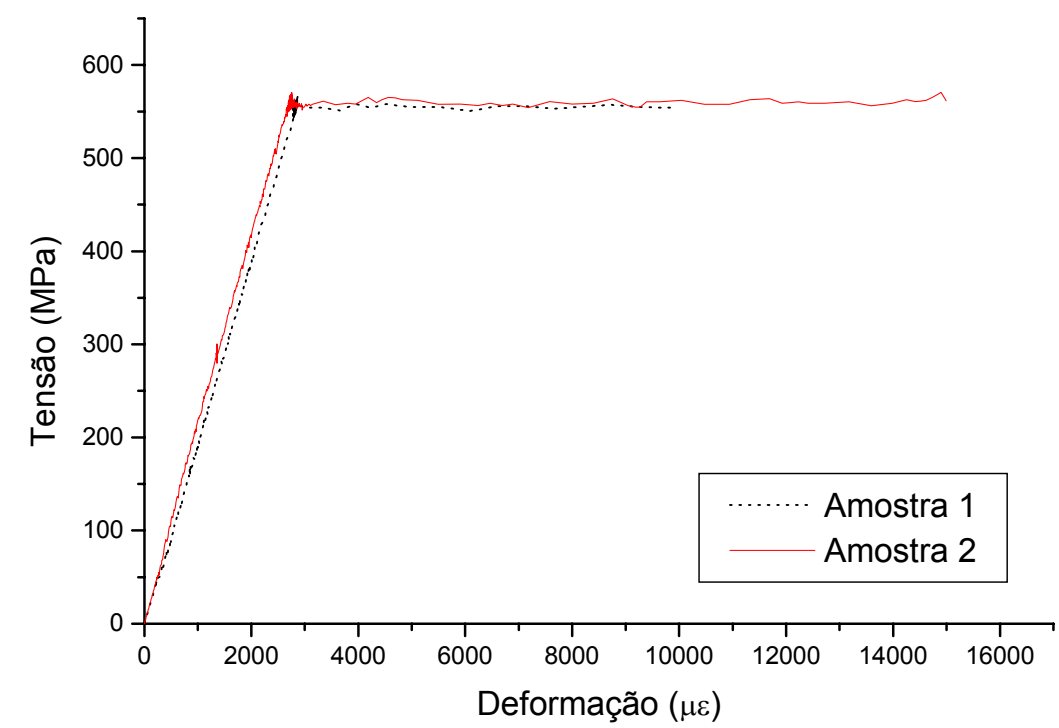

Figura 7.5 - Diagrama tensão-deformação das armaduras longitudinais

\subsubsection{Sistema de reforço por encamisamento}

O encamisamento dos pilares foi efetuado com o sistema SIKAWRAP ${ }^{\circledR}$, que consiste na colagem de tecidos unidirecionais de fibras de carbono (SIKAWRAP 
HEX-230 C) com resina epóxi (SIKADUR-330). Na Figura 7.6 são apresentados os materiais componentes do sistema de reforço.

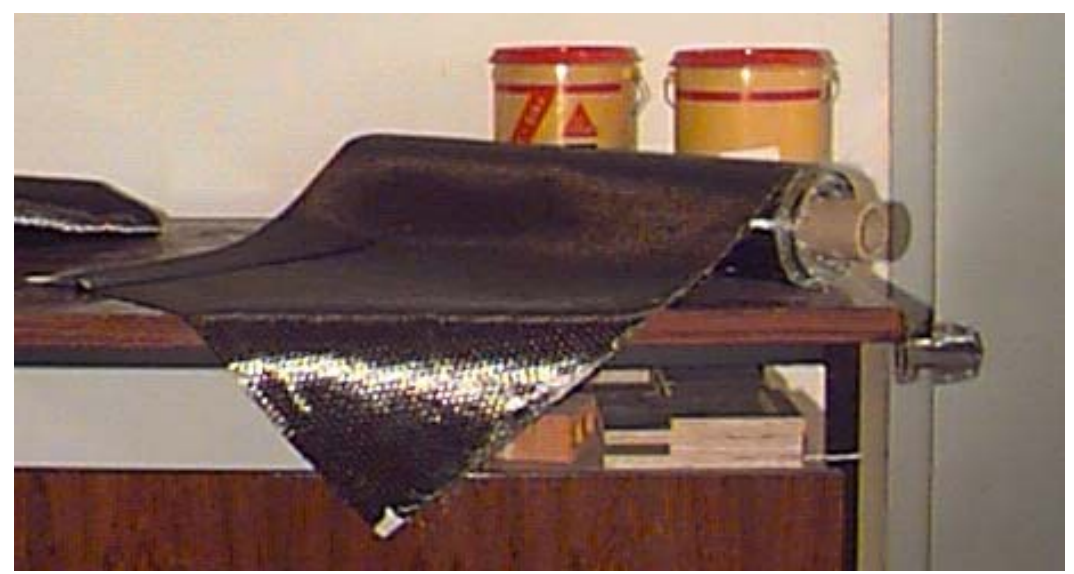

Figura 7.6 - Sistema de reforço estrutural SIKAWRAP ${ }^{\circledR}$

As características das fibras de carbono são apresentadas na Tabela 7.4, segundo dados fornecidos pelo fabricante.

Tabela 7.4 - Propriedades dos tecidos de fibras de carbono

SIKAWRAP HEX-230 C

\begin{tabular}{cc}
\hline Orientação das fibras & $0^{\circ}$ (unidirecional) \\
Massa / área & $225 \mathrm{~g} / \mathrm{m}^{2}$ \\
Espessura* & $0,13 \mathrm{~mm}$ \\
Módulo de elasticidade à tração & $230 \mathrm{GPa}$ \\
Resistência à tração & $3500 \mathrm{MPa}$ \\
Alongamento de ruptura & $1,5 \%$ \\
Largura do tecido & $610 \mathrm{~mm}$ \\
\hline *Baseada na área total das fibras de carbono
\end{tabular}

A resina epóxi é do tipo bi-componente, e suas características estão na Tabela 7.5 .

Tabela 7.5 - Propriedades da resina epóxi SIKADUR-330

\begin{tabular}{cc}
\hline Massa específica & $1,31 \mathrm{~kg} / \mathrm{dm}^{3}$ \\
Dosagem A:B & $1: 4$ \\
Pot-life $(5 \mathrm{~kg})$ & $90 \mathrm{~min}\left(15^{\circ} \mathrm{C}\right)$ \\
& $30 \mathrm{~min}\left(35^{\circ} \mathrm{C}\right)$ \\
Resistência à tração & $30 \mathrm{MPa}(7 \mathrm{dias})$ \\
Módulo de elasticidade à tração & $3,8 \mathrm{GPa}(7 \mathrm{dias})$ \\
\hline
\end{tabular}

A resina foi misturada com um misturador elétrico durante o tempo necessário para se obter uma mistura homogênea e de coloração uniforme. Após a mistura aplicou-se a resina sobre as superfícies a serem encamisadas. O consumo de epóxi foi de $1,0 \mathrm{~kg} / \mathrm{m}^{2}$ para as superfícies de concreto e de $0,75 \mathrm{~kg} / \mathrm{m}^{2}$ para as 
superfícies já cobertas com fibras de carbono ( $2^{\mathrm{a}}$ ou $3^{\mathrm{a}}$ camadas). Após a impregnação da superfície com a resina aplicou-se os tecidos unidirecionais, expulsando-se o ar com um pequeno rolo plástico. Utilizou-se uma sobreposição dos tecidos na direção das fibras de $10 \mathrm{~cm}$. Na direção transversal às fibras não foi necessária sobreposição. Na Figura 7.7 apresenta-se uma ilustração da aplicação do tecido de fibras de carbono.

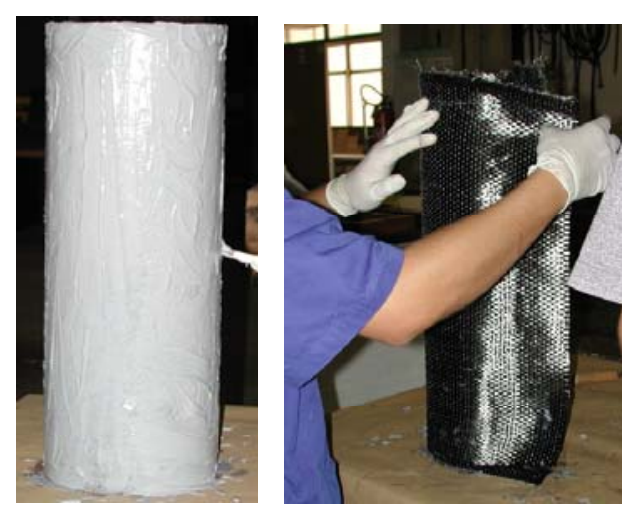

Figura 7.7 - Aplicação do sistema de reforço

Após a cura do compósito (uma semana em temperatura ambiente) retirou-se as rebarbas das extremidades do modelo com o auxílio de uma lixadeira elétrica, para preparação do ensaio.

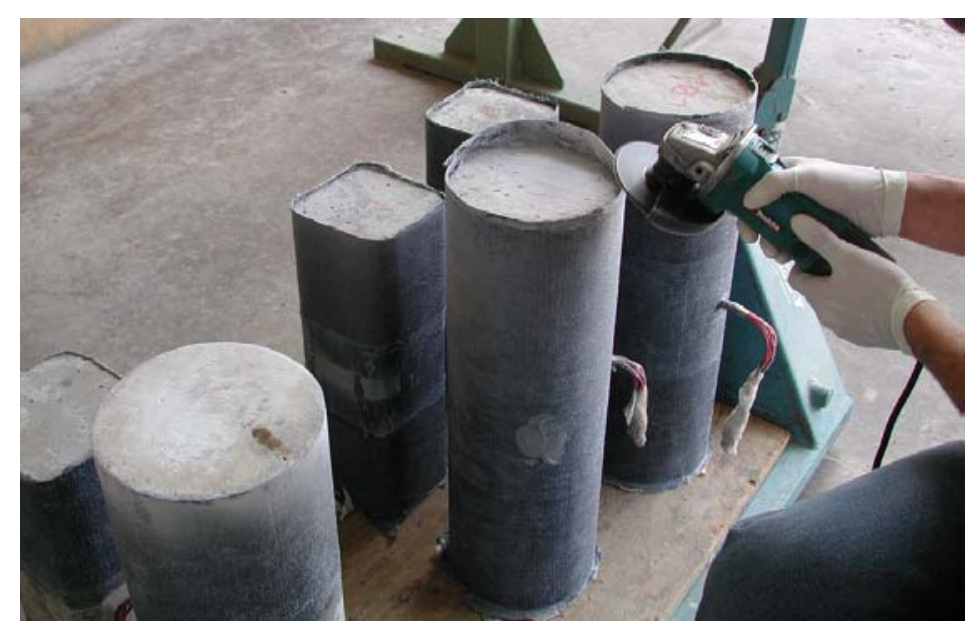

Figura 7.8 - Uniformização das extremidades

$\mathrm{Na}$ região de passagem dos fios provenientes da instrumentação das armaduras houve um pequeno desvio das fibras de maneira a acomodar estes fios. Aplicou-se neste local um reforço adicional de maneira a evitar a ruptura localizada. Na Figura 7.9 apresenta-se um detalhe do modelo ensaiado em que pode-se observar o reforço adicional na região dos fios. Pode-se observar também que aplicou-se 
resina em excesso nas regiões de colagem dos extensômetros para possibilitar o lixamento da superfície. O lixamento foi executado com o cuidado de não danificar as fibras.

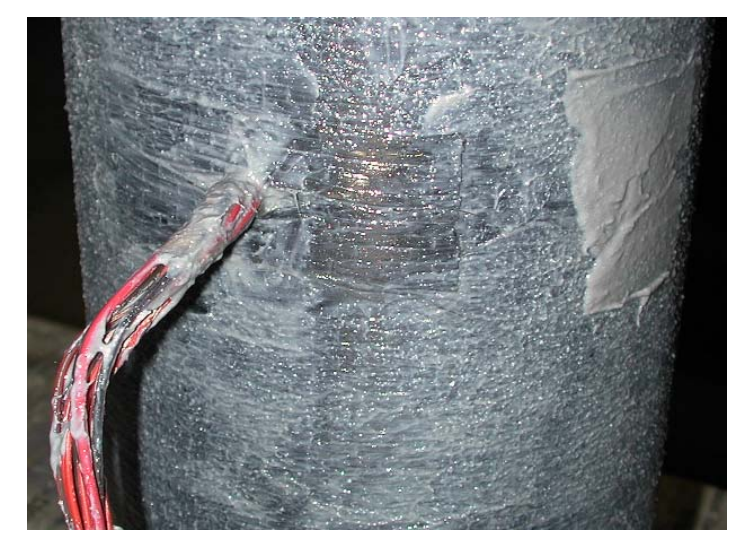

Figura 7.9 - Detalhes da aplicação do tecido

\subsubsection{Instrumentação}

Utilizou-se extensômetros elétricos de resistência da marca KYOWA, sendo que para a camisa de reforço foram empregados extensômetros do tipo KFG-10-C1120-11 e para as armaduras o KFG-5-C1-120-11.

Para registrar os deslocamentos da região central dos modelos empregou-se transdutores de deslocamento da marca KYOWA, com curso de $10 \mathrm{~mm}$ e sensibilidade de $0,03 \mathrm{~mm}$.

\subsubsection{Ensaio à compressão axial}

Após a preparação da instrumentação aplicou-se uma fina camada de massa plástica sobre as superfícies que recebem a carga axial, de maneira a diminuir as imperfeições e melhorar a planicidade. Após o preparo da instrumentação os pilares foram ensaiados à compressão axial centrada com controle de deslocamento em uma máquina universal de ensaios servo-hidráulica da marca INSTRON, Modelo 8506, com capacidade de 2500 kN, indicada na Figura 7.10. 


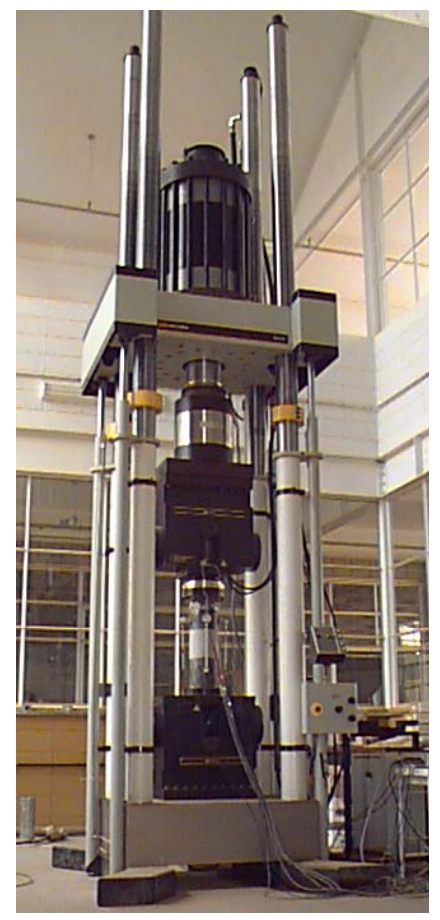

Figura 7.10 - Máquina universal de ensaios

\subsection{Ensaios de caracterização do compósito}

Os ensaios de caracterização do compósito foram realizados em duas etapas: preliminar e definitiva. $\mathrm{Na}$ etapa preliminar foram realizados ensaios de tração e módulo de elasticidade, e a determinação das frações volumétricas dos materiais constituintes. $\mathrm{Na}$ fase definitiva os mesmos ensaios foram refeitos com um número maior de amostras e então foi possível elaborar as conclusões. Todas as amostras foram preparadas com processo de moldagem semelhante ao utilizado no encamisamento dos pilares.

\subsubsection{Ensaios preliminares}

\subsubsection{Frações volumétricas dos materiais constituintes}

As frações volumétricas dos componentes do compósito foram determinadas em 2 amostras quadradas $(10 \times 10 \mathrm{~cm})$ moldadas com 5 camadas de fibras de carbono. Pôde-se determinar também a espessura final por camada de tecido de fibras de carbono impregnado. Utilizou-se um consumo de resina epóxi de $0,5 \mathrm{~kg} / \mathrm{m}^{2}$. Após a aplicação de cada camada retirou-se o ar com aplicação de um pequeno rolo 
compressor manual. As frações em massa dos materiais foram obtidas diretamente da pesagem das amostras. Os dados estão indicados na Tabela 7.6.

Tabela 7.6 - Dados dos ensaios

\begin{tabular}{cccc}
\hline Amostra & 1 & 2 & Média \\
\hline Massa das fibras (g) & 11,8 & 11,3 & 11,6 \\
Massa seca do compósito $(\mathrm{g})$ & 27,1 & 26,2 & 26,7 \\
Espessura média (mm) & 2,095 & 1,97 & 2,0 \\
\hline Densidade do compósito & & 1,335 & \\
$\left(\mathrm{~g} / \mathrm{cm}^{3}\right)$ & &
\end{tabular}

As massas específicas foram adotadas com base nas informações fornecidas pelo fabricante: densidade das fibras $\left(\mathrm{d}_{\mathrm{f}}\right)$ de 1,73 e densidade da matriz $\left(\mathrm{d}_{\mathrm{m}}\right)$ de 1,31 . A densidade das fibras $\left(\mathrm{d}_{\mathrm{f}}\right)$ foi calculada a partir da espessura útil do tecido e da massa/área (Tabela 7.4). A fração volumétrica de vazios foi calculada através da equação (7.1).

$$
v_{v}=1-\frac{\left(W_{f} / d_{f}\right)+\left(W_{c}-W_{f}\right) / d_{m}}{W_{c} / d_{c}}
$$

onde:

- $\quad \mathrm{W}_{\mathrm{f}}$ e $\mathrm{W}_{\mathrm{c}}$ são as massas de fibras e compósito respectivamente;

- $\mathrm{d}_{\mathrm{c}}$ é a densidade do compósito obtida dividindo-se a massa total da amostra pelo seu volume.

Obteve-se a fração volumétrica de vazios $\left(\mathrm{v}_{\mathrm{v}}\right)$ de $8,84 \%$. As frações volumétricas da matriz e das fibras podem ser obtidas através das equações (7.2) e (7.3):

$$
\begin{aligned}
& v_{f}+v_{m}+v_{v}=1 \\
& d_{c}=d_{f} \cdot v_{f}+d_{m} \cdot v_{m}
\end{aligned}
$$

onde $v_{f}$ e $v_{m}$ são as frações volumétricas das fibras e da matriz respectivamente.

Resolvendo-se o sistema de equações obteve-se as frações volumétricas das fibras e da matriz, de $33,52 \%$ e 57,64\%, respectivamente. Determinou-se também a espessura média da camada de compósito, de $0,40 \mathrm{~mm}$.

\subsubsection{Resistência à tração e módulo de elasticidade}

Procurou-se seguir os procedimentos de ensaio sugeridos pela ASTM D 3039 (1995). Ensaiou-se 5 amostras à tração, sendo que uma destas foi instrumentada para 
avaliar o módulo de elasticidade e a flexão ocorrida no ensaio. Utilizou-se uma máquina universal de ensaios da marca INSTRON, Modelo TTDM/L, com capacidade de 100 kN, do Departamento de Engenharia de Materiais da Escola de Engenharia de São Carlos / Universidade de São Paulo. As dimensões das amostras ensaiadas estão indicadas na Figura 7.11. Algumas dimensões diferiram das recomendadas pela ASTM D 3039 (1995), como a largura e a espessura do trecho central da amostra, que deveriam ser de 15 e $1 \mathrm{~mm}$ respectivamente. $\mathrm{Na}$ caracterização final do compósito foram utilizadas as dimensões recomendadas pela ASTM D 3039 (1995).
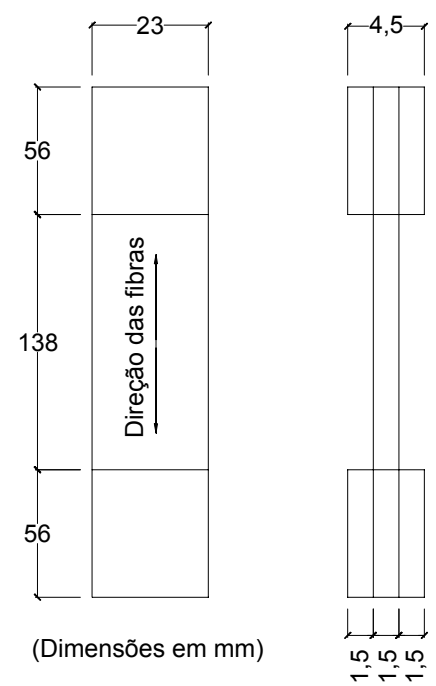

\section{Vista frontal Vista lateral}

Figura 7.11 - Dimensões das amostras do ensaio à tração

\subsubsection{Ensaio à tração}

Na Tabela 7.7 são apresentadas as dimensões finais da seção transversal da amostra (região central), a carga de ruptura e a tensão de ruptura:

Tabela 7.7 - Resultados dos ensaios de tração

\begin{tabular}{ccccc}
\hline Amostra & Espessura $(\mathrm{mm})$ & Largura $(\mathrm{mm})$ & Carga (kgf) & Tensão (MPa) \\
\hline 1 & 1,527 & 21,32 & 2700 & 813 \\
2 & 1,654 & 23,58 & 3000 & 754 \\
3 & 1,690 & 22,64 & 3175 & 814 \\
4 & 1,717 & 23,07 & 3008 & 745 \\
5 & 1,727 & 23,07 & 2850 & 701 \\
\hline
\end{tabular}


O resultado da amostra 5 foi descartado da análise pois ficou $8 \%$ abaixo da média. Descartando-se este valor obteve-se uma tensão média de 781,5 MPa com um coeficiente de variação de $4,75 \%$.

\subsubsection{Módulo de elasticidade}

A amostra 3 foi instrumentada com três extensômetros fixados na direção longitudinal conforme recomendações da ASTM D 3039 (1995) para verificação da flexão durante o ensaio e determinação do módulo de elasticidade. Na Figura 7.12 pode-se ver esquema da instrumentação da amostra 3.
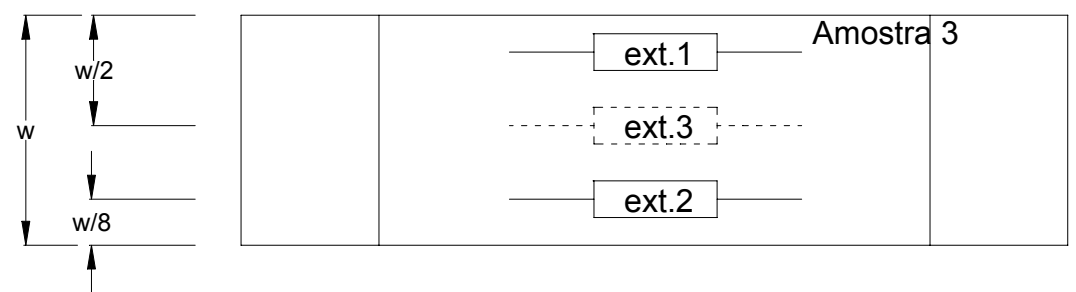

Figura 7.12 - Instrumentação da amostra 3

Durante o ensaio efetuou-se a leitura das deformações indicadas pelos extensômetros em três níveis de carga: 300, 600 e 900 kgf, para a amostra disposta nas quatro posições possíveis na máquina de ensaio. Após as leituras nas quatro posições indicadas na Figura 7.13 a amostra foi ensaiada até a ruptura. Estas cargas foram definidas por representarem deformações próximas a 1000, 2000 e $3000 \mu \epsilon$.

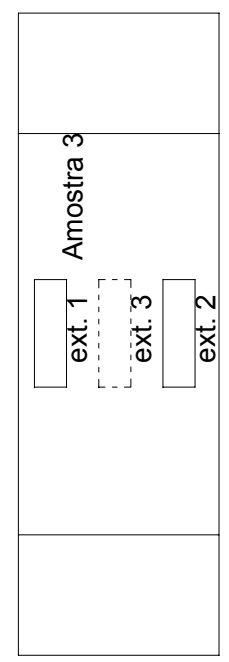

Posicão 1
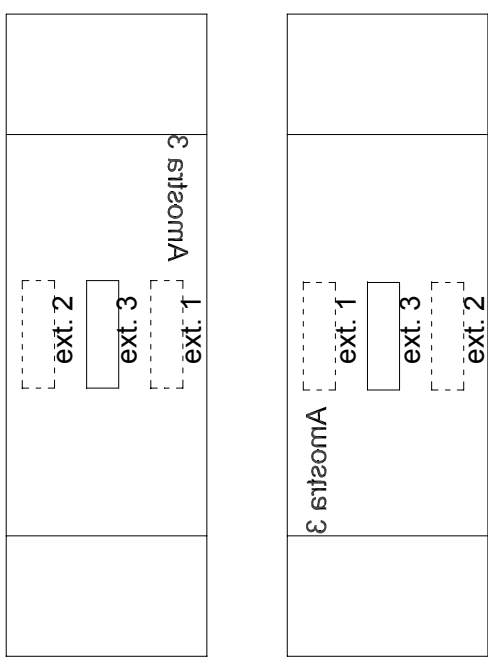

Posicão 2

Posicão 3

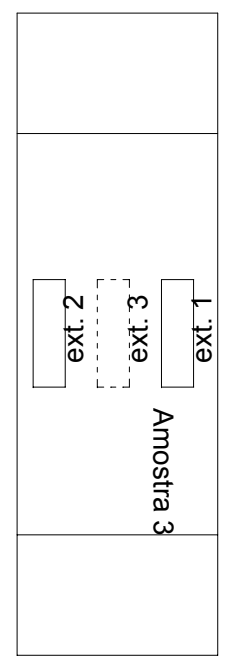

Posicão 4

Figura 7.13 - Posições de ensaio da amostra 3 
Na Figura 7.14 apresenta-se as médias das leituras obtidas em cada posição. Pode-se notar que o ensaio na posição 4 foi o único incoerente com o comportamento elástico linear esperado. Provavelmente ocorreu um erro de leitura. Logo os resultados na posição 4 foram descartados da obtenção do módulo de elasticidade. Com interpolação linear dos demais resultados obteve-se um módulo de elasticidade de $67,33 \mathrm{GPa}$.

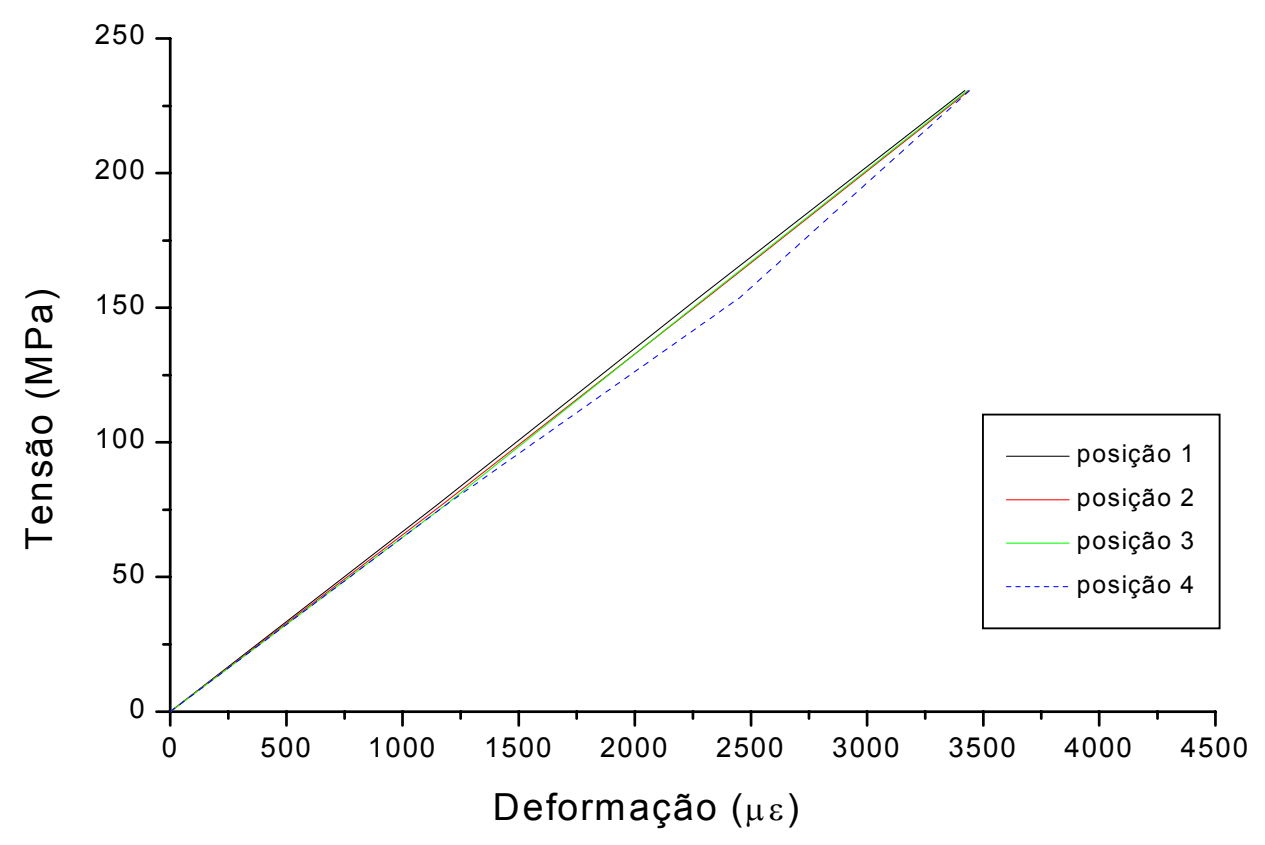

Figura 7.14 - Diagrama tensão-deformação do compósito

Na Tabela 7.8 são apresentadas as leituras dos três extensômetros para todas as posições e cargas. 
Tabela 7.8 - Resultados dos ensaios nas 4 posições

\begin{tabular}{c|ccc|ccc}
\hline & \multicolumn{5}{|c}{ Deformações $(\mu \varepsilon)$} \\
\hline $\begin{array}{c}\text { Carga } \\
(\mathrm{kN})\end{array}$ & e1 & e) 2 & e3 3 & e1 & e2 & e3 \\
\hline 0 & 0 & 0 & 0 & 0 & 0 & 0 \\
300 & 1003 & 1423 & 1089 & 1257 & 1255 & 1086 \\
600 & 2040 & 2758 & 2154 & 2313 & 2563 & 2185 \\
900 & 3114 & 4036 & 3265 & 3425 & 3776 & 3276 \\
\hline Carga & \multicolumn{3}{|c}{ posição 3} & \multicolumn{3}{c}{ posição } \\
$(\mathrm{kN})$ & e1 & e2 & e3 & e1 & e2 & e3 \\
\hline 0 & 0 & 0 & 0 & 0 & 0 & 0 \\
300 & 1005 & 1462 & 1141 & 1292 & 1205 & 1129 \\
600 & 2099 & 2740 & 2192 & 2390 & 2981 & 2220 \\
900 & 3182 & 3975 & 3287 & 3497 & 3675 & 3296 \\
\hline
\end{tabular}

\subsubsection{Avaliação da flexão}

Observou-se grandes flexões durante o ensaio. A análise foi feita segundo recomendações da ASTM D 3039 (1995). Foram anotadas medidas de deformação dos extensômetros com as cargas de 300, 600 e 900 kgf.

As porcentagens de flexão em cada posição segundo a ASTM D 3039 (1995) são dadas pelas expressões:

$$
\begin{aligned}
& B_{y}=\frac{\varepsilon_{\text {med }}-\varepsilon_{3}}{\varepsilon_{\text {med }}} \cdot 100 \\
& \mathrm{~B}_{\mathrm{z}}=\frac{4 / 3 \cdot\left(\varepsilon_{2}-\varepsilon_{1}\right)}{\varepsilon_{\text {med }}} \cdot 100 \\
& \varepsilon_{\text {med }}=\frac{\left(\varepsilon_{1}+\varepsilon_{2}\right) / 2+\varepsilon_{3}}{2}
\end{aligned}
$$

onde:

- $B_{y}$ é a flexão em relação à espessura da amostra;

- $B_{z}$ é a flexão em relação à largura da amostra;

- $\varepsilon_{1}, \varepsilon_{2}$ e $\varepsilon_{3}$ são as leituras dos extensômetros 1,2 e 3 respectivamente.

A flexão total é dada por:

$B_{\text {total }}=\left|B_{y}\right|+\left|B_{z}\right|$

Os resultados do cálculo da flexão estão na Tabela 7.9. 
Tabela 7.9 - Porcentagens de flexão

\begin{tabular}{cccc|cccc}
\hline $\begin{array}{c}\text { Posição 1 } \\
\text { Carga }(\mathrm{kN})\end{array}$ & $\mathrm{B}_{\mathrm{y}}(\%)$ & $\mathrm{B}_{\mathrm{z}}(\%)$ & $\mathrm{B}_{\text {total }}(\%)$ & $\begin{array}{c}\text { Posição } 2 \\
\text { Carga }(\mathrm{kN})\end{array}$ & $\mathrm{B}_{\mathrm{y}}(\%)$ & $\mathrm{B}_{\mathrm{z}}(\%)$ & $\mathrm{B}_{\text {total }}(\%)$ \\
\hline 300 & 5 & 49 & 54 & 300 & 7 & 0 & 7 \\
600 & 5 & 42 & 47 & 600 & 5 & 14 & 20 \\
900 & 5 & 36 & 40 & 900 & 5 & 14 & 18 \\
\hline Posição 3 & & & & Posição 4 & & & \\
Carga $(\mathrm{kN})$ & $\mathrm{B}_{\mathrm{y}}(\%)$ & $\mathrm{B}_{\mathrm{z}}(\%)$ & $\mathrm{B}_{\text {total }}(\%)$ & Carga $(\mathrm{kN})$ & $\mathrm{B}_{\mathrm{y}}(\%)$ & $\mathrm{B}_{\mathrm{z}}(\%)$ & $\mathrm{B}_{\text {total }}(\%)$ \\
\hline 300 & 4 & 51 & 55 & 300 & 5 & -10 & 15 \\
600 & 5 & 37 & 42 & 600 & 9 & 32 & 42 \\
900 & 4 & 31 & 35 & 900 & 4 & 7 & 11 \\
\hline
\end{tabular}

Segundo a ASTM D 3039 (1995) a porcentagem de flexão para um bom ensaio deveria estar entre 3 e 5\%. Este nível não foi alcançado. No entanto foram feitas algumas observações úteis para a melhoria do ensaio:

- As diferenças de leitura dos extensômetros 1 e 2 em todas as posições de ensaio podem indicar falhas na moldagem da amostra ou no alinhamento dos extensômetros;

- O extensômetro 2 apresentou suas maiores leituras nas posições 1e 3 em que esteve fixo no mesmo lado da máquina de ensaio indicando uma flexão possivelmente originada da máquina de ensaio ou do sistema de fixação da amostra.

Pretendia-se aumentar a confiabilidade do ensaio melhorando a confecção da amostra e o alinhamento dos extensômetros. As principais mudanças foram feitas no processo de corte das amostras (com mais precisão) e no processo de moldagem, especialmente na região de contato com as garras, que ganhou uma superfície de contato mais plana e lisa.

\subsubsection{Ensaios definitivos de caracterização}

Foram ensaiadas 5 amostras conforme recomendações da ASTM D 3039 (1995). Utilizou uma máquina de ensaios da marca DARTEC, modelo M1000 RK, com capacidade de 100 kN, do Laboratório de Madeiras e Estruturas de Madeira.

Observou-se que as propriedades do compósito variaram significativamente em comparação com as obtidas nos ensaios preliminares. Acredita-se que as principais diferenças tenham sido conseqüência da quantidade de resina empregada $\left(0,75 \mathrm{~kg} / \mathrm{m}^{2}\right)$ e do processo de moldagem. 
Nos ensaios preliminares de caracterização o compósito (PRFC 1) apresentou camadas com espessura média de $0,4 \mathrm{~mm}$. Nos ensaios definitivos a espessura da camada do compósito (PRFC 2) foi de $0,617 \mathrm{~mm}$. Conseqüentemente os resultados determinados para resistência à tração e módulo de elasticidade foram bem diferentes como indica a Figura 7.15. No entanto, observou-se que adotando uma espessura constante para o compósito as propriedades obtidas nas duas fases coincidem. Isto motivou a decisão de desprezar a colaboração da matriz sobre as propriedades mecânicas do compósito. Utilizou-se assim a espessura das fibras para o cálculo das tensões. Desta maneira o comportamento observado foi o mesmo para os dois compósitos (Fibras 1 e Fibras 2).

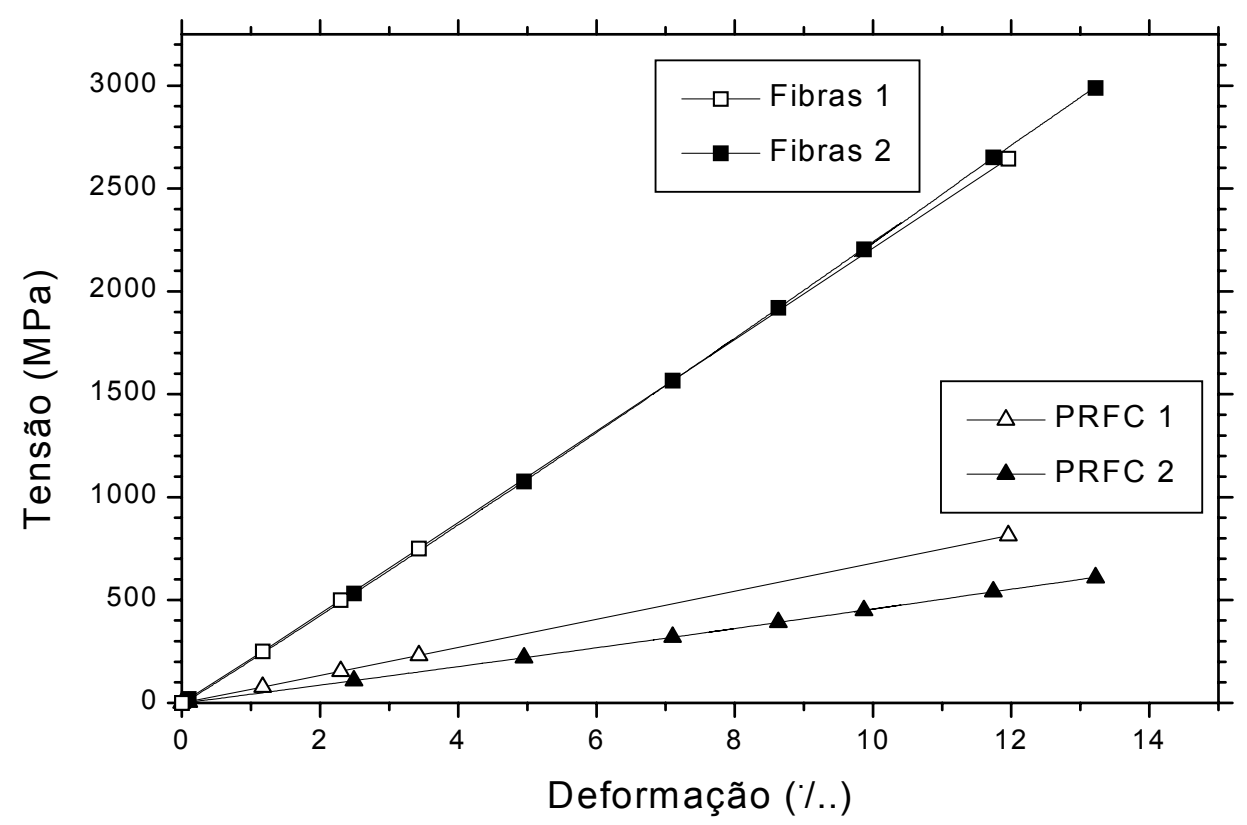

Figura 7.15 - Diagramas tensão-deformação compósito x fibras

Este procedimento foi sugerido por FIORELLI \& DIAS (2001) e já adotado por alguns pesquisadores em seus modelos teóricos. Para a avaliação do confinamento serão consideradas as propriedades das fibras, cujos resultados da análise definitiva são apresentados a seguir. 
Tabela 7.10 - Resultados dos ensaios de tração

\begin{tabular}{cccc}
\hline Amostra & Tensão $(\mathrm{MPa})$ & $\varepsilon_{\mathrm{fu}}(\%)$ & $\mathrm{E}_{\mathrm{f}}(\mathrm{GPa})$ \\
\hline 1 & 2981,07 & 13,232 & 218,43 \\
$2^{*}$ & 2584,13 & 12,434 & 225,46 \\
3 & 2679,07 & 12,015 & 220,81 \\
4 & 2621,55 & 11,887 & 217,64 \\
5 & 2922,41 & 13,021 & 218,93 \\
\hline Média & 2757,65 & 12,539 & 218,95 \\
${ }^{*}$ Utilizada apenas para cálculo da tensão \\
\hline
\end{tabular}

Observou-se uma considerável variação na resistência e deformação última das amostras. No entanto o módulo de elasticidade apresentou uniformidade. O módulo de elasticidade médio adotado foi de 218,95 GPa.

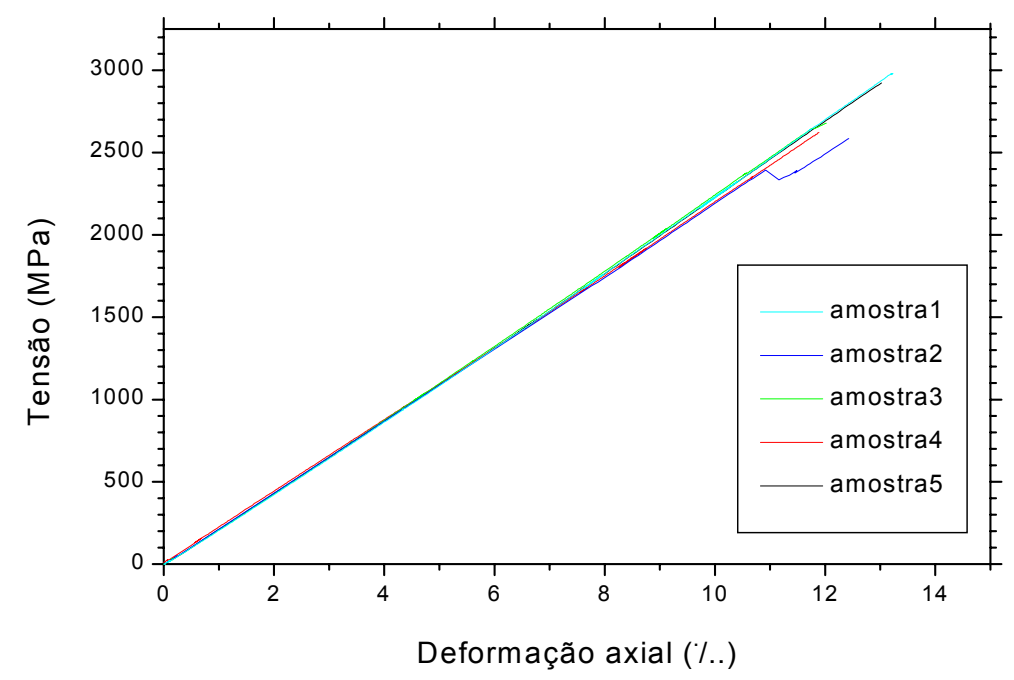

Figura 7.16 - Diagramas tensão-deformação - ensaios de tração definitivos

\subsubsection{Aplicabilidade dos resultados do compósito}

Supondo-se que duas amostras sejam moldadas com o mesmo número de camadas de compósito, porém com processos de moldagem ou quantidade de resina um pouco diferentes, as espessuras finais do compósito serão diferentes. Isto aconteceu comparando-se os ensaios preliminares e definitivos.

A carga de ruptura seria aproximadamente a mesma, logo as tensões nos dois compósitos seriam diferentes. Isto indica que a resistência do compósito não é um bom parâmetro de dimensionamento, pois não seria possível saber com precisão a espessura do compósito obtida com a aplicação do reforço. 
Logo, na análise dos resultados serão utilizadas as propriedades das fibras determinadas nos ensaios definitivos de caracterização. Considerando-se as elevadas propriedades mecânicas das fibras se comparadas à matriz este procedimento pode ser recomendado.

Segundo os valores do fabricante a resistência à tração das fibras é 117 vezes superior à da resina, enquanto o módulo de elasticidade é 61 vezes maior. Muitos autores, como DE LORENZIS \& TEPFERS (2001) utilizam as propriedades mecânicas das fibras para dimensionamento. FIORELLI \& DIAS (2001) também recomendam a utilização da espessura das fibras e não a do compósito, no cálculo da resistência à tração. Segundo os pesquisadores, a utilização da espessura das fibras (constante) diminui a variabilidade dos resultados.

Considerando-se a espessura das fibras para o cálculo da resistência e módulo de elasticidade por meio dos ensaios anteriormente apresentados obteve-se em média 218,95 GPa de módulo de elasticidade e 2757,65 $\mathrm{MPa}$ de resistência à tração. $\mathrm{O}$ módulo de elasticidade obtido nos ensaios é da ordem do valor fornecido pelo fabricante $(230 \mathrm{GPa})$. A resistência à tração foi bem inferior, no entanto. Mas já eram esperados valores inferiores de resistência à tração, devido aos problemas de flexão decorrentes do ensaio, em que as amostras acabam rompendo prematuramente.

Obteve-se na fase de ensaios definitivos uma relação massa / área dos tecidos de $222,5 \mathrm{~g} / \mathrm{m}^{2}$, muito próxima do valor fornecido pelo fabricante, o que indica a uniformidade da espessura recomendada pelo fabricante.

O módulo de elasticidade é o valor mais importante para a análise dos resultados aqui obtidos, pois de posse da deformação das fibras pode-se calcular a tensão atuante.

\subsection{Ensaios de verificação do efeito da aderência}

Foram ensaiados 4 corpos-de-prova cilíndricos de concreto de $10 \mathrm{~cm}$ de diâmetro e $20 \mathrm{~cm}$ de altura. $\mathrm{O}$ objetivo foi verificar a influência do preparo da superfície no desempenho do reforço com fibras de carbono em pilares de seção transversal circular. Utilizou-se um concreto com $34 \mathrm{MPa}$ de resistência à compressão na data de ensaio. Os corpos de prova reforçados (modelos 1, 2 e 3) 
receberam a aplicação de uma camada de reforço com fibra de carbono. As características de cada modelo foram:

- Modelo 1: preparado com lixamento da superfície;

- Modelo 2: sem lixamento da superfície;

- Modelo 3: utilizou-se um filme plástico sobre o concreto para eliminar totalmente a aderência da resina com o concreto;

- Modelo 4: corpo de prova de referência sem reforço.

Na Figura 7.17 estão indicados os diagramas tensão-deformação dos quatro modelos anteriormente citados.

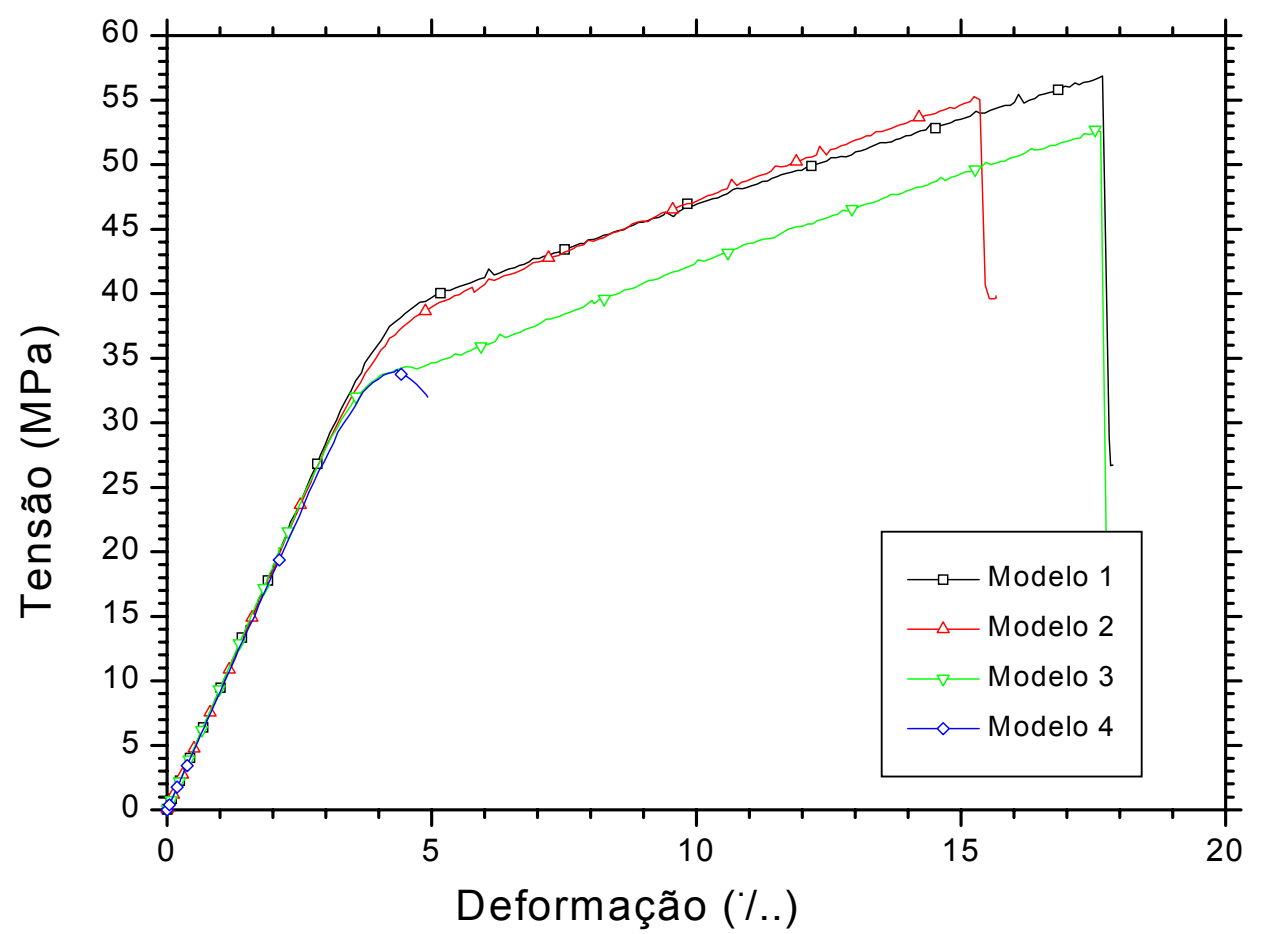

Figura 7.17 - Diagramas tensão-deformação com diferentes aderências

Notou-se que a influência do lixamento não foi significativa, já que os modelos 1 e 2 se comportaram de forma praticamente idêntica. No modelo 3, no entanto, a falta total de aderência provocou uma queda na resistência de $8 \% \mathrm{em}$ relação ao modelo1.

A aderência parece ter permitido um ganho de resistência do concreto próximo da tensão crítica, ou seja, houve um prolongamento do trecho inicial da curva tensão-deformação do concreto não confinado. No caso da ausência de aderência houve um atraso no ganho de resistência do concreto até o ponto em que a microfissuração acabou mobilizando o efeito de confinamento. Os pilares-piloto 
foram confeccionados com lixamento superficial do concreto. No entanto para os pilares definitivos dispensou-se o lixamento dos modelos tendo em vista os resultados dos ensaios aqui apresentados.

\subsection{Ensaios-piloto}

Os ensaios-piloto foram realizados com o objetivo de verificação da metodologia da análise experimental. Foram confeccionados dois pilares de concreto armado, sendo que um destes foi reforçado com o sistema com compósito de fibras de carbono.

\subsubsection{Características geométricas}

Os dois pilares possuíam seção circular com $19 \mathrm{~cm}$ de diâmetro e $57 \mathrm{~cm}$ de altura. As dimensões da seção transversal do pilar (sem reforço), bem como a disposição das armaduras estão indicadas na Figura 7.18. O espaçamento das espirais foi de $5 \mathrm{~cm}$.

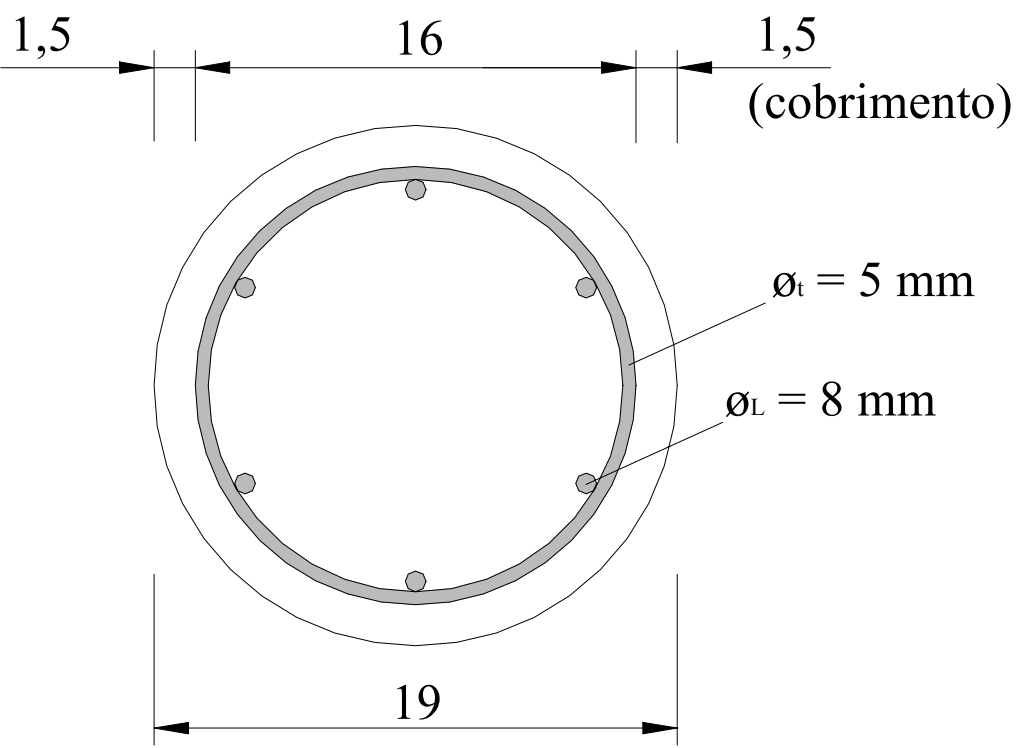

Figura 7.18 - Seção transversal do pilar original

Um dos pilares foi encamisado com duas camadas de fibras de carbono (pilar P2) e o outro pilar, não reforçado, serviu de referência (pilar P0). Aplicou-se uma camada de reforço com compósito nas extremidades dos dois pilares para evitar rupturas localizadas por concentrações de tensões. Na Figura 7.19 está indicado um esquema da aplicação das fibras. 


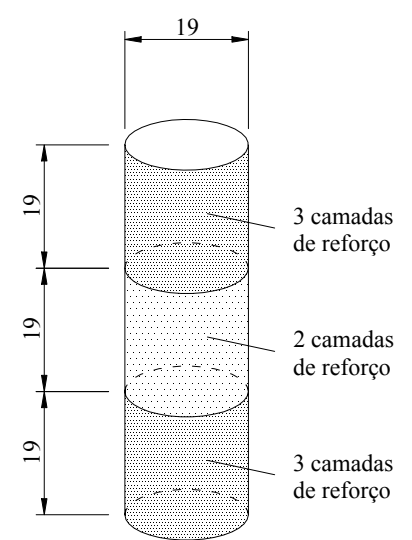

(a)

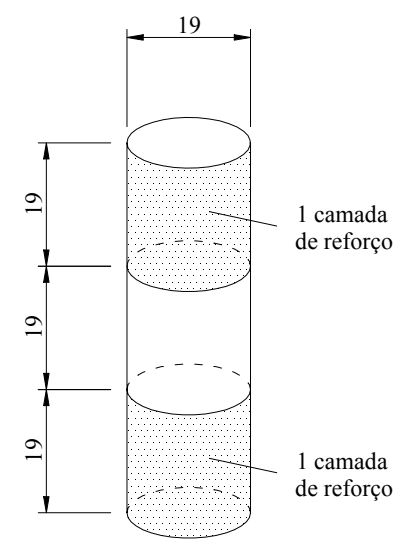

(b)

Figura 7.19 - Características geométricas dos modelos

(a) Modelo reforçado (P2) (b) Modelo de referência (P0)

\subsubsection{Preparação da superfície do concreto}

Após a cura do concreto (uma semana) preparou-se a superfície utilizando um disco para lixamento de aço seguido de um jato de ar para limpeza. O aspecto da superfície obtida pode ser visto na Figura 7.20.

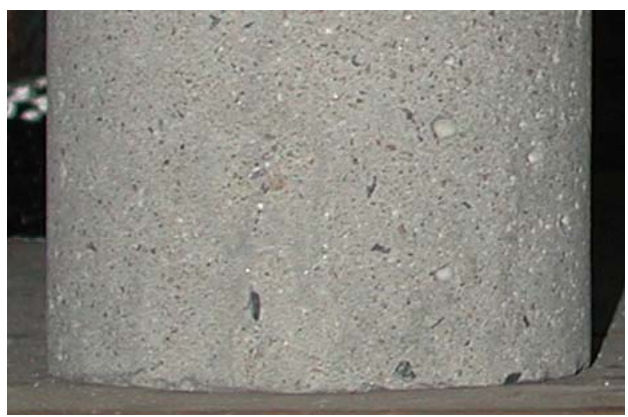

Figura 7.20 - Superfície obtida por lixamento.

Preparada a superfície, aplicou-se a resina epóxi e procedeu-se à colagem dos tecidos unidirecionais de fibras de carbono. O procedimento de preparo da superfície foi descartado nos modelos da série definitiva, tendo em vista os resultados satisfatórios obtidos em corpos de prova encamisados sem preparo da superfície, na fase de verificação da influência da aderência.

\subsubsection{Instrumentação}

A região central dos modelos foi instrumentada com transdutores na direção axial, extensômetros nas armaduras longitudinal e transversal, e na superfície do compósito (direção transversal). Na Figura 7.21 pode ser vista a disposição dos 
transdutores e extensômetros na seção transversal nos modelos. A base de leitura dos transdutores foi de $210 \mathrm{~mm}$. A numeração dos extensômetros é separada dos transdutores.

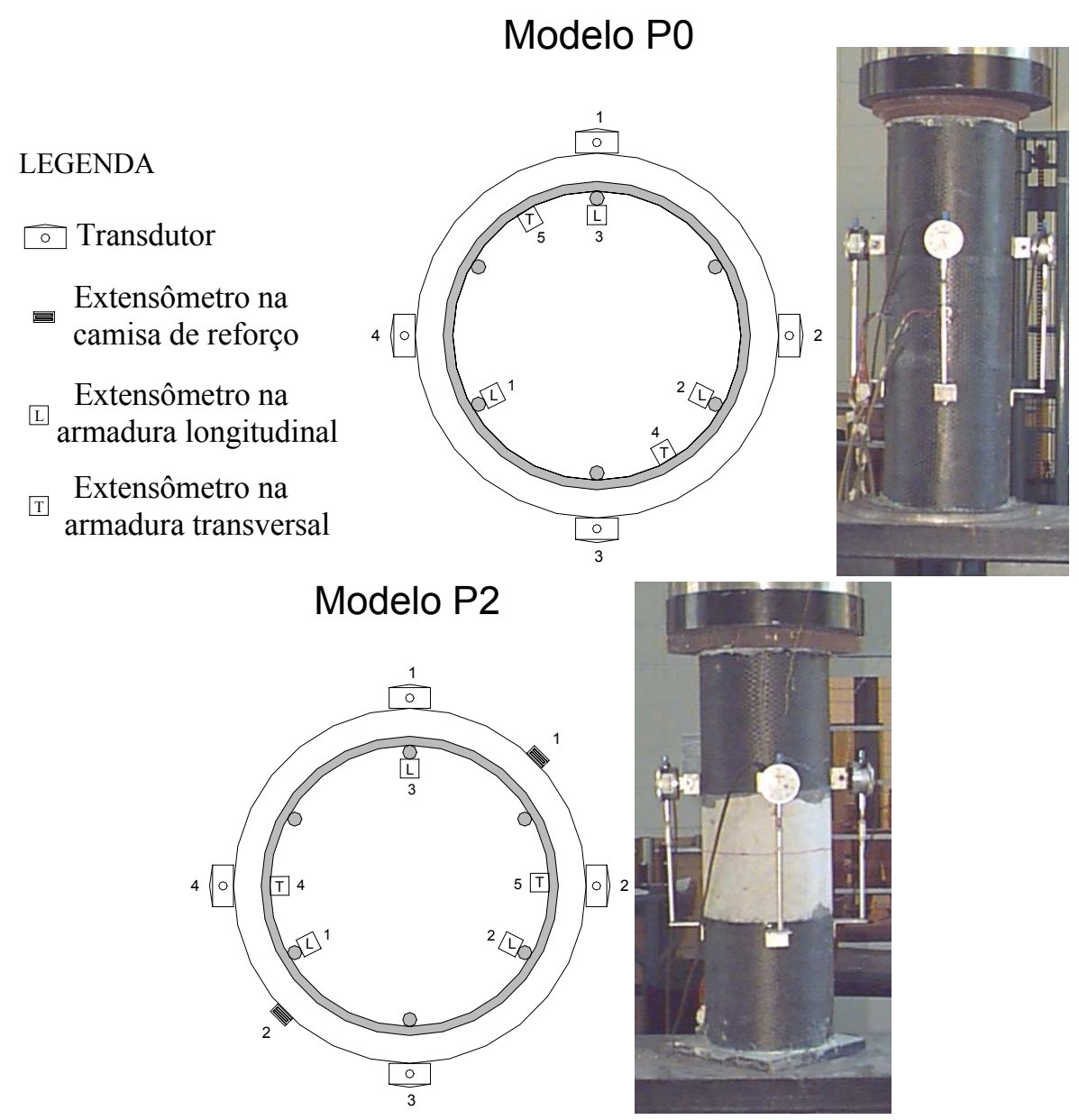

Figura 7.21 - Pilares posicionados na máquina de ensaio

\subsubsection{Ensaios à compressão}

Os pilares-piloto foram ensaiados à compressão axial utilizando-se uma taxa constante de aumento do deslocamento de $0,003 \mathrm{~mm} / \mathrm{s}$. Os ensaios foram realizados aos 35 dias após a concretagem.

\subsubsection{Resultados obtidos}

$\mathrm{Na}$ Figura 7.22 são apresentados os diagramas força-deslocamento dos modelos piloto. Pode-se observar a semelhança do comportamento registrado pelos transdutores e pelo pistão. Ocorreu um sobressalto no diagrama força-deslocamento do modelo reforçado, que não foi verificado na fase definitiva. 

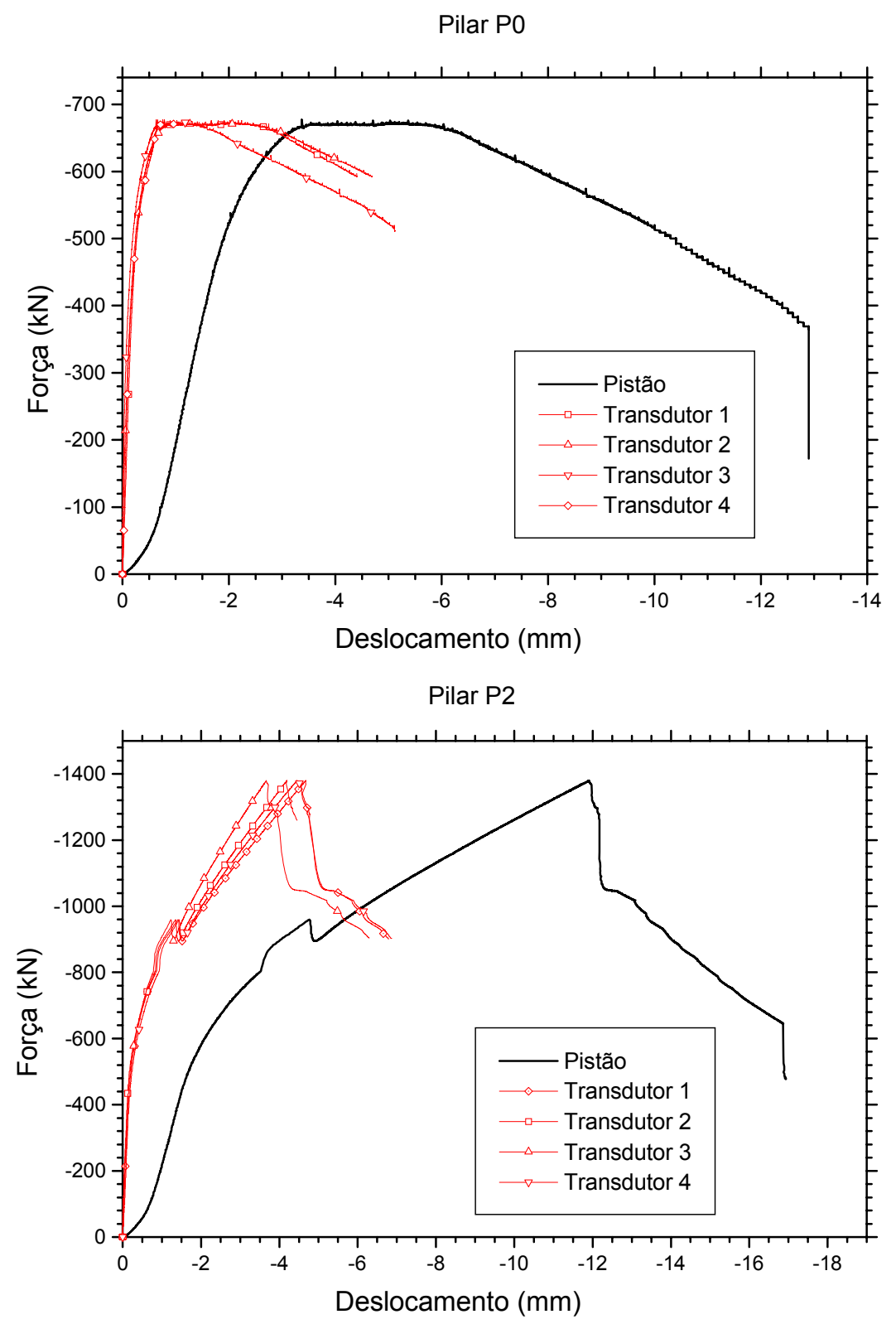

Figura 7.22 - Diagrama força-deslocamento do modelos piloto

Na Figura 7.23 estão indicadas as leituras dos extensômetros em função da carga aplicada. Pode-se observar o escoamento das armaduras longitudinais (em vermelho) e que as leituras das armaduras transversais (verde) não foram representativas do efeito de confinamento. A utilização de extensômetros nas faces externas da espiral não trouxe resultados confiáveis. Daí surgiu a idéia de fixar extensômetros também nas faces internas para os ensaios definitivos. 


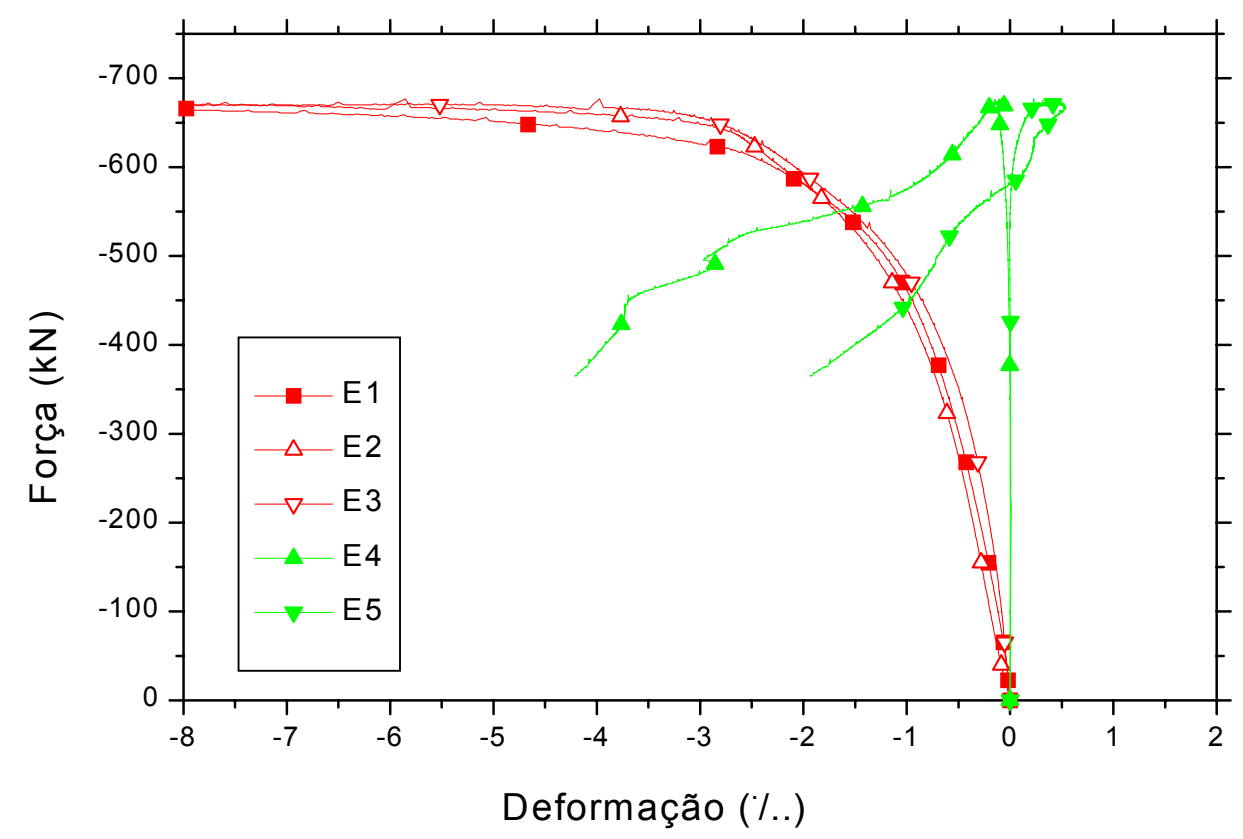

Figura 7.23 - Leituras dos extensômetros do pilar P0

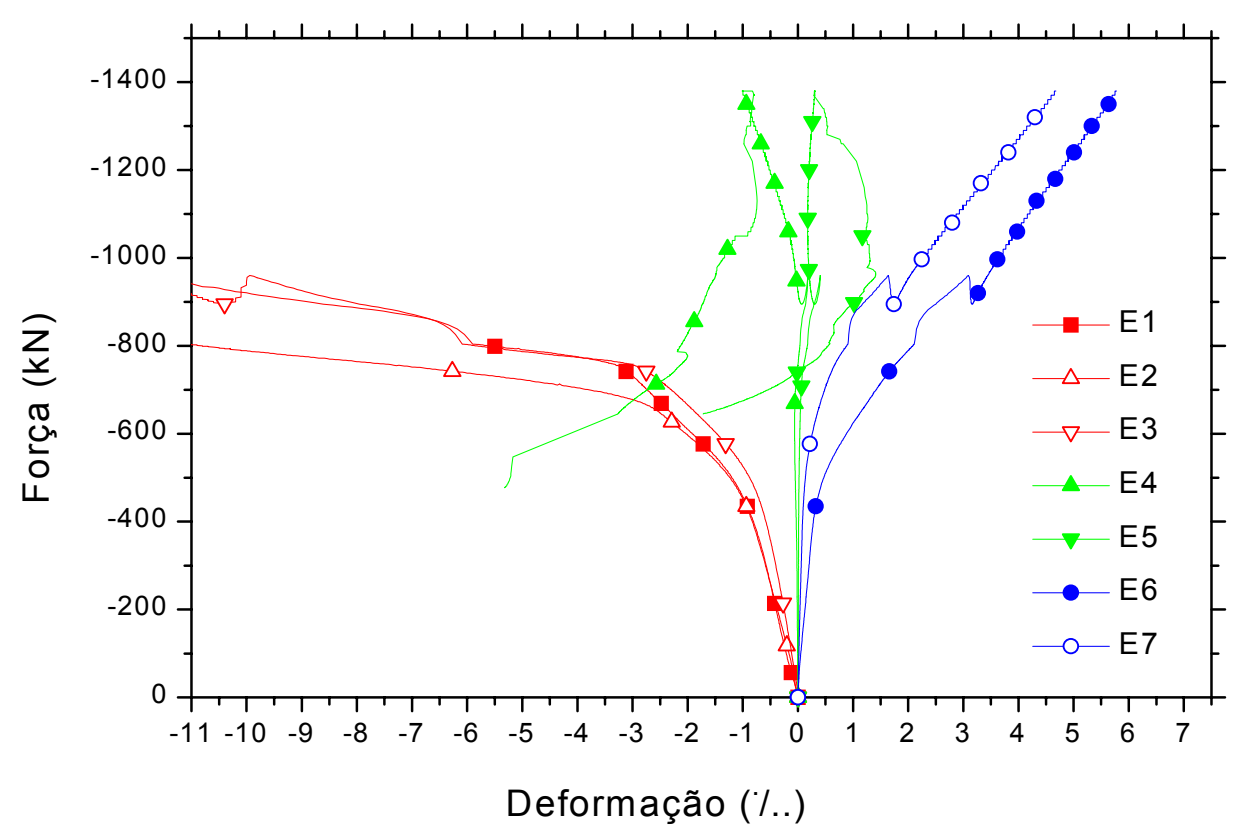

Figura 7.24 - Leituras dos extensômetros do pilar P2

A deformação na camisa de reforço apresentou um comportamento coerente, apesar dos valores baixos de deformação de ruptura.

Na Figura 7.25 são apresentados os diagramas força-deslocamento do pistão dos modelos piloto. Pode-se observar um grande aumento da capacidade resistente e deformação última no modelo reforçado. Observou-se no modelo reforçado que após 
a ruptura da camisa (força última) o modelo mantém uma capacidade resistente residual considerável.

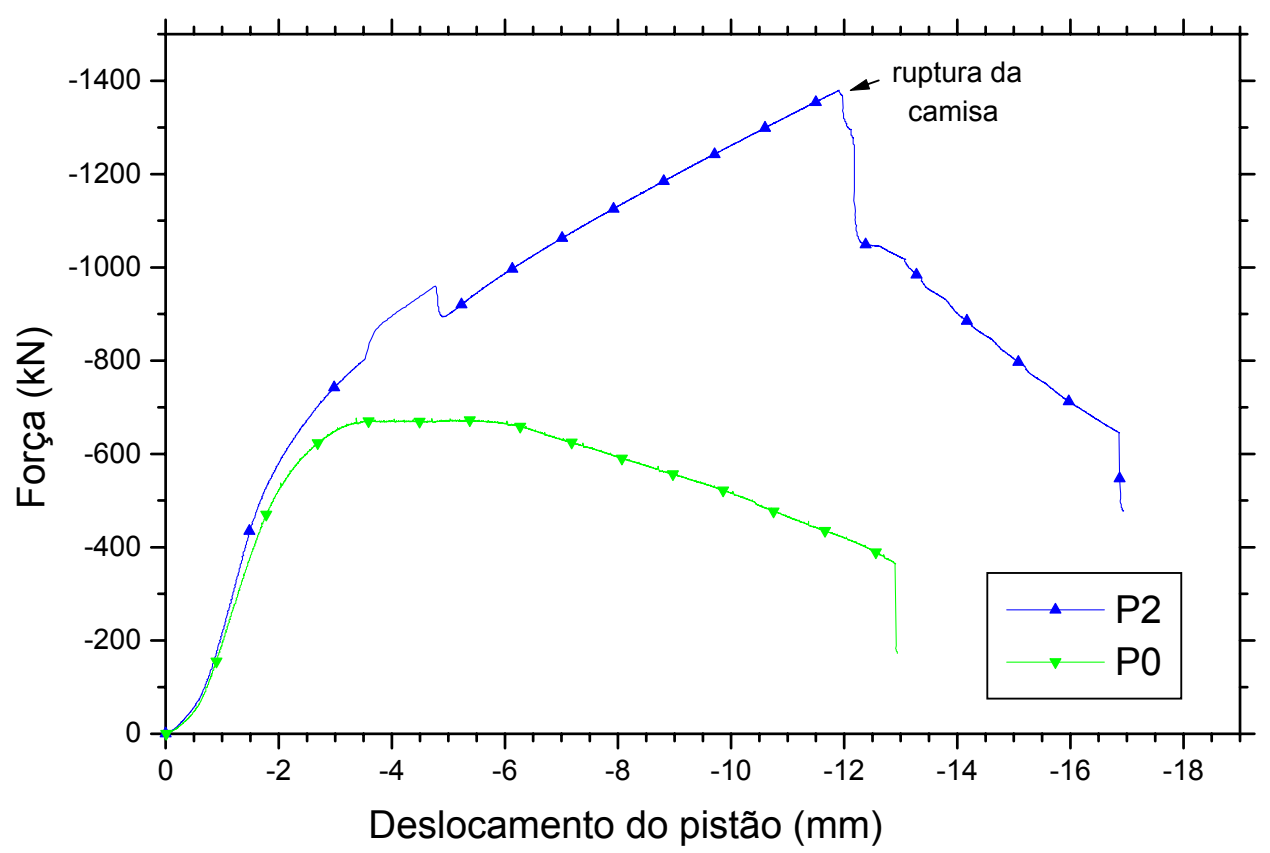

Figura 7.25 - Diagramas força-deslocamento do pistão dos modelos-piloto

\subsection{Ensaios principais}

Os pilares da fase definitiva foram preparados em duas séries referentes a duas concretagens. À série 1 pertencem os pilares C0, C1, C2, C0S50, C1S50 e C2S50. Os pilares da série 2 são o C0S25, C1S25, C2S25, Q0, Q1 e Q2. A resistência à compressão axial do concreto foi obtida com ensaios de corpos-deprova cilíndricos de dimensões de 10 × $20 \mathrm{~cm}$. Obteve-se na data de ensaio dos modelos (21 dias) 32 e 35,3 MPa nas séries 1 e 2, respectivamente.

\subsubsection{Características dos modelos e instrumentação}

Foram confeccionados 9 modelos de seção circular e três de seção transversal quadrada. Nos modelos de seção transversal circular o objetivo principal foi verificar a influência de diferentes taxas volumétricas da armadura transversal $\left(\rho_{\mathrm{s}}\right)$ e do número de camadas de compósito (n). Na Tabela 7.11 apresenta-se um esquema dos modelos de seção circular. 
Tabela 7.11- Modelos circulares da análise experimental

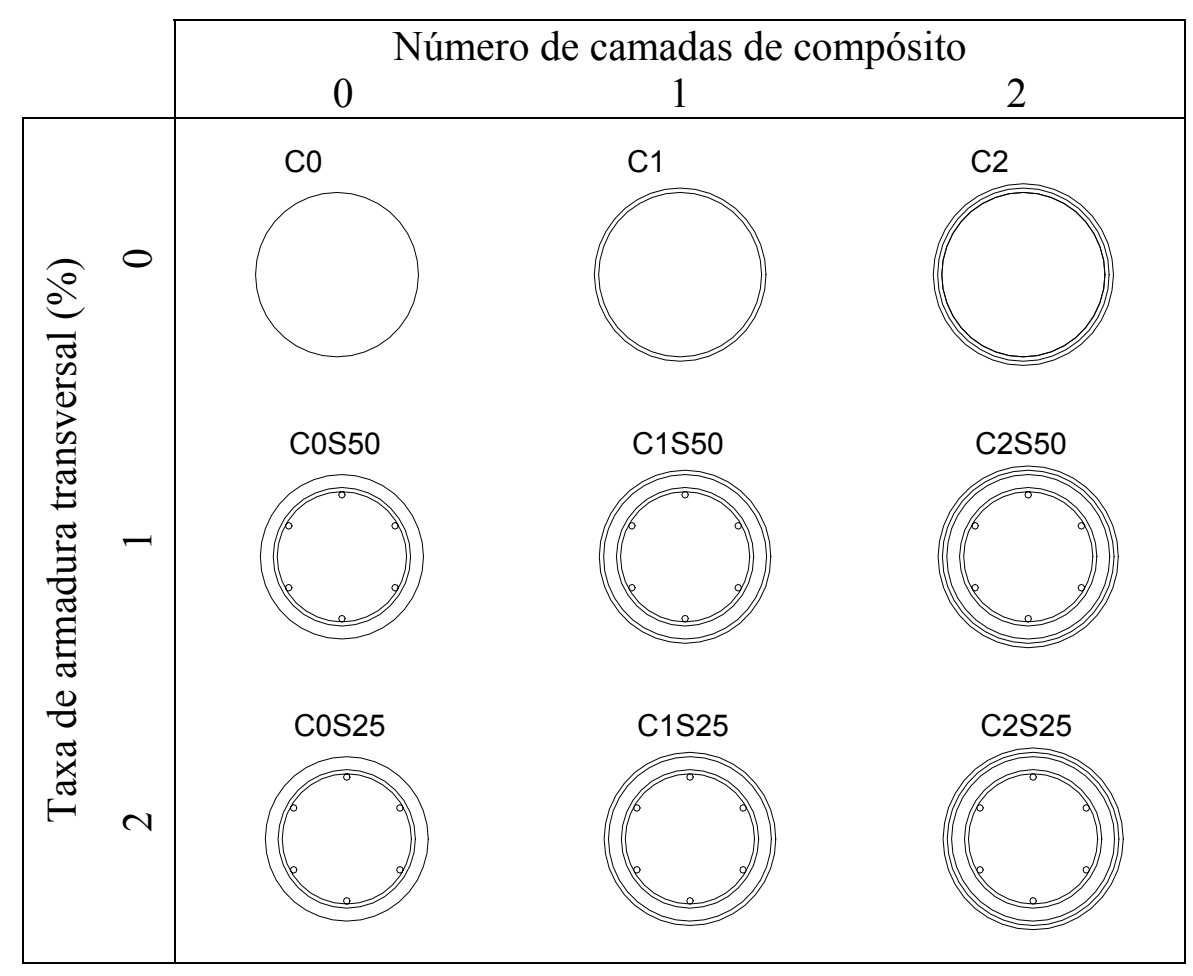

A nomenclatura adotada identifica cada modelo da seguinte maneira: o número após a letra $\mathrm{C}$ indica a quantidade de camadas de reforço com compósito e o número após a letra $\mathrm{S}$ identifica o espaçamento da armadura transversal do pilar (em mm). A instrumentação dos modelos definitivos diferiu dos modelos piloto no número de transdutores (apenas 3) e na instrumentação da armadura transversal, que recebeu extensômetros também nas faces internas da espiral.

Nos modelos de seção transversal quadrada variou-se apenas a quantidade de camadas de reforço nos modelos Q0, Q1 e Q2, com 0, 1 e 2 camadas de reforço respectivamente.

Os modelos de seção circular sem armaduras internas ( $0, C 1$ e $\mathrm{C} 2)$ receberam extensômetros orientados na direção transversal em duas linhas longitudinais ao longo do comprimento, a fim de obter a distribuição de pressões laterais. Foram colocados 3 transdutores na região central dos modelos com comprimento de leitura de $210 \mathrm{~mm}$. Na Figura 7.26 são apresentadas as dimensões e instrumentação dos modelos $\mathrm{C} 0, \mathrm{C} 1$ e C2. 


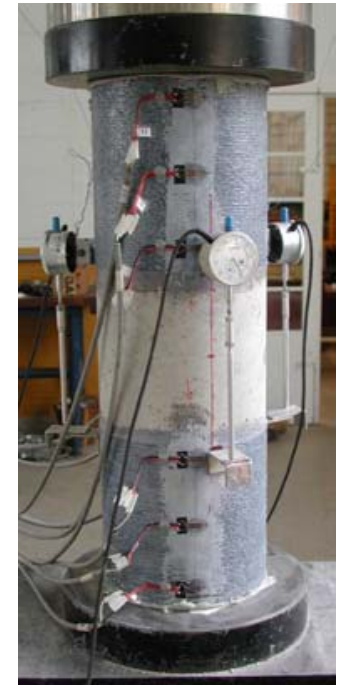

$\mathrm{C} 0$

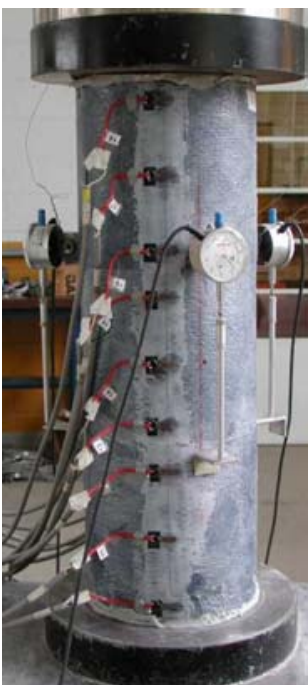

C1

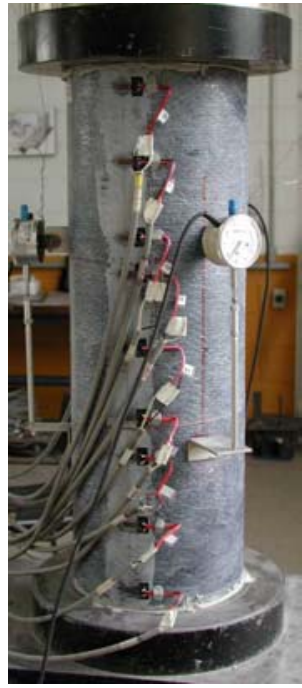

$\mathrm{C} 2$

Detalhe da instrumentação

LEGENDA

Transdutor

Extensômetro na
camisa de reforço

C0 C1 e C2
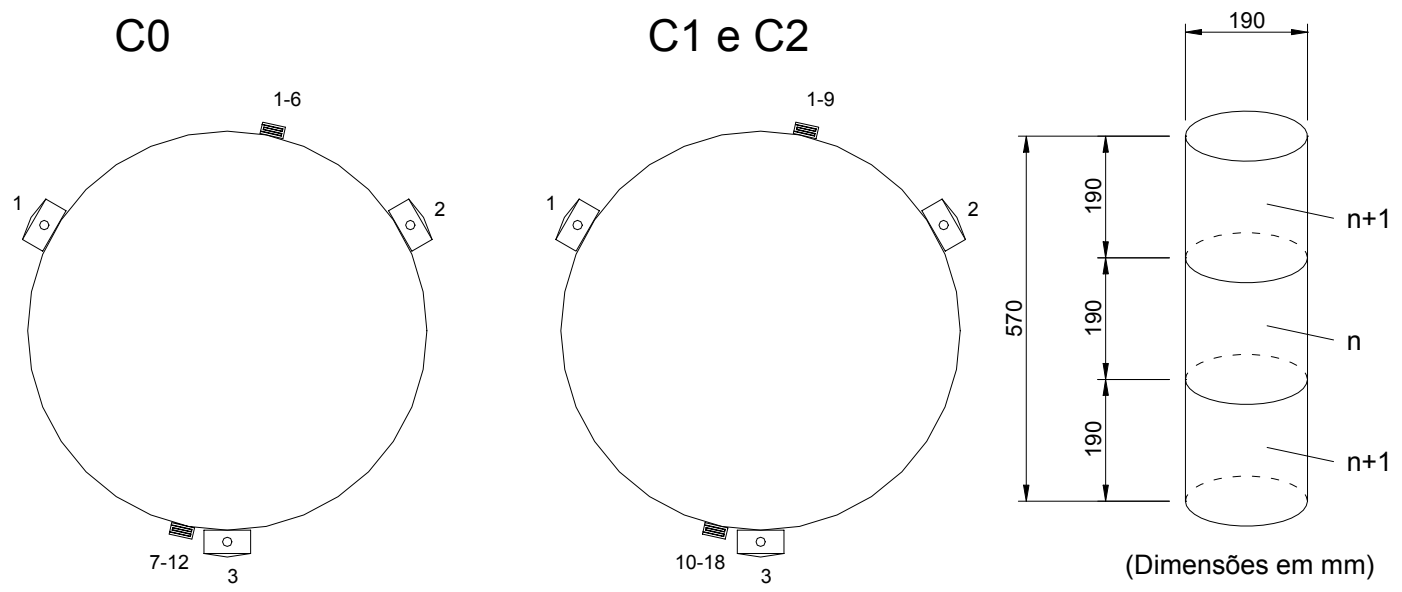

Seção transversal dos modelos

Figura 7.26- Modelos sem armaduras

Os modelos circulares armados receberam transdutores da mesma maneira que os modelos sem armaduras. Na região central dos modelos foram colocados extensômetros nas armaduras longitudinais e transversais. Nas armaduras transversais os extensômetros foram colocados nas faces interna e externa da espiral. Foram utilizados também extensômetros na camisa de reforço, apenas na região central do modelo (com exceção dos modelos C0S50 e C0S25, que não possuíam camisa de reforço na região central). Na Figura 7.27 são apresentadas as dimensões, 
instrumentação e o esquema de colagem dos tecidos nos modelos de seção circular com armaduras.

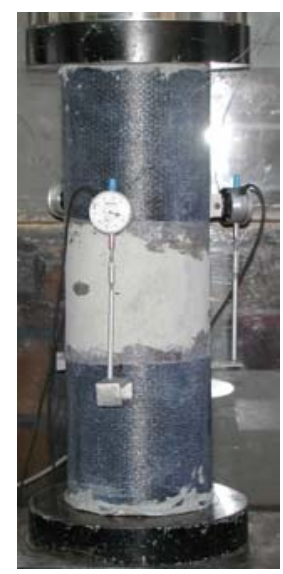

$\mathrm{n}=0$

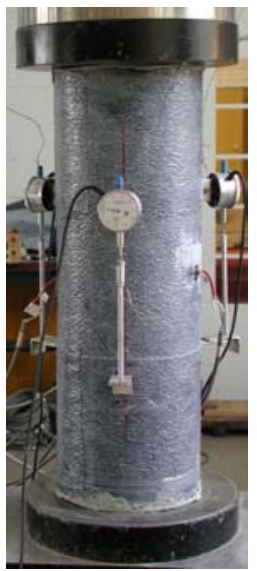

$\mathrm{n}=1$

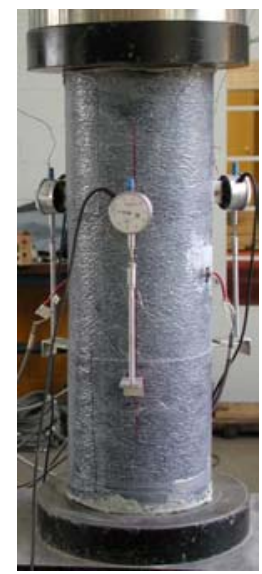

$n=2$

Detalhe da instrumentação

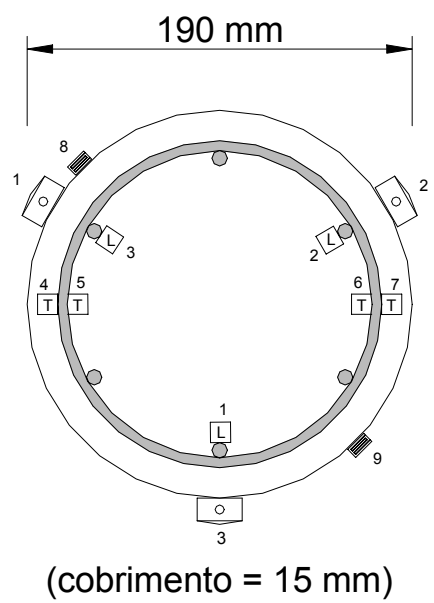

LEGENDA

Transdutor

Extensômetro na camisa de reforço

Extensômetro na armadura longitudinal

Extensômetro na armadura transversal

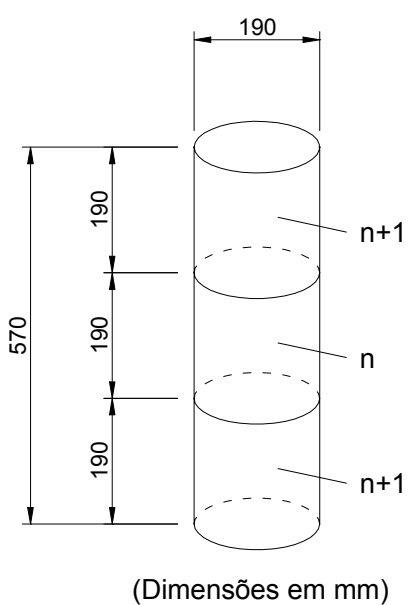

Figura 7.27- Modelos circulares com armaduras

A nomenclatura dos modelos de seção quadrada consiste na letra Q seguida do número de camadas de reforço. Os modelos de seção transversal quadrada receberam 4 transdutores na região central. O modelos Q1 e Q2 receberam ainda extensômetros na camisa de reforço na região central, colocados nos cantos e no meio das faces. As dimensões e a instrumentação utilizadas estão indicadas na Figura 7.28. Observou-se um raio mínimo de curvatura de $3 \mathrm{~cm}$ nos cantos do pilar para evitar rupturas localizadas por concentrações de tensões. Na Figura 7.28 são apresentadas as características geométricas e a instrumentação utilizada nos modelos de seção transversal quadrada. 


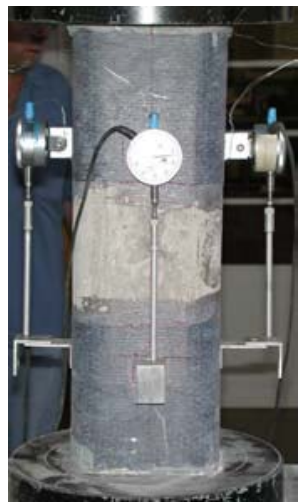

Q0

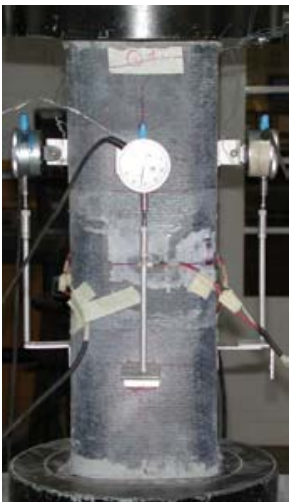

Q1

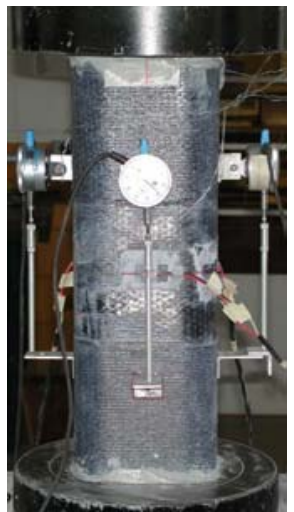

Q2

Detalhe da instrumentação

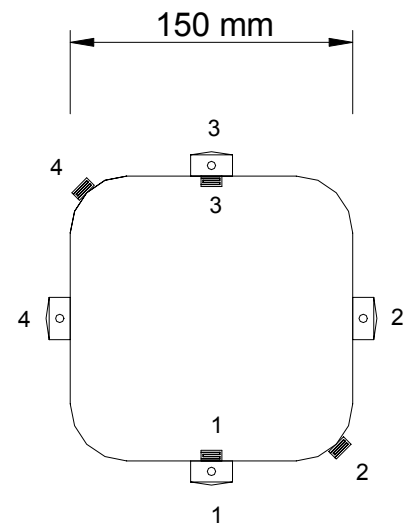

(raio dos cantos $=30 \mathrm{~mm}$ )
LEGENDA

Transdutor

Extensômetro na

camisa de reforço

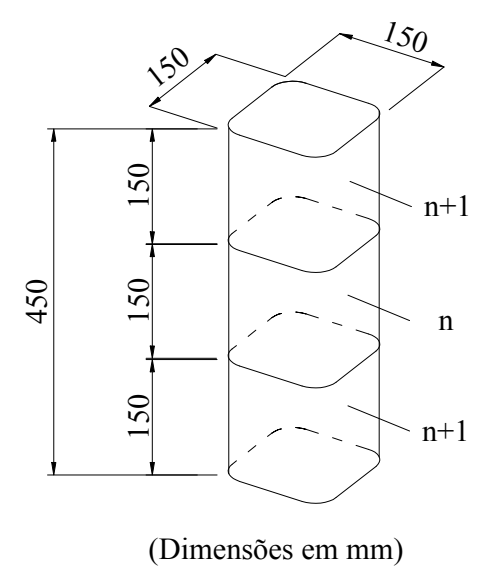

(Dimensões em mm)

Figura 7.28- Modelos de seção transversal quadrada

\subsubsection{Cálculo das deformações axiais}

Dos ensaios de compressão axial foram obtidos diagramas forçadeslocamento com leituras do transdutor e do pistão como as indicadas na Figura 7.29. Os diagramas força-deslocamento dos demais modelos estão apresentados no Apêndice I. 


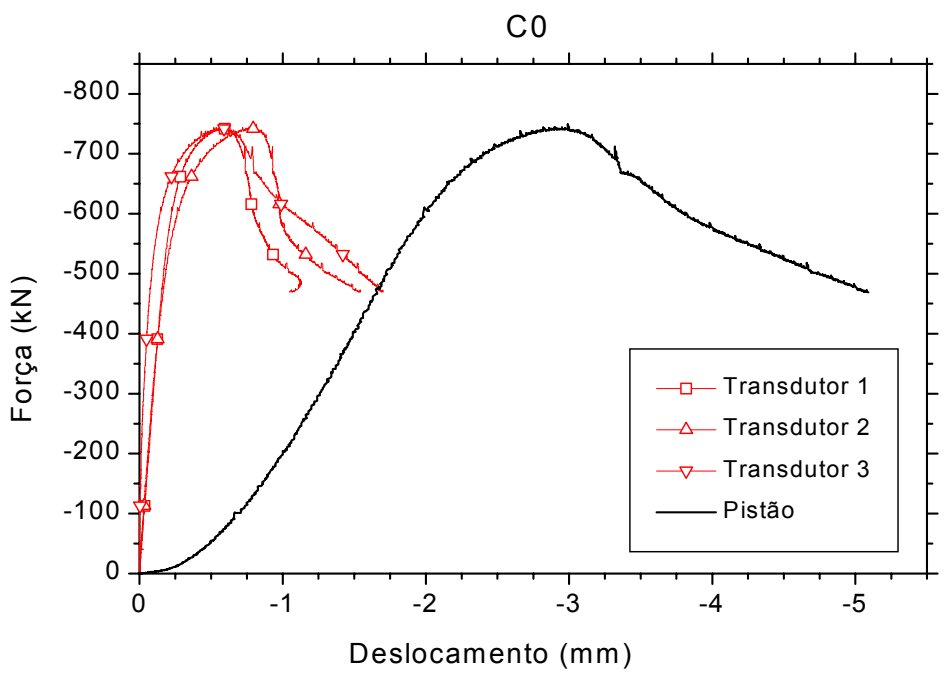

Figura 7.29 - Diagramas força-deslocamento - Modelo C0

A primeira diferença nas leituras de deslocamento obtidas pelo transdutor e pelo pistão são as bases de leitura. Para o cálculo das deformações as bases de leitura são de $210 \mathrm{~mm}$ para os transdutores, $570 \mathrm{~mm}$ para o pistão e $450 \mathrm{~mm}$ para o pistão nos modelos de seção transversal quadrada.

$\mathrm{Na}$ Figura 7.30 são apresentados diagramas força-deformação axial do modelo $\mathrm{C} 0$, com deformações provenientes do pistão e da média dos transdutores. Apresenta-se também um esquema da forma de correção dos dados.

Ajustou-se retas nos trechos iniciais dos diagramas força-deformação dos modelos. A reta ajustada nos dados dos transdutores é adotada como referência para os dados do pistão, já que as leituras do transdutor praticamente não apresentam acomodação e a inclinação inicial foi considerada a mais realista. A reta ajustada para o pistão possibilita eliminar a acomodação inicial do ensaio e a correção de todo o diagrama tensão-deformação obtido as leituras do pistão.

Esta correção é feita: adotando-se para os dados do pistão a inclinação inicial obtida com o transdutor até a carga inicial do trecho de interpolação do pistão (neste caso $250 \mathrm{kN}$ ); para cargas acima deste valor trata-se as leituras do pistão retirando-se a acomodação (coeficiente linear $=-0,97017$ no exemplo) e rebatendo a inclinação da reta do pistão até a do transdutor. Isto é feito retirando-se da leitura do pistão o valor resultante da multiplicação da carga pela diferença do coeficiente angular entre as duas retas (neste caso 0,002893). 


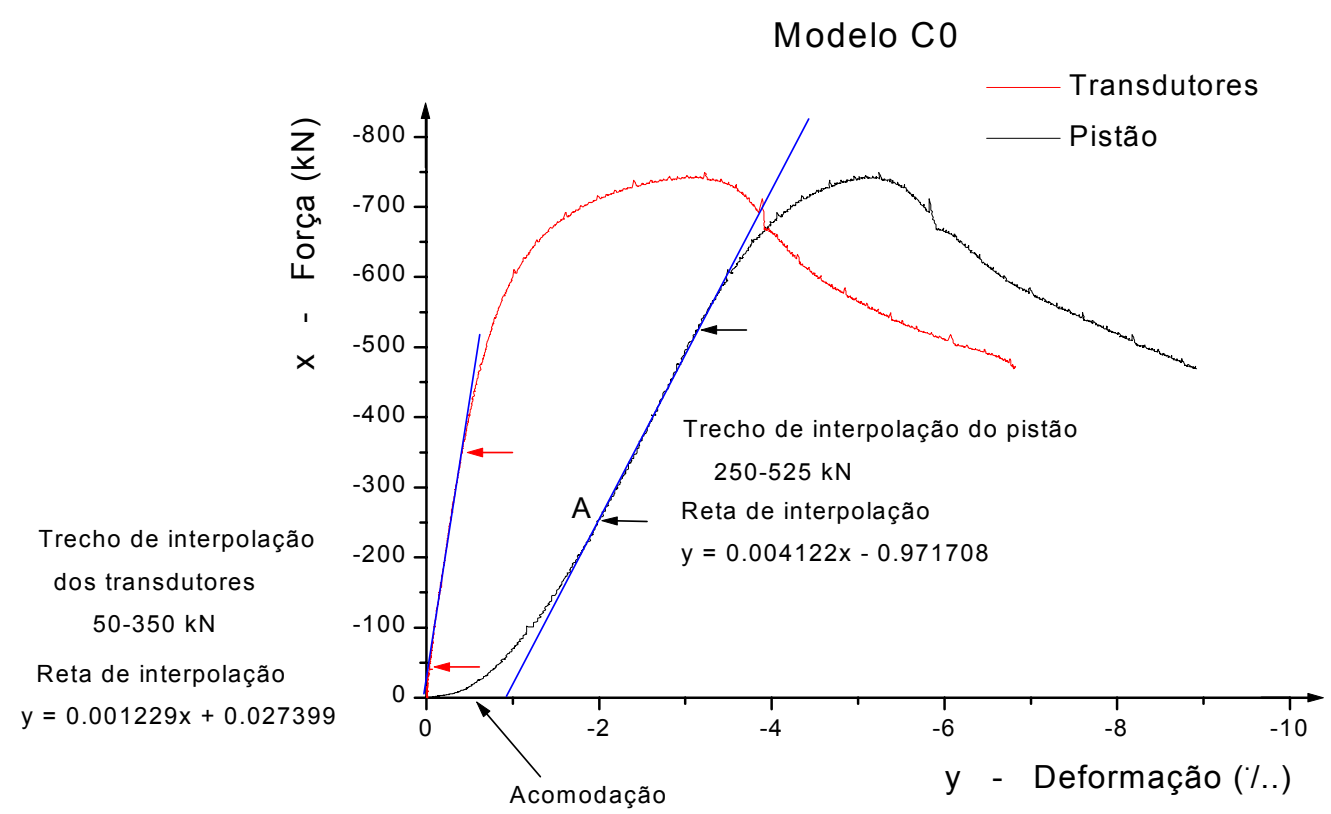

Figura 7.30 - Diagramas força-deformação - Modelo C0

Como resultado da correção o diagrama força-deformação obtido com as leituras do pistão possui inclinação inicial igual à obtida com o transdutor. A utilização da força atuante ao invés da tensão durante a correção não faz diferença alguma. Optou-se pelo tratamento com força-deformação já que em alguns modelos o cálculo da tensão atuante no concreto não pode ser feito de uma maneira direta.

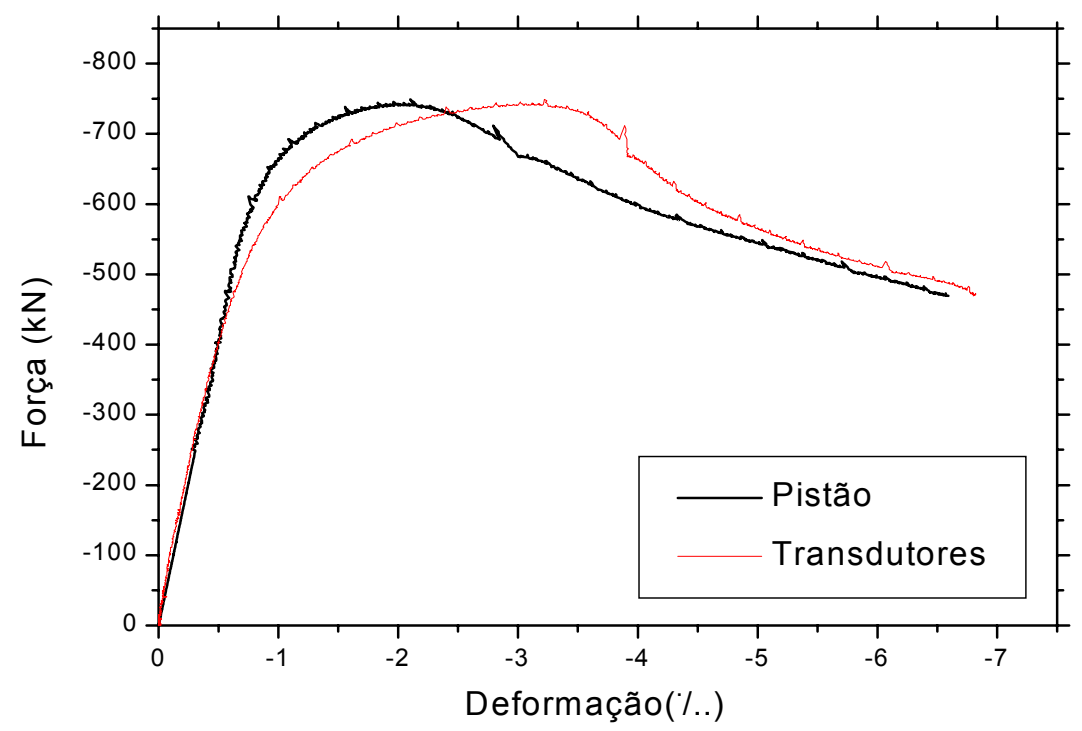

Figura 7.31 - Diagramas força-deformação corrigidos - Modelo C0

A partir deste ponto todos os resultados apresentados de deformação ou deslocamento axial do concreto são provenientes de leituras do pistão e foram tratados como explicado anteriormente. Os resultados brutos dos ensaios, com leituras dos transdutores e do pistão são apresentados no Apêndice I. 


\subsubsection{Justificativa do tratamento}

O tratamento das leituras do pistão mostrava-se necessário já que em alguns modelos ensaiados não foi possível obter a curva tensão-deformação completa com leituras dos transdutores.

Além disso, notou-se uma certa variabilidade nas leituras dos transdutores, principalmente a carregamentos elevados (correspondentes a tensões acima da resistência do concreto não confinado).

A grande diferença nas leituras obtidas do pistão e dos transdutores começa pelo fato de com bases de leitura diferentes, estas leituras representarem regiões diferentes do modelo. Os resultados obtidos com os transdutores referem-se à região central dos modelos, mais deformável. As leituras do pistão englobam o comprimento inteiro do modelo, sendo deformações referentes ao elemento estrutural.

$\mathrm{Na}$ Figura 7.32 são apresentados os diagramas tensão-deformação do concreto não confinado (modelo $\mathrm{C} 0$ ) obtidos com as duas leituras. Pode-se observar que o aspecto do diagrama-tensão deformação obtido com o pistão é mais semelhante às curvas tensão-deformação indicadas na Figura 3.1. Além disso, podese observar que a deformação de pico do concreto não confinado na Figura 3.1 para o mesmo nível de resistência fica em torno de $2 \%$, muito próximo do valor obtido pela leitura do pistão corrigida.

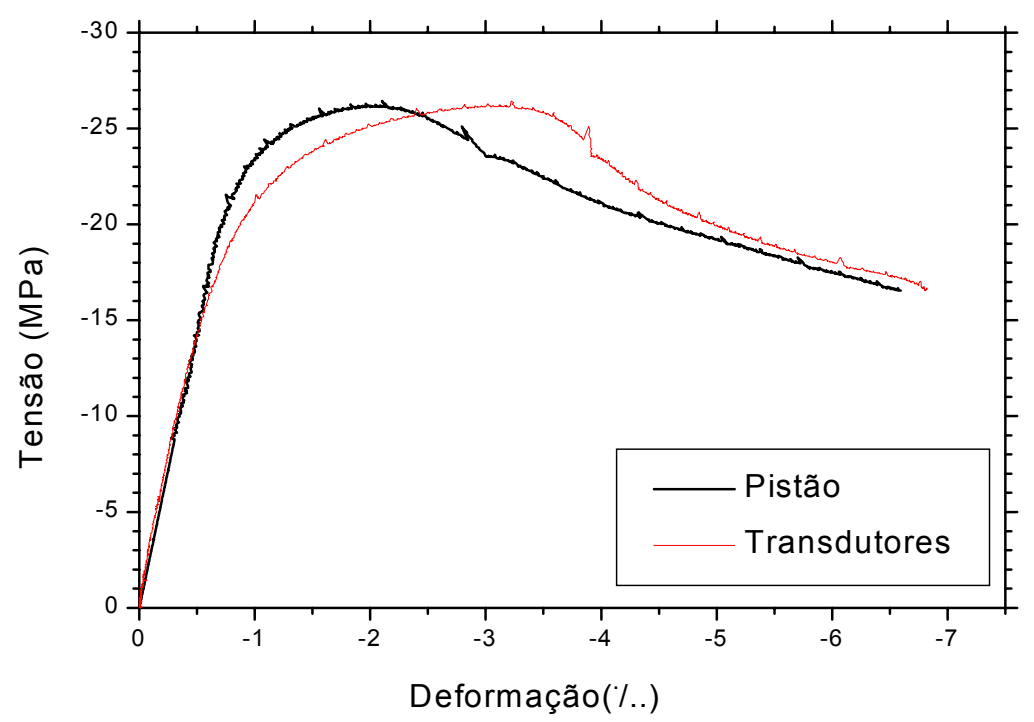

Figura 7.32 - Diagramas tensão-deformação do concreto não confinado 
Foram feitas comparações dos dois diagramas tensão-deformação com a curva dada por POPOVICS ${ }^{14}$. Pode-se observar que as leituras obtidas com o pistão foram bem melhor ajustadas pela equação de POPOVICS ${ }^{14}$. As leituras dos transdutores mostraram uma discrepância muito grande no trecho pós-pico, indicando que o comportamento observado foge do esperado para o concreto não confinado.
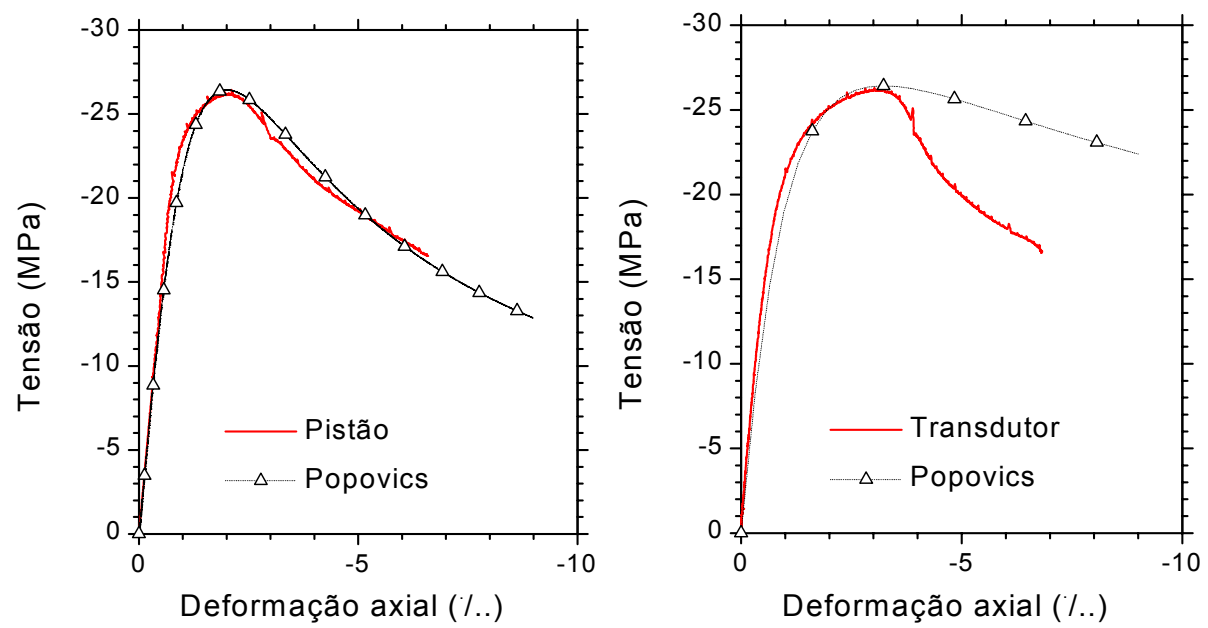

Figura 7.33 - Comparação dos diagramas tensão-deformação do concreto confinado com a equação de POPOVICS.

\subsubsection{Diagramas força-deslocamento}

Os diagramas força-deslocamento aqui apresentados incorporam as correções anteriormente explicadas.

Em todos os pilares encamisados a força última ocorreu com a ruptura da camisa de reforço. Nos pilares armados, no entanto, observou-se que após a ruptura da camisa ocorreu um trecho dúctil no diagrama força-deslocamento, devido ao confinamento da armadura transversal, que permaneceu até a sua ruptura. Todos os ensaios foram levados até a ruptura das espirais. As fotos dos pilares durante os ensaios são apresentadas no Apêndice II.

$\mathrm{Na}$ Figura 7.34 são apresentados os diagramas força-deslocamento dos modelos sem armaduras. Pode-se observar o acréscimo da capacidade resistente e deslocamento último com o aumento do número de camadas de reforço. 


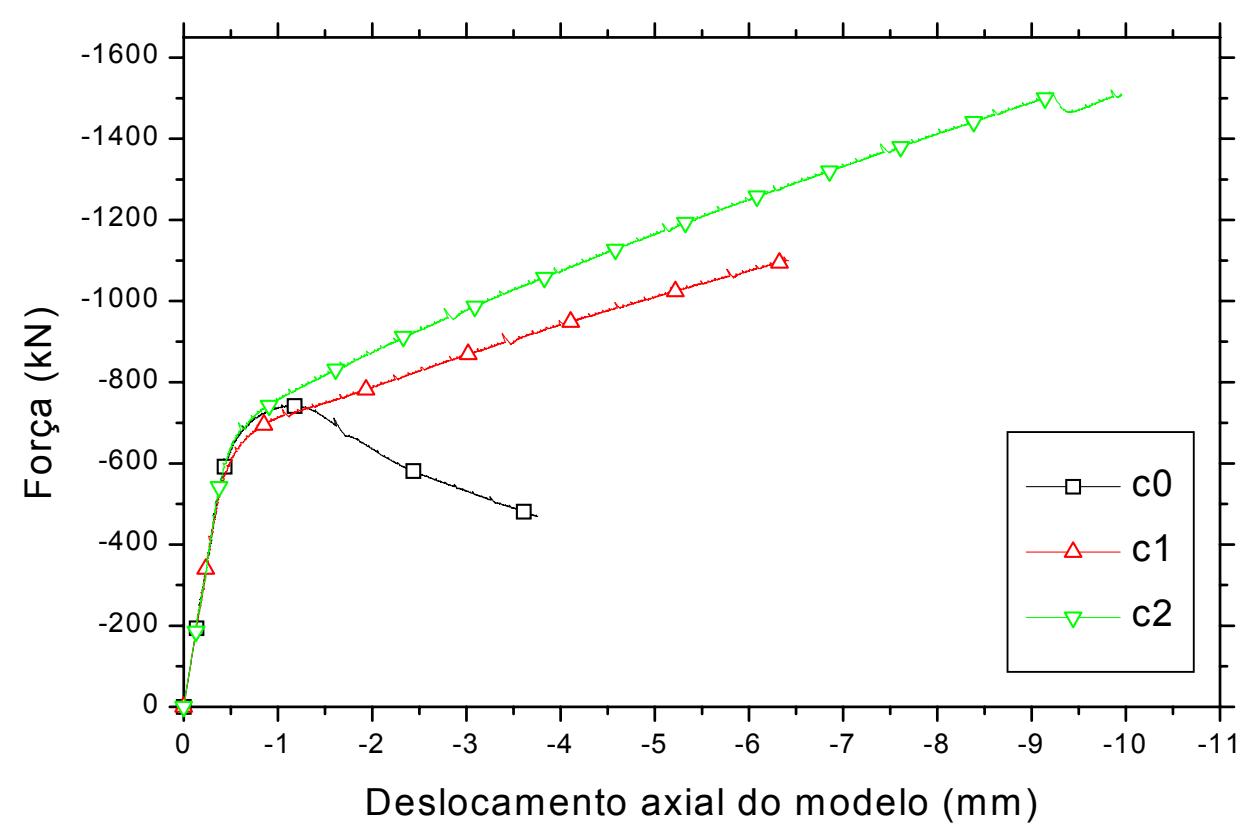

Figura 7.34 - Diagramas força-deslocamento dos modelos circulares sem armaduras

O modelo C1S25 apresentou problemas no ensaio, que fizeram com que este fosse descarregado a uma carga de 954,63 kN, representando $56,3 \%$ da carga última. O modelo foi então carregado novamente e levado até a ruptura. No entanto o $1^{\mathrm{o}}$ carregamento afetou significativamente o comportamento do modelo. Na Figura 7.35 são apresentados os diagramas força-deslocamento do $1^{\circ}$ e do $2^{\circ}$ carregamento em conjunto.

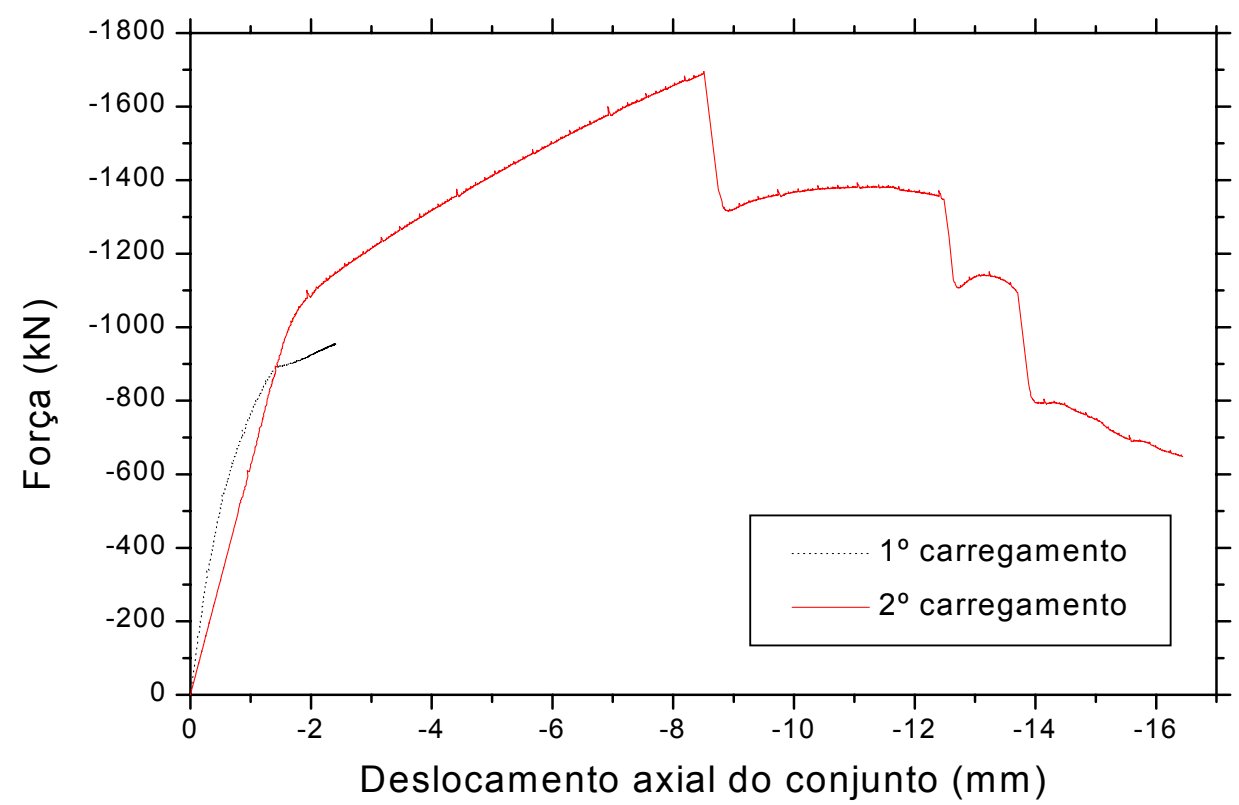

Figura 7.35 - Diagramas força-deslocamento - Modelo C1S25 
Durante o primeiro ensaio a pressão do fluido na máquina de ensaio não foi suficiente, e a carga estabilizou a partir de $890 \mathrm{kN}$, como indica a Figura 7.36. O deslocamento do modelo, no entanto, continuou crescendo até o final do $1^{\mathrm{o}}$ carregamento.
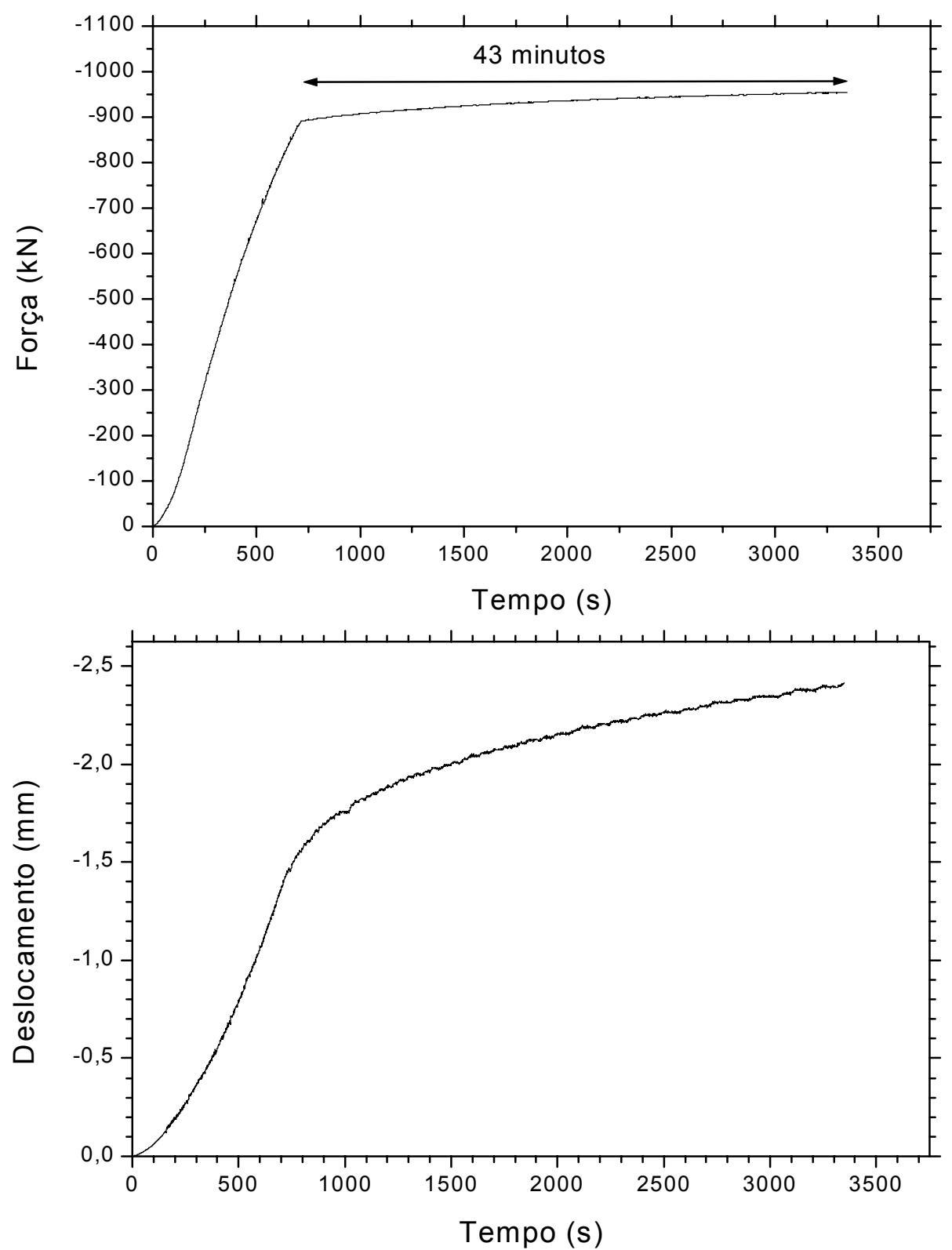

Figura $7.36-1^{\circ}$ carregamento do modelo C1S25

Para a correção dos resultados do ensaio adicionou-se o deslocamento plástico residual do $1^{\circ}$ carregamento ao início do $2^{\circ}$ carregamento. Este procedimento é indicado na Figura 7.37. A inclinação inicial do recarregamento foi adotada como representativa do descarregamento, independente da curva de descarregamento adotada (não foi obtida no ensaio). Obteve-se então um deslocamento plástico após o 
descarregamento de $0,893 \mathrm{~mm}$. Este deslocamento foi acrescentado ao início do $2^{\circ}$ carregamento.

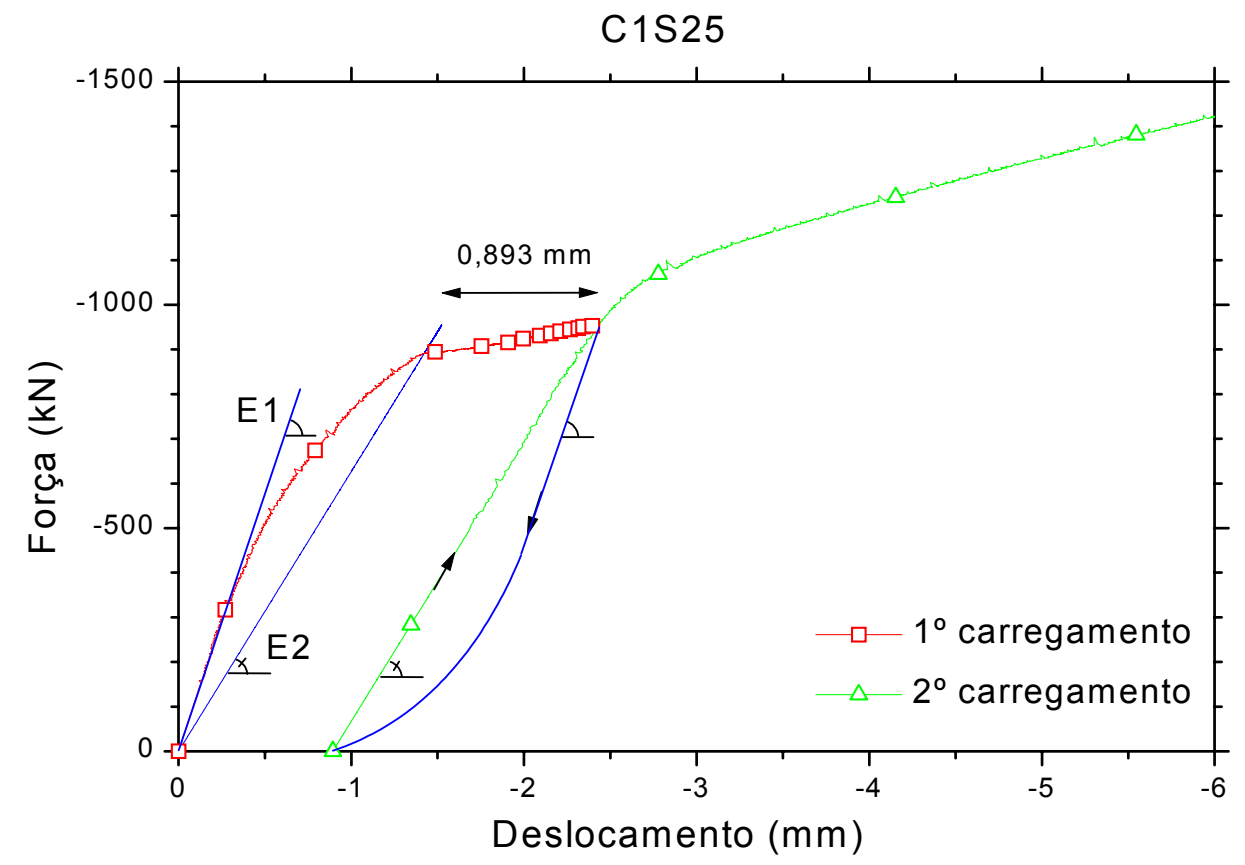

Figura 7.37 - Deslocamento plástico do $1^{\circ}$ carregamento

O gráfico força-deslocamento transladado das deformações plásticas é apresentado na Figura 7.38. Pode-se observar um comportamento coerente do diagrama força-deslocamento com a correção aqui sugerida.

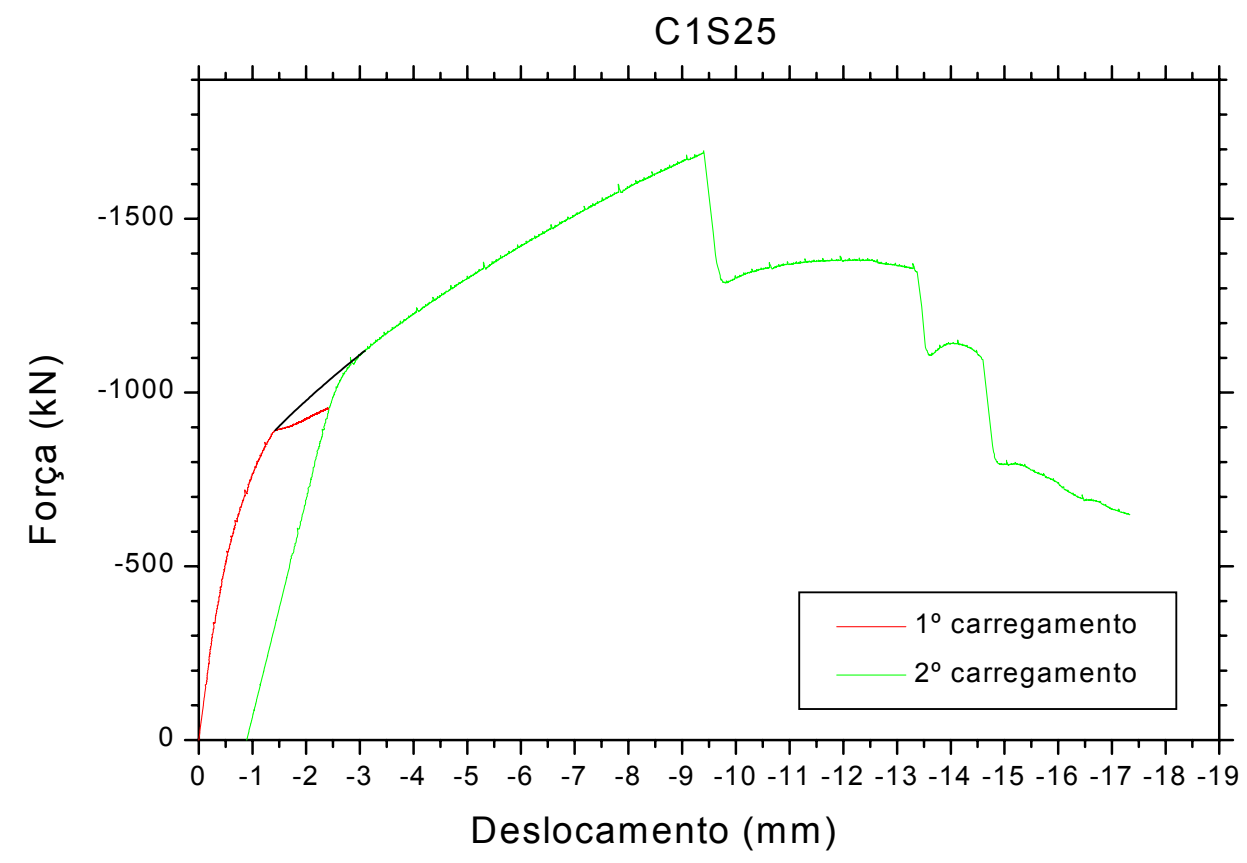

Figura 7.38 - Força-deslocamento com o $2^{\circ}$ carregamento corrigido 
Na Figura 7.39 apresenta-se uma comparação do modelo corrigido com os demais modelos com $2 \%$ de taxa de armadura transversal.

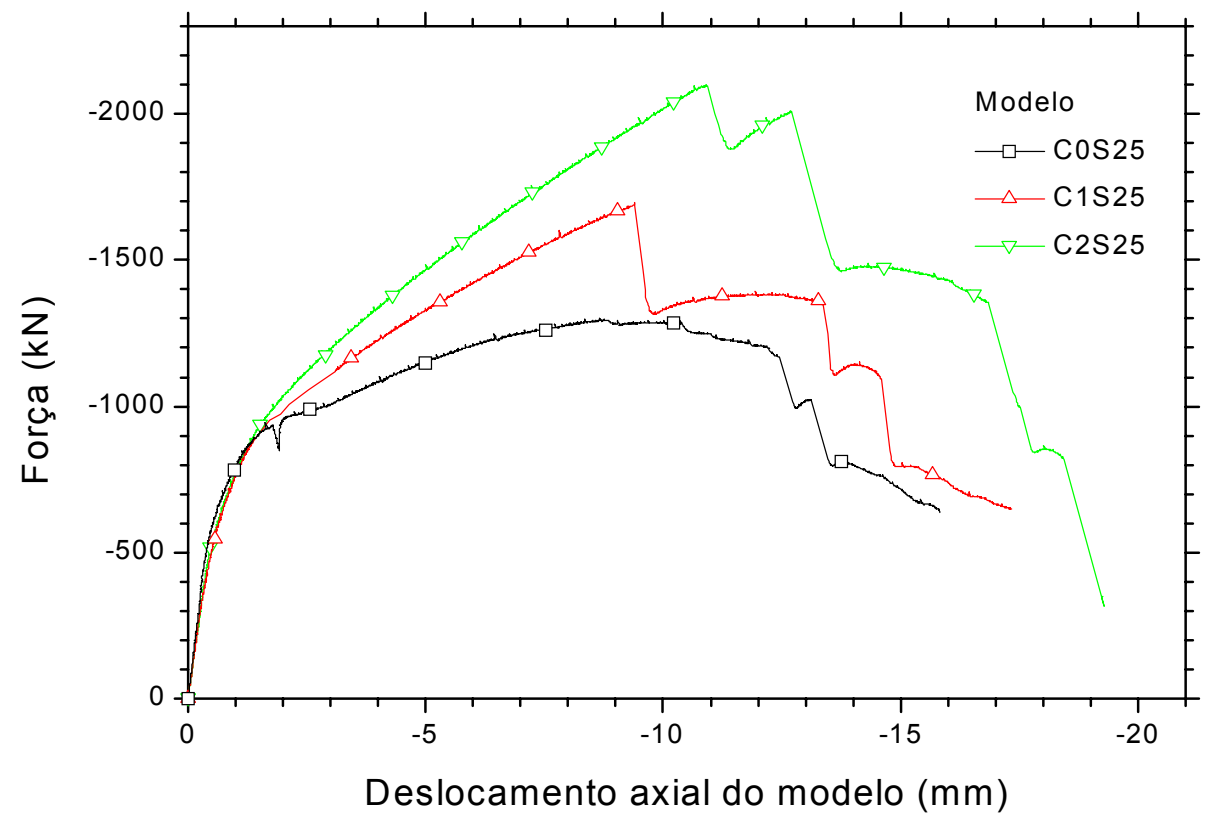

Figura 7.39 - Diagramas força-deslocamento dos modelos com $\rho_{\mathrm{s}}=\mathbf{2 \%}$

$\mathrm{Na}$ Figura 7.40 são apresentados os diagramas força-deslocamento dos modelos com taxa de armadura transversal de $1 \%$.

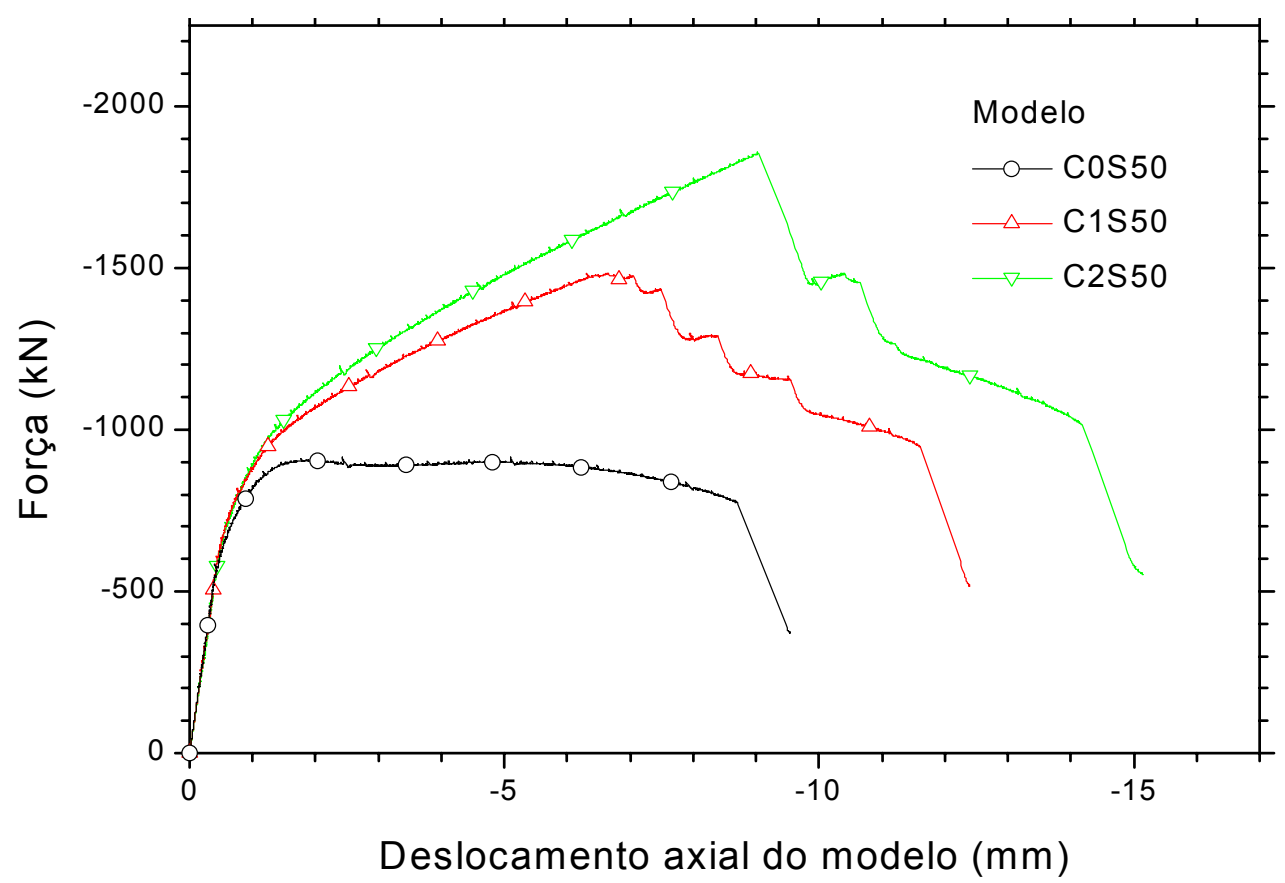

Figura 7.40- Diagramas força-deslocamento dos modelos com $\rho_{\mathrm{s}}=1 \%$

$\mathrm{Na}$ Figura 7.41 são apresentados os diagramas força-deslocamento dos modelos de seção transversal quadrada. 


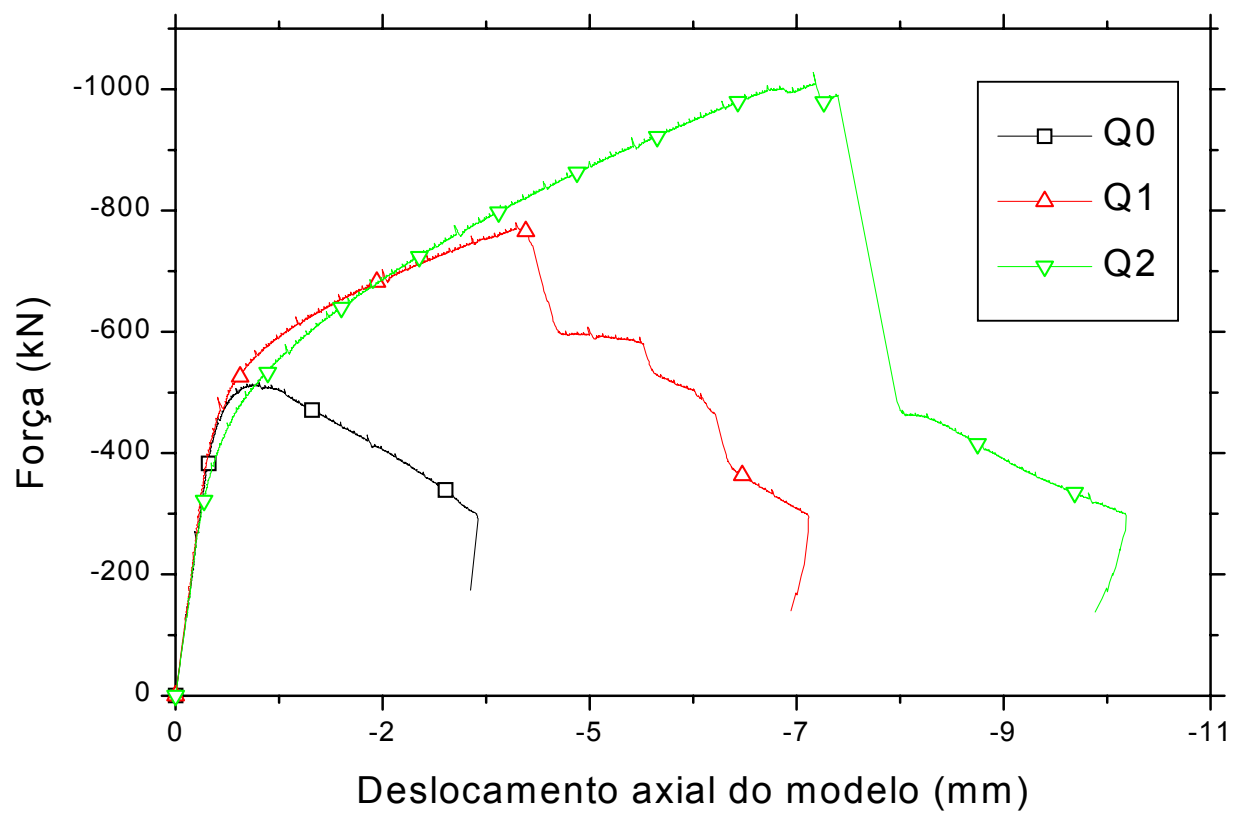

Figura 7.41 - Diagramas força-deslocamento - Modelos de seção quadrada

\subsubsection{Deformações registradas pelos extensômetros}

A seguir são apresentadas as leituras dos extensômetros em função da carga no ensaio. Pode-se observar nas figuras a seguir que os extensômetros da camisa de reforço próximos à região central do modelo foram mais solicitados. No modelo C0 pode-se observar que mesmo após a carga última do modelo as tensões continuam crescendo na camisa de reforço aplicada nas extremidades do pilar. 


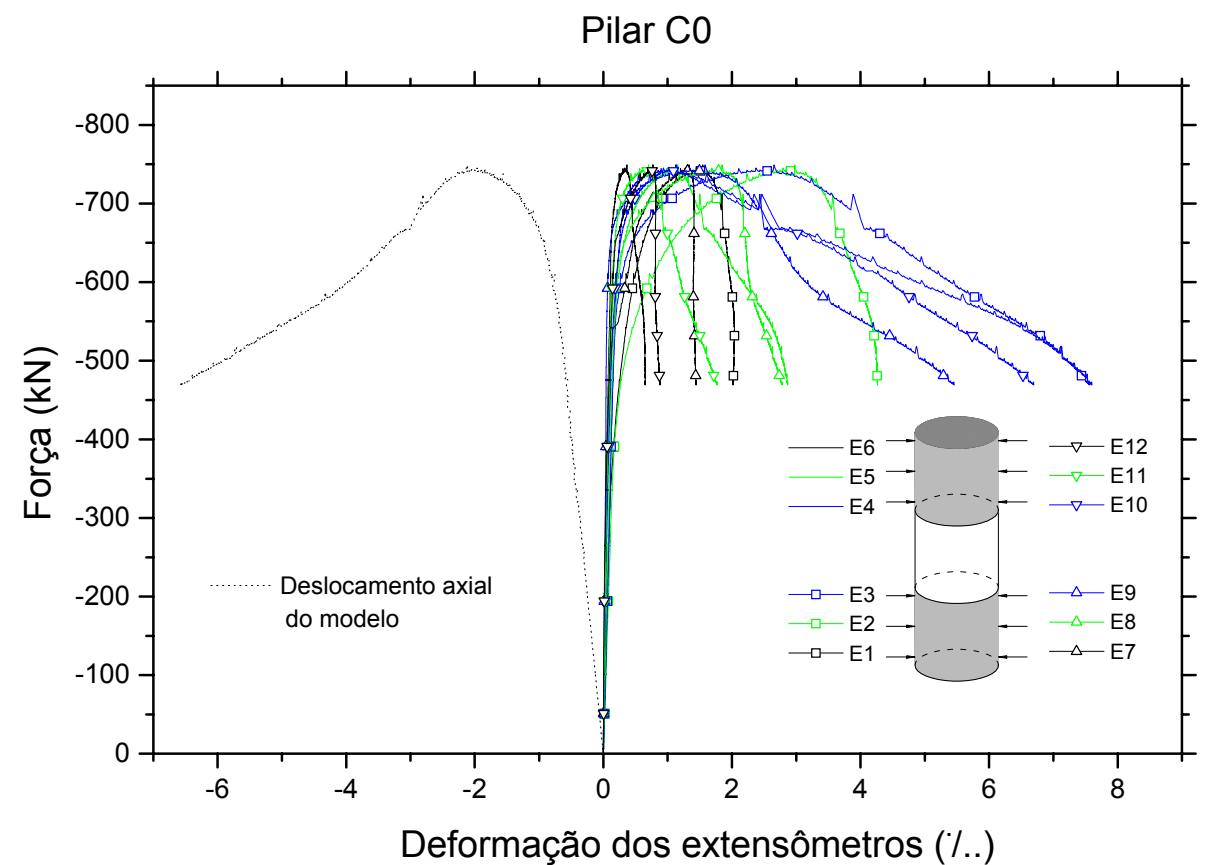

Figura 7.42 - Leituras dos extensômetros - Modelo Co

Nos modelos C1 e C2 observou-se também o crescimento das deformações na camisa de reforço até o final do ensaio, onde a camisa rompeu na região central. Pode-se observar claramente que a camisa foi mais solicitada na região central.

Pilar C1

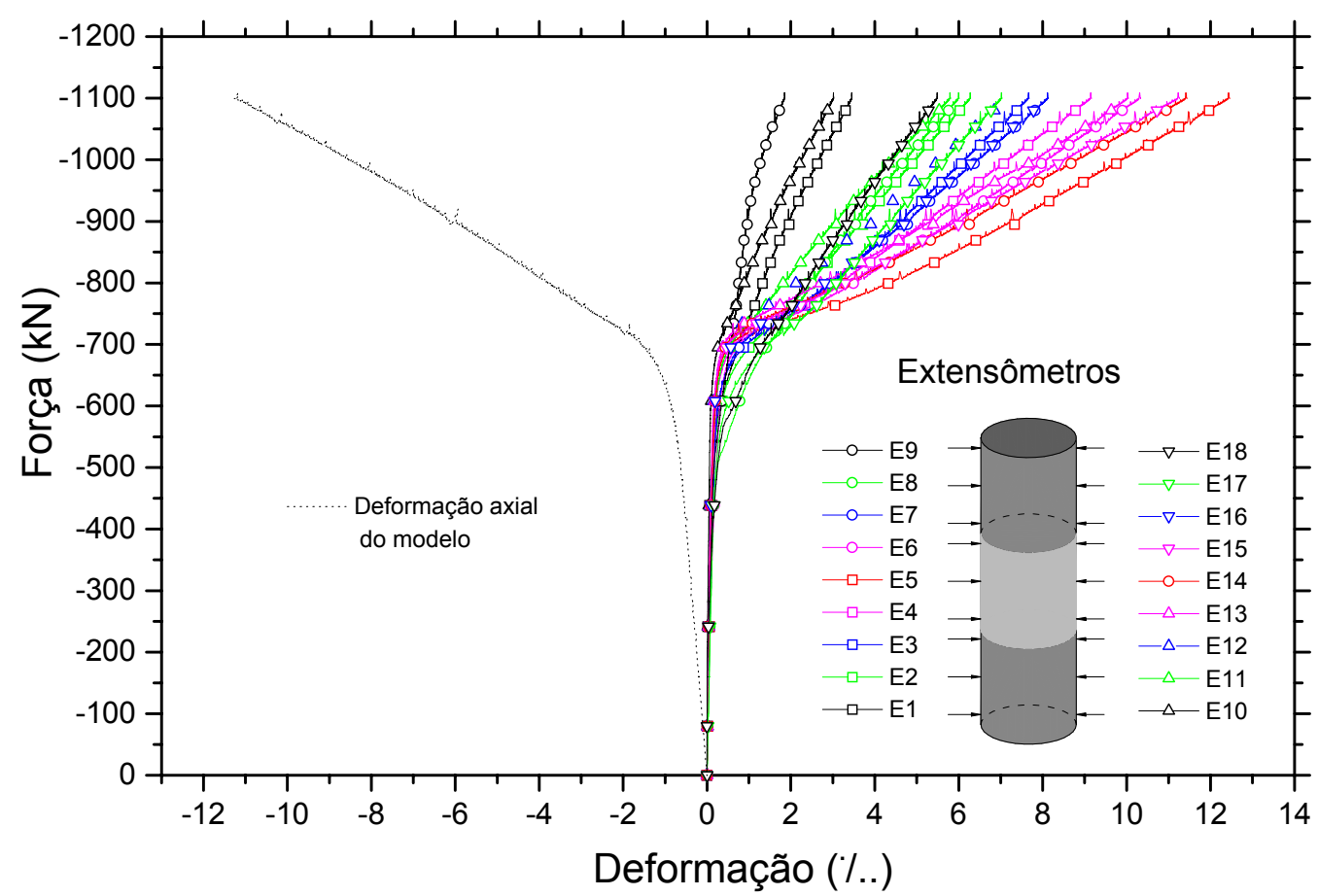

Figura 7.43 - Leituras dos extensômetros - Modelo C1 


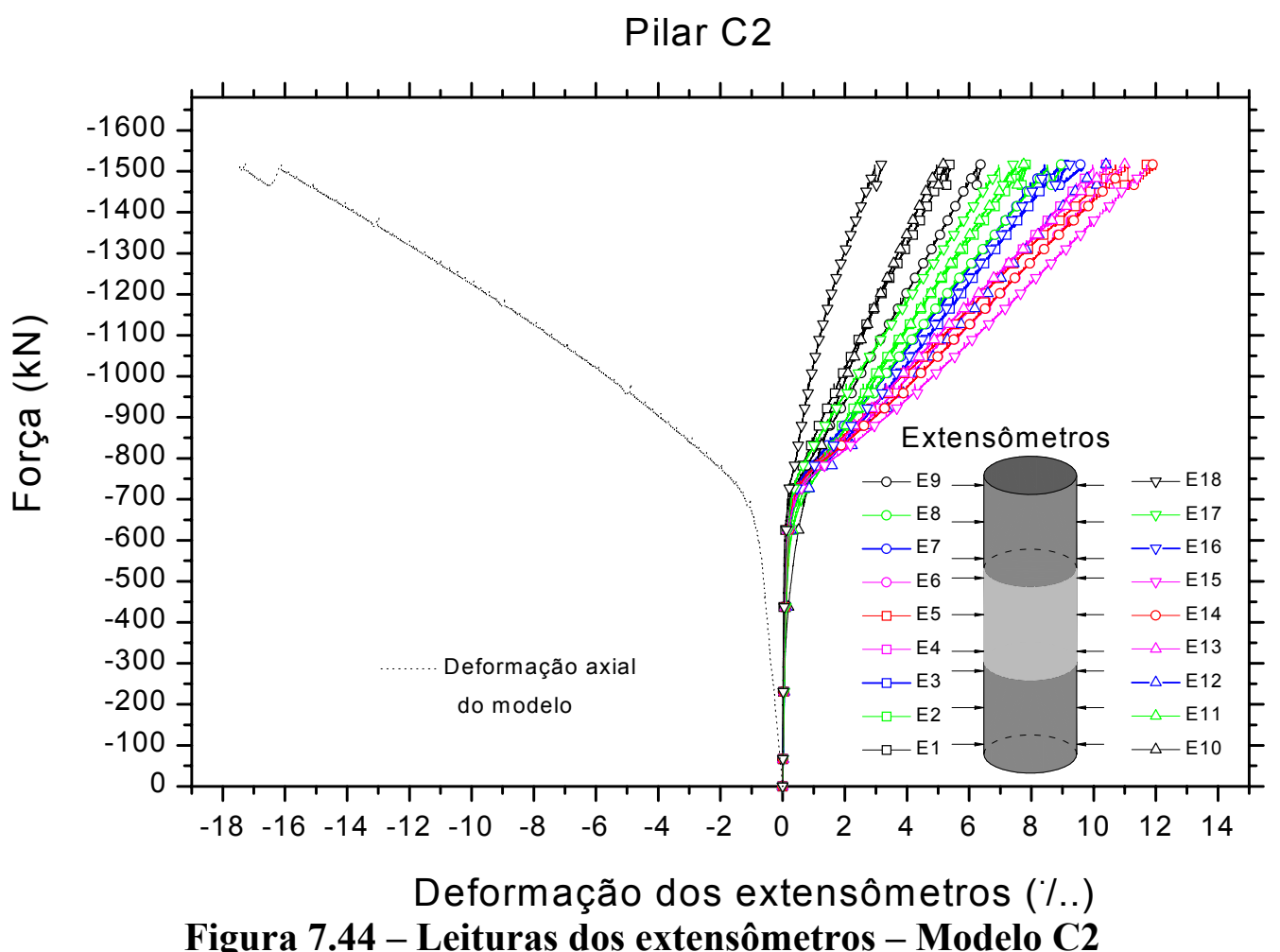

Nas Figuras a seguir são apresentadas as leituras dos extensômetros dos vários modelos com armaduras. No modelo C0S50 fica fácil observar o escoamento das armaduras transversais e longitudinais. As leituras indicadas pelos extensômetros internos das armaduras transversais representam este comportamento. As leituras indicadas pelos extensômetros externos não representam o escoamento. Provavelmente um mecanismo de flexão localizado da armadura provocou a diferença de leituras. A média das leituras externas e interna parece ser representativa do comportamento do modelo. 


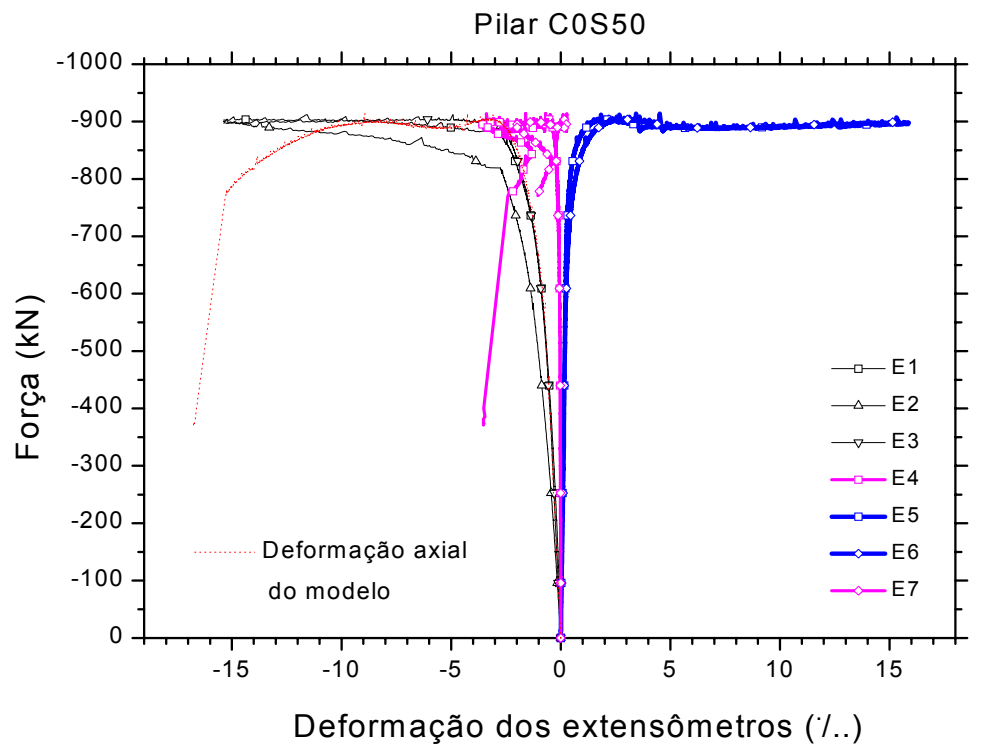

Figura 7.45 - Leituras dos extensômetros - C0S50

Pode-se observar que no modelo C1S50 a armadura longitudinal escoa a um nível de carregamento de aproximadamente $1000 \mathrm{kN}$. A armadura transversal e a camisa de reforço apresentam comportamentos semelhantes. O mesmo comportamento foi observado no modelo C2S50.

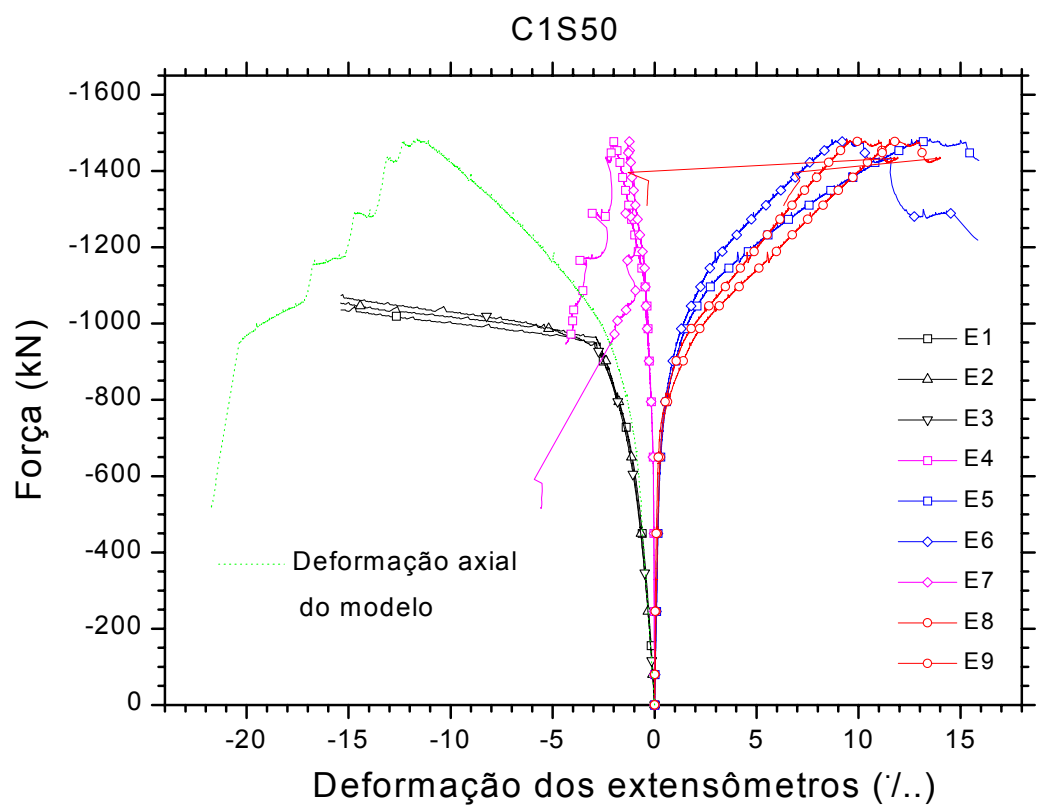

Figura 7.46 - Leituras dos extensômetros - C1S50 


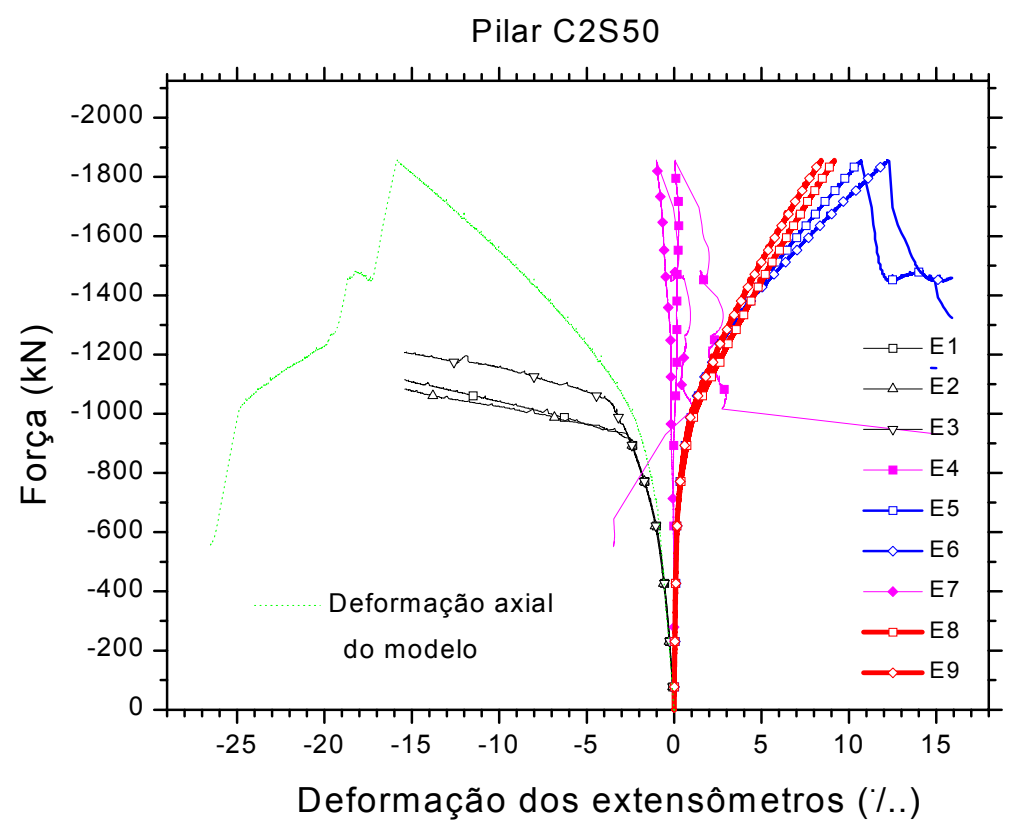

Figura 7.47 - Leituras dos extensômetros do pilar C2S50

No modelo C0S25 pode-se observar o escoamento das armaduras, sendo que as armaduras longitudinais escoaram antes das transversais.

Pilar C0S25

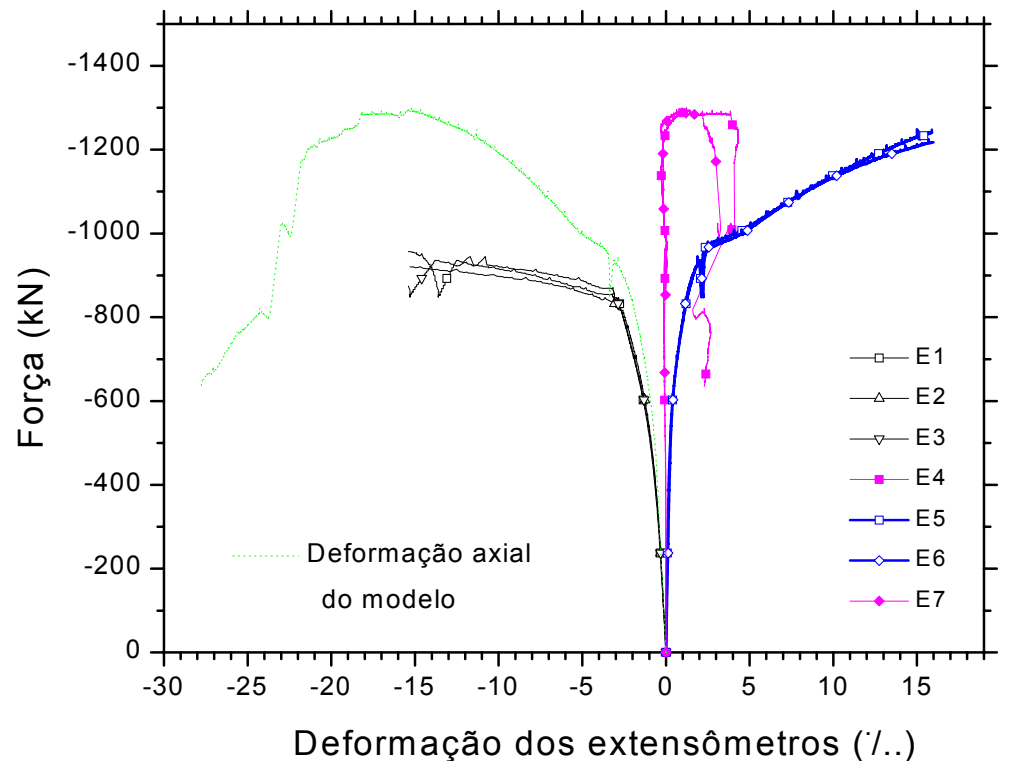

Figura 7.48 - Leituras dos extensômetros do pilar C0S25 
Pode-se observar que as armaduras longitudinais escoaram no primeiro carregamento do modelo $\mathrm{C} 1 \mathrm{~S} 25$. As armaduras transversais no entanto não atingiram o escoamento.

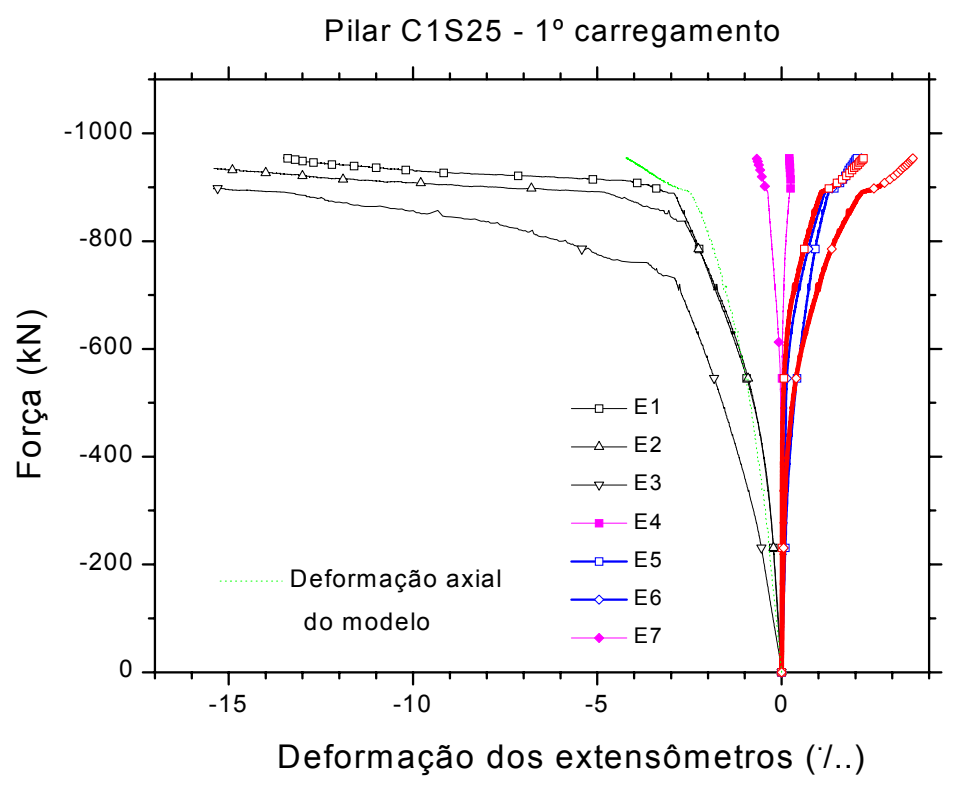

Figura 7.49 - Leituras dos extensômetros do pilar C1S25 - $1^{\circ}$ carregamento

No segundo carregamento o modelo C1S25 apresentou um comportamento diferente dos demais no trecho inicial do ensaio. O comportamento tensãodeformação indica um enrijecimento do material no trecho inicial. As leituras das armaduras longitudinais no $2^{\circ}$ carregamento foram perdidas. A armadura transversal novamente apresentou um comportamento muito próximo ao da camisa de PRFC.

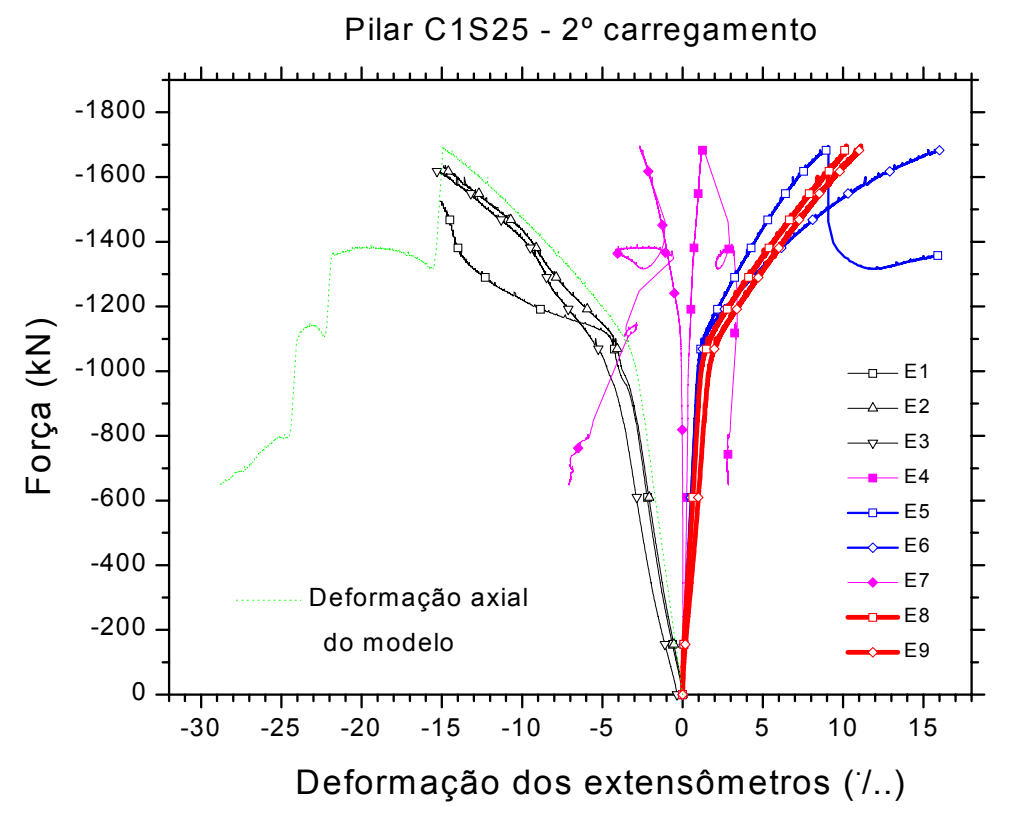

Figura 7.50 - Leituras dos extensômetros do pilar C1S25 - $2^{\circ}$ carregamento 
No modelo C2S25 observou-se o escoamento da armadura longitudinal e que a armadura transversal apresentou comportamento próximo ao da camisa de reforço até um certo nível de carga. Após certo nível de carga as armaduras transversais atingiram maiores deformações.

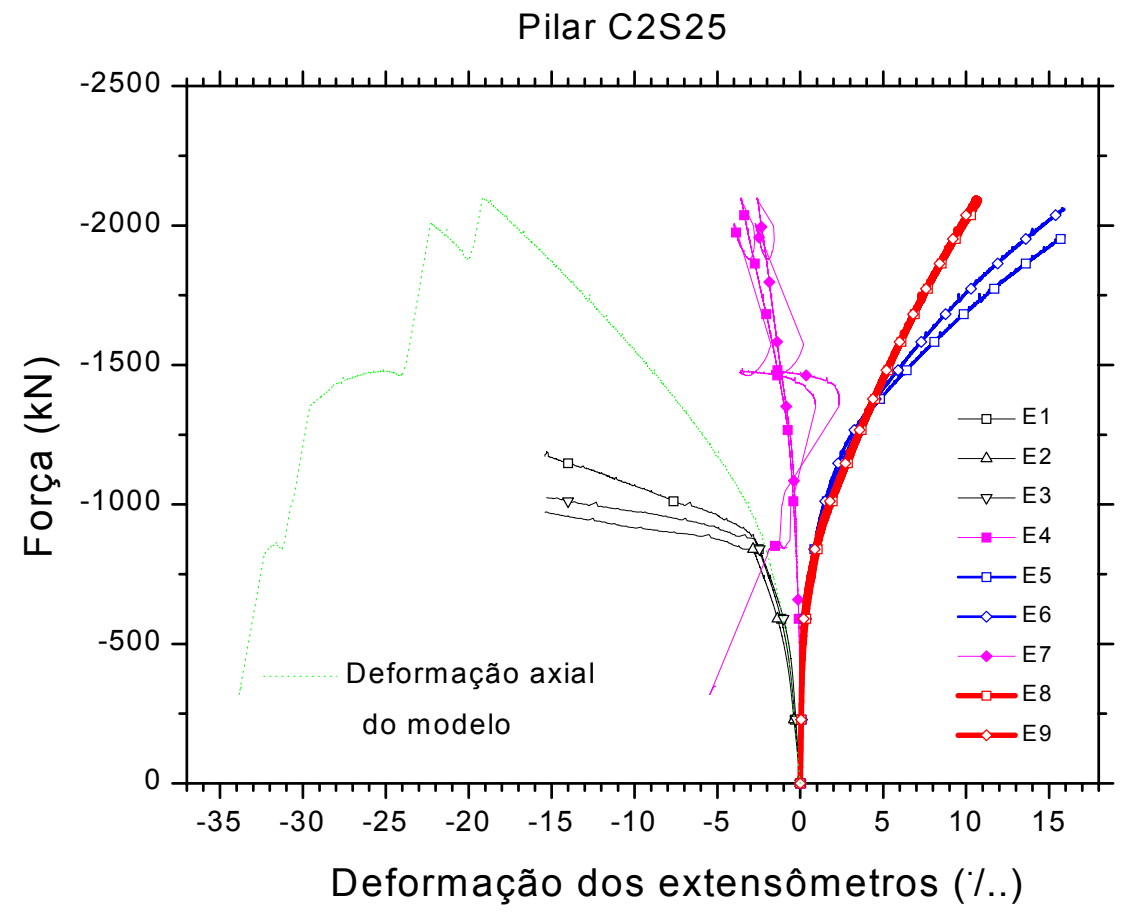

Figura 7.51 - Leituras dos extensômetros do pilar C2S25

No modelo de seção quadrada (Q2) observou-se que as leituras dos extensômetros nos cantos (em vermelho) foram menores que as leituras obtidas nos centros das faces dos modelos (preto). Devido a problemas na gravação dos dados as leituras dos extensômetros do modelo Q1 não foram obtidas. 


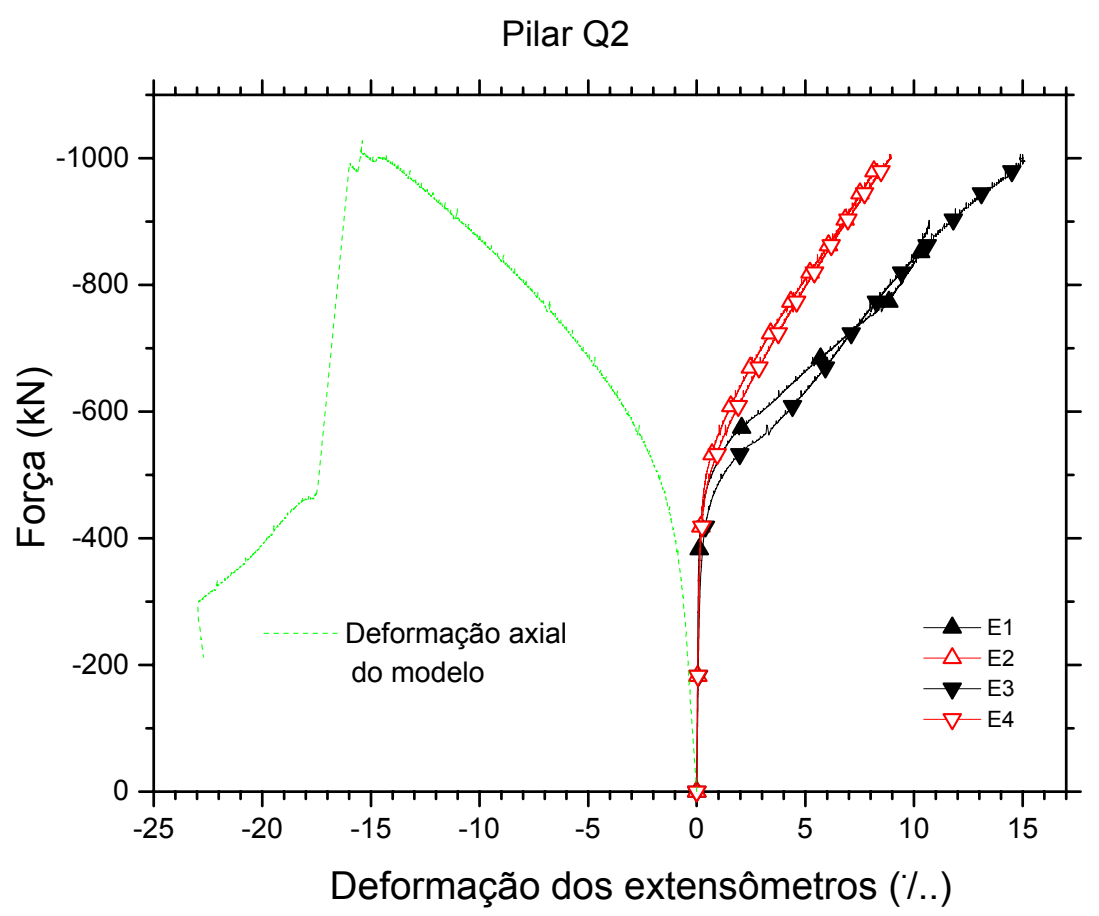

Figura 7.52 - Deformações dos extensômetros na camisa de reforço - Q2

\subsubsection{Cálculo das tensões no concreto confinado}

Nos modelos confinados apenas com PRFC o cálculo da tensão é feito apenas dividindo-se a carga atuante no modelo pela área de concreto. Nos modelos confinados com armaduras transversais o procedimento é mais complexo, pois existem duas regiões de comportamentos diferentes, como indica a Figura 7.53. Estas regiões são delimitadas pelo centro das armaduras transversais.

Região 1

Região 2

\section{Figura 7.53 - Regiões de comportamento distinto}

A região 1 é o núcleo de concreto confinado pelas armaduras transversais. Apesar da área efetiva do núcleo ser um pouco menor que a delimitada pelo centro das espirais, esta área pode ser considerada como representativa do núcleo de concreto confinado. A região 2 é o cobrimento. 


\subsubsection{Influência do cobrimento}

Sabe-se que em um certo nível de solicitação o concreto do cobrimento deixa de colaborar para a capacidade resistente do elemento. Seu comportamento foi associado ao do concreto não confinado por MANDER et al (1988-b). No entanto ainda não foi possível representar o comportamento do cobrimento de maneira precisa, como será mostrado aqui.

Segundo MANDER et al. (1998-a), a tensão no concreto confinado é obtida por meio da divisão da carga atuante no núcleo confinado pela sua área. A carga atuante no núcleo é dada por:

$$
F_{c c}=F_{t o t}-F_{s l}-F_{c o b}
$$

onde:

- $\mathrm{F}_{\mathrm{cc}}$ é a força no núcleo

- $\mathrm{F}_{\text {tot }}$ é a força total atuante no modelo

- $\mathrm{F}_{\mathrm{sl}} \mathrm{e}$ a força nas armaduras longitudinais

- $\mathrm{F}_{\text {cob }}$ é a força no cobrimento

A força nas armaduras longitudinais é obtida a partir das deformações registradas pelos extensômetros e do diagrama tensão-deformação dos ensaios de tração (Figura 7.5). Adotou-se um comportamento elasto-plástico perfeito, com modulo de elasticidade de 201,5 GPa e tensão de escoamento de 554,8 MPa.

MANDER et al. (1988-b) adotam para o concreto do cobrimento o comportamento tensão-deformação do concreto não confinado até uma deformação de $2 \varepsilon_{\mathrm{co}}$. Utilizou-se a equação de POPOVICS ${ }^{14}$ para representar este comportamento. A partir deste ponto adotam uma reta que encontra o eixo das abscissas no ponto onde assume-se a perda do cobrimento $\varepsilon_{\mathrm{sp}}$. No exemplo de MANDER et al. (1988-b) adotou-se $\varepsilon_{\mathrm{sp}} \cong 3,4 \varepsilon_{\mathrm{co}}$. Na Figura 7.54 apresenta-se o diagrama tensão-deformação adimensional para o cobrimento adotando-se o procedimento de MANDER et al. (1988-b) anteriormente descrito. 


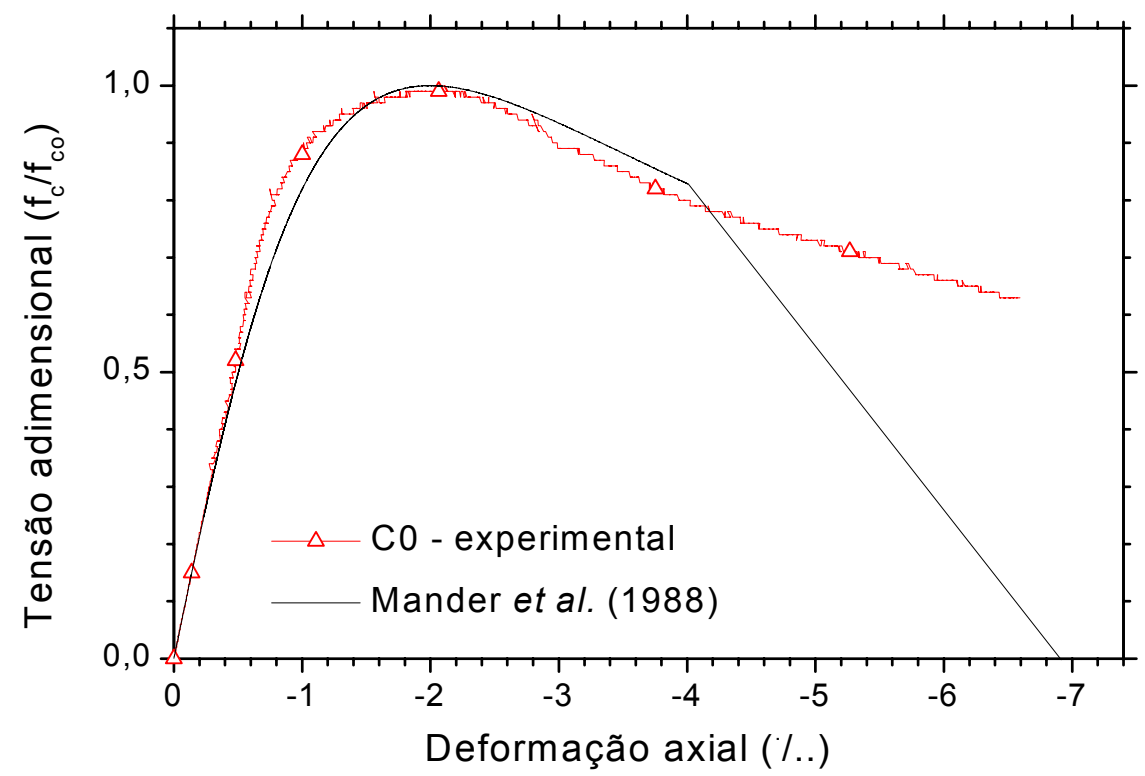

Figura 7.54 - Diagrama tensão-deformação do cobrimento adotado de acordo com MANDER et al. (1988-b)

Na Figura 7.55 é apresentado o diagrama força-deslocamento do modelo COS50. São apresentadas as forças atuantes nas armaduras longitudinais, no cobrimento e no núcleo, e a força total atuante no modelo. Pode-se observar que adotando-se o comportamento sugerido por MANDER et al. (1988-b) para o cobrimento o núcleo apresenta um diagrama força-deslocamento com inclinação descontínua.

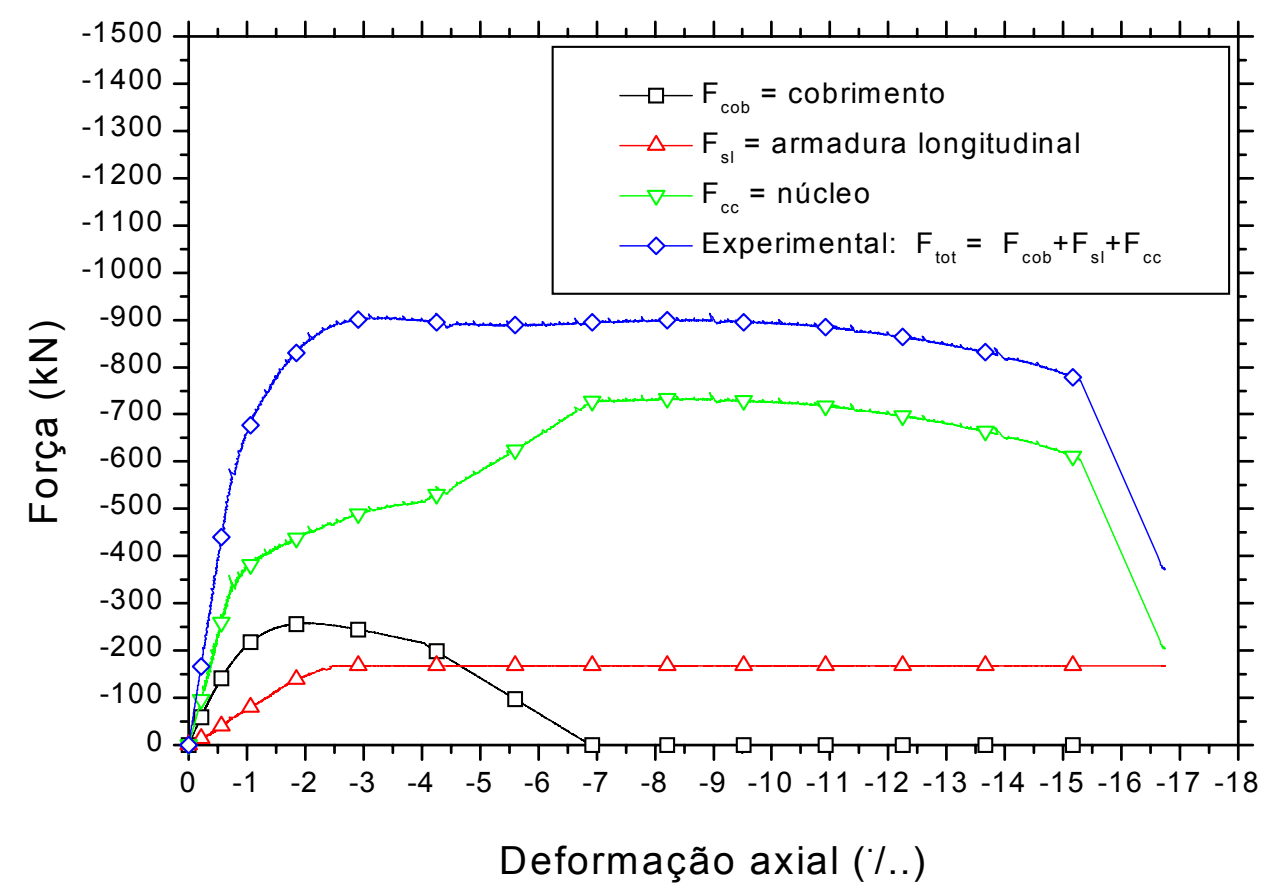

Figura 7.55 - Distribuição de forças no pilar C0S50 
Uma outra tentativa de se representar o comportamento do diagrama tensãodeformação do cobrimento foi por meio de uma equação polinomial, aproximando-se do comportamento do concreto não confinado. Na Figura 7.56 é apresentada a curva experimental do concreto não confinado e do polinômio utilizado para representar o cobrimento.

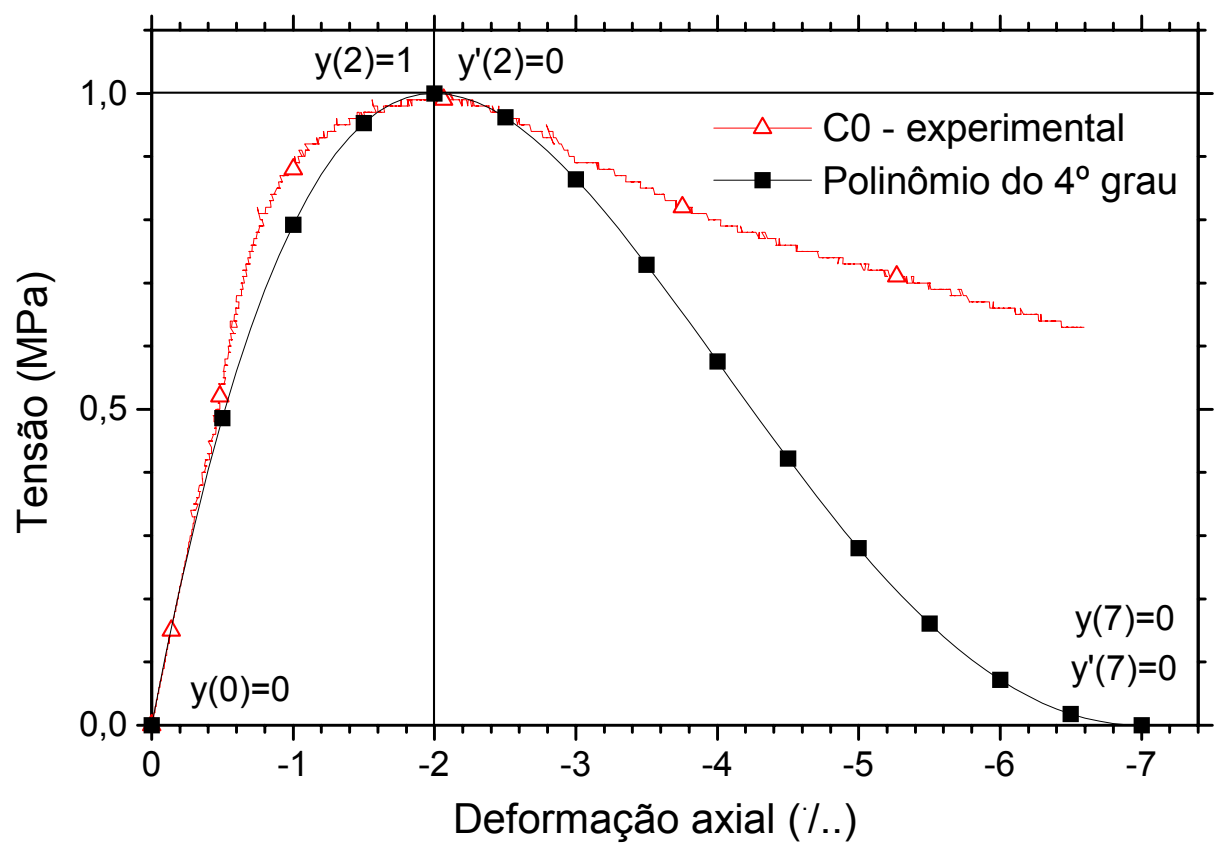

Figura 7.56 - Função polinomial adotada para o cobrimento

O polinômio foi determinado com as 5 condições de contorno apresentadas na Figura 7.56. A equação é dada a seguir, com $\mathrm{y}=$ tensão (adimensional) e $\mathrm{x}=$ deformação axial (módulo).

$$
y(x)=-0,002 \cdot x^{4}+0,052 \cdot x^{3}-0,434 \cdot x^{2}+1,176 \cdot x
$$

Adotando-se este comportamento para o cobrimento pode-se obter a distribuição de forças nos pilares $\operatorname{CoS} 50$ e $\operatorname{CoS} 25$, representados na Figura 7.57 e na Figura 7.58. 


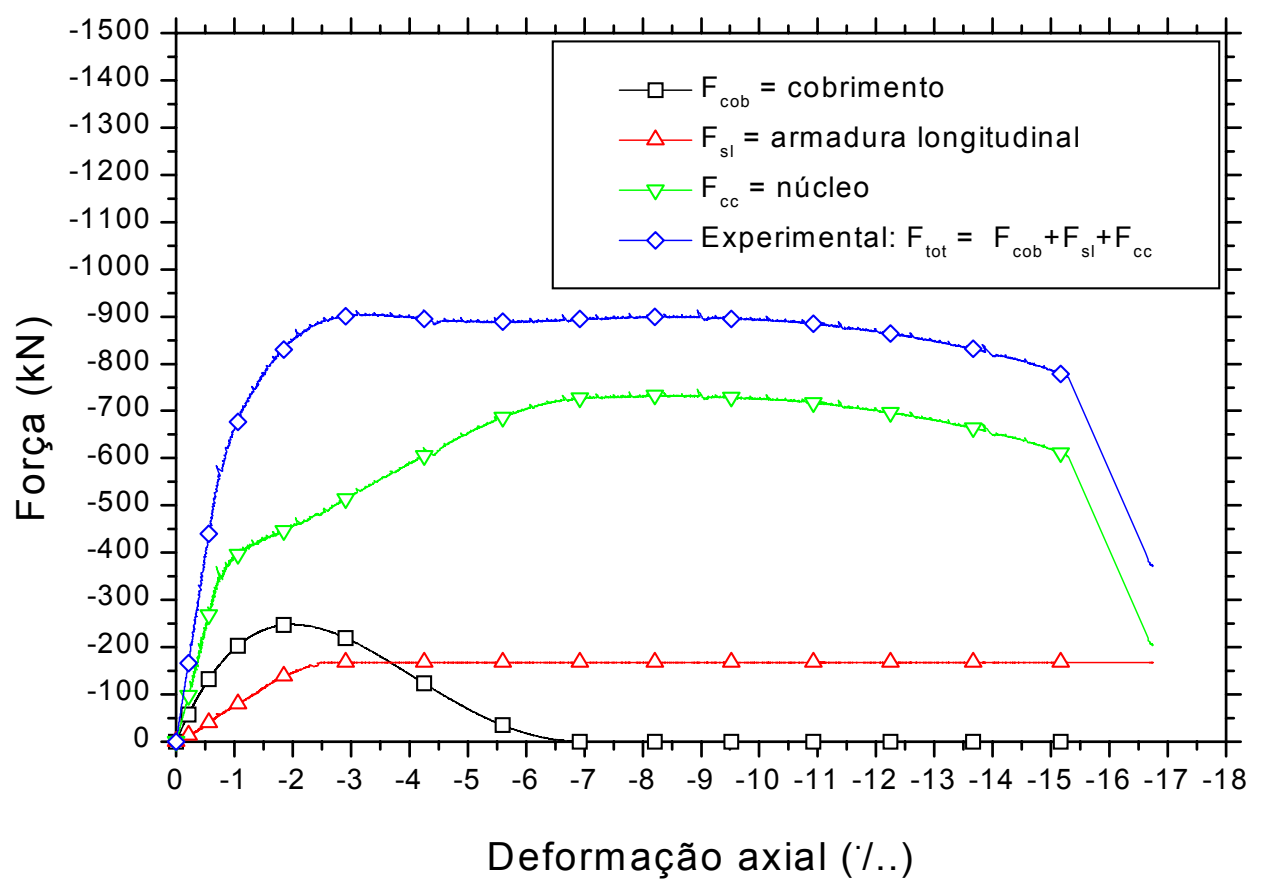

Figura 7.57 - Forças atuantes no modelo - C0S50

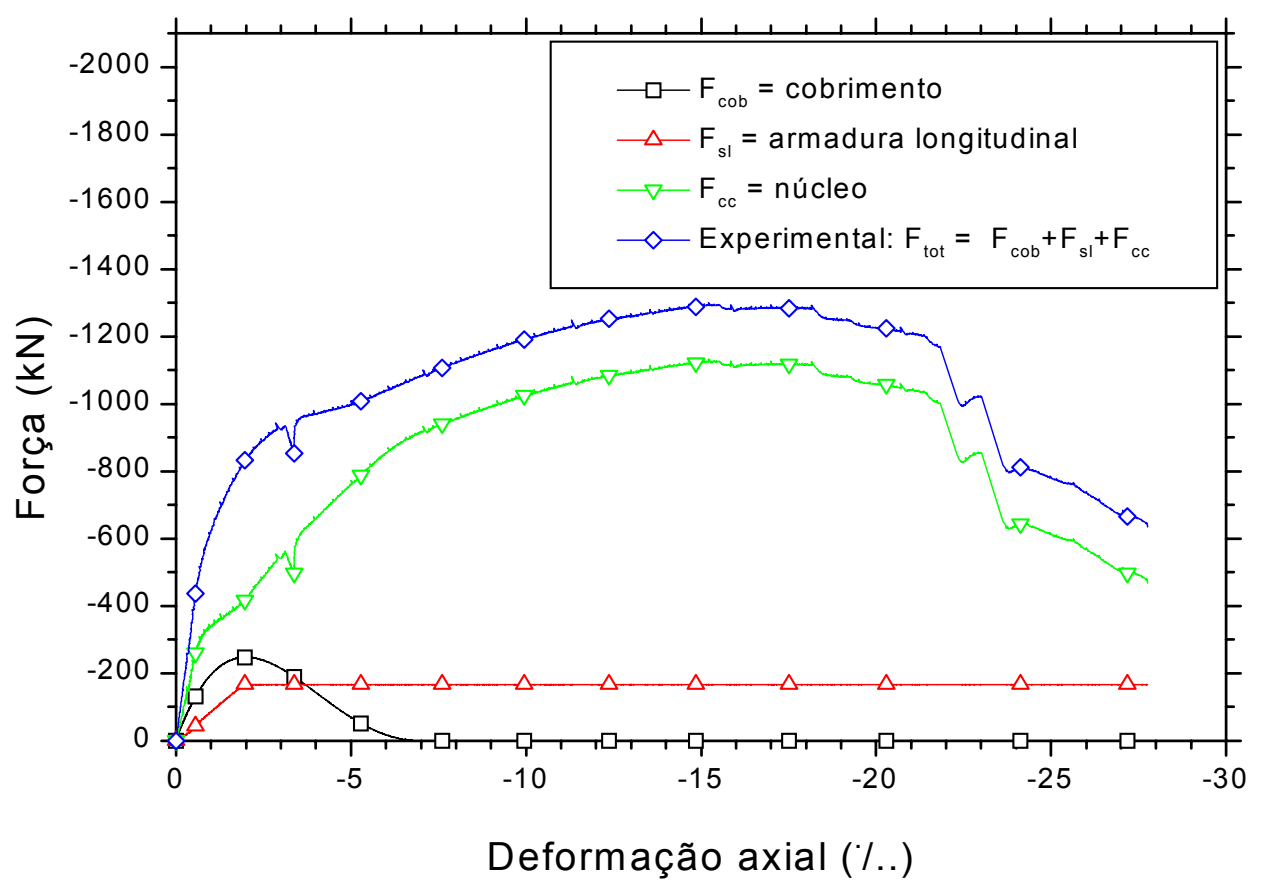

Figura 7.58 - Forças atuantes no modelo - C0S25

Observando as Figuras 7.55, 7.57 e 7.58 pode-se ter idéia da dificuldade de representar a curva do cobrimento. Não foi encontrada uma curva que o representa-se perfeitamente. Daí decorre a dificuldade de representar adequadamente o diagrama tensão-deformação do concreto confinado por armaduras transversais. De qualquer maneira, cientes das limitações impostas, os diagramas tensão-deformação do 
concreto confinado nos modelos C0S50 e C0S25 serão apresentados eliminando-se a contribuição do cobrimento por meio da representação polinomial.

Nos modelos que possuem em conjunto armaduras transversais e camisas de PRFC a análise também deve incluir as duas regiões apresentadas na Figura 7.53. Neste caso, as comparações serão feitas em termos de capacidade resistente e deformações axiais dos modelos, devido à impossibilidade de calcular uma tensão representativa da seção transversal como um todo.

\subsubsection{Cálculo das tensões no concreto não confinado}

$\mathrm{O}$ modelo de referência $\mathrm{C} 0$ foi concretado na série 1 , com as mesmas dimensões dos demais modelos circulares e procedimentos de execução idênticos. No entanto a resistência do modelo foi significativamente menor que a obtida com corpos-de-prova cilíndricos de 10x20 cm. Obteve-se 26,16 MPa no modelo C0 e 32 MPa nos corpos de prova, resultando uma relação de $81,75 \%$.

$\mathrm{Na}$ série 2 não foi ensaiado nenhum modelo de referência não confinado. Desta maneira adotou-se a relação de $81,75 \%$ entre o modelo e o corpo de prova para estimar $\mathrm{f}_{\mathrm{co}}$. Como a média dos corpos de prova resultou em $35,3 \mathrm{MPa}$ adotou-se $\mathrm{f}_{\mathrm{co}}=$ 28,86 na série 2. A resistência do concreto não confinado utilizada nas simulações teóricas foi adotada com base nos valores de pilares de iguais dimensões aos pilares reforçados. 


\section{Capitulo 8 Análise dos resultados e simulações teóricas}

\subsection{Capacidade resistente dos pilares de seção circular}

Observou-se significativos aumentos de capacidade resistente dos pilares de seção circular com o aumento do número de camadas de fibras de carbono, para todas as taxas de armadura transversal. Ocorreram também grandes aumentos da deformação última destes pilares. A Tabela 8.1 apresenta a capacidade resistente dos pilares de seção transversal circular. É feita uma comparação dos modelos reforçados com os modelos de referência (sem camisa de PRFC).

Tabela 8.1 - Capacidade resistente dos pilares de seção transversal circular

\begin{tabular}{ccccccc}
\hline \multicolumn{6}{c}{ Capacidade resistente dos modelos } \\
\hline \multicolumn{4}{c}{$\rho_{\mathrm{s}}=0$} & \multicolumn{2}{c}{$\rho_{\mathrm{s}}=1 \%$} & \multicolumn{2}{c}{$\rho_{\mathrm{s}}=2 \%$} \\
\hline $\mathrm{n}$ & $\mathrm{Fu}(\mathrm{kN})$ & $\mathrm{Fu} / \mathrm{Fu}^{* *}$ & $\mathrm{Fu}(\mathrm{kN})$ & $\mathrm{Fu} / \mathrm{Fu}^{* *}$ & $\mathrm{Fu}(\mathrm{kN})$ & $\mathrm{Fu} / \mathrm{Fu}$ \\
\hline 0 & $741,7^{* * *}$ & 1,000 & $903,7^{* *}$ & 1,000 & $1291,0^{* * *}$ & 1,000 \\
1 & 1100,5 & 1,484 & 1481,5 & 1,639 & 1691,5 & 1,310 \\
2 & 1507,55 & 2,033 & 1854,7 & 2,052 & 2097,4 & 1,625 \\
\hline
\end{tabular}

Observou-se maiores ganhos de capacidade resistente pelo efeito da camisa de reforço nos pilares com menores taxas de armadura transversal. Com o acréscimo da armadura transversal de 1 a $2 \%$ o ganho relativo de capacidade resistente foi menor. Isto ocorreu porque o ganho de resistência com a aplicação da camisa é relacionado à resistência do concreto não confinado e à pressão lateral desenvolvida pela camisa. O concreto confinado com armaduras transversais já apresenta por si só um considerável ganho de resistência, relacionado à taxa de armadura transversal. Logo, comparativamente o ganho de resistência pelo efeito da camisa de reforço é menor quando a taxa de armadura cresce significativamente. 


\subsection{Deformação última dos pilares de seção transversal circular}

Observou-se aumentos significativos da deformação última com a aplicação do reforço com PRFC. A Tabela 8.2 apresenta a deformação última dos pilares e a comparação entre modelos reforçados e de referência. Ocorreram grandes aumentos da deformação última nos modelos sem armaduras. Aumentando-se a taxa de armadura transversal existente no pilar o reforço traz relativamente menores ganhos de deformação última.

Tabela 8.2 - Comparação da deformação última dos pilares de seção transversal circular

\begin{tabular}{ccccccc}
\hline \multicolumn{6}{c}{ Capacidade resistente dos modelos } \\
\hline \multicolumn{4}{c}{$\rho_{\mathrm{s}}=0$} & \multicolumn{2}{c}{$\rho_{\mathrm{s}}=1 \%$} & \multicolumn{2}{c}{$\rho_{\mathrm{s}}=2 \%$} \\
\hline $\mathrm{n}$ & $\varepsilon_{\mathrm{cc}}(\% \mathrm{o})$ & $\varepsilon_{\mathrm{cc}} / \varepsilon_{\mathrm{cc}} *$ & $\varepsilon_{\mathrm{cc}}(\%)$ & $\varepsilon_{\mathrm{cc}} / \varepsilon_{\mathrm{cc}} * *$ & $\varepsilon_{\mathrm{cc}}(\% \mathrm{o})$ & $\varepsilon_{\mathrm{cc}} \varepsilon_{\mathrm{cc}} * *$ \\
\hline 0 & $2,028^{*}$ & 1,000 & $8,552^{* *}$ & 1,000 & $15,231 * * *$ & 1,000 \\
1 & 11,180 & 5,513 & 11,643 & 1,361 & 16,482 & 1,082 \\
2 & 16,196 & 7,986 & 15,837 & 1,852 & 19,185 & 1,260 \\
\hline
\end{tabular}

\subsection{Concreto confinado com PRFC}

Na Tabela 8.3 são apresentados os resultados obtidos para o concreto confinado com PRFC em pilares de seção transversal circular. Nestes pilares a pressão lateral $\left(\mathrm{f}_{1}\right)$ foi calculada com a deformações de ruptura das fibras registradas nos respectivos ensaios $\left(\varepsilon_{\mathrm{fu}}\right)$ conforme a expressão $(8.1)$ :

$$
f_{l}=\frac{2 \cdot t_{f} \cdot n \cdot \varepsilon_{f u} \cdot E_{f}}{D}
$$

onde:

- $\quad t_{\mathrm{f}}$ é a espessura das fibras $(0,13 \mathrm{~mm})$;

- $\mathrm{n}$ é o número de camadas das fibras;

- $\varepsilon_{\mathrm{fu}}$ é a deformação última das fibras;

- $\mathrm{E}_{\mathrm{f}}$ é o módulo de elasticidade das fibras. 
Tabela 8.3 - Resultados experimentais

\begin{tabular}{cccccccc}
\hline Pilar & $\mathrm{n}$ & $\mathrm{F}_{\mathrm{u}}(\mathrm{kN})$ & $\delta_{\mathrm{u}}$ & $\begin{array}{c}\varepsilon_{\mathrm{fu}} \\
(\%)\end{array}$ & $\begin{array}{c}\mathrm{f}_{\mathrm{l}} \\
(\mathrm{MPa})\end{array}$ & $\mathrm{f}_{\mathrm{cc}}(\mathrm{MPa})$ & $\varepsilon_{\mathrm{cc}}(\% \mathrm{o})$ \\
\hline $\mathrm{C} 0$ & 0 & 741,66 & 1,156 & - & - & 26,16 & 2,028 \\
$\mathrm{C} 1$ & 1 & 1100,50 & 6,373 & 11,92 & 3,571 & 38,81 & 11,180 \\
$\mathrm{C} 2$ & 2 & 1507,55 & 9,957 & 11,90 & 7,131 & 53,17 & 17,469 \\
$\mathrm{C} 2{ }^{*}$ & 2 & 1505,08 & 9,231 & 10,89 & 6,526 & 53,08 & 16,196 \\
\hline \multicolumn{6}{c}{ Valores do $1^{\circ}$ pico de resistência } \\
\hline
\end{tabular}

onde:

- $\mathrm{F}_{\mathrm{u}}$ é a força última do pilar;

- $\delta_{\mathrm{u}}$ é o deslocamento último do pilar.

Na Tabela 8.4 são apresentadas a resistência e a deformação última do concreto confinado com PRFC obtidas experimentalmente e as previsões dadas por alguns dos modelos teóricos encontrados na literatura. Para fins de análise do confinamento é mais interessante utilizar os dados de $\mathrm{C} 2{ }^{*}$ no lugar de $\mathrm{C} 2$. O módulo de elasticidade tangente do concreto $\left(\mathrm{E}_{\mathrm{co}}\right)$ obtido do modelo de referência $\mathrm{C} 0$ foi de 28,616 GPa. Como este valor foi muito próximo ao obtido com os corpos-de-prova de controle este será utilizado para as análises e comparações.

Tabela 8.4-Comparação dos resultados experimentais com os modelos teóricos

\begin{tabular}{|c|c|c|c|c|c|c|c|c|}
\hline \multirow[b]{2}{*}{$\begin{array}{c}\mathrm{f}_{\mathrm{co}}=26,16 \mathrm{MPa} \\
\varepsilon_{\mathrm{co}}=2,028\end{array}$} & \multicolumn{4}{|c|}{ C1 (1 camada de reforço) } & \multicolumn{4}{|c|}{ C2 (2 camadas de reforço) } \\
\hline & $\begin{array}{c}\mathrm{f}_{\mathrm{cc}} \\
(\mathrm{MPa})\end{array}$ & $\frac{f_{c c}}{f_{c . \text { exp }}}$ & $\varepsilon_{\mathrm{cc}}(\%)$ & $\frac{\varepsilon_{c c}}{\varepsilon_{c c . \text { exp }}}$ & $\begin{array}{c}\mathrm{f}_{\mathrm{cc}} \\
(\mathrm{MPa})\end{array}$ & $\frac{f_{c c}}{f_{c c . \text { exp }}}$ & $\varepsilon_{\mathrm{cc}}(\%)$ & $\frac{\varepsilon_{c c}}{\varepsilon_{c c . \mathrm{exp}}}$ \\
\hline Experimental & 38,81 & - & 11,180 & - & 53,08 & - & 16,196 & - \\
\hline Richart et al. & 40,80 & 1,051 & 7,703 & 0,689 & 52,92 & 0,997 & 12,400 & 0,766 \\
\hline Mander et al. & 45,17 & 1,164 & 9,397 & 0,841 & 55,94 & 1,054 & 13,573 & 0,838 \\
\hline Cusson \& Paultrè & 39,79 & 1,025 & 9,140 & 0,818 & 50,27 & 0,947 & 18,801 & 1,161 \\
\hline Razvi \&Saatcioglu & 45,43 & 1,171 & 9,497 & 0,849 & 57,95 & 1,092 & 14,349 & 0,886 \\
\hline Miyauchi et al. & 38,61 & 0,995 & 12,256 & 1,096 & 48,90 & 0,921 & 14,835 & 0,916 \\
\hline Kono et al. & 31,50 & 0,812 & 4,056 & 0,363 & 35,92 & 0,677 & 5,734 & 0,354 \\
\hline Saaman et al. [12] & 40,78 & 1,051 & 15,431 & 1,380 & 48,46 & 0,913 & 19,399 & 1,198 \\
\hline Toutanji [15] & 43,01 & 1,108 & 9,345 & 0,836 & 54,29 & 1,023 & 13,547 & 0,836 \\
\hline Saafi et al. [16] & 36,96 & 0,952 & 6,567 & 0,587 & 44,09 & 0,831 & 13,770 & 0,850 \\
\hline Spoelstra \& Monti & 34,23 & 0,882 & 16,268 & 1,455 & 44,43 & 0,837 & 19,139 & 1,182 \\
\hline
\end{tabular}

Em geral os modelos teóricos tiveram melhor desempenho na previsão da resistência do que na deformação última do concreto confinado.

O modelo de EL DASH \& AHMAD (1995) não pôde ser utilizado, pois a formulação da envoltória não pode ser isolada apenas em função da pressão lateral. 
O modelo de RICHART et al. (1929) proporcionou bons resultados de previsão da resistência, no entanto ocasionou erros na deformação última, já que foi desenvolvido para confinamento ativo e com aço.

Os modelos de MANDER et al. (1988-b) e RAZVI \& SAATCIOGLU (1999b) superestimaram o ganho de resistência, como já era esperado. A deformação última também não foi bem representada por se tratar de modelos para confinamento com aço. O modelo de CUSSON \& PAULTRE (1995) foi o mais aproximado na previsão do ganho de resistência entre os modelos desenvolvidos para confinamento com aço. Porém a deformação última também não foi adequada.

Dentre os modelos desenvolvidos para confinamento com PRFC o de MIYAUCHI et al. (1997) obteve os melhores resultados, tanto na resistência quanto na deformação última. O modelo de SAMAAN et al. (1998) também apresentou um bom desempenho, com maiores erros na previsão da deformação última.

O modelo de KONO et al. (1998) obteve valores baixos de resistência e deformação última. Talvez o problema deste modelo esteja em relacionar o ganho de resistência $\left(\mathrm{f}_{\mathrm{cc}} / \mathrm{f}_{\mathrm{co}}\right)$ e deformação última $\left(\varepsilon_{\mathrm{cc}} / \varepsilon_{\mathrm{co}}\right)$ diretamente com a pressão lateral, e não com a taxa $\mathrm{f}_{1} / \mathrm{f}_{\mathrm{co}}$.

Os modelos de SAAFI et al. ${ }^{17}$ e SPOELSTRA \& MONTI ${ }^{18}$ foram um pouco conservadores no ganho de resistência. O modelo de SAAFI et al. ${ }^{17}$ preveu baixos valores de deformação última enquanto o de SPOELSTRA \& MONTI ${ }^{18}$ superestimou esta previsão.

Observou-se nos pilares circulares reforçados um diagrama tensãodeformação do concreto confinado por PRFC praticamente bi-linear (Figura 8.1), concordando com o proposto por vários modelos teóricos. O aumento da taxa volumétrica do material de reforço (número de camadas) provocou uma alteração significativa na inclinação do segundo trecho do diagrama tensão-deformação. 


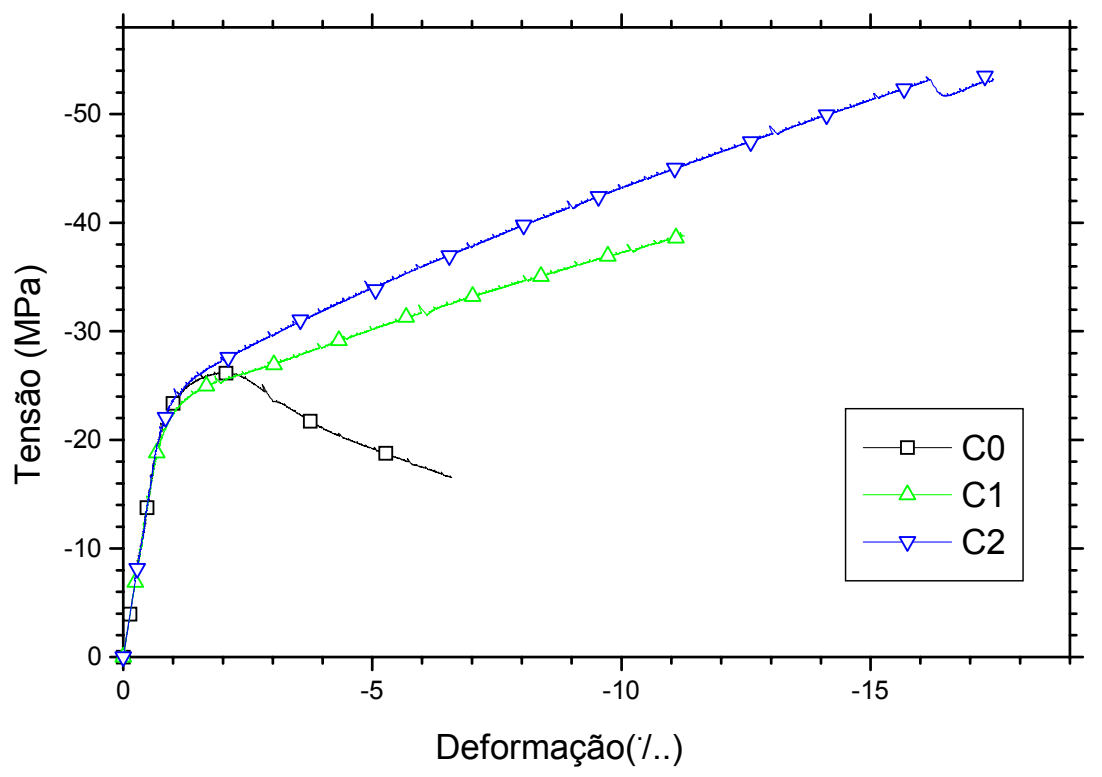

Figura 8.1 - Diagramas tensão-deformação dos modelos sem armaduras

Alguns pesquisadores relacionam esta inclinação à rigidez da camisa de reforço. O primeiro trecho praticamente não sofre alterações, e depende apenas das características do concreto não confinado.

Alguns modelos teóricos sugerem equações específicas para o diagrama tensão-deformação de pilares circulares encamisados com PRF. Estas equações procuram simular o comportamento bi-linear do concreto confinado com PRF, sendo o primeiro trecho governado pelas características do concreto não confinado e o segundo trecho dependente da rigidez da camisa de reforço.

$\mathrm{Na}$ Figura 8.2 apresenta-se uma comparação dos diagramas tensãodeformação obtidos experimentalmente com os sugeridos por alguns modelos teóricos. Dentre os modelos apresentados está o de MANDER et al. (1988-b). Este modelo foi desenvolvido para o confinamento com aço e como se pode observar, ele superestima o ganho de resistência, além de seu comportamento tensão-deformação ser bem diferente do concreto confinado por PRF.

O diagrama proposto por MIYAUCHI et al. (1997) foi o mais próximo do comportamento experimental, representando a curva com maior precisão. O modelo de SAMAAN et al. (1998) não teve um desempenho tão adequado por superestimar o ganho na deformação última. As mesmas observações podem ser feitas a respeito do diagrama do pilar C2 (Figura 8.3). Não foi calculada a deformação de ruptura para o modelo de MANDER et al. (1988-b). 
Pilar C1

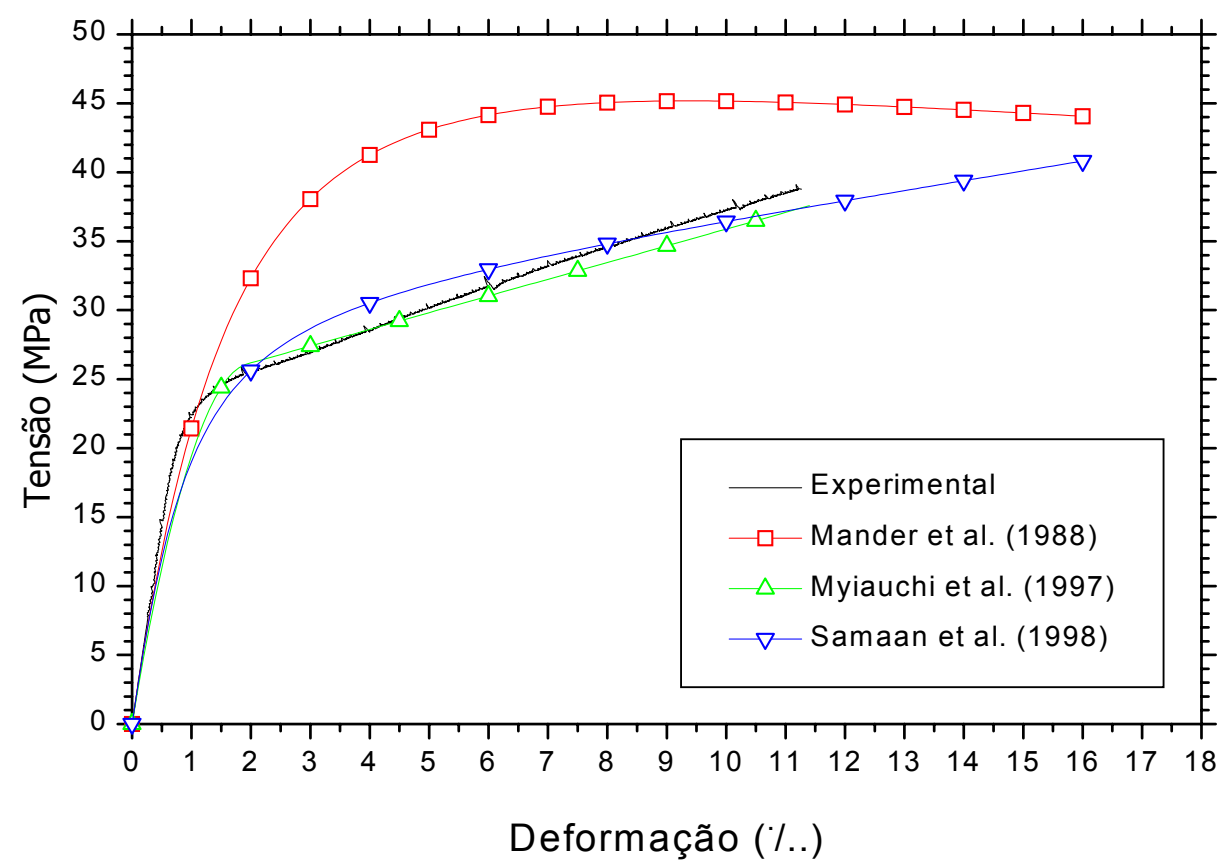

Figura 8.2 - Diagrama tensão-deformação: teórico x experimental - Modelo C1 Pilar C2

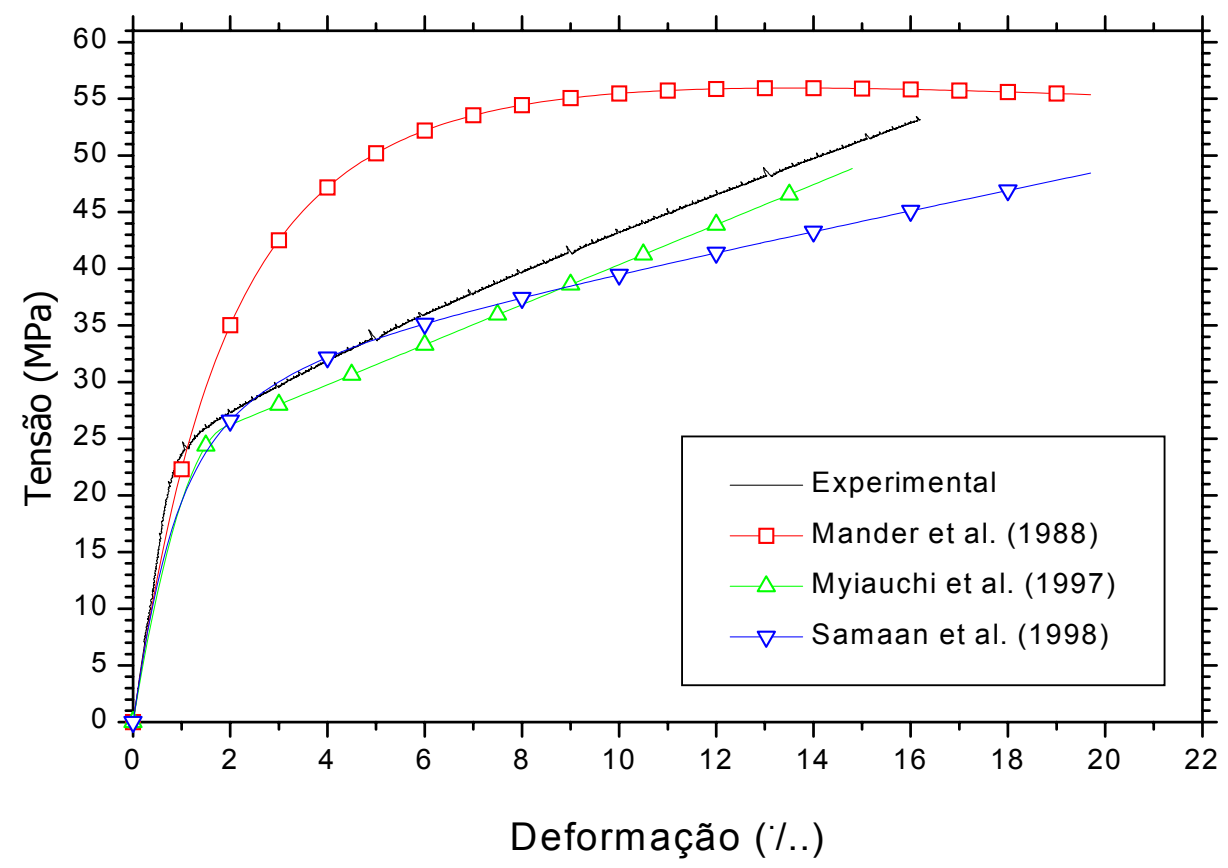

Figura 8.3 - Diagrama tensão-deformação: teórico x experimental - Modelo C2

\subsection{Concreto confinado com aço}

Foram confeccionados 6 modelos com armaduras. Dois destes modelos não apresentam camisa de reforço, sendo o confinamento apenas de espirais, com duas 
taxas volumétricas de armadura (1 e 2\%). Na Tabela 8.5 são apresentados os resultados dos modelos confinados apenas com armaduras transversais.

Tabela 8.5 - Resultados experimentais dos modelos confinados com armadura transversal

\begin{tabular}{ccccccccc}
\hline Modelo & $\begin{array}{c}\text { Espaçamento } \\
\text { entre espirais } \\
(\mathrm{mm})\end{array}$ & $\begin{array}{c}\rho_{\mathrm{s}} \\
(\%)\end{array}$ & $\begin{array}{c}\mathrm{f}_{\mathrm{co}} \\
(\mathrm{MPa})\end{array}$ & $\begin{array}{c}\mathrm{F}_{\mathrm{u}} \\
(\mathrm{kN})\end{array}$ & $\begin{array}{c}\delta_{\mathrm{u}} \\
(\mathrm{mm})\end{array}$ & $\begin{array}{c}\mathrm{f}_{\mathrm{l}} \\
(\mathrm{MPa})\end{array}$ & $\begin{array}{c}\mathrm{f}_{\mathrm{cc} . \exp } \\
(\mathrm{MPa})\end{array}$ & $\begin{array}{c}\varepsilon_{\text {cc.exp }} \\
(\% \mathrm{o})\end{array}$ \\
\hline C0S50 & 50 & 1,01 & 26,16 & 903,7 & 1,864 & 3,831 & 39,66 & 3,270 \\
C0S50 & 50 & 1,01 & 26,16 & 899,6 & 4,875 & 3,831 & 39,44 & 8,552 \\
$\mathrm{C} 0 \mathrm{~S} 25$ & 25 & 2,03 & 28,86 & 1291,0 & 8,682 & 7,661 & 60,52 & 15,231 \\
\hline
\end{tabular}

No modelo COS50 a resistência do concreto confinado foi calculada com o resultado do $2^{\circ}$ pico do diagrama força $\mathrm{x}$ deslocamento $\left(\operatorname{COS} 50^{*}\right)$, onde se sabe que a carga é distribuída apenas na área do núcleo. No $1^{\circ}$ pico o cobrimento participa consideravelmente na capacidade resistente do elemento. Para o cálculo da tensão no concreto confinado descontou-se a força nas armaduras longitudinais, que após seu escoamento atingiu o valor máximo de $167,3 \mathrm{kN}$. A área de concreto confinado no núcleo é de $18567,6 \mathrm{~mm}^{2}$. A Tabela 8.6 e a Tabela 8.7 mostram os resultados experimentais e as previsões dos modelos teóricos.

Tabela 8.6 - Pilar C0S50: resultados experimentais $x$ teóricos

\begin{tabular}{|c|c|c|c|c|c|c|}
\hline \multirow[b]{2}{*}{$\begin{array}{c}\mathrm{f}_{\mathrm{co}}=26,16 \mathrm{MPa} \\
\varepsilon_{\mathrm{co}}=2,028\end{array}$} & \multicolumn{6}{|c|}{$\operatorname{CoS} 50$} \\
\hline & $\mathbf{k}_{\mathbf{e}}$ & $\mathbf{f}_{\mathrm{le}}$ & $\begin{array}{c}\mathrm{f}_{\mathrm{cc}} \\
(\mathrm{MPa})\end{array}$ & $\frac{f_{c c}}{f_{c c . \text { exp }}}$ & $\varepsilon_{\mathrm{cc}}(\%)$ & $\frac{\varepsilon_{c c}}{\varepsilon_{c c . \text { exp }}}$ \\
\hline Experimental & - & - & 39,44 & - & 8,552 & - \\
\hline Richart et al. & 1,000 & 3,831 & 41,87 & 1,062 & 8,116 & 0,949 \\
\hline Mander et al. & 0,869 & 3,328 & 44,14 & 1,119 & 8,996 & 1,052 \\
\hline El-Dash \& Ahmad & 0,492 & 1,885 & 34,59 & 0,877 & 3,878 & 0,454 \\
\hline Cusson \& Paultrè & 0,869 & 3,328 & 39,13 & 0,992 & 8,337 & 0,975 \\
\hline Razvi \& Saatcioglu & 1,000 & 3,831 & 46,59 & 1,181 & 9,946 & 1,163 \\
\hline Miyauchi et al. & 0,869 & 3,328 & 37,76 & 0,957 & 11,991 & 1,402 \\
\hline Kono et al. & 0,869 & 3,328 & 31,14 & 0,786 & 3,918 & 0,458 \\
\hline Samaan et al. & 0,869 & 3,328 & 40,08 & 1,016 & - & - \\
\hline Toutanji & 0,869 & 3,328 & 42,03 & 1,066 & - & - \\
\hline Saafi et al. & 0,869 & 3,328 & 36,34 & 0,921 & - & - \\
\hline Spoelstra \& Monti & 0,869 & 3,328 & 33,22 & 0,842 & - & - \\
\hline
\end{tabular}

O modelo de EL-DASH \& AHMAD (1995) não representou bem o comportamento deste pilar. A pressão lateral efetiva é muito baixa. As previsões mais próximas dos resultados experimentais do pilar C0S50 foram as de CUSSON \& 
PAULTRE (1995). O modelo de RICHART et al. (1929) também deu bons resultados. Os modelos de MANDER et al. (1988-b) e de RAZVI \& SAATCIOGLU (1999-b) superestimaram a resistência e a deformação última. Com exceção do modelo de KONO et al. (1998), que subestimou o ganho de resistência e a deformação última, os demais modelos de confinamento para PRF deram bons resultados de resistência. A previsão da deformação última do concreto confinado com armaduras transversais não pôde ser obtida com os demais modelos de confinamento com PRF, pois suas formulações possuem variáveis específicas deste tipo de confinamento.

Tabela 8.7 - Pilar C0S25: resultados experimentais $x$ teóricos

\begin{tabular}{|c|c|c|c|c|c|c|}
\hline \multirow[b]{2}{*}{$\begin{array}{c}\mathrm{f}_{\mathrm{co}}=28,86 \mathrm{MPa} \\
\varepsilon_{\mathrm{co}}=2,028\end{array}$} & \multicolumn{6}{|c|}{ C0S25 } \\
\hline & $\mathbf{k}_{\mathrm{e}}$ & $\mathbf{f}_{\mathrm{le}}$ & $\begin{array}{c}\mathrm{f}_{\mathrm{cc}} \\
(\mathrm{MPa})\end{array}$ & $\frac{f_{c c}}{f_{c c . \text { exp }}}$ & $\varepsilon_{\mathrm{cc}}(\% 0)$ & $\frac{\varepsilon_{c c}}{\varepsilon_{c c . \text { exp }}}$ \\
\hline Experimental & - & - & 60,52 & - & 15,231 & - \\
\hline Richart et al. & 1,000 & 7,661 & 60,27 & 0,996 & 13,064 & 0,856 \\
\hline Mander et al. & 0,951 & 7,284 & 61,99 & 1,024 & 13,667 & 0,888 \\
\hline El-Dash \& Ahmad & 0,641 & 4,909 & 48,25 & 0,797 & 9,421 & 0,619 \\
\hline Cusson \& Paultrè & 0,951 & 7,284 & 51,98 & 0,859 & 22,246 & 1,461 \\
\hline Razvi \& Saatcioglu & 1,000 & 7,661 & 65,17 & 1,077 & 14,786 & 0,971 \\
\hline Miyauchi et al. & 0,951 & 7,284 & 52,24 & 0,863 & 14,891 & 0,978 \\
\hline Kono et al. & 0,951 & 7,284 & 40,88 & 0,675 & 6,164 & 0,405 \\
\hline Samaan et al. & 0,951 & 7,284 & 52,95 & 0,875 & - & - \\
\hline Toutanji & 0,951 & 7,284 & 60,20 & 0,995 & - & - \\
\hline Saafi et al. & 0,951 & 7,284 & 48,83 & 0,807 & - & - \\
\hline Spoelstra \& Monti & 0,951 & 7,284 & 49,27 & 0,814 & - & - \\
\hline
\end{tabular}

Os modelos de RICHART et al. (1929), MANDER et al. (1988-b) e RAZVI \& SAATCIOGLU (1999-b) tiveram o melhor desempenho na previsão da resistência e deformação última do pilar C0S25. O modelo de EL-DASH \& AHMAD (1995) novamente deu previsões muito baixas de resistência e deformação última. CUSSON \& PAULTRE (1995) previram resistência inferior e deformação última exagerada.

Os modelos de confinamento para PRF conduziram a ganhos de resistência inferiores aos obtidos experimentalmente, com exceção de TOUTANJI (1999) que obteve resistência próxima da experimental.

Na Figura 8.4 são apresentados os diagramas tensão-deformação dos modelos $\operatorname{CoS} 50$ e CoS25 em conjunto com o diagrama tensão-deformação do concreto não- 
confinado. A tensão no concreto confinado foi calculada sobre a área do núcleo, retirando-se da carga total a contribuição das armaduras longitudinais e do cobrimento. Adotou-se a equação (7.9) para representar o cobrimento.

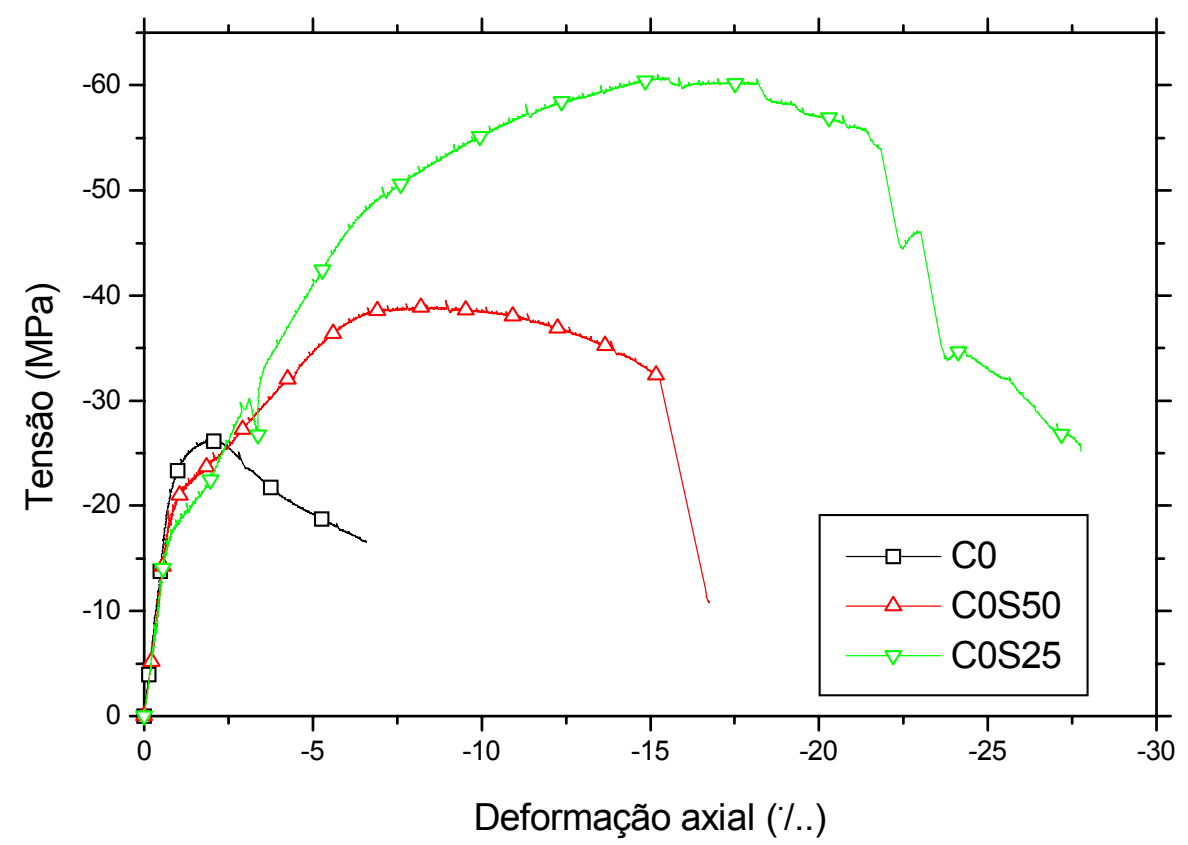

Figura 8.4 - Diagramas tensão-deformação dos modelos confinados com aço

Na Figura 8.5 são apresentados os diagramas tensão-deformação do modelo COS50 obtidos experimentalmente e as previsões dadas por alguns dos modelos teóricos.

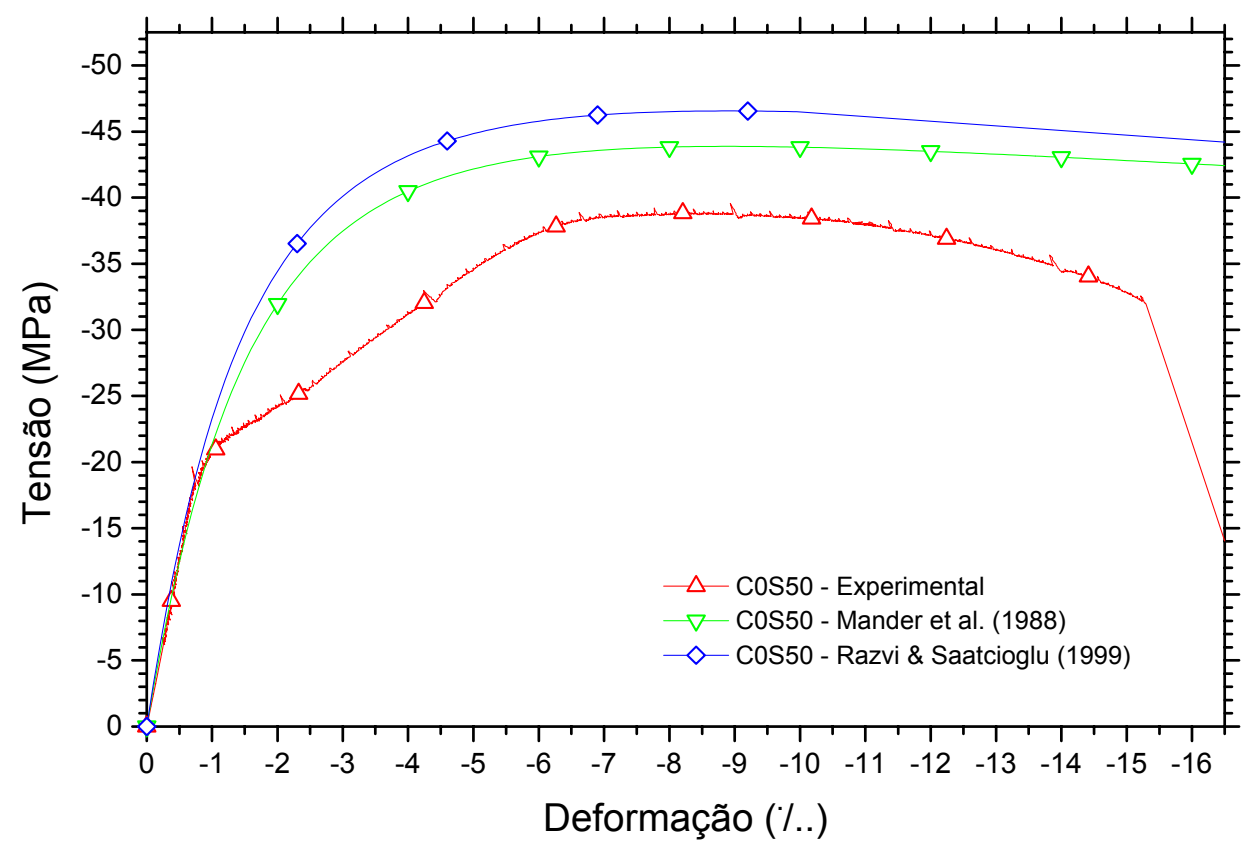

Figura 8.5 - Diagrama tensão-deformação pilar C0S50 - experimental x modelos teóricos 
Na Figura 8.6 são apresentados os diagramas tensão-deformação do modelo COS25 obtidos experimentalmente e por meio dos modelos teóricos.

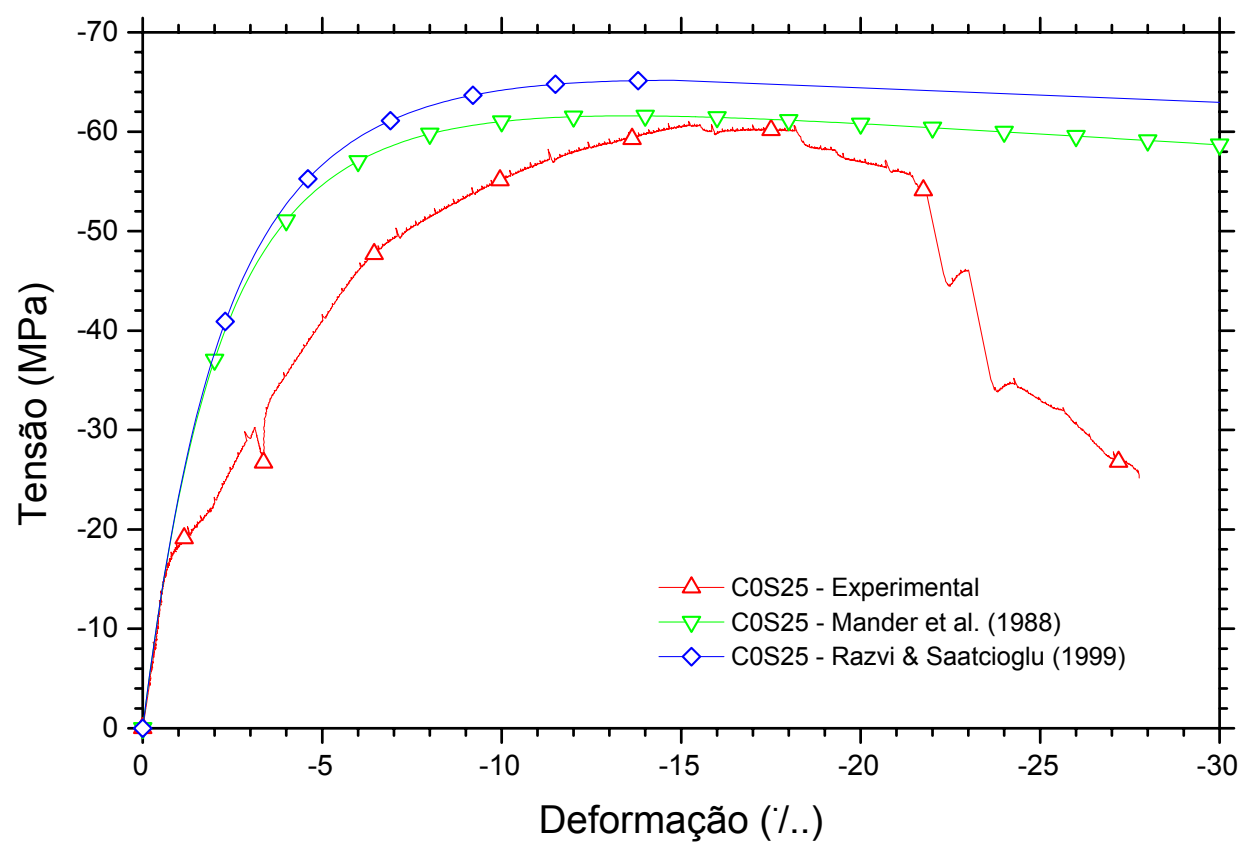

Figura 8.6 - Diagrama tensão deformação pilar C0S25 - experimental x modelos teóricos

\subsection{Concreto confinado com aço e PRFC}

Quatro pilares ensaiados possuíam armaduras transversais e camisa de reforço de PRFC. Na Tabela 8.8 são apresentados os resultados experimentais de capacidade resistente, deslocamento e deformação axial última dos modelos.

Tabela 8.8 - Resultados experimentais dos modelos

\begin{tabular}{|c|c|c|c|c|c|c|c|}
\hline Modelo & & $\begin{array}{l}\text { Espaçamento } \\
\text { entre espirais } \\
(\mathrm{mm})\end{array}$ & $\rho_{\mathrm{s}}(\%)$ & $\mathrm{f}_{\mathrm{co}}(\mathrm{MPa})$ & $\mathrm{F}_{\mathrm{u}}(\mathrm{kN})$ & $\delta_{\mathrm{u}}(\mathrm{mm})$ & $\begin{array}{c}\varepsilon_{\text {cc.exp }} \\
(\% 0)\end{array}$ \\
\hline & & & & & & & \\
\hline & & & & & & & \\
\hline C1S25 & & & & & 1691,5 & 9,3 & 16,4 \\
\hline $\mathrm{C} 2 \mathrm{~S} 25$ & & 25 & 2,03 & 28,86 & 2097,4 & 10,935 & 19,18 \\
\hline
\end{tabular}

$\mathrm{Na}$ Figura 8.7 são apresentadas novamente as duas regiões de comportamentos distintos. Na região 1 o concreto é confinado tanto pela camisa de reforço, quanto pela armadura transversal. Na região 2 o concreto é confinado apenas pela camisa de reforço. As simulações teóricas irão abordar este problema com 2 hipóteses. 


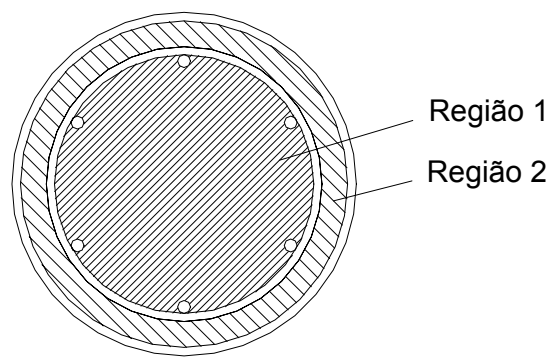

Figura 8.7 - Regiões 1 e 2

A $1^{a}$ hipótese é a sobreposição das pressões confinantes na região do núcleo. A pressão na região 1 é dada pela soma da pressão originária da camisa de reforço com a pressão desenvolvida pelas armaduras transversais. Utilizando-se a pressão resultante no núcleo calcula-se o ganho de resistência do concreto devido ao confinamento, estimando a capacidade resistente do núcleo. O concreto na região 2 é confinado apenas pela camisa de reforço. Somando-se as forças das regiões 1 e 2 com a força nas armaduras longitudinais obtém-se uma capacidade resistente teórica do pilar que é então comparada ao valor experimental.

A $2^{\text {a }}$ hipótese é o cálculo do ganho de resistência do concreto devido aos dois mecanismos confinantes em separado e a posterior sobreposição de efeitos. O concreto na região 1 tem uma resistência teórica de $\mathrm{f}_{\mathrm{co}}$ sem o efeito de confinamento. Com o efeito de confinamento da camisa de reforço este concreto experimenta um ganho de resistência $\mathrm{f}_{\mathrm{c} 1}$. Com o confinamento da armadura transversal soma-se um ganho de resistência $\mathrm{f}_{\mathrm{c} 2}$. Assim a resistência do concreto no núcleo será dada por:

$$
f_{c c}=f_{c o}+f_{c 1}+f_{c 2}
$$

$\mathrm{O}$ concreto da região 2 vai ter um ganho de resistência devido à camisa de reforço apenas, do mesmo modo que na primeira hipótese.

Outro fator considerado nas simulações teóricas é o efeito de perda de efetividade no confinamento devido ao espaçamento das armaduras. Serão adotadas duas hipóteses adicionais para o cálculo da pressão lateral do núcleo. A hipótese $a$ é a utilização da pressão lateral ideal, dada pela equações (4.11) e (4.12). A hipótese $b$ é a utilização do coeficiente de efetividade $\left(\mathrm{k}_{\mathrm{e}}\right)$ de MANDER et al. (1988-b).

Estas hipóteses foram testadas com os diversos modelos de confinamento e os resultados em termos de capacidade resistente comparados com os resultados experimentais. A Tabela 8.9 resume as hipóteses adotadas em um quadro explicativo. 
Tabela 8.9 - Hipóteses de cálculo nas simulações teóricas

\begin{tabular}{|c|c|c|c|}
\hline \multicolumn{2}{|c|}{ Hipótese 1 } & \multicolumn{2}{c|}{ Hipótese 2 } \\
\hline $\begin{array}{c}\text { Superposição das pressões laterais no } \\
\text { núcleo de concreto confinado (região 1) }\end{array}$ & \multicolumn{2}{c|}{$\begin{array}{c}\text { Superposição dos ganhos de resistência no } \\
\text { núcleo de concreto confinado (região 1) }\end{array}$} \\
\hline a & b & a & b \\
\hline $\begin{array}{c}\text { Pressão lateral } \\
\text { ideal }\end{array}$ & $\begin{array}{c}\text { Pressão lateral } \\
\text { efetiva }\end{array}$ & $\begin{array}{c}\text { Pressão lateral } \\
\text { ideal }\end{array}$ & $\begin{array}{c}\text { Pressão lateral } \\
\text { efetiva }\end{array}$ \\
\hline
\end{tabular}

\subsubsection{Pilar C1S50}

Na Tabela 8.10 são apresentados os dados do modelo, incluindo-se a pressão lateral ideal e a efetiva.

Tabela 8.10 - Pressões laterais - C1S50

\begin{tabular}{cccccc}
\hline \multirow{2}{*}{ C1S50 } & \multicolumn{4}{c}{ Pressões laterais (MPa) } \\
& \multicolumn{4}{c}{ Camisa de PRFC } & Espiral \\
\hline $\mathrm{f}_{\mathrm{co}}(\mathrm{MPa})$ & 26,16 & $\mathrm{f}_{\mathrm{l}}$ & 3,296 & Ideal: $\mathrm{f}_{\mathrm{l}}$ & 3,831 \\
$\varepsilon_{\mathrm{fu}}(\% \mathrm{\%})$ & 11,00 & & - & Efetiva: $\mathrm{f}_{\mathrm{le}}$ & 3,328 \\
\hline
\end{tabular}

$\mathrm{Na}$ Tabela 8.11 são apresentadas as previsões de resistência do concreto confinado segundo os diversos modelos teóricos para as pressões laterais desenvolvidas pela camisa de reforço, pelas armaduras transversais e pelo efeito sobreposto no núcleo. Pode-se observar que a resistência prevista por CUSSON \& PAULTRE (1995) foi próxima da prevista pelos modelos para confinamento com PRF de SAMAAN et al. (1998) e MIYAUCHI et al. (1997).

\section{Tabela 8.11 - Previsão da resistência do concreto confinado - C1S50}

\begin{tabular}{cccccc}
\hline \multicolumn{2}{c}{ Resistência do concreto confinado para as diferentes pressões (MPa) } \\
\hline & $\begin{array}{c}\text { Pressão da camisa } \\
\text { de PRFC }\end{array}$ & $\begin{array}{c}\text { Pressão da armadura } \\
\text { transversal no núcleo }\end{array}$ & \multicolumn{2}{c}{$\begin{array}{c}\text { Soma das pressões } \\
\text { no núcleo (região 1) }\end{array}$} \\
Modelo & $(3,296 \mathrm{MPa})$ & $\begin{array}{c}\text { Ideal } \\
(3,831 \mathrm{MPa})\end{array}$ & $\begin{array}{c}\text { Efetiva } \\
\text { (3,328 MPa) }\end{array}$ & $\begin{array}{c}\text { Ideal } \\
\text { (7,127 MPa) }\end{array}$ & $\begin{array}{c}\text { Efetiva } \\
(6,624 \mathrm{MPa})\end{array}$ \\
\hline Richart & 39,67 & 41,87 & 39,80 & 55,38 & 53,32 \\
Mander & 44,00 & 46,25 & 44,14 & 57,81 & 56,26 \\
Cusson & 39,05 & 40,48 & 39,13 & 48,27 & 47,16 \\
Razvi & 44,19 & 46,59 & 44,34 & 60,36 & 58,34 \\
Miyauchi & 37,65 & 39,51 & 37,76 & 51,00 & 49,24 \\
Samaan & 39,99 & 41,52 & 40,08 & 49,88 & 48,70 \\
Toutanji & 41,90 & 44,05 & 42,03 & 56,48 & 54,65 \\
\hline
\end{tabular}

$\mathrm{Na}$ Tabela 8.12 são apresentados os erros das previsões teóricas e a capacidade resistente do pilar C1S50, dentro das diversas hipóteses adotadas. 
Tabela 8.12 - Erro percentual das simulações teóricas - C1S50

\begin{tabular}{|c|c|c|c|c|c|c|}
\hline \multicolumn{7}{|c|}{ Erro percentual - C1S50 } \\
\hline \multicolumn{3}{|c|}{$F_{\text {u.exp }}=1481,5 \mathrm{kN}$} & \multicolumn{2}{|c|}{$\begin{array}{c}\text { Hipótese } \\
1\end{array}$} & \multicolumn{2}{|c|}{$\begin{array}{c}\text { Hipótese } \\
2\end{array}$} \\
\hline Combinação & Espiral & Camisa & a & b & a & b \\
\hline 1 & Richart & Richart & 6,09 & 3,51 & 6,09 & 3,50 \\
\hline 2 & Mander & Mander & 11,91 & 9,97 & 19,78 & 17,14 \\
\hline 3 & Cusson & Cusson & $-3,21$ & $-4,60$ & 3,18 & 1,49 \\
\hline 4 & Razvi & Razvi & 15,23 & 12,70 & 20,57 & 17,75 \\
\hline 5 & Richart & Miyauchi & 4,80 & 2,22 & 2,27 & $-0,32$ \\
\hline 6 & Richart & Samaan & 6,30 & 3,72 & 6,70 & 4,11 \\
\hline 7 & Richart & Toutanji & 7,52 & 4,94 & 10,32 & 7,72 \\
\hline 8 & Mander & Miyauchi & 7,85 & 5,90 & 7,76 & 5,11 \\
\hline 9 & Mander & Samaan & 9,34 & 7,40 & 12,19 & 9,55 \\
\hline 10 & Mander & Toutanji & 10,57 & 8,62 & 15,81 & 13,16 \\
\hline 11 & Cusson & Miyauchi & $-4,11$ & $-5,50$ & 0,53 & $-1,16$ \\
\hline 12 & Cusson & Samaan & $-2,61$ & $-4,00$ & 4,96 & 3,27 \\
\hline 13 & Cusson & Toutanji & $-1,39$ & $-2,78$ & 8,57 & 6,88 \\
\hline 14 & Razvi & Miyauchi & 11,04 & 8,51 & 8,19 & 5,37 \\
\hline 15 & Razvi & Samaan & 12,54 & 10,01 & 12,62 & 9,80 \\
\hline 16 & Razvi & Toutanji & 13,76 & 11,23 & 16,23 & 13,41 \\
\hline 17 & Miyauchi & Miyauchi & $-0,69$ & $-2,89$ & $-0,69$ & $-2,88$ \\
\hline 18 & Samaan & Samaan & $-0,59$ & $-2,07$ & 6,26 & 4,46 \\
\hline 19 & Toutanji & Toutanji & 8,90 & 6,61 & 13,05 & 10,52 \\
\hline
\end{tabular}

A utilização dos modelos de RAZVI \& SAATCIOGLU (1999-b) e MANDER et al. (1988-b) no núcleo e na camisa deram os maiores erros contra a segurança na previsão da capacidade resistente. O modelo de CUSSON \& PAULTRE (1995) deu resultados a favor da segurança. A combinação dos modelos de confinamento para aço no núcleo com modelos de PRFC para a camisa reduziu os valores das previsões, porém elas ficaram acima do valor experimental. A previsão mais conservadora foi com a combinação de CUSSON \& PAULTRE (1995) no núcleo e MIYAUCHI et al. (1997) na camisa.

\subsubsection{Pilar C2S50}

$\mathrm{Na}$ Tabela 8.13 são apresentadas as pressões laterais do Pilar C2S50.

Tabela 8.13 - Pressões laterais - C2S50

\begin{tabular}{cccccc}
\hline \multirow{2}{*}{ C2S50 } & \multicolumn{4}{c}{ Pressões laterais (MPa) } \\
& \multicolumn{4}{c}{ Camisa de PRFC } & Espiral \\
\hline $\mathrm{f}_{\text {co }}(\mathrm{MPa})$ & 26,16 & $\mathrm{f}_{1}$ & 5,261 & Ideal: $\mathrm{f}_{\mathrm{l}}$ & 3,831 \\
$\varepsilon_{\mathrm{fu}}(\% \mathrm{o})$ & 8,78 & & - & Efetiva: $\mathrm{f}_{\mathrm{le}}$ & 3,328 \\
\hline
\end{tabular}


Na Tabela 8.14 são apresentadas as previsões de resistência do concreto confinado segundo os diversos modelos teóricos.

Tabela 8.14 - Previsão da resistência do concreto confinado - C2S50

\begin{tabular}{|c|c|c|c|c|c|}
\hline \multicolumn{6}{|c|}{ Resistência do concreto confinado (MPa) } \\
\hline \multirow[b]{2}{*}{ Modelo } & \multirow{2}{*}{$\begin{array}{c}\text { Pressão da camisa } \\
\text { de PRFC } \\
(5,261 \mathrm{MPa})\end{array}$} & \multicolumn{2}{|c|}{$\begin{array}{l}\text { Pressão da armadura } \\
\text { transversal no núcleo }\end{array}$} & \multicolumn{2}{|c|}{$\begin{array}{c}\text { Soma das pressões } \\
\text { no núcleo (região 1) }\end{array}$} \\
\hline & & $\begin{array}{c}\text { Ideal } \\
(3,831 \mathrm{MPa})\end{array}$ & $\begin{array}{c}\text { Efetiva } \\
(3,328 \mathrm{MPa})\end{array}$ & $\begin{array}{c}\text { Ideal } \\
(9,092 \mathrm{MPa})\end{array}$ & $\begin{array}{c}\text { Efetiva } \\
(8,589 \mathrm{MPa})\end{array}$ \\
\hline Richart & 47,73 & 41,87 & 39,80 & 63,44 & 61,37 \\
\hline Mander & 51,69 & 46,25 & 44,14 & 63,34 & 62,00 \\
\hline Cusson & 44,04 & 40,48 & 39,13 & 52,38 & 51,35 \\
\hline Razvi & 52,74 & 46,59 & 44,34 & 68,02 & 66,09 \\
\hline Miyauchi & 44,49 & 39,51 & 37,76 & 57,85 & 56,09 \\
\hline Samaan & 45,34 & 41,52 & 40,08 & 54,29 & 53,19 \\
\hline Toutanji & 49,58 & 44,05 & 42,03 & 63,45 & 61,69 \\
\hline
\end{tabular}

Na Tabela 8.15 são apresentados os erros percentuais das previsões teóricas.

Tabela 8.15 - Erro percentual das simulações teóricas - C2S50

\begin{tabular}{|c|c|c|c|c|c|c|}
\hline \multicolumn{7}{|c|}{ Erro percentual - C2S50 } \\
\hline \multicolumn{3}{|c|}{$F_{\text {u.exp }}=1854,7 \mathrm{kN}$} & \multicolumn{2}{|c|}{$\begin{array}{c}\text { Hipótese } \\
1\end{array}$} & \multicolumn{2}{|c|}{$\begin{array}{c}\text { Hipótese } \\
2\end{array}$} \\
\hline Combinação & Espiral & Camisa & $\mathbf{a}$ & b & $\mathbf{a}$ & b \\
\hline 1 & Richart & Richart & $-3,06$ & $-5,14$ & $-3,06$ & $-5,14$ \\
\hline 2 & Mander & Mander & $-1,14$ & $-2,48$ & 7,31 & 5,20 \\
\hline 3 & Cusson & Cusson & $-16,02$ & $-17,05$ & $-10,04$ & $-11,39$ \\
\hline 4 & Razvi & Razvi & 4,08 & 2,15 & 9,24 & 6,99 \\
\hline 5 & Richart & Miyauchi & $-4,72$ & $-6,79$ & $-7,96$ & $-10,04$ \\
\hline 6 & Richart & Samaan & $-4,29$ & $-6,36$ & $-6,68$ & $-8,75$ \\
\hline 7 & Richart & Toutanji & $-2,12$ & $-4,19$ & $-0,27$ & $-2,34$ \\
\hline 8 & Mander & Miyauchi & $-4,82$ & $-6,16$ & $-3,58$ & $-5,69$ \\
\hline 9 & Mander & Samaan & $-4,39$ & $-5,73$ & $-2,29$ & $-4,41$ \\
\hline 10 & Mander & Toutanji & $-2,22$ & $-3,56$ & 4,12 & 2,01 \\
\hline 11 & Cusson & Miyauchi & $-15,79$ & $-16,82$ & $-9,36$ & $-10,71$ \\
\hline 12 & Cusson & Samaan & $-15,36$ & $-16,39$ & $-8,07$ & $-9,42$ \\
\hline 13 & Cusson & Toutanji & $-13,19$ & $-14,22$ & $-1,66$ & $-3,01$ \\
\hline 14 & Razvi & Miyauchi & $-0,13$ & $-2,07$ & $-3,24$ & $-5,49$ \\
\hline 15 & Razvi & Samaan & 0,30 & $-1,63$ & $-1,95$ & $-4,21$ \\
\hline 16 & Razvi & Toutanji & 2,47 & 0,54 & 4,46 & 2,21 \\
\hline 17 & Miyauchi & Miyauchi & $-10,32$ & $-12,08$ & $-10,33$ & $-12,08$ \\
\hline 18 & Samaan & Samaan & $-13,45$ & $-14,55$ & $-7,03$ & $-8,47$ \\
\hline 19 & Toutanji & Toutanji & $-2,11$ & $-3,87$ & 1,92 & $-0,11$ \\
\hline
\end{tabular}

Acredita-se que a deformação de ruptura das fibras obtida no ensaio possa estar abaixo da real. Com isto a pressão lateral desenvolvida pela camisa de reforço 
foi subestimada, fazendo com que as previsões dos modelos teóricos indicassem menores ganhos de resistência.

No entanto observou-se que o comportamento relativo das previsões foi semelhante. Os modelos de confinamento com aço deram as maiores previsões e os de PRF e de CUSSON \& PAULTRE (1995) as menores.

\subsubsection{Pilar C1S25}

Na Tabela 8.16 são apresentadas as pressões laterais do Pilar C1S25.

Tabela 8.16 - Pressões laterais - C1S25

\begin{tabular}{cccccc}
\hline \multirow{2}{*}{ C1S25 } & \multicolumn{4}{c}{ Pressões laterais (MPa) } \\
& \multicolumn{4}{c}{ Camisa de PRFC } & Espiral \\
\hline $\mathrm{f}_{\mathrm{co}}(\mathrm{MPa})$ & 28,86 & $\mathrm{f}_{1}$ & 3,185 & Ideal: $\mathrm{f}_{1}$ & 7,661 \\
$\varepsilon_{\mathrm{fu}}(\% \mathrm{\%})$ & 10,63 & & - & Efetiva: $\mathrm{f}_{\mathrm{le}}$ & 7,284 \\
\hline
\end{tabular}

$\mathrm{Na}$ Tabela 8.17 são apresentadas as previsões de resistência do concreto confinado segundo os diversos modelos teóricos. Na Tabela 8.18 são apresentados os erros percentuais das previsões teóricas.

Tabela 8.17 - Previsão da resistência do concreto confinado - C1S25

\begin{tabular}{|c|c|c|c|c|c|}
\hline \multicolumn{6}{|c|}{ Resistência do concreto confinado (MPa) } \\
\hline \multirow[b]{2}{*}{ Modelo } & \multirow{2}{*}{$\begin{array}{c}\text { Pressão da camisa } \\
\text { de PRFC } \\
(3,185 \mathrm{MPa})\end{array}$} & \multicolumn{2}{|c|}{$\begin{array}{l}\text { Pressão da armadura } \\
\text { transversal no núcleo }\end{array}$} & \multicolumn{2}{|c|}{$\begin{array}{c}\text { Soma das pressões } \\
\text { no núcleo (região 1) }\end{array}$} \\
\hline & & $\begin{array}{c}\text { Ideal } \\
(7,661 \mathrm{MPa})\end{array}$ & $\begin{array}{c}\text { Efetiva } \\
(7,284 \mathrm{MPa})\end{array}$ & $\begin{array}{c}\text { Ideal } \\
(10,846 \mathrm{MPa})\end{array}$ & $\begin{array}{c}\text { Efetiva } \\
(10,469 \mathrm{MPa})\end{array}$ \\
\hline Richart & 41,92 & 60,27 & 58,72 & 73,33 & 71,78 \\
\hline Mander & 46,54 & 63,16 & 61,99 & 71,96 & 70,01 \\
\hline Cusson & 41,82 & 52,81 & 51,98 & 59,41 & 58,66 \\
\hline Razvi & 46,38 & 65,17 & 63,68 & 77,32 & 75,91 \\
\hline Myiauchi & 39,96 & 55,56 & 54,24 & 66,66 & 65,34 \\
\hline Samaan & 42,36 & 53,81 & 52,95 & 60,69 & 59,91 \\
\hline Toutanji & 44,38 & 61,58 & 60,20 & 72,82 & 71,52 \\
\hline
\end{tabular}


Tabela 8.18 - Erro percentual das simulações teóricas - C1S25

\begin{tabular}{|c|c|c|c|c|c|c|}
\hline \multicolumn{7}{|c|}{ Erro percentual - C1S25 } \\
\hline \multicolumn{3}{|c|}{$F_{u . e x p}=1691,5 \mathrm{kN}$} & \multicolumn{2}{|c|}{$\begin{array}{c}\text { Hipótese } \\
1\end{array}$} & \multicolumn{2}{|c|}{$\begin{array}{l}\text { Hipótese } \\
2\end{array}$} \\
\hline Combinação & Espiral & Camisa & a & b & a & b \\
\hline 1 & Richart & Richart & 13,89 & 12,19 & 13,89 & 12,19 \\
\hline 2 & Mander & Mander & 14,97 & 12,83 & 24,72 & 23,44 \\
\hline 3 & Cusson & Cusson & $-1,45$ & $-2,27$ & 5,53 & 4,62 \\
\hline 4 & Razvi & Razvi & 20,77 & 19,22 & 26,66 & 25,03 \\
\hline 5 & Richart & Miyauchi & 12,79 & 11,09 & 10,64 & 8,94 \\
\hline 6 & Richart & Samaan & 14,13 & 12,43 & 14,62 & 12,92 \\
\hline 7 & Richart & Toutanji & 15,27 & 13,57 & 17,97 & 16,27 \\
\hline 8 & Mander & Miyauchi & 11,29 & 9,14 & 13,81 & 12,53 \\
\hline 9 & Mander & Samaan & 12,63 & 10,49 & 17,79 & 16,51 \\
\hline 10 & Mander & Toutanji & 13,76 & 11,62 & 21,14 & 19,86 \\
\hline 11 & Cusson & Miyauchi & $-2,49$ & $-3,31$ & 2,45 & 1,54 \\
\hline 12 & Cusson & Samaan & $-1,15$ & $-1,97$ & 6,43 & 5,52 \\
\hline 13 & Cusson & Toutanji & $-0,01$ & $-0,84$ & 9,78 & 8,87 \\
\hline 14 & Razvi & Miyauchi & 17,17 & 15,62 & 16,02 & 14,38 \\
\hline 15 & Razvi & Samaan & 18,51 & 16,97 & 20,00 & 18,36 \\
\hline 16 & Razvi & Toutanji & 19,65 & 18,10 & 23,35 & 21,71 \\
\hline 17 & Miyauchi & Miyauchi & 5,47 & 4,02 & 5,47 & 4,02 \\
\hline 18 & Samaan & Samaan & 0,26 & $-0,60$ & 7,53 & 6,58 \\
\hline 19 & Toutanji & Toutanji & 14,71 & 13,28 & 19,41 & 17,89 \\
\hline
\end{tabular}

As previsões de RAZVI \& SAATCIOGLU (1999-b) foram as de maior erro contra a segurança. Os modelos de RICHART et al. (1929) e MANDER et al. (1988b) também deram previsões acima dos valores experimentais. O modelo de CUSSON \& PAULTRE (1995) obteve resultados próximos aos experimentais e aos de SAMAAN et al. (1998). Os modelos de MYIAUCHI et al. (1997) e TOUTANJI (1999) ficaram contra a segurança.

\subsubsection{Pilar C2S25}

Na Tabela 8.19 são apresentadas as pressões laterais do Pilar C2S25.

Tabela 8.19 - Pressões laterais - C2S25

\begin{tabular}{cccccc}
\hline \multirow{2}{*}{ C2S25 } & \multicolumn{4}{c}{ Pressões laterais (MPa) } \\
& \multicolumn{4}{c}{ Camisa de PRFC } & Espiral \\
\hline $\mathrm{f}_{\text {co }}(\mathrm{MPa})$ & 28,86 & $\mathrm{f}_{1}$ & 6,382 & Ideal: $\mathrm{f}_{1}$ & 7,661 \\
$\varepsilon_{\mathrm{fu}}(\% \mathrm{o})$ & 10,65 & & - & Efetiva: $\mathrm{f}_{\mathrm{le}}$ & 7,284 \\
\hline
\end{tabular}


$\mathrm{Na}$ Tabela 8.20 são apresentadas as previsões de resistência do concreto confinado segundo os diversos modelos teóricos. Na Tabela 8.21 são apresentados os erros percentuais das previsões teóricas.

Tabela 8.20 - Previsão da resistência do concreto confinado - C2S25

\begin{tabular}{|c|c|c|c|c|c|}
\hline \multicolumn{6}{|c|}{ Resistência do concreto confinado (MPa) } \\
\hline \multirow[b]{2}{*}{ Modelo } & \multirow{2}{*}{$\begin{array}{c}\text { Pressão da camisa } \\
\text { de PRFC } \\
(6,382 \mathrm{MPa})\end{array}$} & \multicolumn{2}{|c|}{$\begin{array}{l}\text { Pressão da armadura } \\
\text { transversal no núcleo }\end{array}$} & \multicolumn{2}{|c|}{$\begin{array}{c}\text { Soma das pressões } \\
\text { no núcleo (região 1) }\end{array}$} \\
\hline & & $\begin{array}{c}\text { Ideal } \\
(7,661 \mathrm{MPa})\end{array}$ & $\begin{array}{c}\text { Efetiva } \\
(7,284 \mathrm{MPa})\end{array}$ & $\begin{array}{c}\text { Ideal } \\
(14,043 \mathrm{MPa})\end{array}$ & $\begin{array}{c}\text { Efetiva } \\
(13,666 \mathrm{MPa})\end{array}$ \\
\hline Richart & 55,03 & 60,27 & 58,72 & 86,44 & 84,87 \\
\hline Mander & 59,03 & 63,16 & 61,99 & 79,18 & 78,39 \\
\hline Cusson & 49,94 & 52,81 & 51,98 & 65,46 & 64,76 \\
\hline Razvi & 60,06 & 65,17 & 63,68 & 88,90 & 87,54 \\
\hline Myiauchi & 51,10 & 55,56 & 54,24 & 77,80 & 76,47 \\
\hline Samaan & 50,82 & 53,81 & 52,95 & 67,00 & 66,27 \\
\hline Toutanji & 56,87 & 61,58 & 60,20 & 83,62 & 82,35 \\
\hline
\end{tabular}

Tabela 8.21 - Erro percentual das simulações teóricas - C2S25

\begin{tabular}{ccccccc}
\hline \multicolumn{9}{c}{ Erro percentual - C2S25 } & \multicolumn{3}{c}{ Hipótese } & \multicolumn{2}{c}{ Hipótese } \\
\hline \multicolumn{2}{c}{$\mathbf{F}_{\text {u.exp }}=\mathbf{2 0 9 7 , 4} \mathbf{~ k N}$} & $\mathbf{1}$ & $\mathbf{2}$ \\
Combinação & Espiral & Camisa & $\mathbf{A}$ & $\mathbf{b}$ & $\mathbf{a}$ & $\mathbf{b}$ \\
\hline 1 & Richart & Richart & 9,38 & 7,99 & 9,38 & 8,01 \\
2 & Mander & Mander & 4,76 & 4,06 & 17,29 & 16,25 \\
3 & Cusson & Cusson & $-11,49$ & $-12,11$ & $-4,03$ & $-4,76$ \\
4 & Razvi & Razvi & 13,83 & 12,63 & 20,45 & 19,13 \\
5 & Richart & Miyauchi & 7,60 & 6,21 & 4,13 & 2,75 \\
6 & Richart & Samaan & 7,48 & 6,09 & 3,75 & 2,38 \\
7 & Richart & Toutanji & 10,21 & 8,82 & 11,84 & 10,47 \\
8 & Mander & Miyauchi & 1,18 & 0,48 & 6,68 & 5,65 \\
9 & Mander & Samaan & 1,05 & 0,35 & 6,31 & 5,27 \\
10 & Mander & Toutanji & 3,79 & 3,09 & 14,40 & 13,37 \\
11 & Cusson & Miyauchi & $-10,97$ & $-11,59$ & $-2,48$ & $-3,21$ \\
12 & Cusson & Samaan & $-11,09$ & $-11,71$ & $-2,85$ & $-3,59$ \\
13 & Cusson & Toutanji & $-8,36$ & $-8,98$ & 5,24 & 4,50 \\
14 & Razvi & Miyauchi & 9,78 & 8,58 & 8,46 & 7,14 \\
15 & Razvi & Samaan & 9,66 & 8,45 & 8,09 & 6,77 \\
16 & Razvi & Toutanji & 12,39 & 11,19 & 16,18 & 14,86 \\
17 & Miyauchi & Miyauchi & $-0,04$ & $-1,22$ & $-0,04$ & $-1,21$ \\
18 & Samaan & Samaan & $-9,73$ & $-10,38$ & $-1,97$ & $-2,73$ \\
19 & Toutanji & Toutanji & 7,72 & 6,59 & 13,00 & 11,78 \\
\hline
\end{tabular}

As previsões utilizando o modelo de CUSSON \& PAULTRE (1995) foram conservadoras. Os demais modelos para confinamento com aço mostraram-se contra a segurança. O erro cometido por MANDER et al. (1988-b) no entanto reduziu-se 
neste pilar, devido ao aumento da pressão lateral em relação aos casos anteriores. $O$ modelo de MYIAUCHI et al. (1997) foi bem próximo ao resultado experimental. O de SAMAAN et al. (1998) foi mais conservador. TOUTANJI (1999) novamente superestimou a resistência nas previsões.

\subsubsection{Observações gerais sobre as previsões}

Os modelos teóricos desenvolvidos para confinamento com aço resultaram nos maiores erros contra a segurança. O modelo de CUSSON \& PAULTRE (1995) é uma exceção entre estes modelos, já que sua envoltória parece assemelhar-se à dos modelos de confinamento com PRFC, que ficaram mais próximos dos resultados experimentais.

Utilizando-se modelos de confinamento com aço na previsão do confinamento das armaduras transversais combinados com modelos para PRFC no confinamento da camisa de reforço, os resultados foram mais próximos dos experimentais, porém ainda contra a segurança. A utilização de modelos para PRFC em ambos sistemas de confinamento resultou nas melhores previsões, com um pequeno erro a favor da segurança, com exceção do modelo de TOUTANJI (1999), que como será mostrado adiante superestimou as previsões.

As previsões de uma maneira geral deram bons resultados. Na Tabela 8.22 são apresentadas as médias das previsões para cada modelo ensaiado e a geral.

Tabela 8.22 - Previsões teóricas $x$ experimental

\begin{tabular}{ccc}
\hline $\mathrm{F}_{\mathrm{u}} / \mathrm{F}_{\mathrm{u} . \exp }$ & Média & Desvio-padrão \\
\hline Geral & 1,044 & 0,093 \\
\hline C1S50 & 1,064 & 0,062 \\
$\mathrm{C} 2 \mathrm{~S} 50$ & 0,951 & 0,061 \\
$\mathrm{C} 1 \mathrm{~S} 25$ & 1,118 & 0,075 \\
$\mathrm{C} 2 \mathrm{~S} 25$ & 1,042 & 0,081 \\
\hline
\end{tabular}

Na Tabela 8.23 é apresentada a média das previsões dos 4 pilares ensaiados. São comparadas as previsões dos modelos para PRFC, para aço e suas combinações. Pode-se observar que a utilização dos modelos para PRFC resultou em uma média mais próxima das resultados experimentais e com menor desvio-padrão. 
Tabela 8.23 - Previsões teóricas x experimental - média dos modelos teóricos

\begin{tabular}{|c|c|c|c|}
\hline \multicolumn{2}{|c|}{$\mathrm{F}_{\mathrm{u}} / \mathrm{F}_{\mathrm{u} . \exp }$} & \multirow[b]{2}{*}{ Média } & \multirow[b]{2}{*}{ Desvio-padrão } \\
\hline $\begin{array}{l}\text { Modelo da } \\
\text { espiral }\end{array}$ & $\begin{array}{l}\text { Modelo da } \\
\text { camisa }\end{array}$ & & \\
\hline Aço & Aço & 1,069 & 0,106 \\
\hline Aço & PRFC & 1,044 & 0,088 \\
\hline PRFC & PRFC & 1,012 & 0,085 \\
\hline
\end{tabular}

Quanto às hipóteses de cálculo adotadas pode-se dizer de uma maneira geral que as previsões obtidas com a hipótese 1-b (sobreposição de pressões - pressão efetiva da armadura transversal) foram as mais próximas dos resultados experimentais. $\mathrm{Na}$ Tabela 8.24 é apresentada a média das previsões de todos os modelos para as diversas hipóteses de cálculo.

Tabela 8.24 - Previsões teóricas x experimental

\begin{tabular}{ccc}
\hline $\mathrm{F}_{\mathrm{u}} / \mathrm{F}_{\mathrm{u} \cdot \exp }$ & Média & Desvio-padrão \\
\hline $1-\mathrm{a}$ & 1,033 & 0,093 \\
$1-\mathrm{b}$ & 1,018 & 0,091 \\
$2-\mathrm{a}$ & 1,071 & 0,090 \\
$2-\mathrm{b}$ & 1,054 & 0,090 \\
\hline
\end{tabular}

Realizou-se uma comparação entre as previsões de cada modelo analítico para os 4 pilares adotando-se a hipótese 1-b (soma de pressões no núcleo e pressão lateral efetiva). Em média os resultados foram muito bons. O maior erro contra a segurança foi obtido com o modelo de RAZVI \& SAATCIOGLU (1999-b). O modelo de CUSSON \& PAULTRE (1995) deu as previsões mais conservadoras.

O modelo de MYIAUCHI et al. (1997) foi o mais próximo dos resultados experimentais e um dos que apresentou menor variabilidade de resultados. $\mathrm{O}$ de SAMAAN et al. (1998) deu resultados conservadores. Entre os modelos de confinamento para PRFC o de TOUTANJI (1999) deu as maiores previsões de resistência. 
Tabela 8.25 - Previsões teóricas dos modelos teóricos

\begin{tabular}{ccccc}
\hline \multicolumn{5}{c}{$\mathrm{F}_{\mathrm{u}} / \mathrm{F}_{\text {u.exp }}$ (hipótese 1-b) } \\
Combinação & Espiral & Camisa & Média & Desvio padrão \\
\hline 1 & Richart & Richart & 1,046 & 0,074 \\
2 & Mander & Mander & 1,061 & 0,068 \\
3 & Cusson & Cusson & 0,910 & 0,068 \\
4 & Razvi & Razvi & 1,117 & 0,071 \\
5 & Richart & Miyauchi & 1,032 & 0,076 \\
6 & Richart & Samaan & 1,040 & 0,078 \\
7 & Richart & Toutanji & 1,058 & 0,075 \\
8 & Mander & Miyauchi & 1,023 & 0,067 \\
9 & Mander & Samaan & 1,031 & 0,073 \\
10 & Mander & Toutanji & 1,049 & 0,067 \\
11 & Cusson & Miyauchi & 0,907 & 0,061 \\
12 & Cusson & Samaan & 0,915 & 0,067 \\
13 & Cusson & Toutanji & 0,933 & 0,061 \\
14 & Razvi & Miyauchi & 1,077 & 0,073 \\
15 & Razvi & Samaan & 1,085 & 0,077 \\
16 & Razvi & Toutanji & 1,103 & 0,073 \\
17 & Miyauchi & Miyauchi & 0,970 & 0,067 \\
18 & Samaan & Samaan & 0,931 & 0,067 \\
19 & Toutanji & Toutanji & 1,057 & 0,071 \\
\hline \multicolumn{5}{c}{}
\end{tabular}

A razão da variabilidade dos resultados entre os diferentes tipos de confinamento está associada às diferenças nas envoltórias dos modelos de confinamento. Na Figura 8.8 são apresentadas as envoltórias de alguns modelos teóricos para confinamento com aço e para PRFC.

Existem alguns motivos para as diferenças entre as envoltórias apresentadas. Uma é a diferença nos materiais utilizados, que acabam respondendo de maneira diferente em estados de compressão triaxial.

Outro problema é o cálculo da pressão lateral. Em alguns modelos teóricos desenvolvidos para aço a pressão lateral leva em conta o efeito do espaçamento da armadura através de coeficientes de efetividade ou procedimentos similares. Outros autores consideram para espirais $\mathrm{k}_{\mathrm{e}}=1$, indicando que não há perda de efetividade.

Nos modelos desenvolvidos para PRFC o problema é a utilização da deformação de ruptura correta para as fibras. Observou-se na literatura e nos ensaios aqui realizados uma certa variabilidade na deformação de ruptura da camisa. Os valores de deformação de ruptura registrados nos ensaios de compressão de pilares encamisados são inferiores aos especificados pelo fabricante e mesmo aos obtidos nos ensaios de tração. 
Alguns modelos teóricos não fazem referência à deformação de ruptura das fibras no ensaio. Logo algumas envoltórias são baseadas em pressões laterais teóricas muito maiores que as ocorridas no ensaio. Com isto as envoltórias acabam resultando em ganhos de resistência baixos para determinados níveis de pressão lateral.

$\mathrm{Na}$ Figura 8.8 são apresentadas envoltórias dos modelos teóricos utilizados nas simulações teóricas. Pode-se observar que para maiores pressões laterais o modelo de CUSSON \& PAULTRE (1995) é o mais conservador. A envoltória de SAMAAN et al. (1998) é próxima a de CUSSON \& PAULTRE (1995).

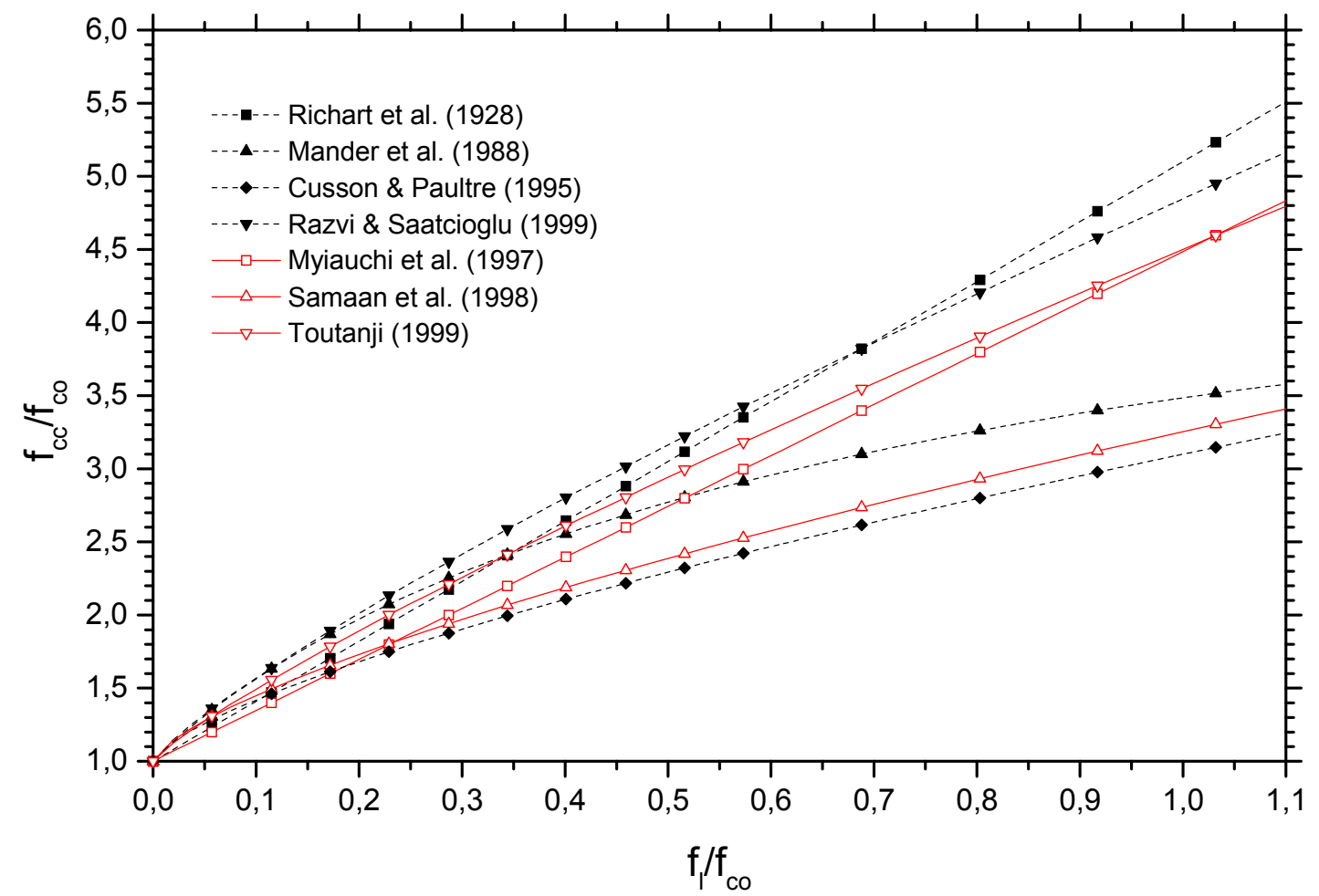

Figura 8.8 - Envoltórias de resistência do concreto confinado $\left(f_{c o}=26,16 \mathrm{MPa}\right)$

\subsection{Pilares de seção transversal quadrada}

Foram ensaiados três pilares de seção transversal quadrada com 0,1 e 2 camadas de PRFC. Observou-se deformações maiores no centro das faces dos modelos em comparação com os cantos. A leitura máxima registrada nos extensômetros dos cantos foi da ordem de 8,9 \%o. Este comportamento difere do observado na literatura. Em alguns ensaios relatou-se a ruptura das fibras nos cantos dos modelos.

Apenas em um dos modelos foi possível registrar as deformações da camisa de reforço até a ruptura. Estas deformações infelizmente não foram aproveitadas para o 
cálculo da capacidade resistente. Um dos extensômetros estava em uma região de ruptura localizada das fibras e realizou sua última leitura a 10,8\%, sendo que o ensaio ainda teve continuidade. Neste instante o outro extensômetro indicava 11,7 \%. Este seguiu registrando as deformações até atingir a limite de leitura 15\%. Verificou-se então que o extensômetro estava com problemas de fixação.

No procedimento de análise dos resultados destes modelos optou-se por adotar as deformações de ruptura da camisa de reforço dos modelos circulares $\mathrm{C} 1$ e C2 para os modelos Q1 e Q2, respectivamente.

Supondo-se que a pressão lateral seja uniforme ao longo do perímetro do pilar (como em pilares circulares) pode-se calcular uma pressão idealizada por meio de:

$$
f_{l i}=\frac{2 \cdot t}{b} \cdot \varepsilon_{f u} \cdot E_{f}
$$

onde b é a largura do pilar.

Entretanto observou-se que a pressão não é uniforme ao longo do perímetro do pilar. Estimou-se então uma pressão lateral efetiva através da expressão (8.4), baseada no modelo de RICHART et al. $(1929)^{10}$.

$$
f_{l e}=\frac{f_{c c}-f_{c o}}{4,1}
$$

A Tabela 8.26 apresenta os resultados obtidos, as pressões adotadas dos pilares circulares $\left(f_{l}\right)$ e as pressões $f_{\text {le }}$ calculadas com a expressão (8.4). Apresenta-se também um coeficiente de efetividade $\mathrm{k}_{\mathrm{e}}$ dado por:

$$
k_{e}=\frac{f_{l e}}{f_{l i}}
$$

Tabela 8.26 - Resultados experimentais

\begin{tabular}{cccccccccc}
\hline Modelo & $\mathrm{n}$ & $\mathrm{F}_{\mathrm{u}}(\mathrm{kN})$ & $\delta_{\mathrm{u}}$ & $\begin{array}{c}\varepsilon_{\mathrm{fu}} \\
\left(10^{-3}\right)\end{array}$ & $\begin{array}{c}\mathrm{f}_{\mathrm{l}} \\
(\mathrm{MPa})\end{array}$ & $\begin{array}{c}\mathrm{f}_{\mathrm{le}} \\
(\mathrm{MPa})\end{array}$ & $\mathrm{k}_{\mathrm{e}}$ & $\mathrm{f}_{\mathrm{cc}}(\mathrm{MPa})$ & $\varepsilon_{\mathrm{cc}}(\% \mathrm{o})$ \\
\hline Q0 & 0 & 512,08 & 0,840 & - & - & - & - & 23,57 & 1,867 \\
Q1 & 1 & 770,59 & 3,724 & 11,92 & 4,545 & 2,902 & 0,639 & 35,47 & 8,275 \\
Q2 & 2 & 1009,32 & 6,953 & 11,92 & 9,091 & 5,580 & 0,614 & 46,45 & 15,453 \\
\hline
\end{tabular}

Nota-se assim que a pressão lateral efetivamente desenvolvida em pilares de seção transversal quadrada é menor que aquela idealizada para pilares de seção circular, como se podia esperar.

O mesmo procedimento para o cálculo das pressões laterais foi utilizado para comparação com os resultados obtidos por SHEHATA et al. (2001). Os modelos de 
seção transversal quadrada ensaiados por SHEHATA et al. (2001) possuíam lados de $15 \mathrm{~cm}$ e os cantos arredondados com um raio de $1 \mathrm{~cm}$. A tabela 5 resume os resultados obtidos e as comparações.

Tabela 5 - Pilares de seção transversal quadrada, SHEHATA et al (2001)

\begin{tabular}{ccccccc}
\hline Nomenclatura & $\begin{array}{c}\mathrm{f}_{\mathrm{co}} \\
(\mathrm{MPa})\end{array}$ & $\mathrm{n}$ & $\begin{array}{c}\mathrm{f}_{\mathrm{cc}} \\
(\mathrm{MPa})\end{array}$ & $\begin{array}{c}\mathrm{f}_{\mathrm{li}} \\
(\mathrm{MPa})\end{array}$ & $\begin{array}{c}\mathrm{f}_{\mathrm{le}} \\
(\mathrm{MPa})\end{array}$ & $\mathrm{k}_{\mathrm{e}}$ \\
\hline \multirow{2}{*}{$\mathrm{S} 1-25$} & 23,7 & 1 & 27,4 & 7,81 & 0,90 & 0,12 \\
& & 2 & 36,5 & 15,62 & 3,12 & 0,20 \\
$\mathrm{~S} 2-30$ & 29,5 & 1 & 40,4 & 7,81 & 2,66 & 0,34 \\
& 2 & 43,7 & 15,62 & 3,46 & 0,22 \\
\hline
\end{tabular}

SHEHATA et al. (2001) relata que a ruptura das camisas dos pilares de seção quadrada ocorreu nos cantos, devido a concentração de tensões nestes pontos. $\mathrm{O}$ menor raio de curvatura adotado $(1 \mathrm{~cm})$ talvez explique esta forma de ruptura e os menores coeficientes de efetividade obtidos.

O diagrama tensão-deformação dos modelos de seção transversal quadrada apresentou algumas diferenças em relação aos modelos de seção circular. Uma das diferenças foi a maior não linearidade no segundo trecho, suposto linear para pilares de seção circular. Outra diferença foi uma zona de transição mais acentuada em relação à observada nos pilares de seção circular.

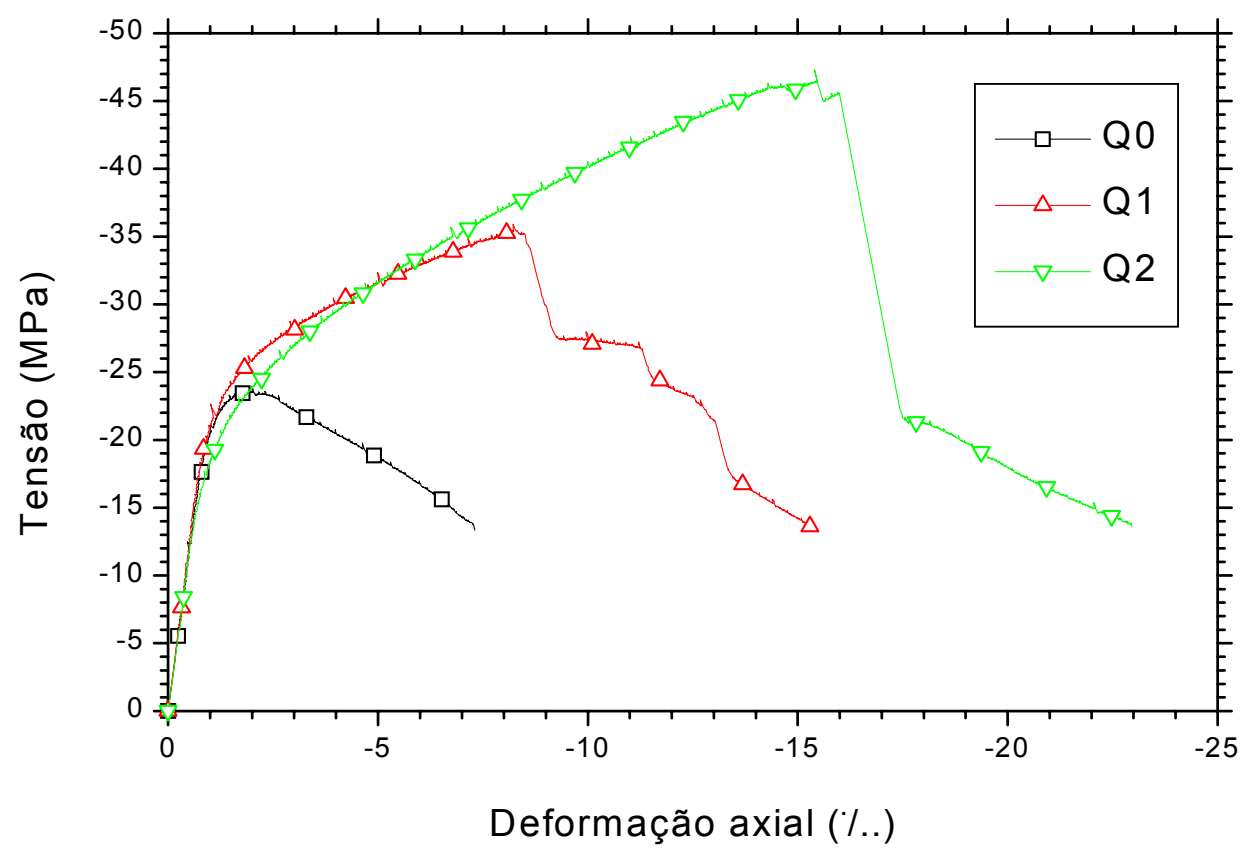

Figura 8.9 Diagramas tensão-deformação dos modelos de seção quadrada 


\subsection{Distribuição de pressões confinantes nos modelos}

Por meio de instrumentação adequada nos modelos de seção transversal circular sem armaduras foi possível observar o comportamento da pressão lateral ao longo do comprimento dos modelos. A pressão lateral foi calculada para cada ponto com a média da leitura dos extensômetros diametralmente opostos da camisa.

No modelo de referência $\mathrm{C} 0$ a camisa de reforço foi colocada nas extremidades do modelo. Na Figura 8.10 são apresentadas as pressões laterais referentes à tensão de pico $\mathrm{f}_{\mathrm{co}} \mathrm{e}$ as últimas leituras do trecho descendente do diagrama tensão-deformação, numa tensão de $0,63 \cdot f_{\mathrm{co}}$.

Pode-se observar que as pressões laterais desenvolvidas no momento da tensão de pico $\left(f_{c o}\right)$ do concreto no modelo são muito baixas. Isto demonstra que não houve grande influência sobre a resistência do concreto não confinado.

No entanto as últimas leituras $\left(0,63 \cdot f_{\text {co }}\right.$ no trecho descendente) indicaram níveis mais significativos de pressão lateral, o que indica a atuação da camisa, restringindo a fissuração do concreto. Talvez isto tenha influenciado a curva do diagrama tensão-deformação no trecho descendente.

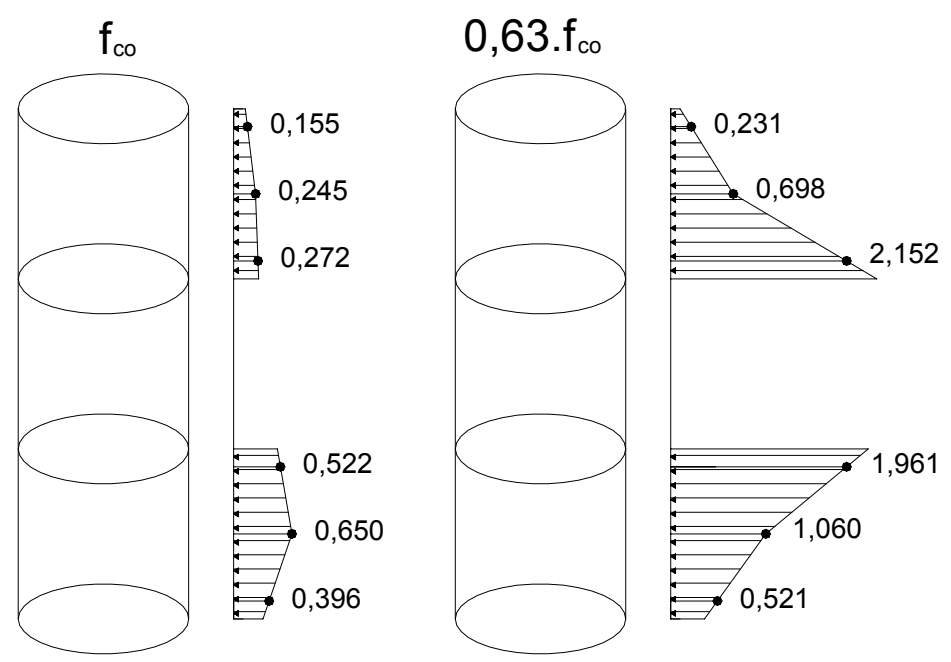

Figura 8.10 - Pressões laterais - Pilar C0

Para os modelo C1 são apresentadas as pressões laterais em três níveis de solicitação. Utilizou-se para comparação com o modelo não confinado a deformação axial de $2 \%$, sendo observados baixos níveis de pressão lateral neste caso, associados à baixa deformação lateral desenvolvida até este ponto. As deformações da camisa foram relativamente próximas ao longo do modelo para a carga de $0,98 \cdot f_{\mathrm{co}}$. 
As diferentes pressões laterais se devem à diferença na espessura das camadas na região central e das extremidades.

A níveis maiores de solicitação houve uma tendência do modelo deformar-se mais na região central. Desta maneira a diferença da pressão lateral entre a região central e as extremidades diminui relativamente.
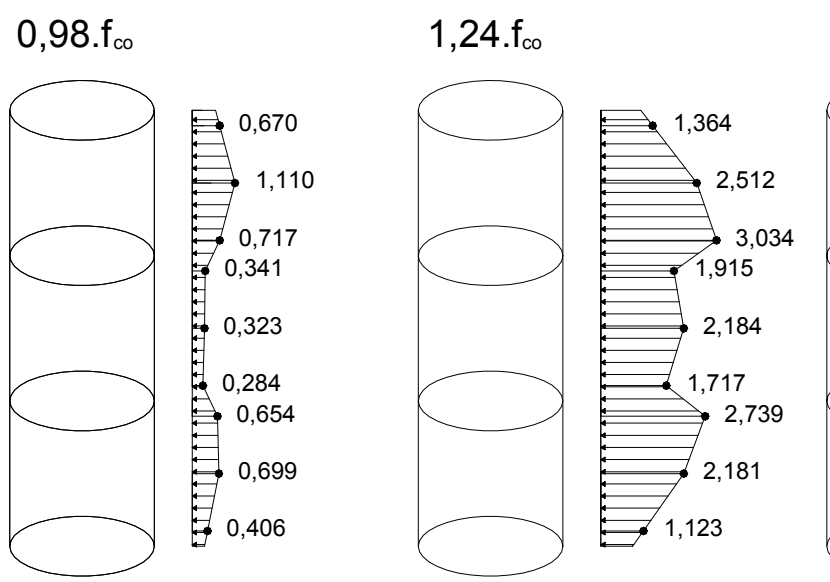

$1,48 . f_{\mathrm{co}}$

Figura 8.11 - Pressões laterais - Pilar C1

No modelo C2 as pressões laterais na região central e nas extremidades foram relativamente mais próximas, já que o número de camadas foi de 2 e 3 camadas respectivamente.
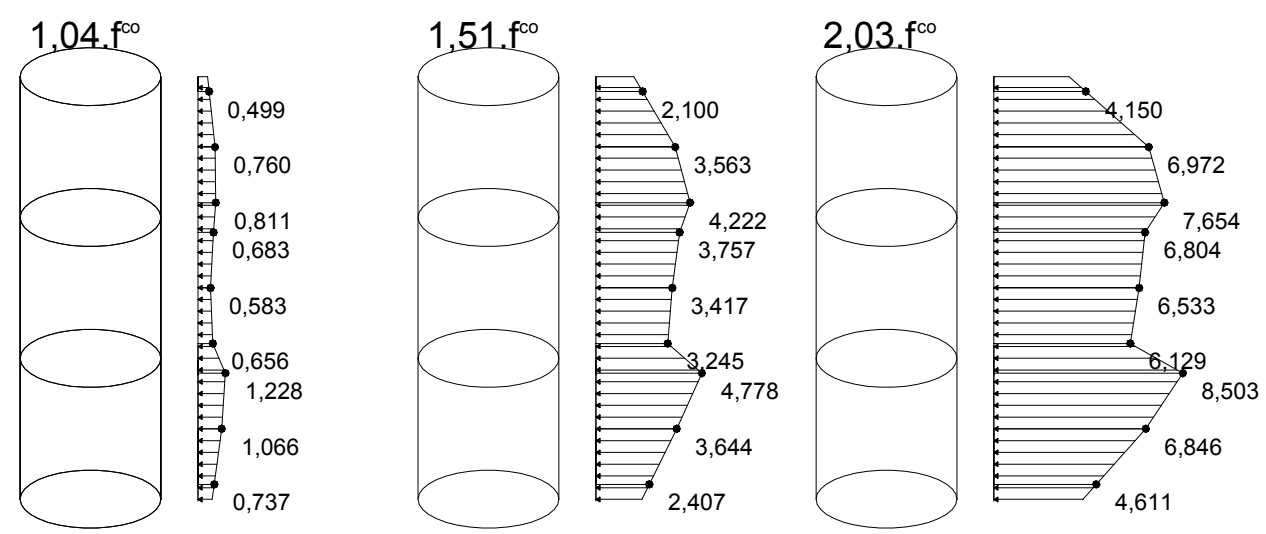

Figura 8.12 - Pressões laterais - Pilar C2

Nas figuras a seguir são apresentadas as pressões laterais médias comparadas com a sua distribuição. 


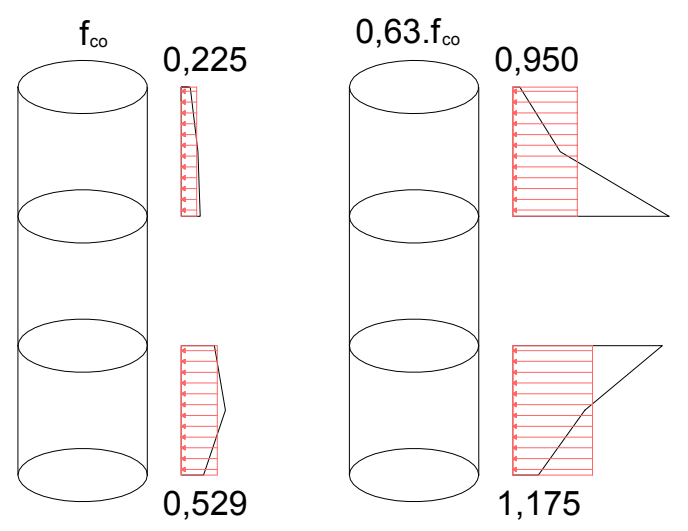

Figura 8.13 - Pressões laterais médias-C0

Nos modelos encamisados por inteiro a pressão média foi muito próxima do valor registrado na região central. Isto ocorreu no nível intermediário de tensão e na tensão última dos modelos $\mathrm{C} 1$ e C2. Este fato pode indicar que o comportamento do modelo como um todo, e não apenas na região central possa ser representado pela pressão lateral obtida na região central.
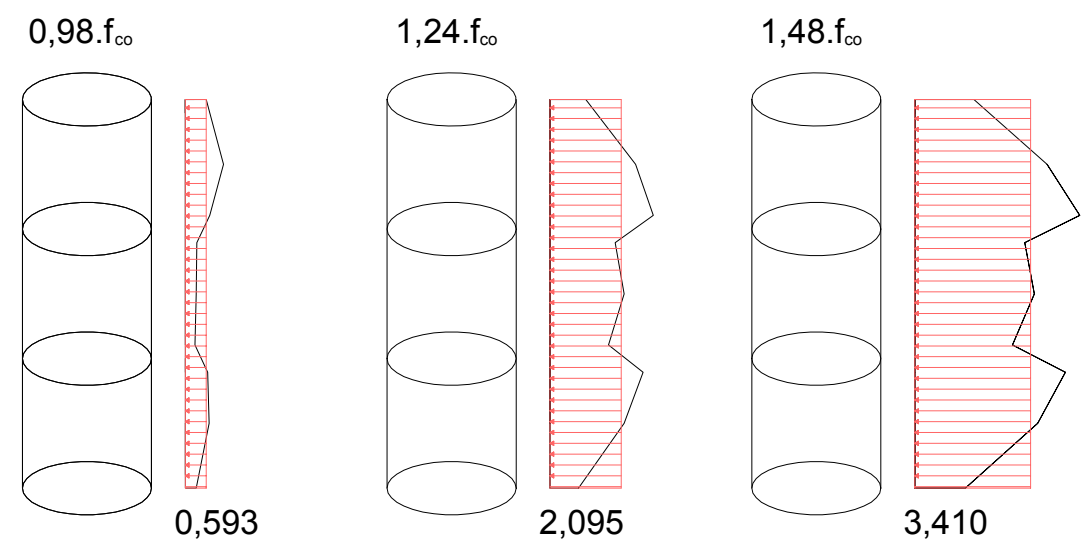

Figura 8.14 - Pressões laterais médias - C1
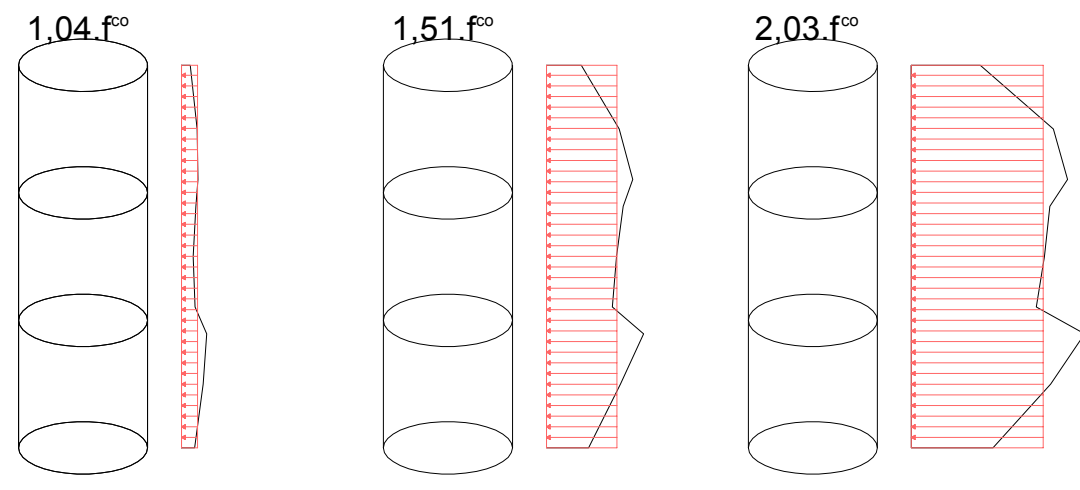

0,780

3,454

6,468

Figura 8.15 - Pressões laterais médias - C2 


\subsection{Expansão lateral e volumétrica}

Na Figura 8.16 são apresentadas as deformações axial, lateral e volumétrica dos modelos de seção circular sem armadura, encamisados com PRFC. Pode-se observar que o concreto experimenta uma contração volumétrica até uma tensão da ordem da resistência do concreto não confinado. Até este momento a deformação lateral é muito reduzida, e se deve apenas ao coeficiente de Poisson (elástico) do concreto. Após a tensão crítica a expansão lateral cresce rapidamente e com isto também cresce a expansão volumétrica (representada aqui por valores positivos).

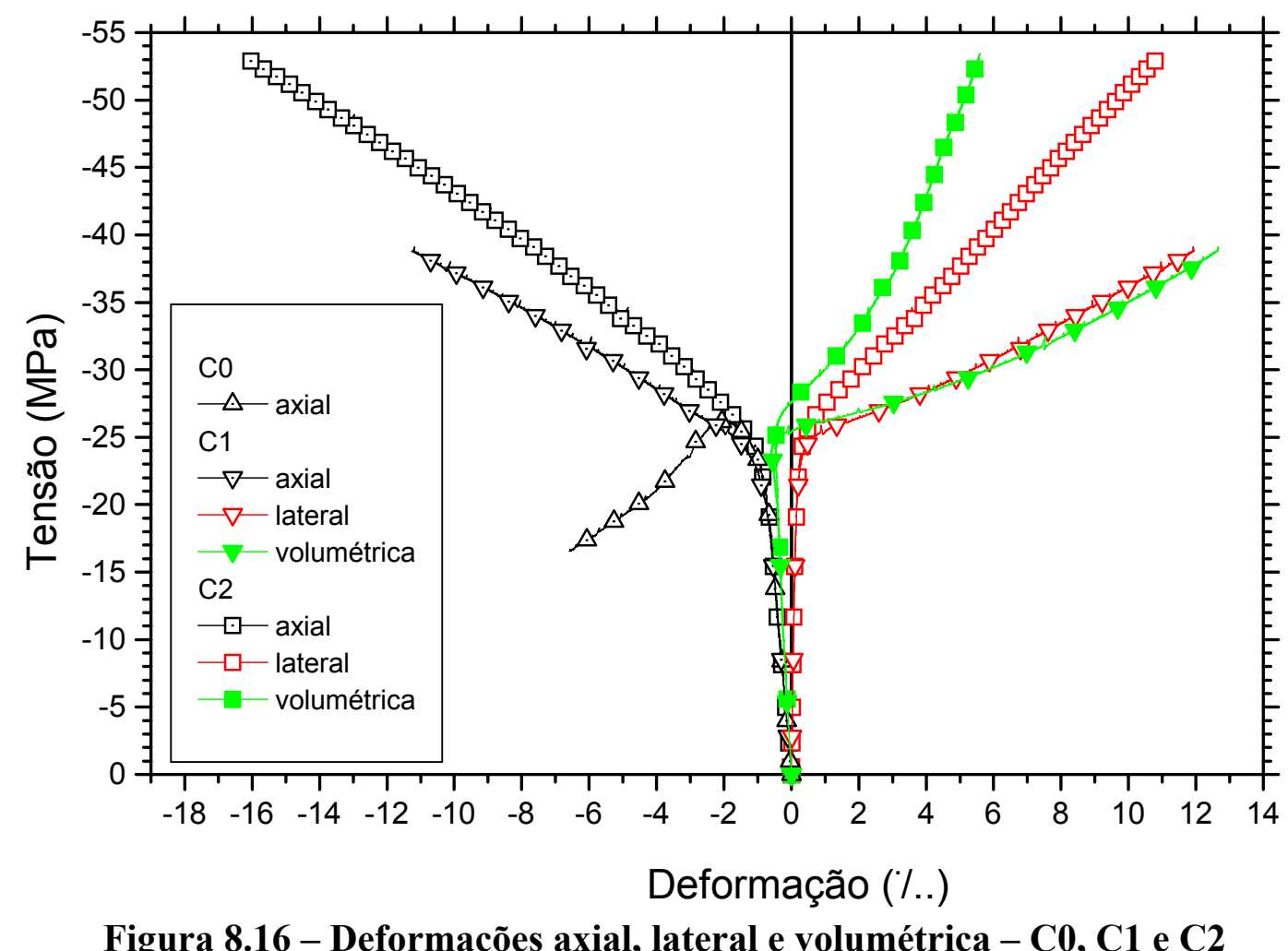

Figura 8.16 - Deformações axial, lateral e volumétrica - C0, C1 e C2

No entanto deve-se observar que a taxa volumétrica da camisa de reforço aqui empregada é relativamente baixa, e com isto a deformabilidade lateral é elevada. Nos modelos ensaiados por SAMAAN et al. (1998) as taxas volumétricas eram superiores e a deformação volumétrica, após experimentar uma leve expansão retornava no sentido da contração volumétrica e o concreto rompia com grande contração de volume (ver Figura 4.6). Isto ocorreu porque a rigidez da camisa era maior e restringia a deformação lateral com mais eficiência.

Acredita-se que aumentando o número de camadas de reforço o comportamento do concreto confinado seria semelhante ao indicado por SAMAAN 
et al. (1998). Isto pode ser verificado na Figura 8.16, comparando-se as deformações volumétricas dos modelos $\mathrm{C} 1$ e $\mathrm{C} 2$. No modelo $\mathrm{C} 1$ a deformação volumétrica acompanhou a lateral, já apresentando uma certa curvatura. No modelo C2 a mesma não acompanhou a deformação lateral e a curvatura é mais próxima do comportamento indicado por SAMAAN et al. (1998).

Para os modelos confinados apenas com armadura transversal o comportamento foi diferente (Figura 8.17). Com o crescimento da expansão lateral a deformação volumétrica cresceu rapidamente. Não houve uma tendência de contração volumétrica após o escoamento da armadura transversal, pois o escoamento da armadura transversal permitiu uma expansão lateral significativa. As deformações da armadura transversal foram adotadas como a média dos extensômetros localizados nas faces interna e externa da espiral.

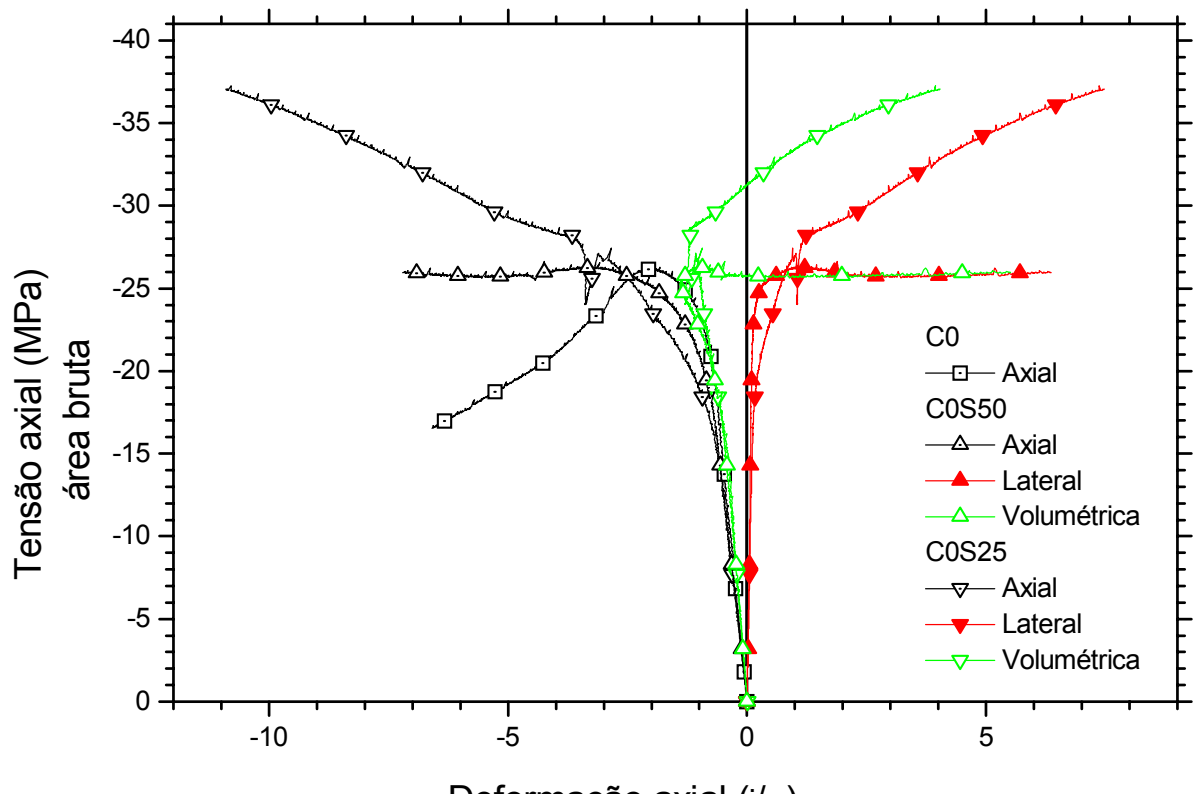

Deformação axial ( $\%$..)

Figura 8.17 - Deformação axial, lateral e volumétrica - C0, C0S50 e C0S25

Nos modelos com emprego das duas formas de confinamento observou-se algumas particularidades. Pode-se observar na Figura 8.18 a menor deformabilidade do núcleo, devido ao alto grau de restrição das espirais e da camisa. No momento da ruptura da camisa o núcleo sofria uma contração de volume e, como indicam as leituras da camisa, o modelo como um todo sofreu uma expansão volumétrica. Isto mostra que o concreto da região 2 se expandiu de maneira significativa se comparado ao núcleo. 
Este comportamento evidencia o fato de que a armadura transversal existente efetivamente colabora na resistência do núcleo, restringindo sua deformação lateral.

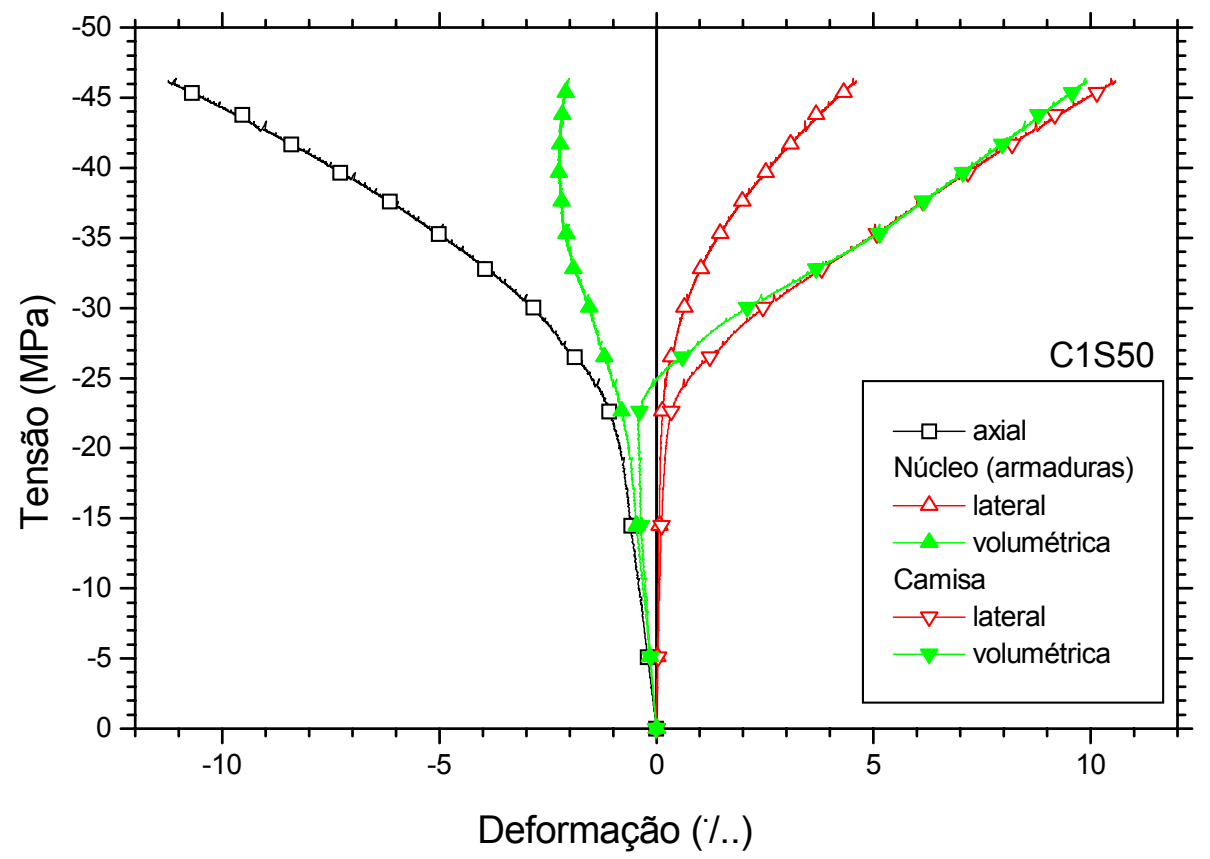

Figura 8.18 - Deformações axial, lateral e volumétrica - C1S50

O mesmo comportamento foi observado no modelo C2S50, destacando-se que a deformabilidade lateral e volumétrica foi mais reduzida em relação ao C1S50, devido ao maior grau de confinamento.

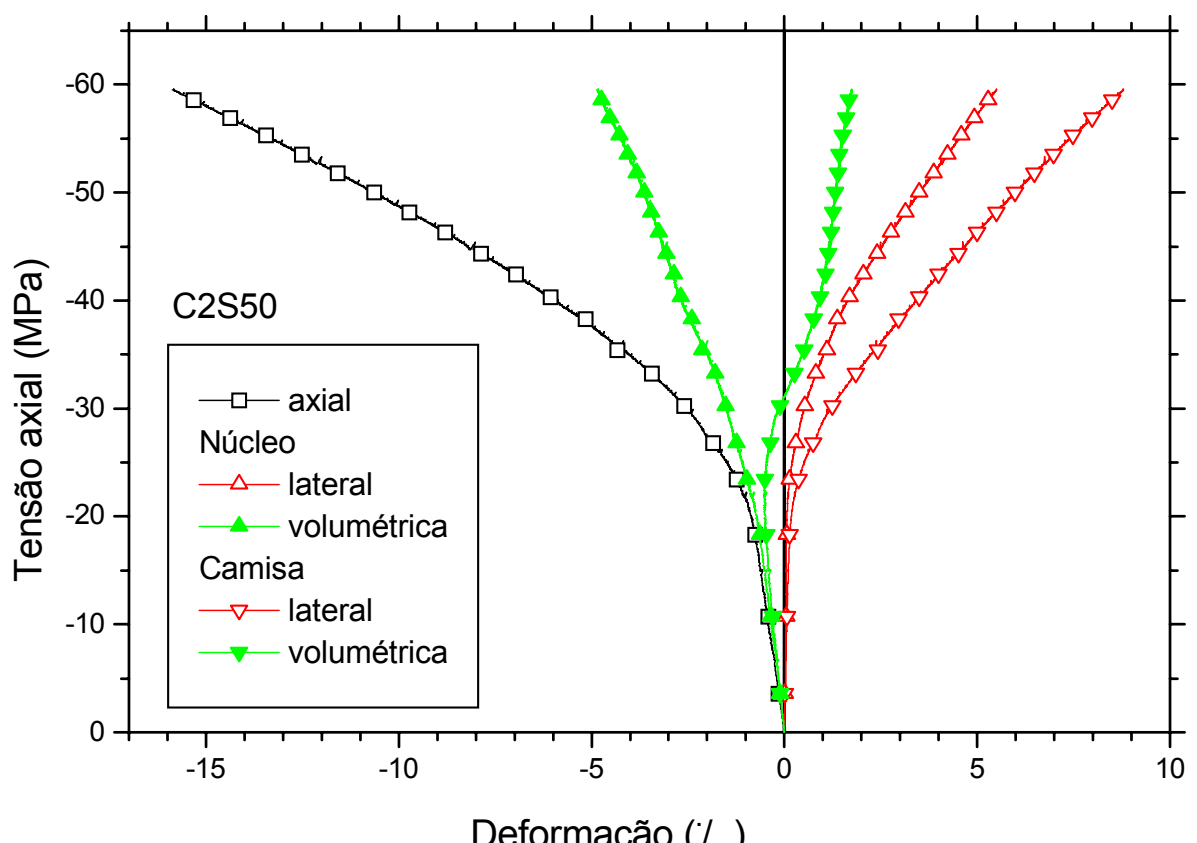

Figura 8.19 - Deformações axial, lateral e volumétrica - C2S50

O mesmo comportamento de C1S50 e C2S50 ocorreu no modelo C2S25, observando-se também uma contração volumétrica no núcleo. 


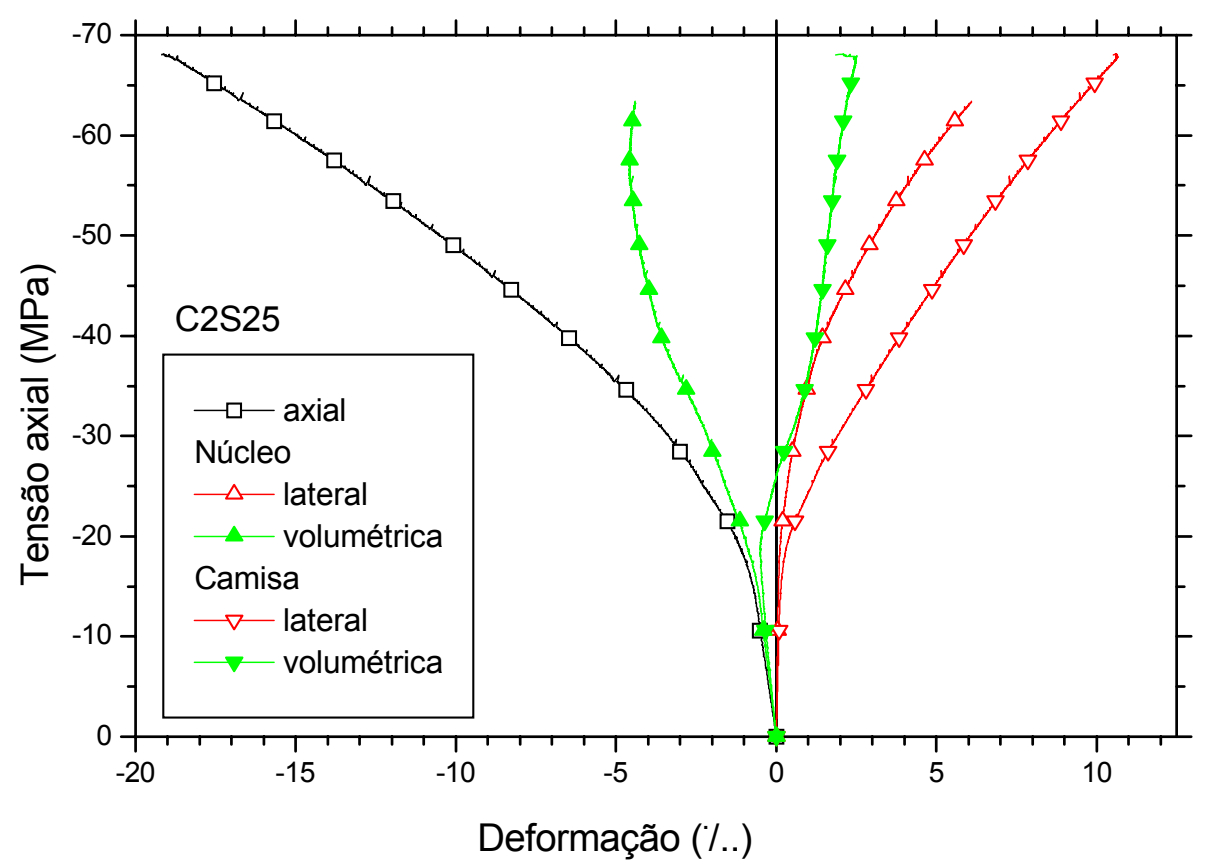

Figura 8.20 - Deformações axial, lateral e volumétrica - C2S25

\subsection{Taxa de dilatação lateral}

A taxa de dilatação lateral $(\mu)$ é definida como a taxa de variação da deformação lateral em relação à deformação axial. Na Figura 8.21 são apresentados $\mu$ dos modelos $\mathrm{C} 1$ e $\mathrm{C} 2$, que apresentaram um comportamento semelhante ao indicado por SAMAAN et al. (1998) na Figura 4.7. No início do carregamento ambos modelos apresentaram para $\mu$ valores um pouco inferiores ao coeficiente de Poisson. Com o início da microfissuração observou-se um grande aumento de $\mu$. Logo após a tensão crítica do concreto não confinado a taxa $\mu$ voltou então a diminuir, tendendo a um valor constante. Este valor constante está relacionado à rigidez da camisa de reforço (ver modelo de SAMAAN et al., 1998). 


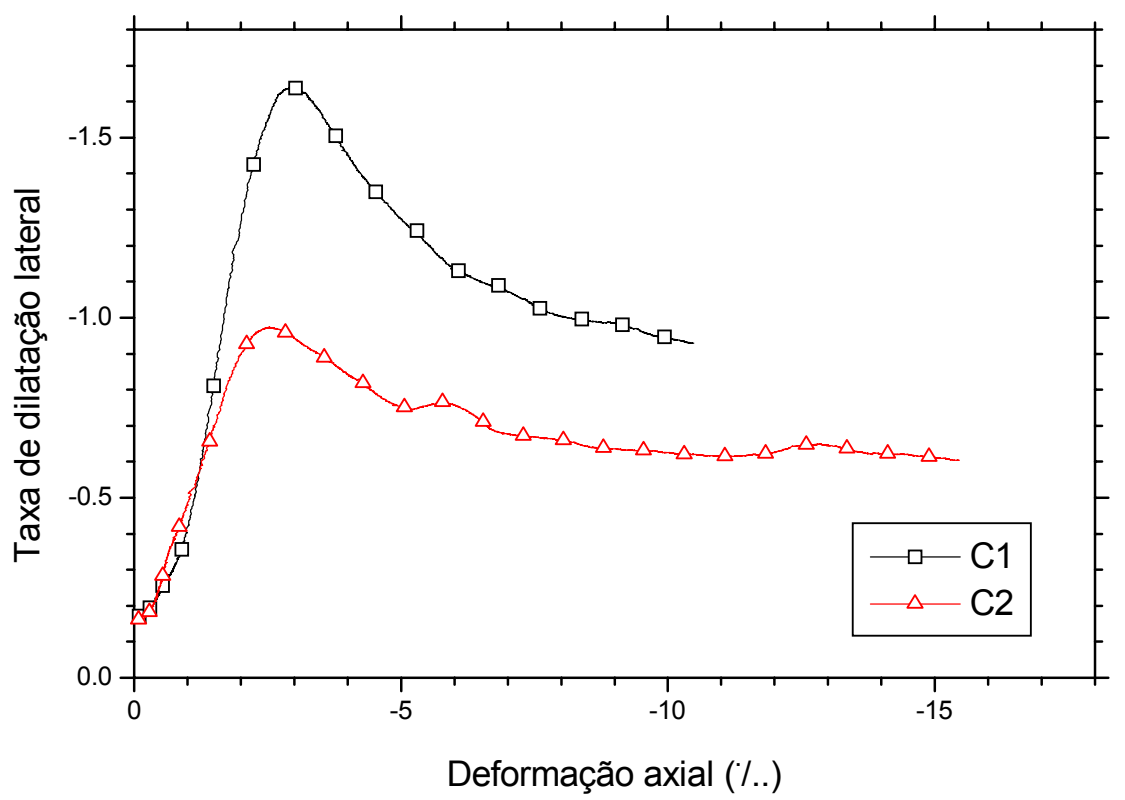

Figura 8.21 - Taxa de dilatação - modelos C1 e C2

O concreto confinado parece apresentar no segundo trecho linear do diagrama tensão-deformação um comportamento semelhante ao elástico linear: a relação entre tensão e deformação axial é constante (inclinação do segundo trecho linear) e a relação entre as deformações axial e lateral também é constante.

Pôde-se notar que com uma maior rigidez da camisa $(\mathrm{C} 2)$ há uma maior restrição da deformação lateral, e conseqüentemente menores valores de $\mu$.

A taxa de dilatação dos modelos confinados com armaduras apresenta grandes diferenças em relação aos confinados com PRFC. Com o escoamento da armadura transversal a taxa de dilatação cresce indefinidamente. Acredita-se que os valores apresentados poderiam ser maiores, já que os extensômetros das armaduras transversais apresentam limite de leitura em $15 \%$. Este comportamento é semelhante ao apresentado por SAMAAN et al. (1998). 


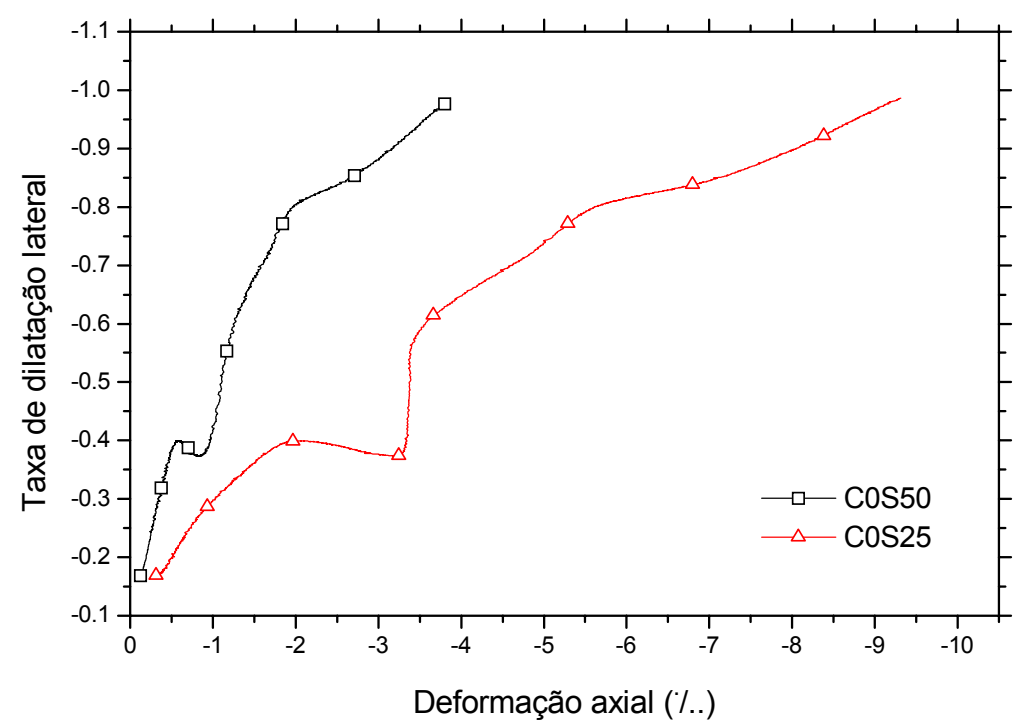

Figura 8.22 - Taxa de dilatação - COS50 e C0S25

Este comportamento das armaduras transversais indica que as mesmas não possuem rigidez suficiente para restringir a deformação lateral do concreto após seu escoamento. Com isto a tensão no concreto permanece constante ou diminui até a sua ruptura.

Para os modelos com armaduras e com camisa de reforço foram válidas as observações feitas por SAMAAN et al. (1998) para pilares confinados com PRFC. A taxa de deformação lateral parece se estabilizar em um determinado valor, dependente da rigidez da camisa. Isto indica a dominância da camisa de reforço sobre a deformabilidade lateral do modelo. O súbito crescimento observado no final da curva na Figura 8.23 é atribuído à ruptura parcial das fibras em parte do modelo, que manteve a carga constante para um dado incremento de deslocamento (ver Figura 7.46).

A deformação lateral da espiral foi comandada pela camisa de reforço nos modelos C1S50 e C2S50. A taxa $\mu$ tendeu a um valor constante tanto nas leituras da camisa de reforço quanto nas leituras armaduras transversais.

No modelo C2S25 a taxa de dilatação $\mu$ registrada pela camisa de reforço também tendeu a um valor constante. Porém as leituras das armaduras transversais tiveram comportamento semelhante ao dos modelos não reforçados com PRFC. Houve uma certa independência do comportamento da armadura transversal em relação à camisa de reforço. 


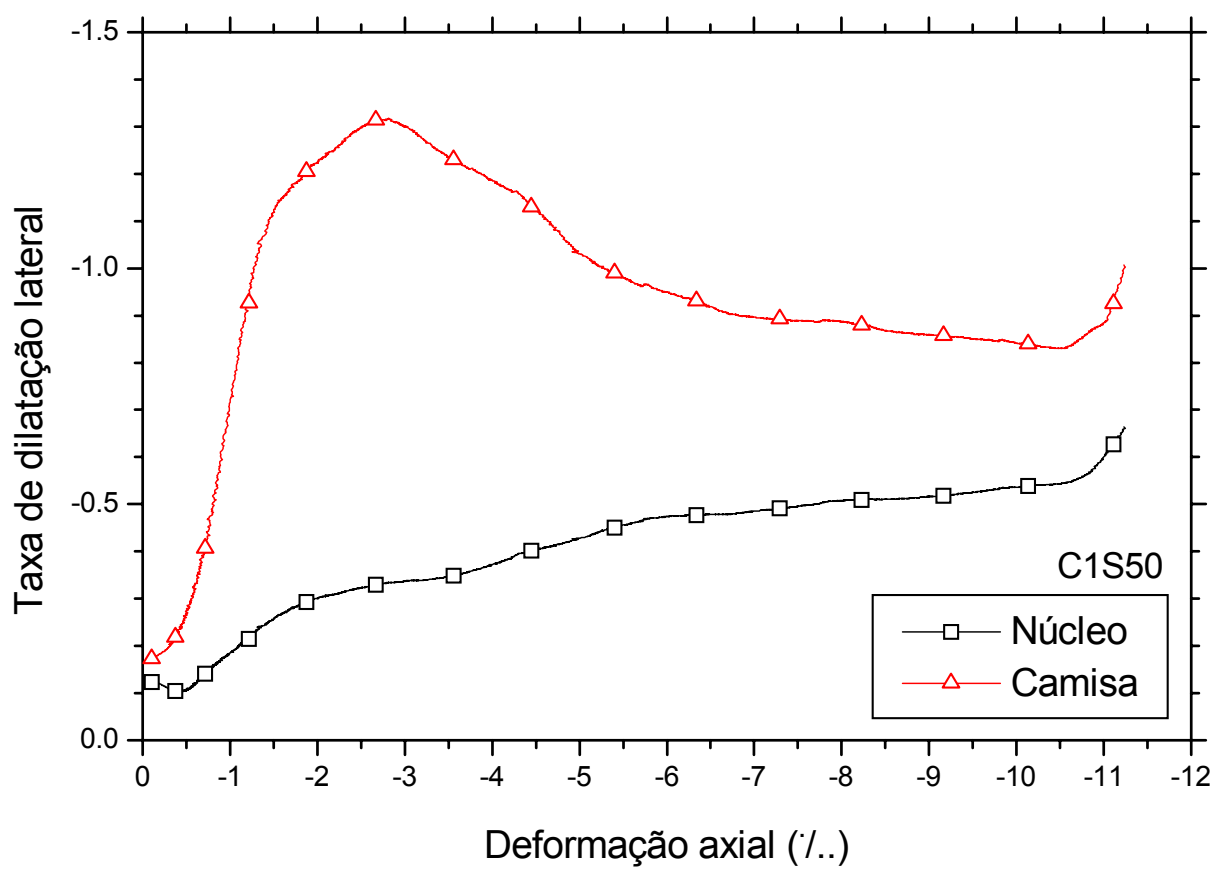

Figura 8.23 - Taxa de dilatação lateral - C1S50

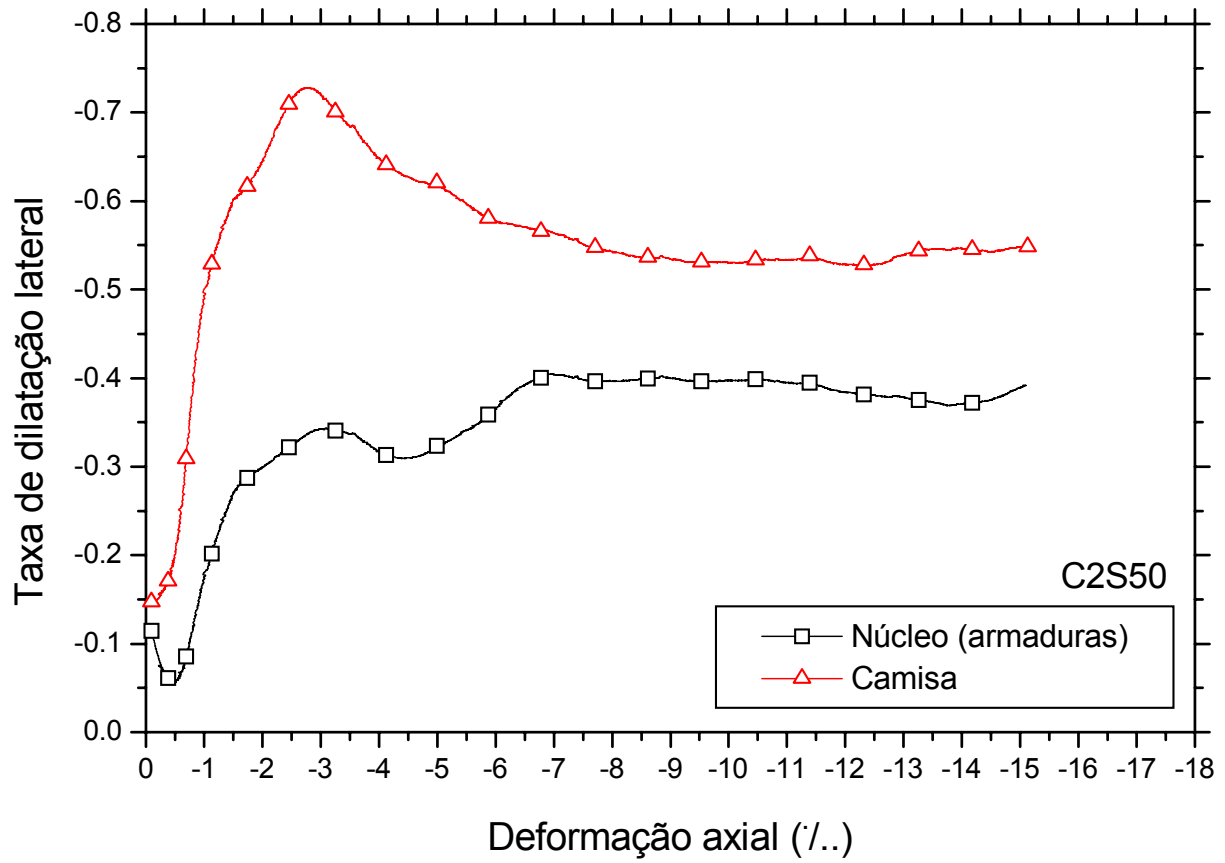

Figura 8.24 - Taxa de dilatação lateral - C2S50 


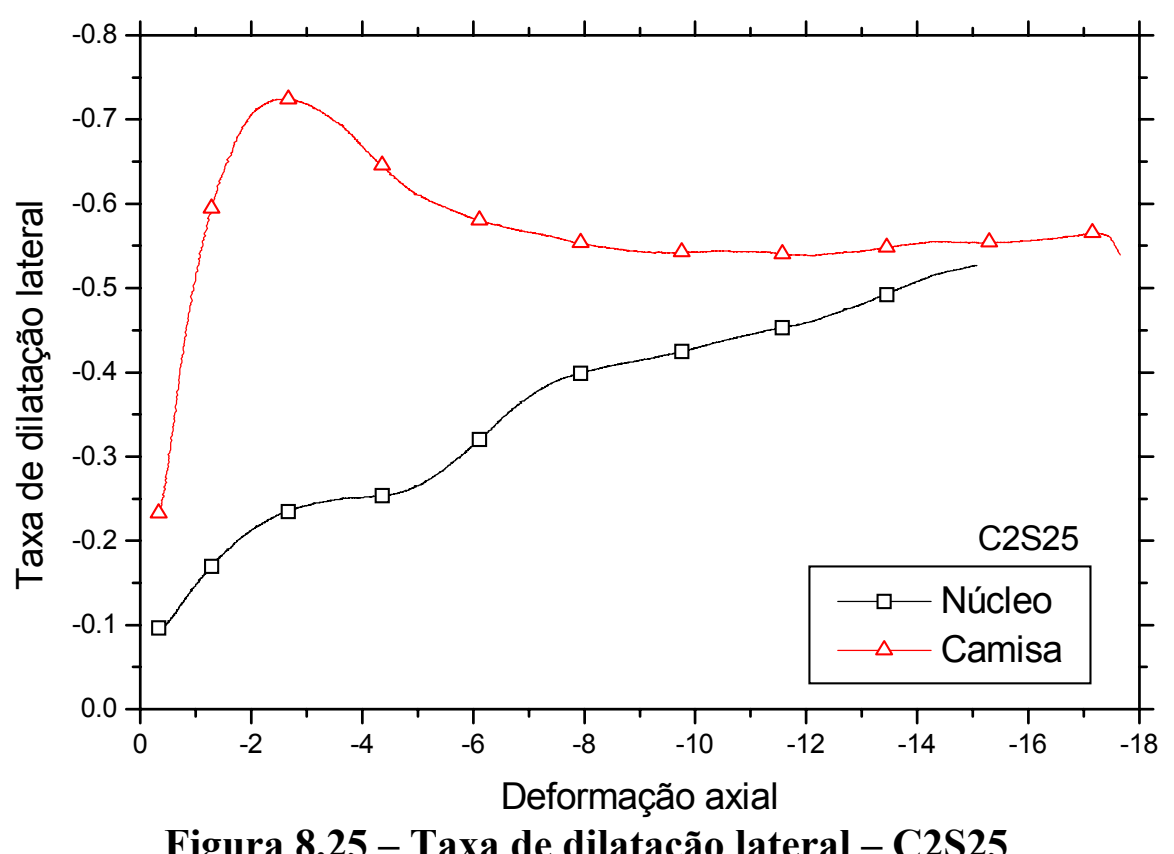

\subsection{Importância de $\rho_{\mathrm{s}}$ e n}

Analisou-se os efeitos da taxa de armadura transversal existente no pilar $\left(\rho_{\mathrm{s}}\right)$ e do número de camadas de PRFC (n) sobre a capacidade resistente e a deformabilidade do pilares ensaiados.

\subsubsection{Capacidade resistente}

Para realizar uma comparação em termos de capacidade resistente dos modelos procurou-se descontar a força das armaduras longitudinais e o efeito das diferentes resistências do concreto não confinado dos pilares. Para isto calculou-se a tensão na área bruta dos pilares, descontando-se a força das armaduras longitudinais. Dividiu-se então esta tensão por $\mathrm{f}_{\mathrm{co}}$. Obteve-se assim tensões normalizadas em

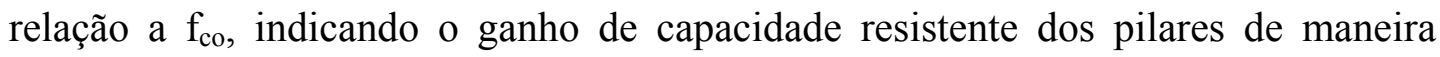
adimensional. Este valor foi aqui denominado de resistência normalizada. Na Tabela 8.27 são apresentadas as resistências normalizadas para as respectivas variáveis.

Tabela 8.27 - Resistência normalizada dos modelos

\begin{tabular}{ccccc}
\hline \multicolumn{2}{c}{$\begin{array}{c}\text { Tensão na área } \\
\text { bruta de concreto }\end{array}$} & \multicolumn{3}{c}{$\mathrm{n}$} \\
\cline { 2 - 5 } & 0 & 1 & 2 \\
\hline \multirow{2}{*}{$\rho_{\mathrm{s}}(\%)$} & 1 & 1,000 & 1,484 & 2,029 \\
& 2 & 1,387 & 1,791 & 2,300 \\
& & & 1,883 & 2,384 \\
\hline
\end{tabular}


Observou-se que há pouca interação de efeitos das variáveis e que a importância relativa de $\mathrm{n}$ foi maior que a de $\rho_{\mathrm{s}}$ sobre a capacidade resistente.

A taxa de armadura transversal apesar de benéfica no efeito de confinamento não trouxe aumentos significativos na resistência normalizada em comparação com os obtidos aumentando-se o número de camadas de fibras de carbono.

Para $n=0$ observou-se o efeito isolado do confinamento com aço. Com uma taxa de armadura de $1 \%$ o ganho de resistência do concreto confinado no núcleo foi anulado pela perda do cobrimento. Para $\rho_{\mathrm{s}}=2 \%$ o aumento de resistência do concreto do núcleo foi suficiente para aumentar a resistência normalizada do pilar em aproximadamente $39 \%$. Para $n=1$ o aumento de $\rho_{\mathrm{s}}$ trouxe ganhos relativamente pequenos de resistência normalizada. Para $n=2$ os ganhos foram ainda menores com $\rho_{\mathrm{s}}$.

Para valores fixos de $\rho_{\mathrm{s}}$ observou-se importantes ganhos de resistência normalizada com o acréscimo de $\mathrm{n}$, em todos os níveis de $\rho_{\mathrm{s}}$. Isto indica que o acréscimo de camadas de PRFC traz aumentos de resistência em todos os níveis de $\rho_{\mathrm{s}}$

\subsubsection{Deformação última no concreto confinado}

$\mathrm{Na}$ Tabela 8.28 são apresentados os resultados de deformação última dos modelos.

Tabela 8.28 - Deformação última dos modelos

\begin{tabular}{ccccc}
\hline \multicolumn{2}{c}{$\begin{array}{c}\text { Deformação última } \\
\text { dos modelos }\end{array}$} & \multicolumn{4}{c}{$\mathrm{n}$} \\
\cline { 2 - 5 }$\rho_{\mathrm{s}}(\%)$ & 0 & 2,028 & 11,180 & 16,196 \\
& 1 & 3,270 & 11,643 & 15,837 \\
& 2 & 15,231 & 16,482 & 19,185 \\
\hline
\end{tabular}

Observou-se que o efeito de interação entre as variáveis não pode ser desprezado. Isto significa que o comportamento de uma variável depende significativamente do nível adotado para a outra variável. O número de camadas de reforço parece ter maior importância que a taxa de armadura transversal, porém estatisticamente ambos possuem pouca importância. 
A presença de grande interação mostra a complexidade da análise. Para modelos sem reforço de PRFC o ganho de deformação última foi muito grande com o aumento da taxa de armadura transversal. Para os modelos reforçados com PRFC (n $=1$ e 2$)$ o aumento de $\varepsilon_{\mathrm{cc}}$ foi desprezível com o acréscimo de $\rho_{\mathrm{s}}$ de 0 a $1 \%$. No entanto passando-se de $\rho_{\mathrm{s}}=1 \%$ a $2 \%$ o aumento foi significativo.

Analisando-se o aumento do número de camadas de reforço o comportamento também foi dependente do nível da taxa de armadura transversal. Para pequenas taxas de armadura transversal o aumento da deformação última foi grande ao aumentar o número de camadas de fibras de carbono. Para a taxa de armadura de $2 \%$ o aumento foi pequeno.

Conclui-se que apenas uma das duas variáveis com um valor elevado é suficiente para garantir uma elevada deformação última, e neste caso o acréscimo do confinamento pela outra variável não trará maiores ganhos de deformação última.

\subsubsection{Deformação de ruptura das fibras de carbono}

Na Tabela 8.29 são apresentadas as deformações de ruptura das fibras de carbono para os diversos modelos. Pode-se observar que aparentemente não houve influência do número de camadas de fibras aplicado. No entanto com o aumento da taxa volumétrica de armadura transversal a deformação de ruptura diminuiu.

Tabela 8.29 - Deformação de ruptura das fibras $(\%$

\begin{tabular}{|c|c|c|c|}
\hline \multirow{2}{*}{$\begin{array}{c}\text { Deformação de } \\
\text { ruptura das fibras }\end{array}$} & \multicolumn{2}{|c|}{$\mathrm{n}$} \\
\cline { 2 - 4 } & 0 & 11,92 & 11,90 \\
\hline \multirow{3}{*}{$\rho_{\mathrm{s}}(\%)$} & 1 & 11,00 & 8,78 \\
\cline { 2 - 4 } & 2 & 10,63 & 10,65 \\
\hline
\end{tabular}

$\mathrm{O}$ valor de $\varepsilon_{\mathrm{fu}}=8,78 \%$ no pilar C2S50 é questionável, por estar abaixo dos valores observados nos demais ensaios e pelo fato de que as previsões de capacidade resistente dadas pelos modelos teóricos ficaram bem abaixo do valor experimental, o que não ocorreu nos outros pilares. 


\section{Capítulo 9 Conclusões}

O reforço de pilares de concreto armado com compósitos de fibras de carbono demonstrou vantagens em relação a outras técnicas de reforço como facilidade de aplicação e ganhos significativos de resistência com pequenas espessuras de reforço. Com 1 camada de reforço da ordem de $0,5 \mathrm{~mm}$ de espessura (considerando-se fibras + matriz) obteve-se acréscimos na capacidade resistente entre 31 e $64 \%$. Com 2 camadas de reforço (aproximadamente $1 \mathrm{~mm}$ de espessura) obtevese acréscimos na capacidade resistente entre 62 e $105 \%$.

Com o aumento da taxa de armadura transversal pré-existente no pilar o ganho na capacidade resistente foi relativamente menor. $\mathrm{O}$ acréscimo na resistência do pilar devido ao efeito de confinamento é função da resistência do concreto não confinado e da pressão lateral. Logo, nos pilares com altas taxas de armadura transversal o concreto já apresenta um ganho elevado de resistência devido ao confinamento exercido pelas armaduras transversais, portanto o acréscimo de resistência devido ao PRFC tem um efeito relativamente menor. Contudo mesmo para a taxa de armadura transversal de $2 \%$ observou-se ganhos importantes na capacidade resistente do pilar (31\% para $n=1$ e $62,5 \%$ para $n=2)$.

Quanto à deformabilidade dos pilares reforçados com PRFC o aumento da deformação última foi elevado para os pilares sem armaduras $\left(\varepsilon_{\mathrm{cc}}\right.$ aumentou de 5,5 a 8 vezes). Nos pilares com armadura transversal ocorreram menores ganhos de deformação última, pelo fato dos próprios pilares de referência apresentarem deformações últimas elevadas devido ao confinamento das armaduras transversais.

Não foi desenvolvido nenhum método para avaliação da ductilidade do concreto confinado por PRFC. No entanto considerando que a deformação última do concreto confinado é um parâmetro indicador da ductilidade, podem ocorrer importantes acréscimos na ductilidade dos pilares reforçados com PRFC. O aumento da ductilidade é maior para pilares sem armaduras. Nos modelos com taxas de 
armaduras elevadas o ganho na ductilidade é menor, e em alguns casos insignificante.

\subsection{Propriedades do compósito}

Algumas propriedades das fibras fornecidas pelo fabricante não podem ser aplicadas diretamente para dimensionamento. A resistência das fibras mostrou-se inferior ao valor fornecido pelo fabricante tanto nos ensaios à tração, quanto nos ensaios dos pilares reforçados com PRFC. O módulo de elasticidade obtido nos ensaios à tração do compósito foi, no entanto, da ordem de $95 \%$ do valor recomendado pelo fabricante. Na relação massa/área dos tecidos obteve-se $99 \%$ do valor do fabricante. Portanto, supondo-se a densidade das fibras correta, a espessura da camada de tecido fornecida pelo fabricante é precisa $(0,13 \mathrm{~mm})$.

A utilização de diferentes quantidades de resina e a mudança do processo de moldagem do compósito influem diretamente na espessura e nas frações volumétricas dos materiais constituintes. Por este motivo não se recomenda a utilização da resistência à tração e do módulo de elasticidade do compósito como parâmetro de projeto para o caso de aplicação manual de tecidos de fibras de carbono em elementos estruturais.

A melhor maneira adotada para representar as propriedades do material do reforço, foi a utilização da resistência e módulo de elasticidade das fibras, desprezando-se a contribuição da resina. A resistência à tração das fibras nos ensaios preliminares foi em média de $2483 \mathrm{MPa}$ enquanto nos ensaios definitivos foi de 2758 $\mathrm{MPa}$. Este valor é inferior ao do fabricante (3500 MPa). Acredita-se que a flexão no ensaio provocou esta redução da resistência.

O módulo de elasticidade à tração das fibras no entanto não foi afetado significativamente pela flexão e pelo processo de moldagem. Obteve-se $218,82 \mathrm{GPa}$ nos ensaios preliminares e 218,95 GPa nos ensaios definitivos, enquanto os dados do fabricante indicavam $230 \mathrm{GPa}$.

Nos ensaios à tração observou-se a presença de flexão, que pode ser ocasionada pela falta de uniformidade das amostras, problemas de alinhamento da amostra na máquina de ensaio, problemas de alinhamento da própria máquina de ensaio ou até mesmo na fixação dos extensômetros. Outra questão a ser considerada 
no dimensionamento do reforço com compósitos é que a deformação de ruptura das fibras nos pilares encamisados é menor que a obtida nos ensaios de tração. Com isto a resistência do compósito no reforço por encamisamento é menor que a obtida em ensaios à tração uniaxial.

Quanto à resina recomenda-se cuidados em relação ao "pot-life". Para maiores temperaturas deve-se preparar quantidades menores de resina, evitando problemas de aplicação. O consumo de epóxi de $1 \mathrm{~kg} / \mathrm{m}^{2}$ para aplicação sobre o concreto demonstrou-se eficiente. O consumo de $0,75 \mathrm{~kg} / \mathrm{m}^{2}$ para aplicação das camadas superiores foi suficiente.

\subsection{Efeito da aderência do reforço}

Apesar do reduzido número de ensaios realizados, verificou-se que o lixamento da superfície de concreto antes da aplicação do reforço não teve uma influência significativa sobre o seu desempenho em pilares de seção transversal circular.

No entanto observou-se no modelo reforçado sem qualquer aderência (isolado do concreto) um ganho de resistência inferior aos modelos reforçados com aderência. O ganho de resistência devido ao efeito da aderência apresentou-se maior no final do primeiro trecho do diagrama tensão-deformação. A inclinação do segundo trecho foi praticamente igual, independentemente da aderência. Com isso o modelo sem aderência acabou rompendo com uma resistência menor $(92 \%$ da resistência do modelo com aderência, como se pode observar na Figura 7.17).

\subsection{Efeitos do confinamento}

Observou-se que o confinamento pode ocasionar significativos acréscimos na resistência e na deformação última do concreto. Apesar do esforço realizado em pesquisas sobre confinamento desde o início do século, seus efeitos sobre o concreto ainda não foram quantificados precisamente para todos os casos.

Observou-se que critérios de ruptura antigos, como o de MOHR-COULOMB podem representar o comportamento do concreto confinado tão eficientemente quanto modelos mais recentes. Tal fato é evidenciado nas comparações do modelo de RICHART et al. (1929) (envoltória semelhante à de MOHR-COLOUMB) a outros modelos mais recentes como o de MANDER et al.(1988-b) (envoltória baseada no 
critério de cinco parâmetros de WILLAN-WARNKE). O modelo de RICHART et al. (1929) obteve previsões de capacidade resistente mais próximas dos resultados experimentais em quase todos os pilares analisados.

Existe uma considerável variabilidade nas envoltórias de ruptura dos modelos de confinamento. As envoltórias dos modelos de confinamento para PRFC tendem a ser mais conservadoras que as dos modelos de confinamento com aço. Uma exceção é a envoltória de CUSSON \& PAULTRE (1995), que apesar de ter sido desenvolvida para confinamento com aço de alta resistência, foi uma das mais conservadoras. As previsões obtidas por este modelo estão entre as que apresentaram melhores resultados.

Esta variabilidade existe porque as envoltórias são baseadas em dados experimentais, que podem ter diferentes parâmetros associados a eles. Uma fonte de variabilidade, por exemplo, pode ser a diferença de propriedades dos concretos utilizados nos ensaios.

Outro parâmetro com considerável influência é a pressão lateral adotada no caso de confinamento passivo. No confinamento com armaduras transversais sabe-se que o espaçamento entre armaduras transversais influencia a efetividade do confinamento. O modelo de MANDER et al (1988-b), por exemplo, sugere um coeficiente de efetividade para a pressão lateral com armaduras transversais. O modelo de EL-DASH \& AHMAD (1995) também propõe uma pressão lateral efetiva, todavia com um coeficiente de efetividade inferior ao proposto por MANDER et al. (1988-b). Outros modelos não consideram sequer o coeficiente de efetividade para pilares de seções transversais circulares, como RAZVI \& SAATCIOGLU (1999-b).

No caso de confinamento com camisas de PRFC, alguns pesquisadores utilizaram na elaboração de seus modelos a deformação de ruptura das fibras obtida em ensaios de tração para o cálculo da pressão lateral. No entanto verificou-se que a deformação de ruptura das fibras nos pilares encamisados pode ser inferior. Outros modelos adotaram a deformação de ruptura real das fibras. Esta variabilidade na pressão lateral adotada compromete a uniformidade das envoltórias dos modelos teóricos de confinamento com PRFC. 


\subsection{Concreto confinado com aço ou PRF}

Segundo DE LORENZIS \& TEPFERS (2001) a ruptura do concreto confinado não depende do meio utilizado para se obter o confinamento, mas da intensidade da pressão lateral desenvolvida. Isto significa que um modelo de confinamento adequado poderia ser aplicado aos diversos tipos de confinamento para prever a resistência do concreto confinado.

CHEN (1982) associa o comportamento tensão-deformação do concreto em ensaios com confinamento ativo ao nível de pressão lateral. Nestes casos o concreto pode ter um comportamento variando de quase frágil, a plástico com amolecimento e endurecimento aumentando-se a pressão lateral.

Pode-se afirmar que a deformabilidade do concreto, que depende da pressão lateral no confinamento ativo, é significativamente influenciada pelas características do material confinante no confinamento passivo. Observou-se que as previsões da deformabilidade do concreto por meio de modelos teóricos de confinamento são dependentes do tipo de material confinante para o qual o modelo foi desenvolvido.

O concreto confinado com aço apresenta um diagrama tensão-deformação diferente do concreto confinado com PRFC. Esta diferença se deve ao próprio diagrama tensão-deformação do material confinante. $O$ aço apresenta comportamento elasto-plástico, enquanto o PRFC é elástico-linear até a ruptura. No confinamento com aço a tensão útima do concreto é atingida após o escoamento da armadura e o concreto apresenta uma considerável deformabilidade até a ruptura da espiral. No confinamento com PRFC a tensão última do concreto coincide com a ruptura da camisa, que ocorre de maneira brusca.

No confinamento com aço o cobrimento é uma variável que ainda não tem o comportamento quantificado com clareza. Procurou-se modelar seu comportamento de maneira aproximada por meio do diagrama tensão-deformação do concreto não confinado. No entanto acredita-se que a capacidade resistente do cobrimento seja inferior à obtida com a resistência do concreto não confinado.

\subsection{Modelos teóricos de confinamento}

Observou-se que os modelos teóricos foram mais precisos na previsão da capacidade resistente do que da deformação última observada nos ensaios. 
Quanto ao ganho de resistência, os modelos de MANDER et al. (1988-b) e RAZVI \& SAATCIOGLU (1999-b) forneceram valores superiores aos resultados experimentais. O modelo de RICHART et al. (1929) apresentou previsões mais próximas dos valores experimentais, no entanto, para pressões laterais mais elevadas superestimou o ganho de resistência.

Entre os modelos de confinamento com aço, o de CUSSON \& PAULTRE (1995) apresentou os resultados mais próximos dos experimentais, tendo uma semelhança nos resultados obtidos com o modelo de SAMAAN et al. (1998). Salienta-se que ao avaliar o confinamento com PRFC, apresentou bons resultados.

Os modelos de confinamento com PRFC apresentaram-se mais próximos dos resultados experimentais que os modelos para aço. As previsões dos modelos desenvolvidos para confinamento com aço na maioria das vezes subestimaram o ganho de resistência. O modelo de MYIAUCHI et al. (1997) obteve as previsões mais próximas dos resultados experimentais.

As previsões de ganho de resistência com o modelo de SAAFI et al. (1999) ficaram entre 10 e $20 \%$ abaixo dos resultados experimentais para confinamento com aço ou PRFC.

Quanto à deformação última o modelo de RICHART et al. (1929) obteve previsões um pouco abaixo dos dados experimentais nos pilares confinados com armaduras transversais. Os modelos de MANDER et al. (1988-b) e RAZVI \& SAATCIOGLU (1999-b) previram a deformação última dos pilares confinados com armaduras transversais de maneira adequada. O modelo de CUSSON \& PAULTRE (1995) previu um aumento da deformação última maior para grandes pressões laterais. Os ganhos de deformação última do concreto confinado também foram superestimados por SAMAAN et al. (1998).

O modelo de MIYAUCHI et al. (1997) forneceu os melhores resultados para a deformação última do concreto confinado com PRFC. O modelo de TOUTANJI (2000) previu a deformação última do concreto confinado com PRFC 16\% abaixo dos valores experimentais.

Nas previsões de SAAFI et al. (1999) a deformação última do concreto confinado se apresenta inferior à obtida experimentalmente e com uma intensa variabilidade. 
Alguns modelos levaram a resultados muito imprecisos. O modelo de ELDASH \& AHMAD (1995) calcula uma pressão lateral efetiva muito baixa. Com isto subestima o ganho de resistência e deformação última, cometendo um erro considerável. Além disso sua envoltória não pode ser isolada em função da pressão lateral e da resistência do concreto não confinado. Logo este modelo não pode ser aplicado a confinamento com PRFC.

O modelo de KONO et al. (1998) não apresentou um desempenho adequado, prevendo ganhos de resistência e deformação última do concreto confinado muito baixas. O problema da previsão talvez esteja na utilização da pressão lateral no equacionamento ao invés do parâmetro $\mathrm{f}_{\mathrm{l}} / \mathrm{f}_{\mathrm{co}}$.

A curva tensão-deformação sugerida por MYIAUCHI et al. (1997) foi a que melhor se ajustou aos dados experimentais do concreto confinado com PRFC.

A utilização do coeficiente de efetividade de MANDER et al. (1988-b) pareceu adequada para prever a pressão lateral do concreto confinado por armaduras transversais.

\subsection{Pilares de seção transversal quadrada}

Utilizou-se um raio de $3 \mathrm{~cm}$ para arredondar os cantos dos modelos de seção transversal quadrada. Este raio mostrou-se suficiente, já que a ruptura dos modelos ocorreu na região central das faces e as deformações nos cantos foram reduzidas.

Os pilares de seção transversal quadrada apresentaram diagramas tensãodeformação próximos de um comportamento bi-linear. Uma ligeira não-linearidade foi observada no segundo trecho, e a zona de transição foi um pouco mais pronunciada em relação aos pilares circulares. A pressão lateral efetiva mostrou-se menor que a idealizada para pilares circulares, com um coeficiente de efetividade próximo a 0,6 ocasionado provavelmente pela forma da seção.

No confinamento com aço ocorre algo parecido. Em seções quadradas ou retangulares obtém-se normalmente maiores ganhos de ductilidade do que de resistência. 


\subsection{Influência de $\rho_{\mathbf{s}}$ e n}

Os modelos teóricos de confinamento ofereceram bons resultados na previsão do comportamento dos pilares de seção transversal circular reforçados com PRFC. Quanto à capacidade resistente os valores calculados foram próximos aos resultados dos ensaios. Observou-se o efeito combinado do confinamento com aço e com PRFC nos pilares circulares.

As análises teóricas considerando a sobreposição das pressões de confinamento no núcleo do pilar mostraram-se próximas aos resultados experimentais. Isto sugere a contribuição efetiva dos dois tipos de confinamento no núcleo.

Os efeitos da taxa de armadura transversal e do número de camadas de PRFC sobre a capacidade resistente não apresentaram interação significativa. $\mathrm{O}$ acréscimo de resistência atribuído ao aumento da taxa de armadura transversal é pequeno se comparado ao ganho devido ao aumento do número de camadas de reforço.

Quanto à deformabilidade não se pode dizer o mesmo. O efeito do aumento do número de camadas de reforço depende da taxa de armadura transversal existente. Para pequenas taxas de armadura transversal o aumento da deformação última foi significativo com o acréscimo do número de camadas de PRFC. Para maiores taxas de armadura transversal o aumento foi reduzido.

Observou-se uma variação da deformação de ruptura das fibras $\left(\varepsilon_{\mathrm{fu}}\right)$ com o valor de $\rho_{\mathrm{s}}$. Com o aumento da taxa de armadura transversal $\left(\rho_{\mathrm{s}}\right)$ a deformação de ruptura das fibras diminuiu. $\mathrm{O}$ aumento do número de camadas de reforço com fibras no entanto não demonstrou uma influência sobre $\varepsilon_{\text {fu }}$.

\subsection{Síntese das conclusões}

A técnica de reforço de pilares por encamisamento com compósitos de fibras de carbono permite grandes ganhos de capacidade resistente e ductilidade em pilares de seção transversal circular e quadrada. Para pilares circulares submetidos a esforços de compressão axial centrada existem modelos teóricos que permitem obter previsões dos ganhos de capacidade resistente e ductilidade. No entanto devido à natureza empírica destes modelos existe uma variabilidade nas previsões obtidas como conseqüência de alguns fatores: 
- Os modelos teóricos adotam diferentes valores para a deformação de ruptura da camisa e, conseqüentemente, para a sua resistência;

- Os diferentes materiais utilizados nos ensaios para elaboração dos modelos teóricos podem ocasionar diferentes respostas, principalmente em relação a deformabilidade.

Observou-se nos ensaios realizados que a deformação de ruptura da camisa de reforço foi um pouco inferior à obtida nos ensaios de tração do compósito.

Observou-se também que quando o pilar a ser reforçado possui uma armadura transversal pré-existente o confinamento devido à armadura transversal pode ser levado em consideração, superpondo-se as pressões de confinamento.

Notou-se que em pilares de seção transversal quadrada é possível obter ganhos significativos de capacidade resistente e ductilidade por meio de encamisamento com compósito de fibras de carbono, desde que observado um raio de mínimo de curvatura nos cantos do pilar. Neste trabalho, com $3 \mathrm{~cm}$ de raio podese evitou-se concentrações de tensão nos cantos, obtendo-se assim ganhos de resistência da ordem de $60 \%$ dos obtidos em pilares circulares.

\subsection{Pesquisas futuras}

A forma da seção transversal do pilar é um fator importante a ser considerado na avaliação do desempenho do reforço. Neste trabalho observou-se que para seções quadradas já ocorre um ganho menor de resistência quando comparado a pilares circulares. Acredita-se que para pilares retangulares os acréscimos de capacidade resistente possam ser ainda mais inferiores. Daí decorre a necessidade de se conhecer o comportamento de pilares de diferentes seções transversais reforçados com esta técnica. Deve-se procurar entender os mecanismos desenvolvidos nestes pilares, de maneira a quantificar a influência da forma da seção transversal sobre a capacidade resistente e ductilidade.

Outra limitação deste trabalho foi restringir o carregamento a esforços de compressão axial centrada. Sabe-se que com a presença da excentricidade o desempenho do elemento reforçado pode ser diferente do observado aqui. Logo, o efeito da excentricidade pode ser outro parâmetro a ser considerado. 
A distribuição de pressões laterais ao longo do elemento pode ser útil em pesquisas futuras para avaliar os efeitos do confinamento com camisas de compósitos de fibras de carbono por meio de simulações numéricas. Utilizando-se uma modelagem numérica adequada pode ser possível observar com maiores detalhes o comportamento de pilares com diferentes geometrias e carregamentos e observar as distribuições de esforços internos. 


\section{Referências Bibliográficas}

AHMAD, S. H. ; KHALOO, A.R. ; IRSHAID, A. (1991). Behaviour of concrete spirally confined by fibreglass filaments. Magazine of Concrete Research, v. 43, p. 143-148.

AMERICAN SOCIETY FOR TESTING AND MATERIALS (1995). ASTM D 3039/ D 3039M - Standard test method for tensile properties of polymer matrix composite materials. Philadelphia.

CHEN, W.F. (1988). Constitutive equations for engineering materials. John Wiley $\&$ Sons.

CUSSON, D. ; PAULTRE, P. (1995). Stress-strain model for confined high- strength concrete. Journal of Structural Engineering, v.121, n.3, p. 468-476, March, 1995.

EDWARDS, K.L. (1998). An overview of the technology of fibre-reinforced plastics for design purposes. Materials and Design, v.19, p.1-10.

EL DASH, K.M. ; AHMAD, S.H. (1995). Model for stress-strain relationship of rectangular confined normal and high strength concrete columns. Magazine of Concrete Research, v.47, n.171, p. 177-184, June.

FARDIS, M.N. ; KHALILI, H. (1981). Concrete encased in fiberglass-reinforced plastic. ACI Journal, v. 78, p. 440-446.

FÉDÉRATION INTERNATIONALE DU BÉTON - FIB (1999). Structural concrete: textbook on behaviour, design and performance. Bulletin 1, v.1, p.35-37, p.206-212.

FIORELLI, J. ; DIAS, A.A. (2001). Caracterização mecânica de tecido unidirecional de fibras de carbono e fibras de vidro. In: JORNADAS SAM-CONAMET, Possadas - Missiones, Argentina, 11-14 setembro.

GIBSON, R.F. (1994). Priciples of composite material mechanics. McGraw-Hill. 
DE LORENZIS, L. ; TEPFERS, R. (2001). A comparative study on confinement of concrete cylinders with frp composites. Göteborg, Sweden, Chalmers University of Technology. 73p. Publication 01:04, Work n.46, http://www.bm.chalmers.se/bm9707/Division/Dindex.htm

MANDER, J.B.; PRIETSLEY, M.J.N ; PARK, R.J.T. (1988-a). Observed stressstrain behaviour of confined concrete. Journal of Structural Engineering, v. 114, p. $1827-1849$.

MANDER, J.B.; PRIETSLEY, M.J.N ; PARK, R.J.T. (1988-b). Theoretical stress strain model for confined concrete. Journal of Structural Engineering, v.114, p.1804-1827.

MENDES, H.O. (1993). Dutilidade de elementos de concreto de alta resistência. Rio de Janeiro. Dissertação (Mestrado) - Universidade Federal do Rio de Janeiro.

MIRMIRAN, A. ; ZAGERS, K. ; YUAN, W. (2000). Nonlinear finite element modeling of concrete confined by fiber composites. Finite Elements in Analysis and Design, v. 35, p.79-96.

MIYAUCHI, K. ; NISHIBAYASHI, S. ; INOUE, S. (1997). Estimation of strenghtening effects with carbon fiber sheet for concrete column. In: INTERNATIONAL SYMPOSIUM, 3., Tokyo, Japan, October. Proc. Tokyo, Japan Concrete Institute. v.1, p.217-225.

RAZVI, S.R. ; SAATCIOGLU, M. (1999-b). Confinement model for high-strength concrete. Journal of Structural Engineering, p.281-289, March.

SAADATMANESH, H. ; EHSANI, M.R. (1994). Strength and ductility of concrete columns externally reinforced with fiber composite straps. ACI Structural Journal, v. 91, p.434-447.

SAATCIOGLU, M. ; RAZVI, S.R. (1992). Strength and ductility of confined concrete. Journal of Structural Engineering, v.118, n.6, p.1590-1607, June.

SAMAAN, M. ; MIRMIRAN, A. ; SHAHAWY, M. (1998). Model of concrete confined by fiber composites. Journal of Structural Engineering, v.124, p.10251031.

SHEIKH, S.A. ; UZUMERI, S.M. (1982). Analytical model for concrete confinement in tied columns. Journal of the Structural Division, v.108, p.27032722, December. 
SHEHATA, I.A.E.M.; CARNEIRO, L.A.V.; SHEHATA, L.C.D. (2001). Strength of short concrete columns confined with CFRP sheets. Materials and Structures, v. 35. 


\section{Bibliografia Complementar}

AMERICAN CONCRETE INSTITUTE (1996). ACI 440R - State-of-the-art report on fiber reinforced plastic (FRP) reinforcement for concrete structures. Detroit.

BEBER, A.J. (1999). Avaliação do desempenho de vigas de concreto armado reforçadas com lâminas de fibra de carbono. Porto Alegre. Dissertação (Mestrado) - Universidade Federal do Rio Grande do Sul.

CÁNOVAS, M.F. (1988). Patologia e terapia do concreto armado. São Paulo, Pini. $522 \mathrm{p}$.

CUSSON, D. ; DE LARRARD, F. ; BOULAY, C. ; PAULTRE, P. (1996). Strain localization in confined high-strength concrete columns. Journal of Structural Engineering, v.122, n.9, p.1055-1061, September.

EL DASH, K.M. ; AHMAD, S.H. (1994). Model for the stress-strain relationship of rectangular confined normal and high strength concrete columns. Materials and Structures, v.27, n.9, p. 572-579, December.

FUKUYAMA, H. ; HIGASHIBATA, Y. ; MIYAUCHI, Y. (2000). Studies on repair and strengthening methods of damaged reinforced concrete columns. Cement \& Concrete Composites, v.22, p. 81-88.

HELENE, P.R.L. (1992). Manual para reparo reforço e proteção de estrutura de concreto. 2.ed. São Paulo, PINI. 203p.

HOSOTANI, M. ; KAWASHIMA, K. ; HOSHIKUMA, J. (1997). A study on confinement effect of concrete cylinders by carbon fiber sheets. In: INTERNATIONAL SYMPOSIUM, 3., Tokyo, Japan, October. Proc. Tokyo, Japan Concrete Institute. v.1, p.209-217.

HOWIE, I.; CASTRO, P.F.; KARBHARI, V.M. (1996). Um estudo experimental sobre reforço de colunas de concreto com manta compósita. Revista IBRACON, v.4, n.12, p.13-18, abril.

LIU, J. ; FOSTER, S.J. (1999). A three-dimensional finite element model for confined concrete structures. Computers \& Structures, v. 77, p. 441-451. 
MARGARIDO, A.F. ; IAGHER, H. ; BOSCOV, P. (1994). Polímeros com fibras no reforço de estruturas de concreto armado. In: REUNIÃO DO INSTITUTO BRASILEIRO DE CONCRETO, 36., Porto Alegre, setembro. Anais. Porto Alegre, IBRACON. p.163-173.

MEHTA, P.K. ; MONTEIRO, P.J.M. (1994). Concreto: estrutura, propriedades e materiais. São Paulo, Pini.

MIRMIRAN, A. ; SAMAAN, M. ; CABRERA, S. (1998). Design, manufacture and testing of a new hibrid column. Construction and Building Materials, v.12, n.1, p.39-49.

PARK, R.J.T. ; PRIETSLEY, M.J.N (1982). Ductility of square-confined concrete columns. Journal of Structural Division, v.108, p.929-950.

PILAKOUTAS, K. ; MORTAZAVI, A.A. (1997). Ductility through external lateral confinement of RC members with FRP. In: INTERNATIONAL SYMPOSIUM, 3., Tokyo, Japan, October. Proc. Tokyo, Japan Concrete Institute. v.1, p.225233.

RAZVI, S.R. ; SAATCIOGLU, M. (1999-a). Circular high-strength concrete columns under concentric compression. ACI Structural Journal, p.817-825, September/October.

RIPPER, T. ; SCHERER, J. (1999). Avaliação do desempenho de plásticos armados com fibras de carbono como elemento de reforço de vigas de betão armado. In: REUNIÃO DO INSTITUTO BRASILEIRO DE CONCRETO, 41., Salvador, setembro, 1999. Anais. Salvador, IBRACON.

SHEIKH, S.A. (1981). A comparative study of confinement models. ACI Structural Journal, p.296-306, July/August.

SOUZA, V.C.; RIPPER, T. (1998). Patologia, recuperação e reforço de estruturas. São Paulo, Pini.

TAKEUTI, A.R. (1999). Reforço de pilares de concreto armado por meio de encamisamento com concreto de alto desempenho. São Carlos. 184p. Dissertação (Mestrado) - Escola de Engenharia de São Carlos, Universidade de São Paulo. 


\section{APÊNDICE I - Diagramas força-deslocamento}

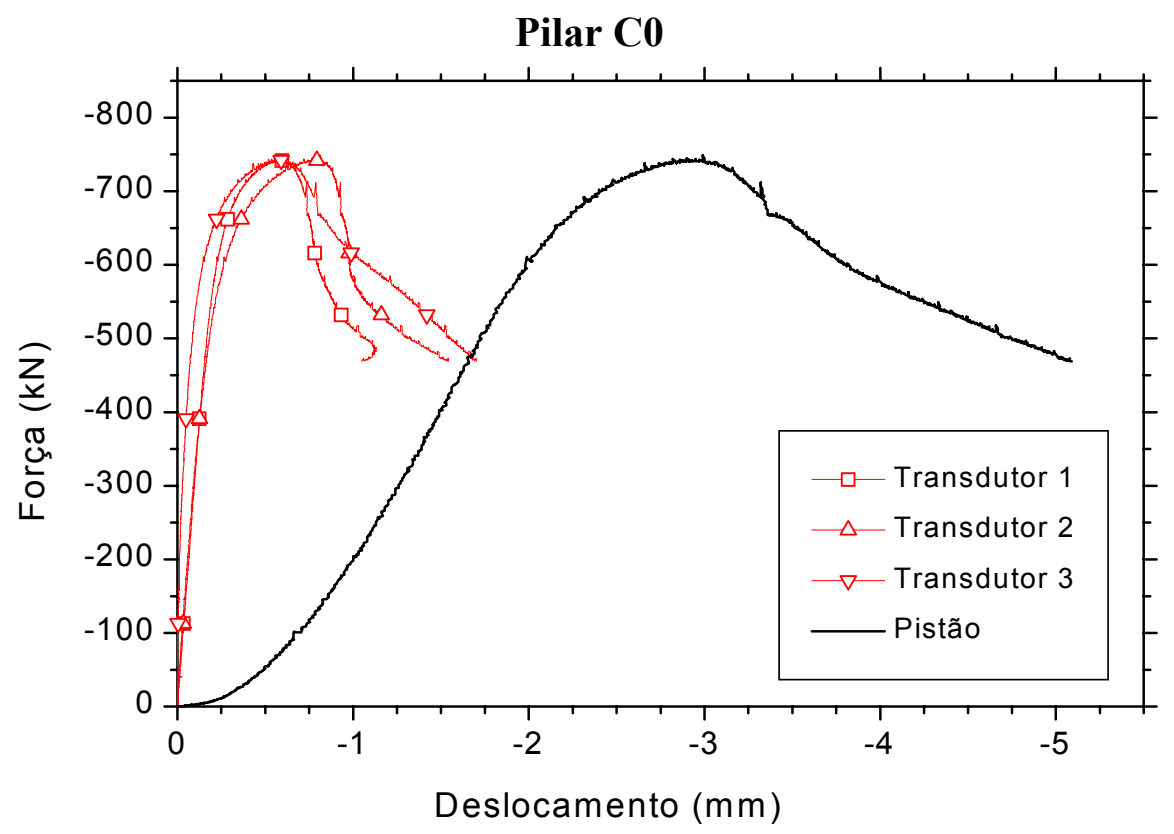

Pilar C1

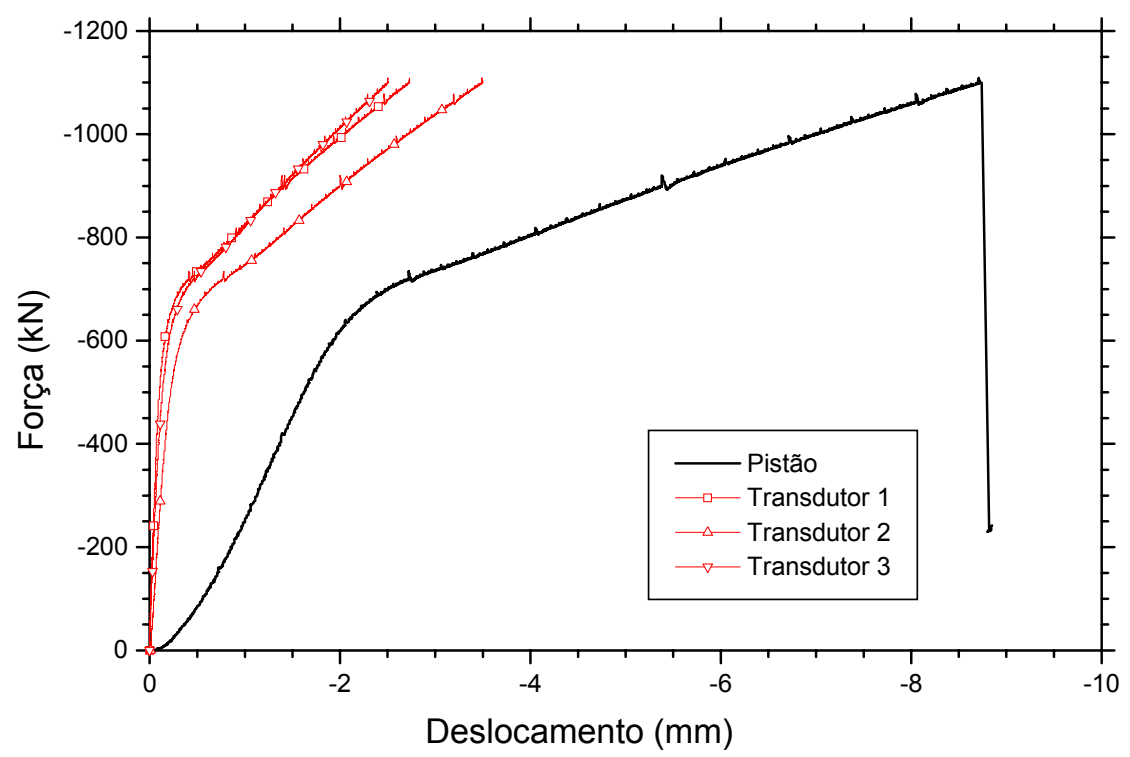


Pilar C2

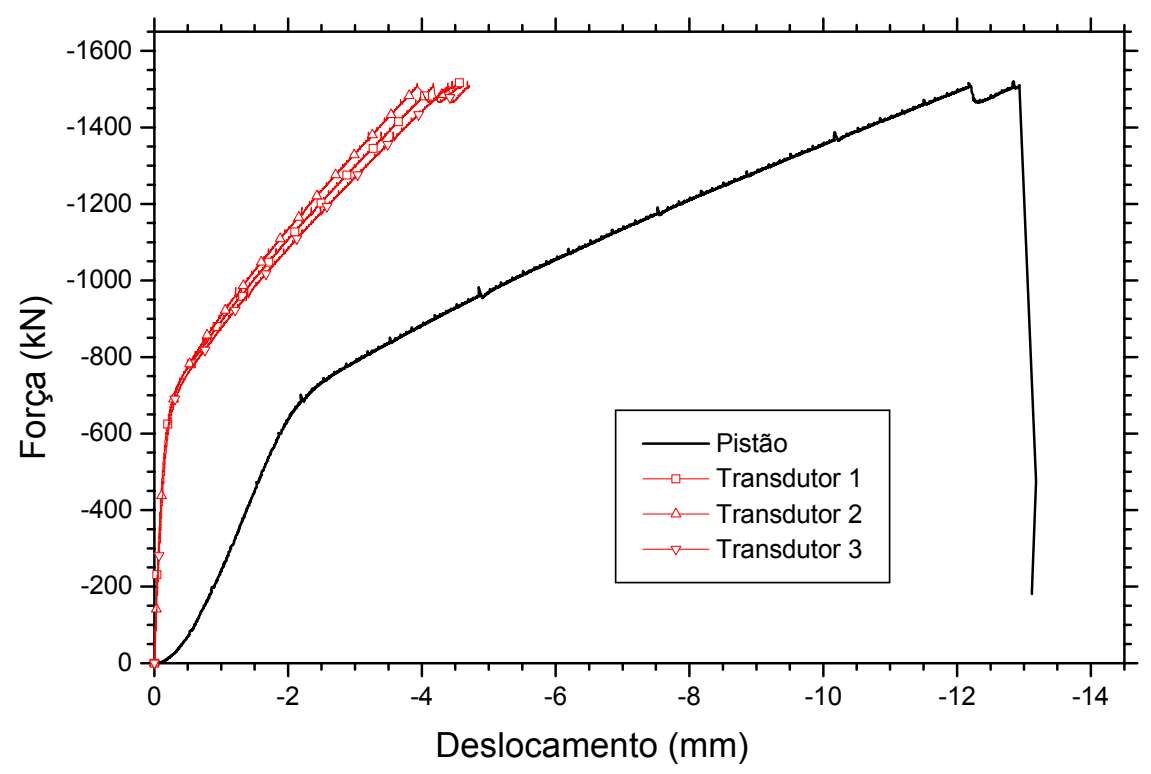

Pilar C0S50

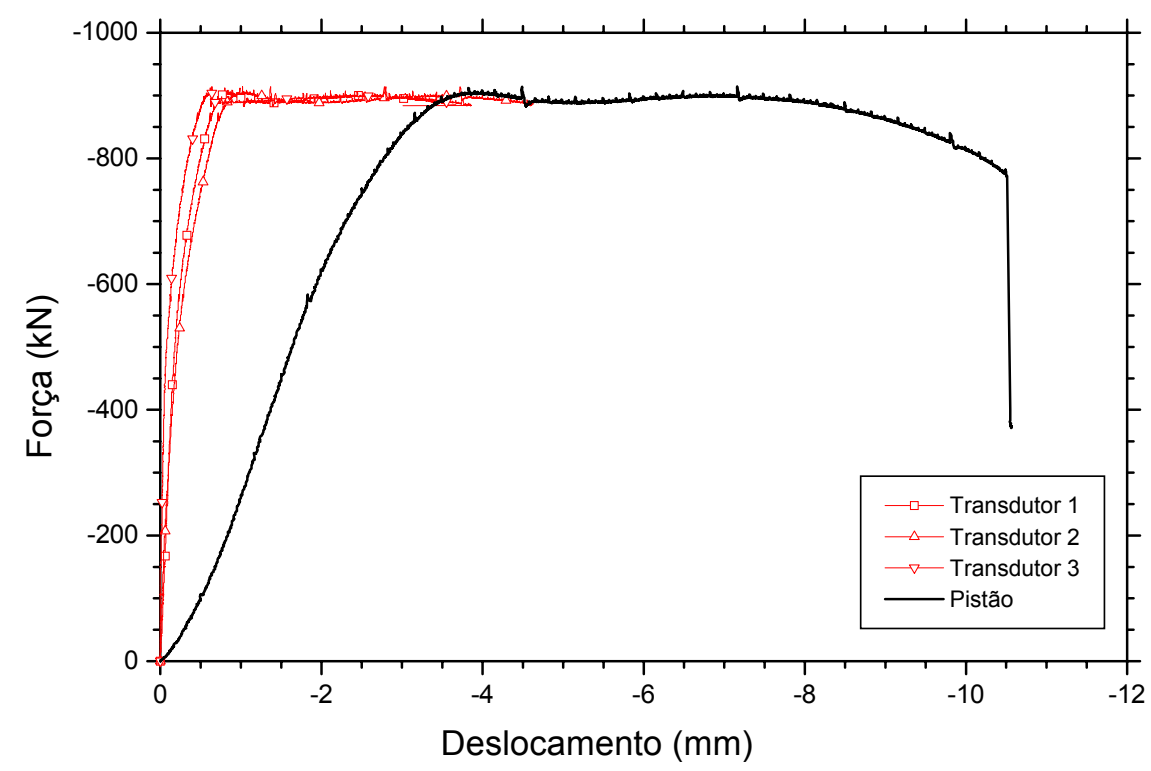


Pilar C1S50

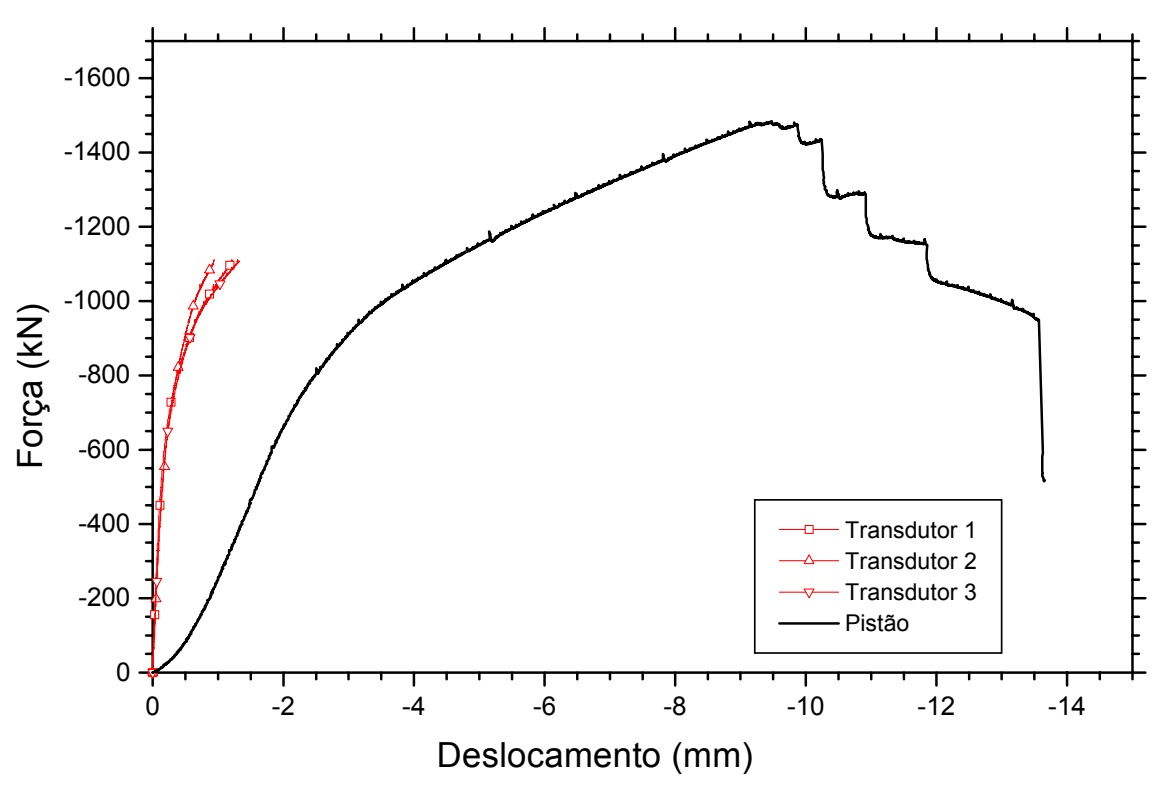

Pilar C2S50

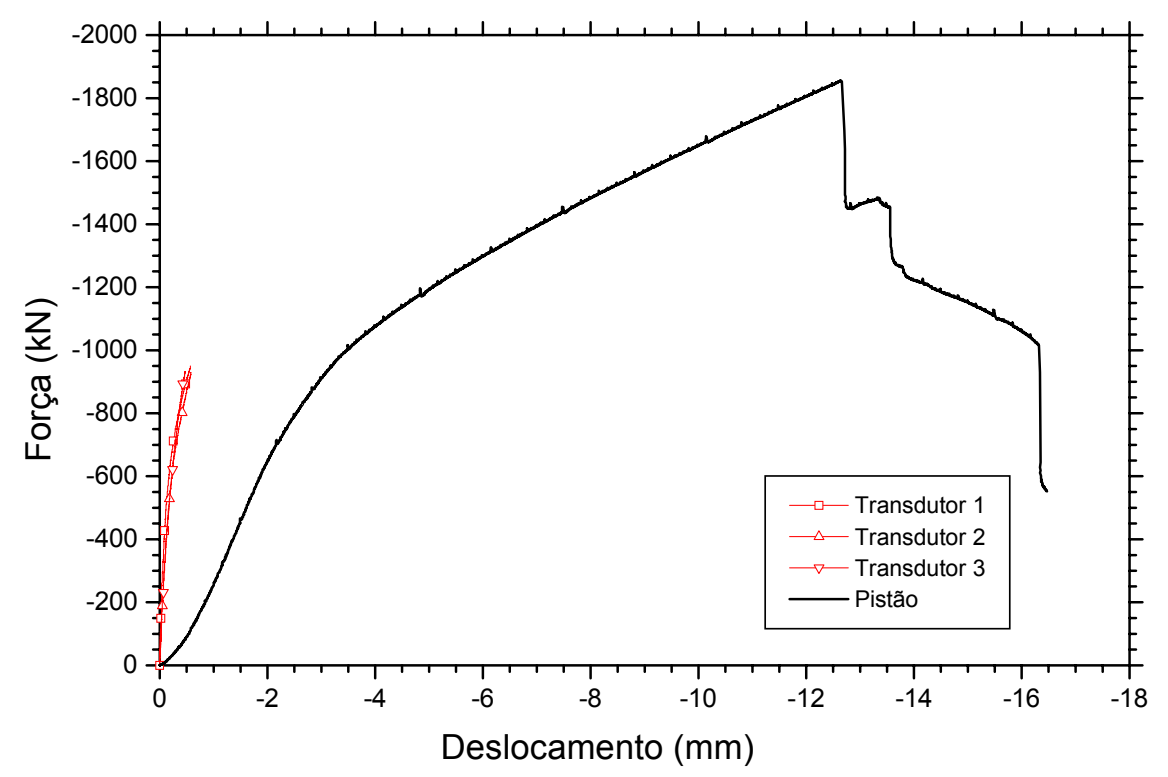


Pilar C0S25

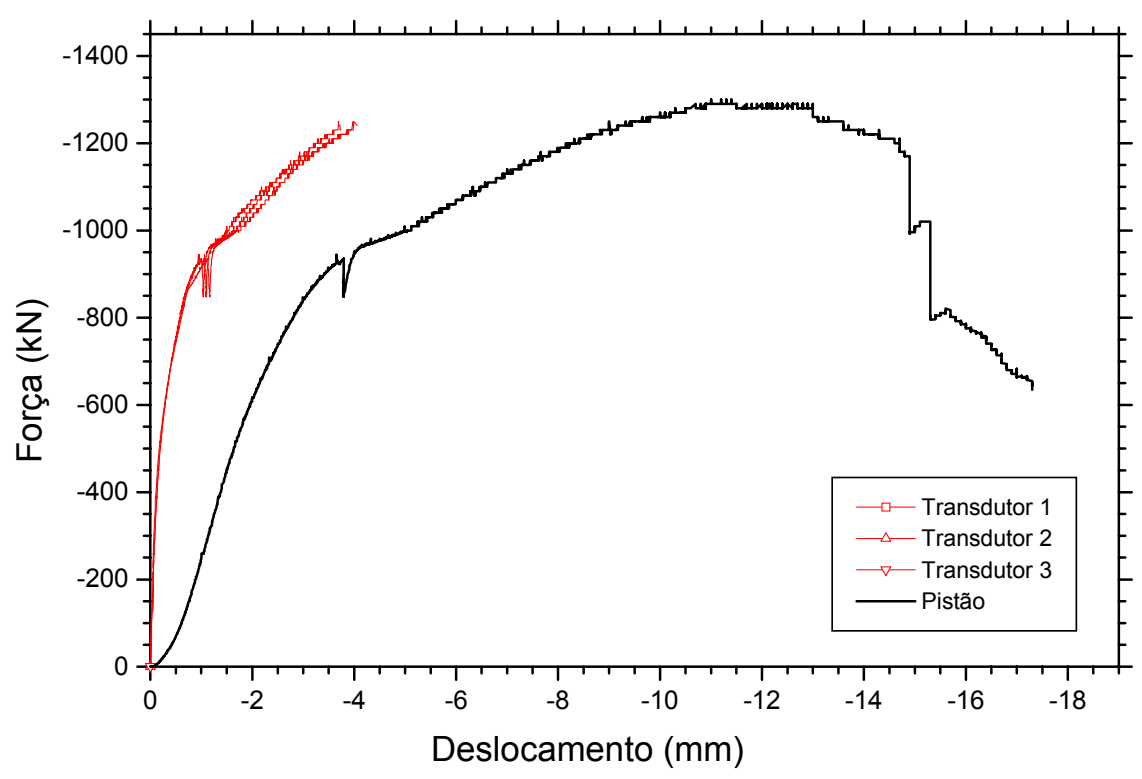

Pilar C1S25

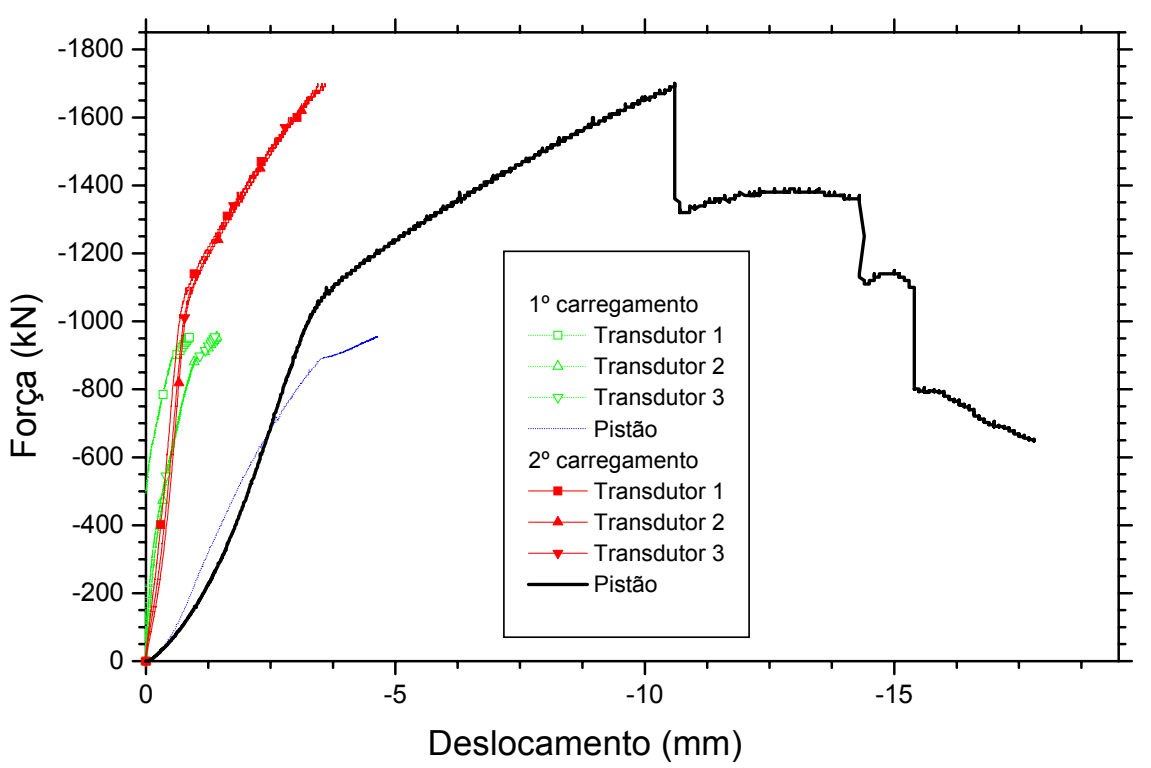


Pilar C2S25

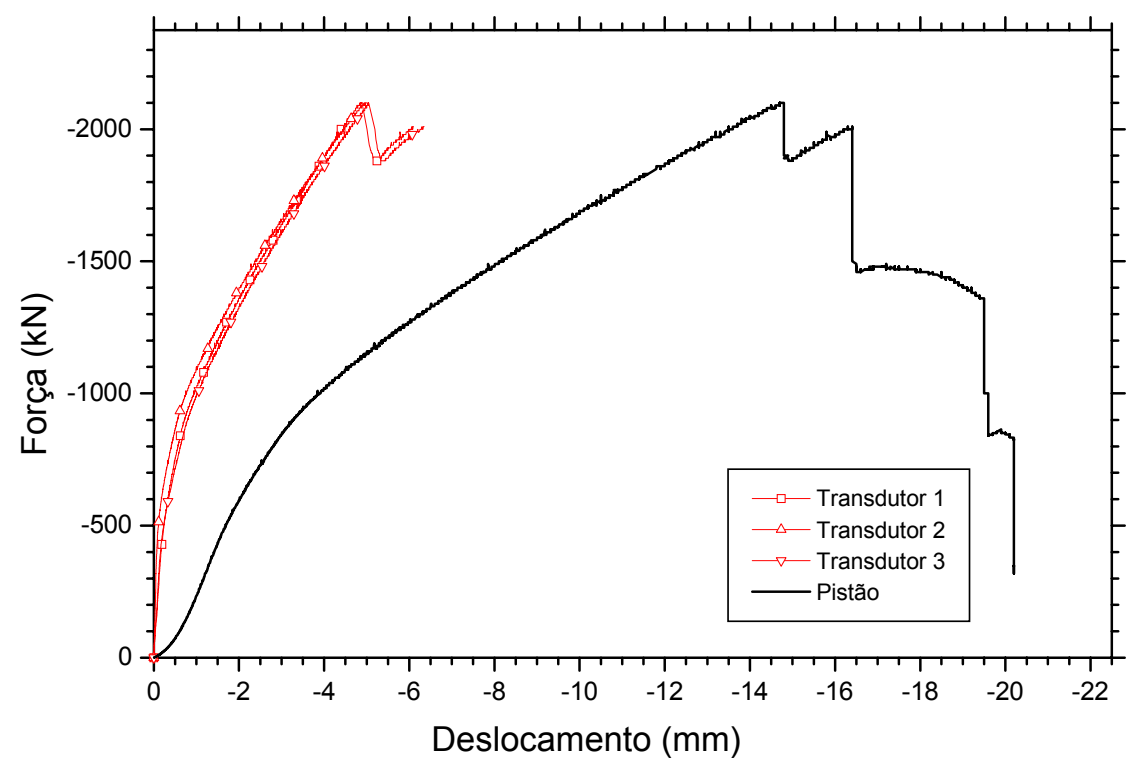

Pilar Q0

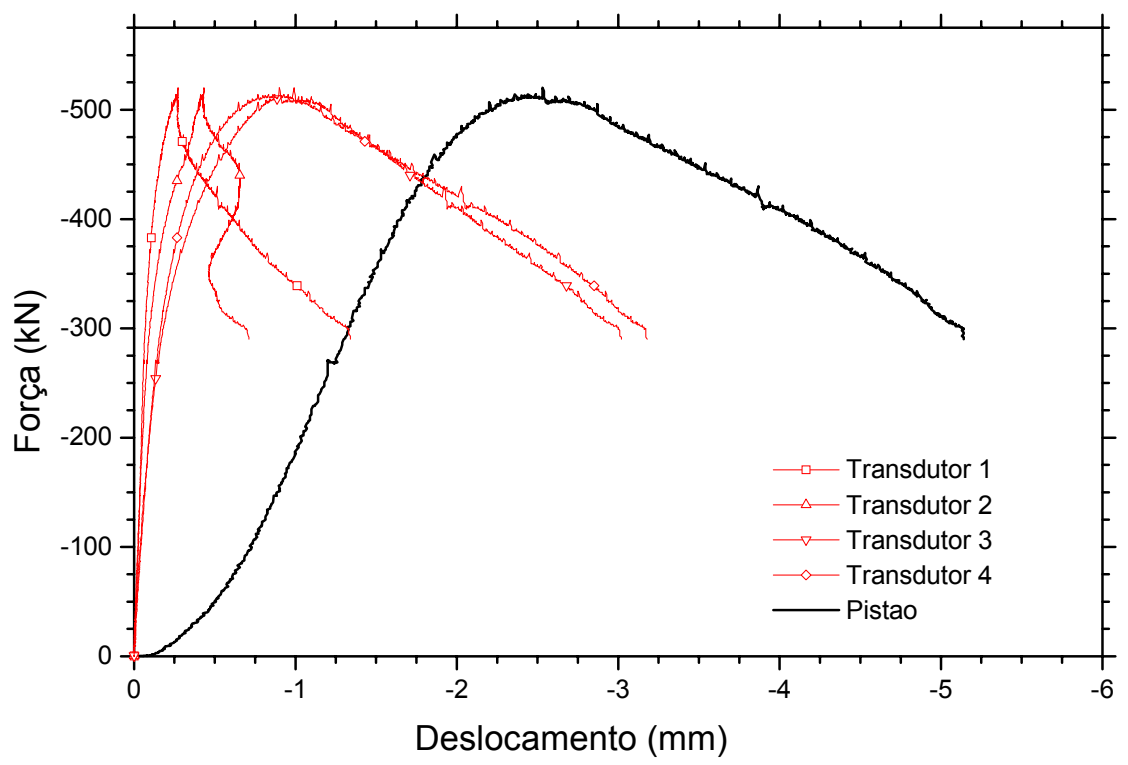


Pilar Q1

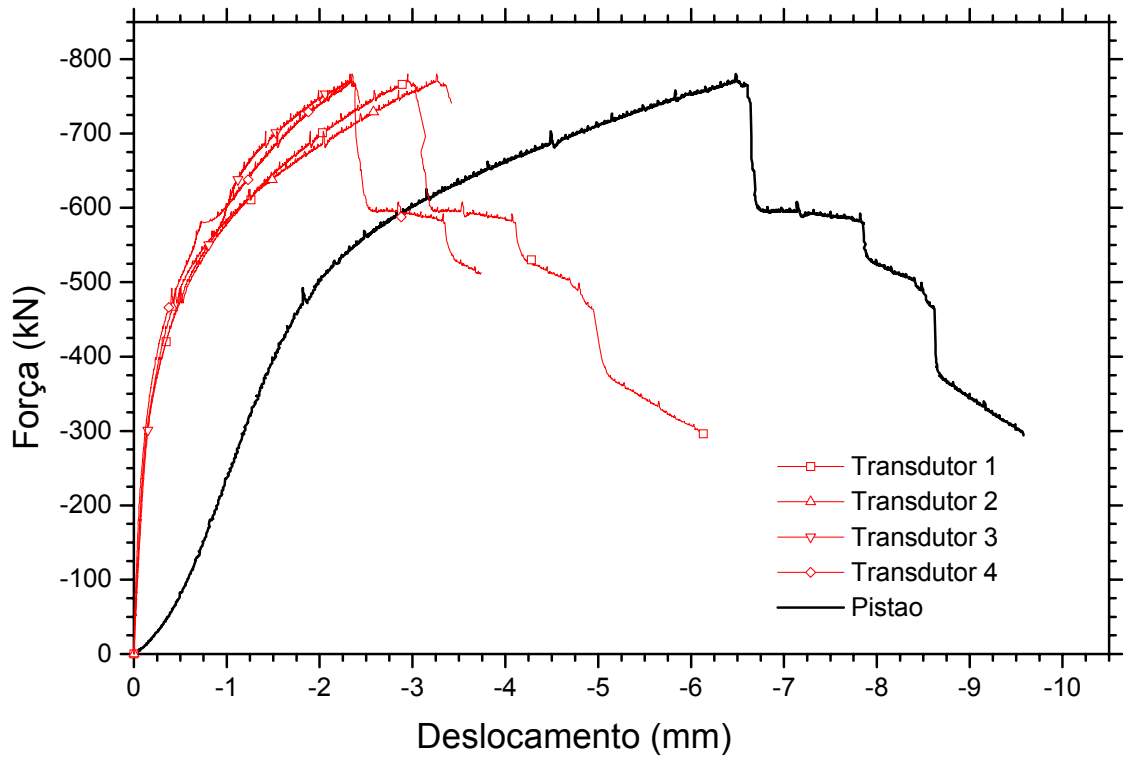

Pilar Q2

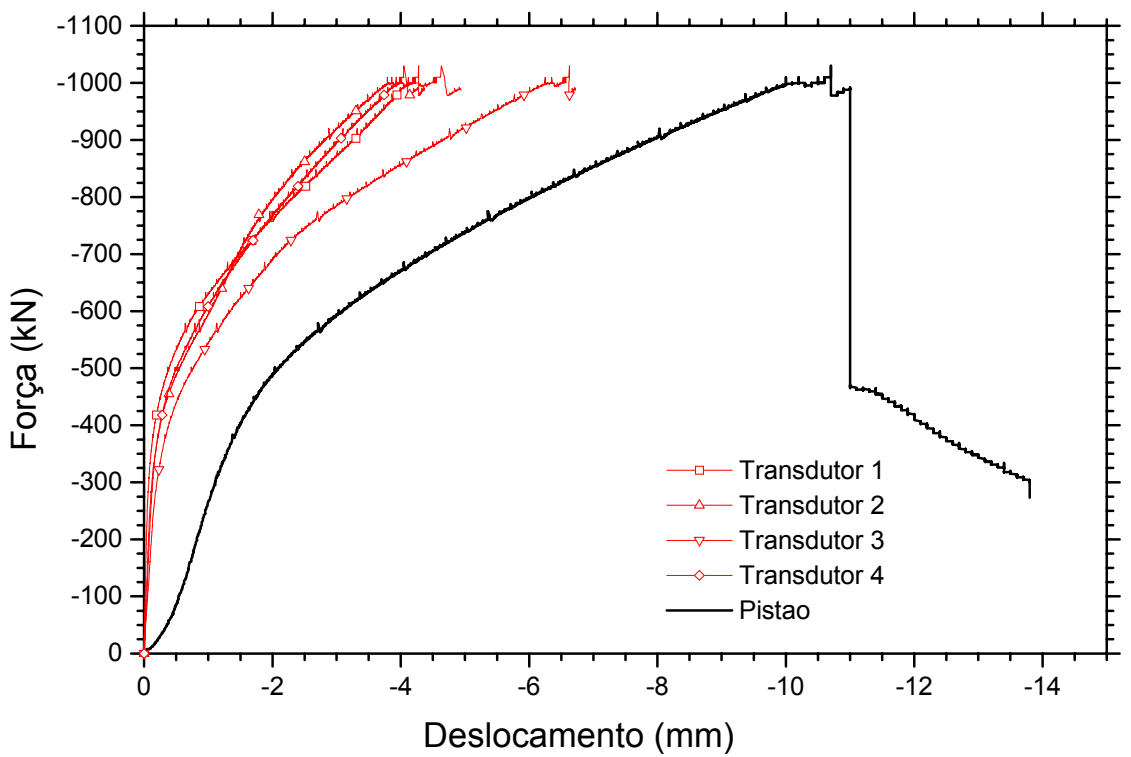




\section{APÊNDICE II - Fotos dos ensaios dos pilares}

\section{PILAR C0}
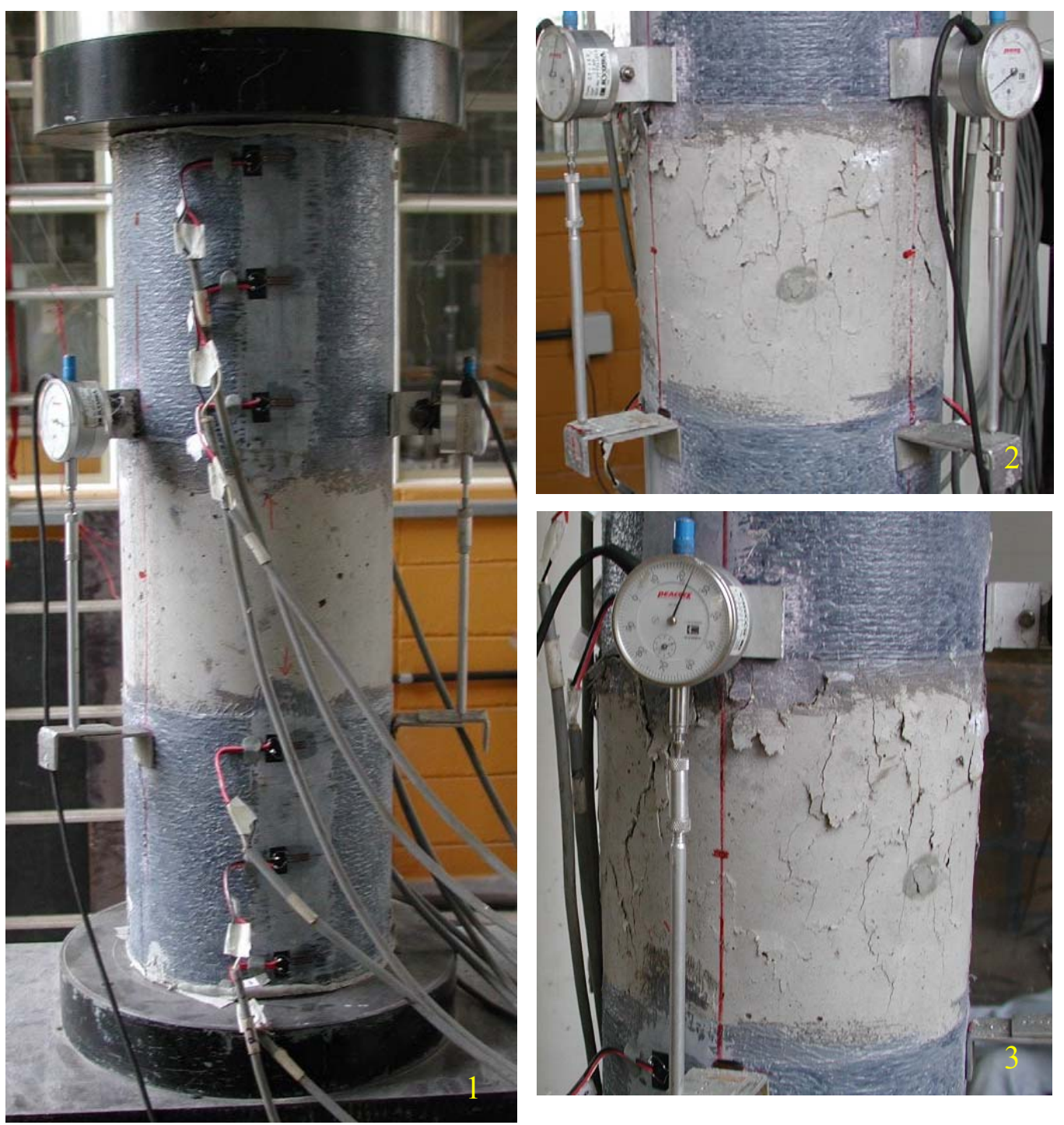

Foto 1 - Modelo preparado para o ensaio

Fotos 2 e 3 - Fissuração do concreto 
PILAR C1
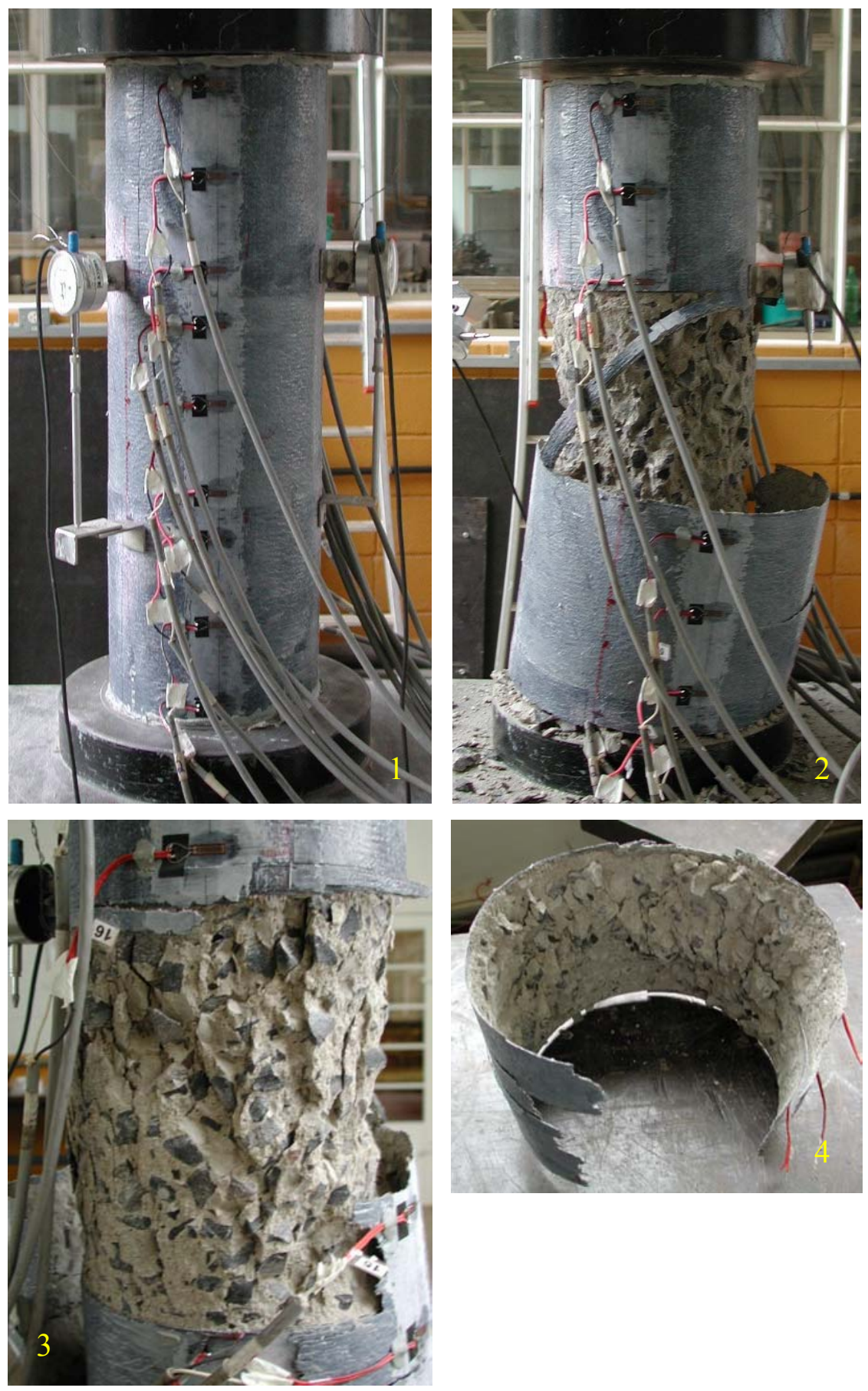

Foto 1 - Modelo preparado para o ensaio

Foto 2 - Ruptura da camisa de reforço

Foto 3 - Detalhe do concreto após a ruptura da camisa de reforço

Foto 4 - Detalhe de parte da camisa de reforço após o ensaio 
PILAR C2
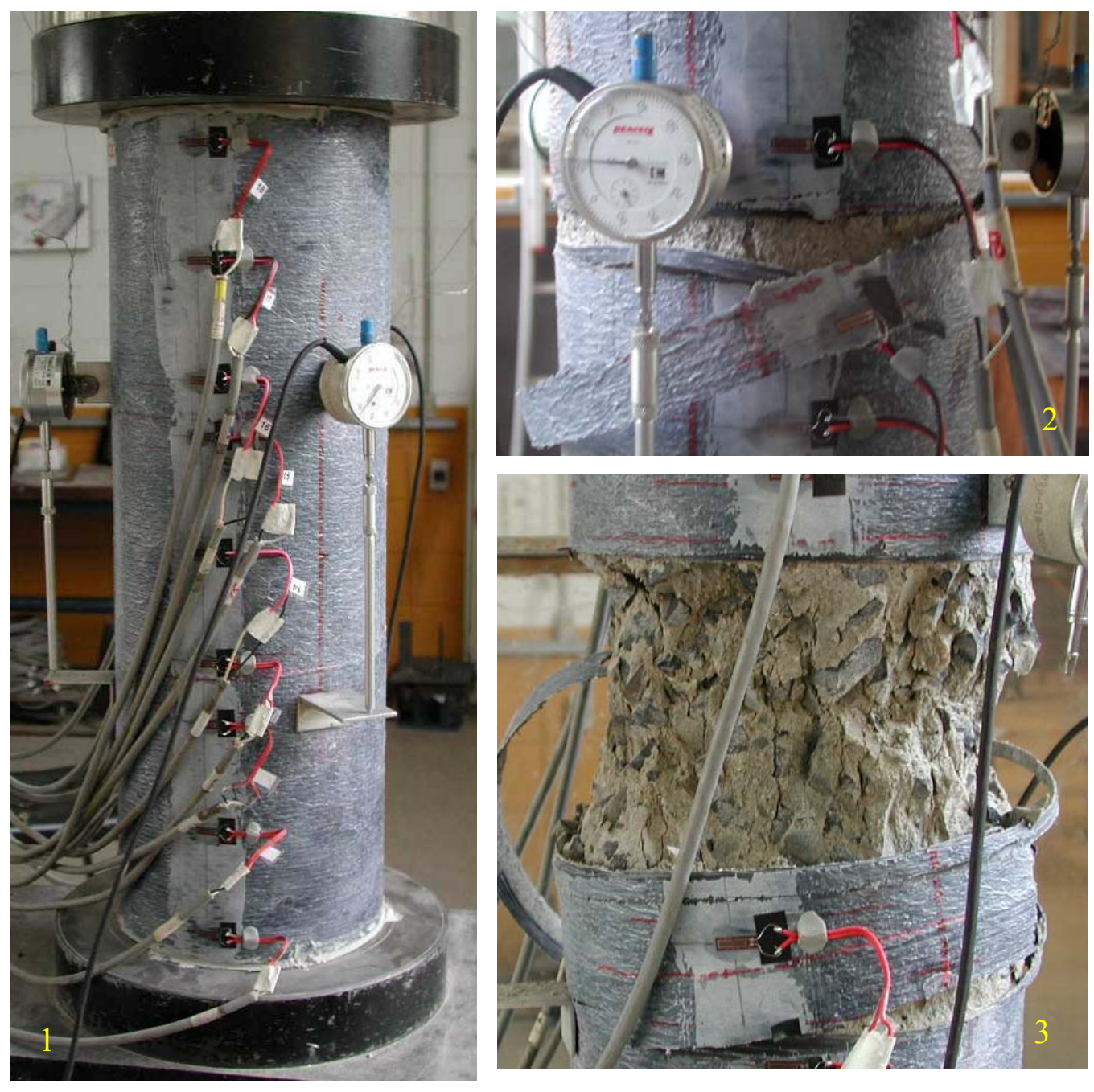

Foto 1 - Modelo preparado para o ensaio

Fotos 2 e 3 - Ruptura da camisa de reforço 
PILAR C0S50
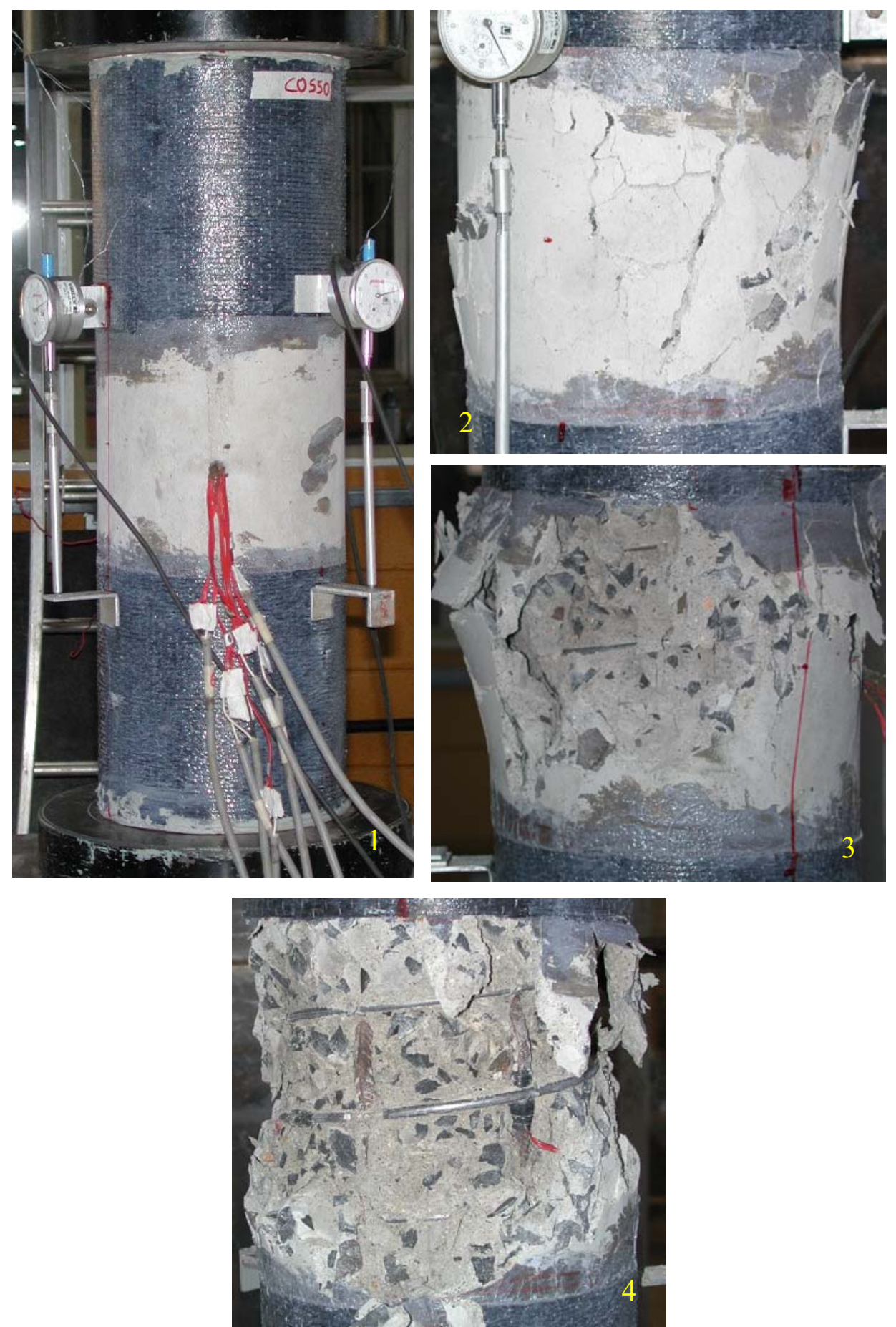

Foto 1 - Vista do modelo antes do ensaio

Foto 2 - Fissuração do concreto do cobrimento

Foto 3 - Desprendimento do concreto do cobrimento

Foto 4 - Ruptura da espiral 
PILAR C1S50
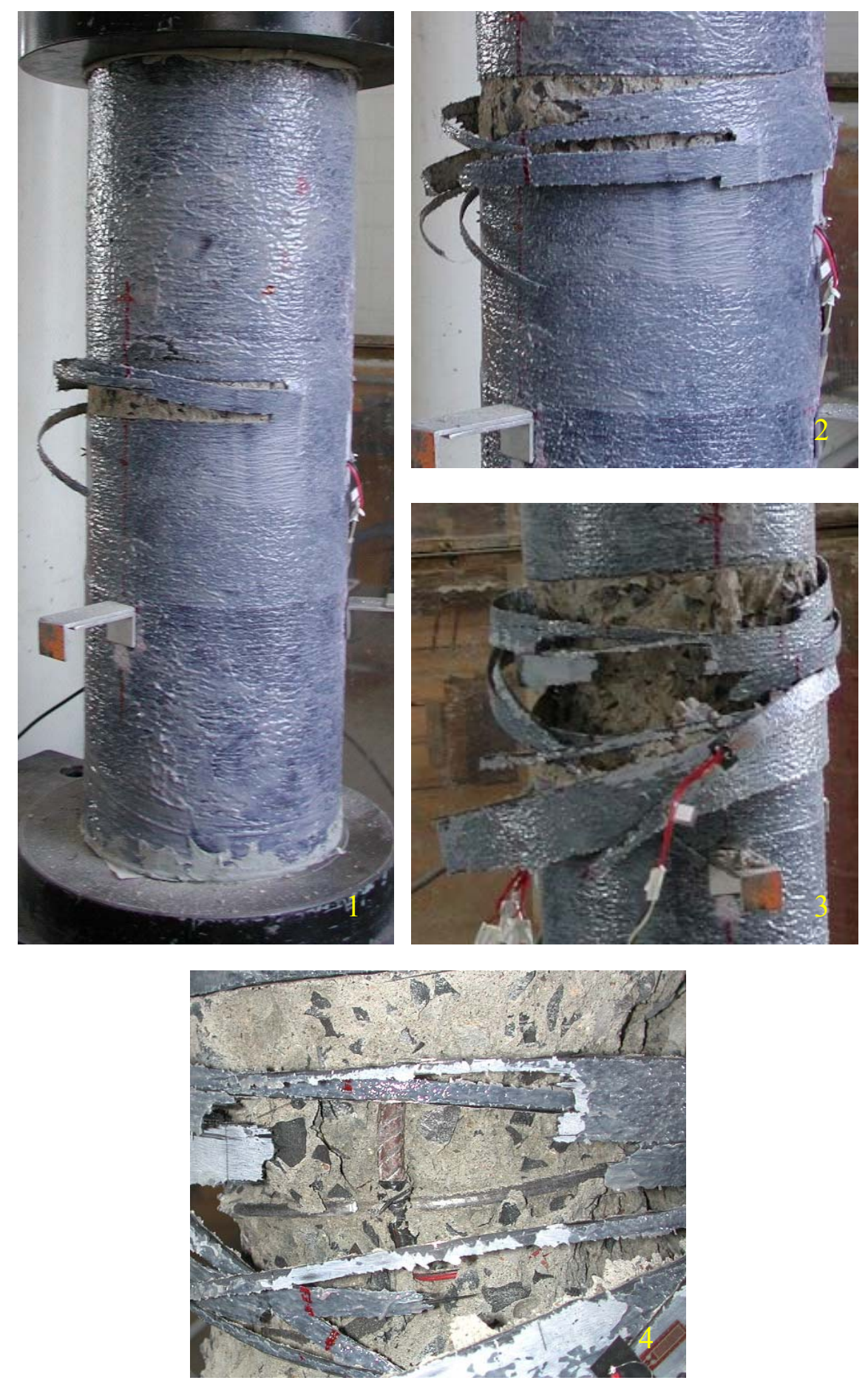

Fotos 1 a 3 - Ruptura da camisa de reforço

Foto 4 - Ruptura da espiral 
PILAR C2S50
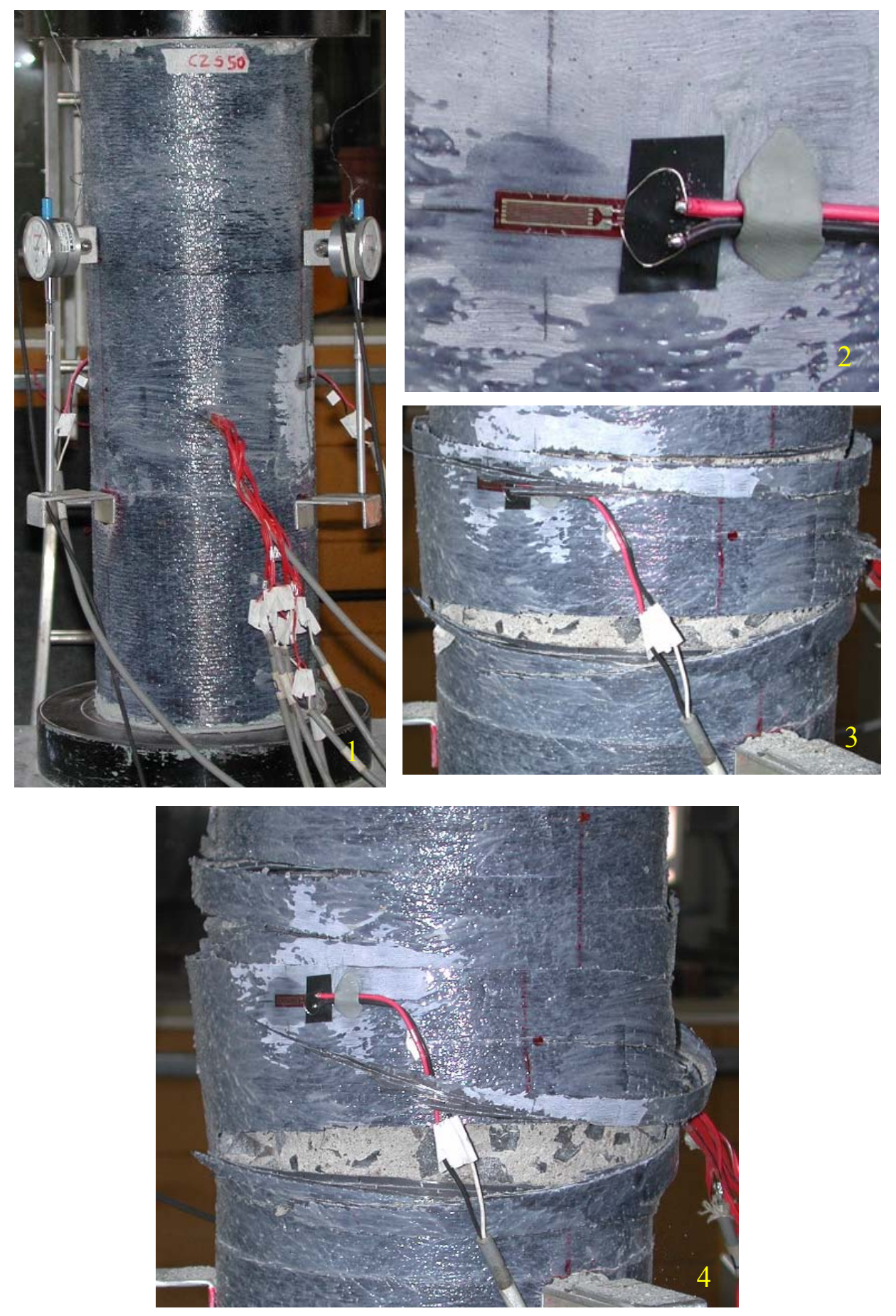

Foto 1 - Vista do modelo antes do ensaio

Foto 2 - Detalhe da fixação de extensômetro

Fotos 3 e 4 - Ruptura da camisa de reforço 
PILAR C0S25
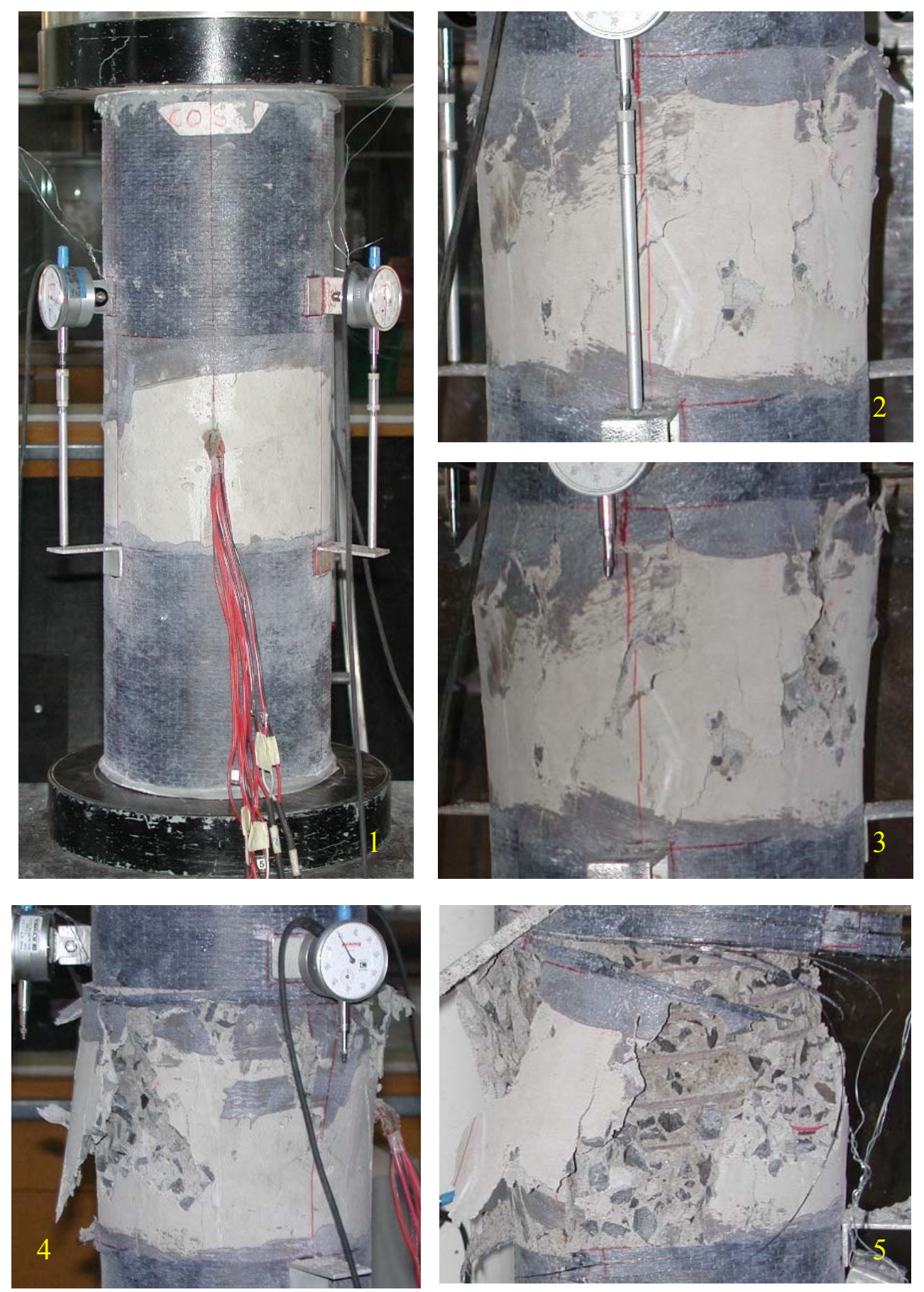

Foto 1 - Vista do modelo antes do ensaio

Fotos 2 e 3 - Fissuração do concreto do cobrimento

Foto 4 - Desprendimento do concreto do cobrimento

Foto 5 - Detalhe da espiral 
PILAR C1S25
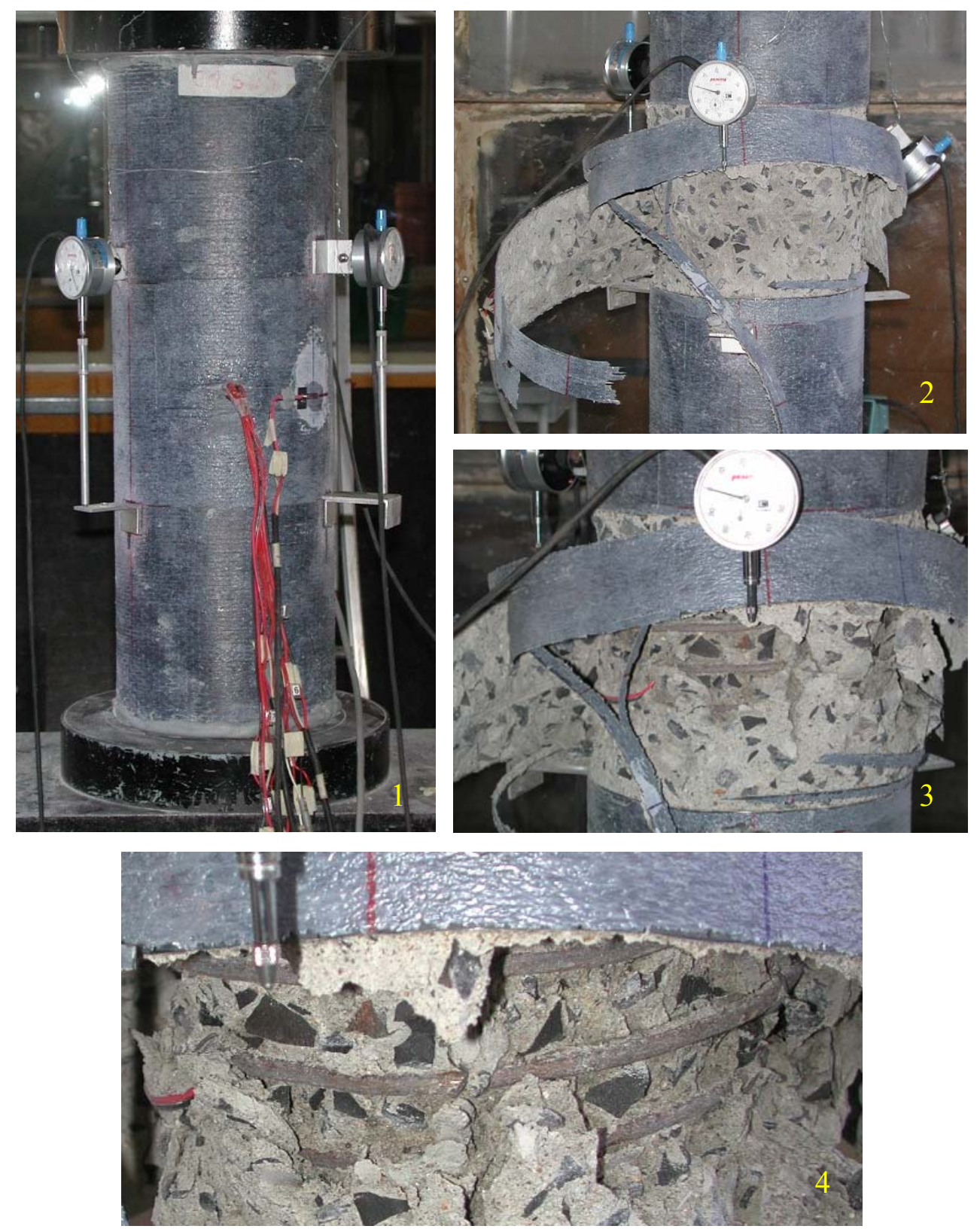

Foto 1 - Vista do modelo antes do ensaio

Foto 2 - Ruptura da camisa de reforço

Foto 3 - Detalhe da espiral

Foto 4 - Ruptura da espiral 
PILAR C2S25
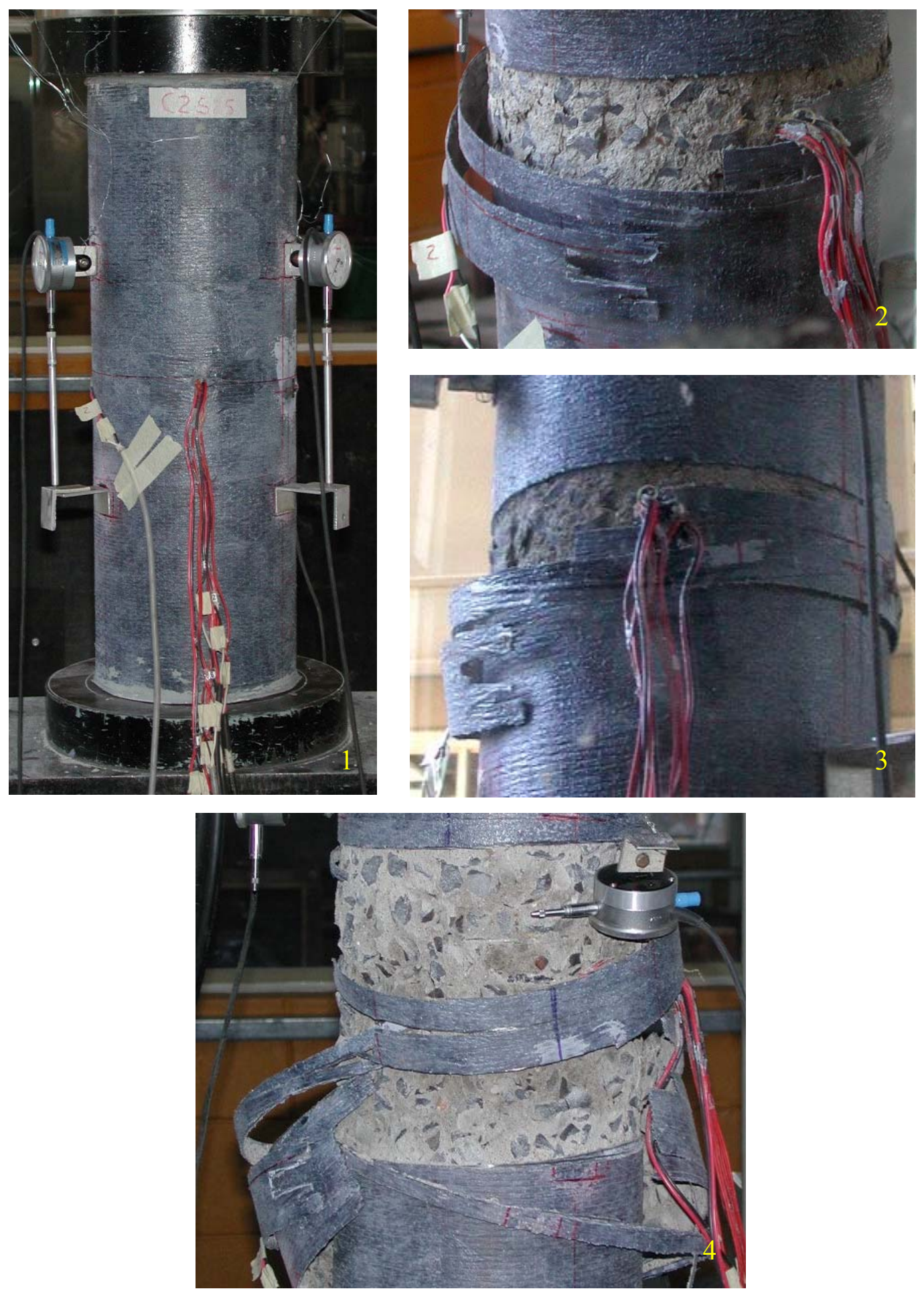

Foto 1 - Vista do modelo antes do ensaio

Fotos 2 a 4 - Ruptura da camisa de reforço 
PILAR Q0
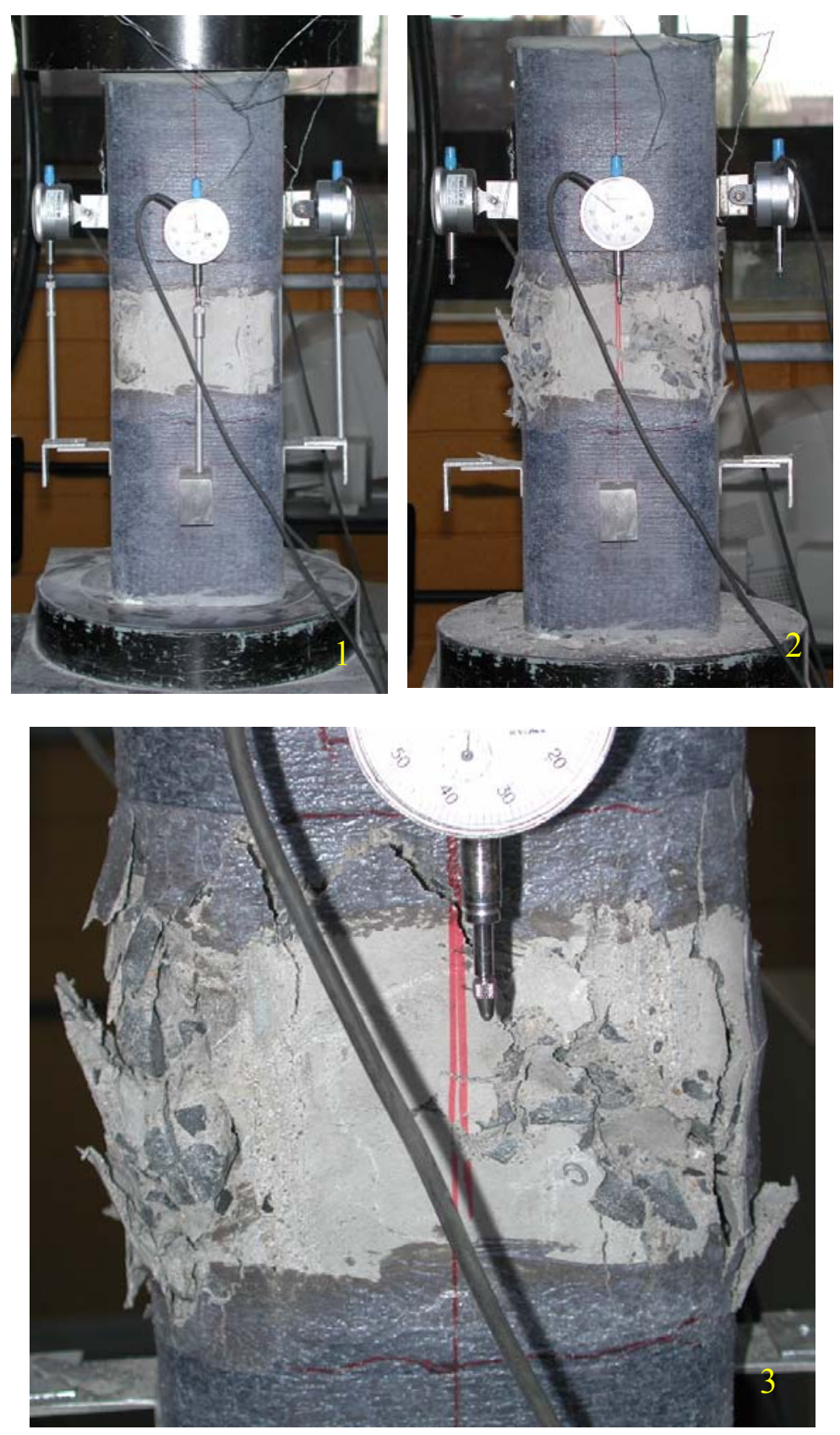

Foto 1 - Vista do modelo antes do ensaio

Foto 2 - Vista do modelo após o ensaio

Foto 3 - Detalhe do concreto após o ensaio 
PILAR Q1
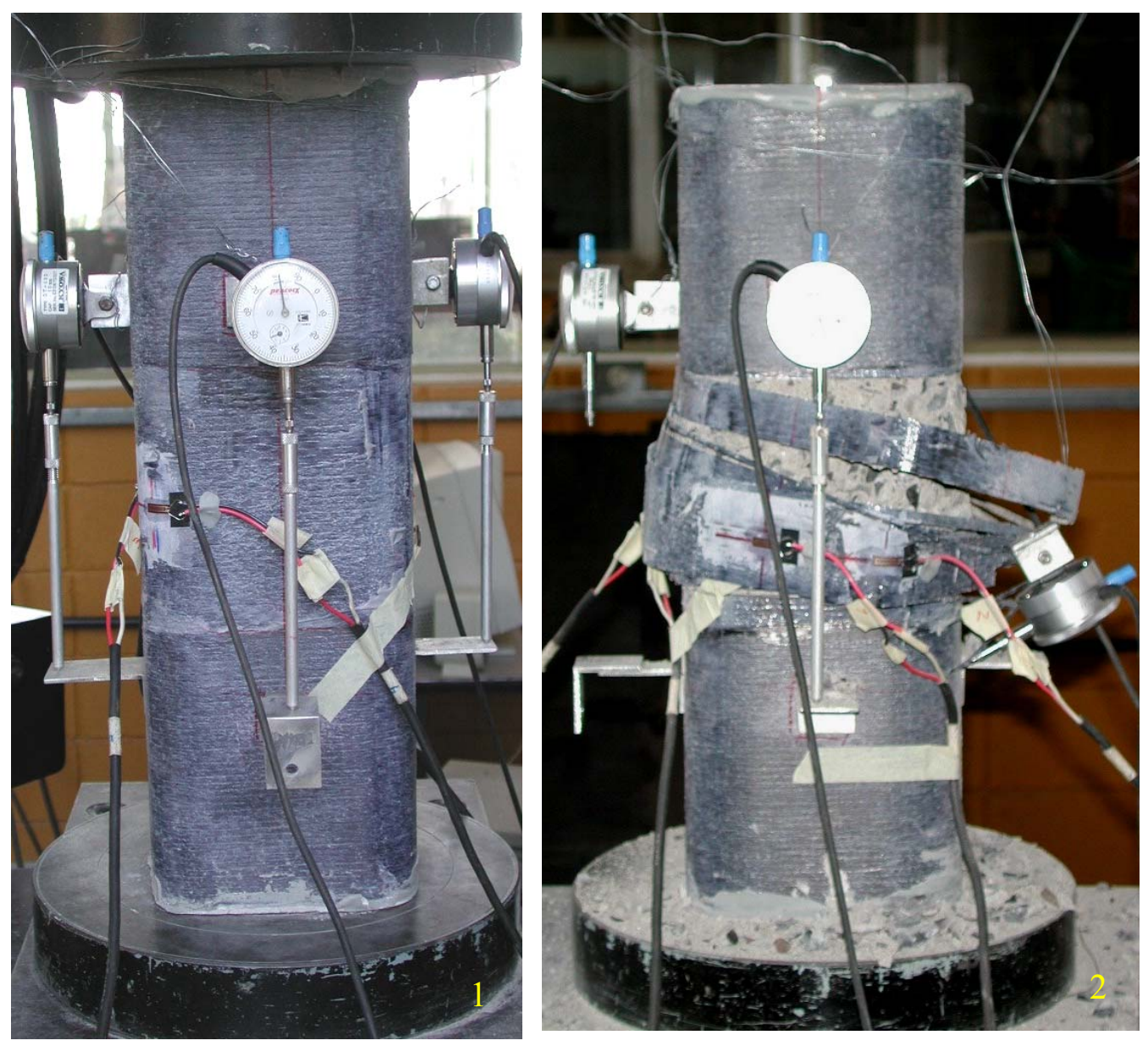

Foto 1 - Vista do modelo antes do ensaio

Foto 2 - Vista do modelo após o ensaio 
PILAR Q2
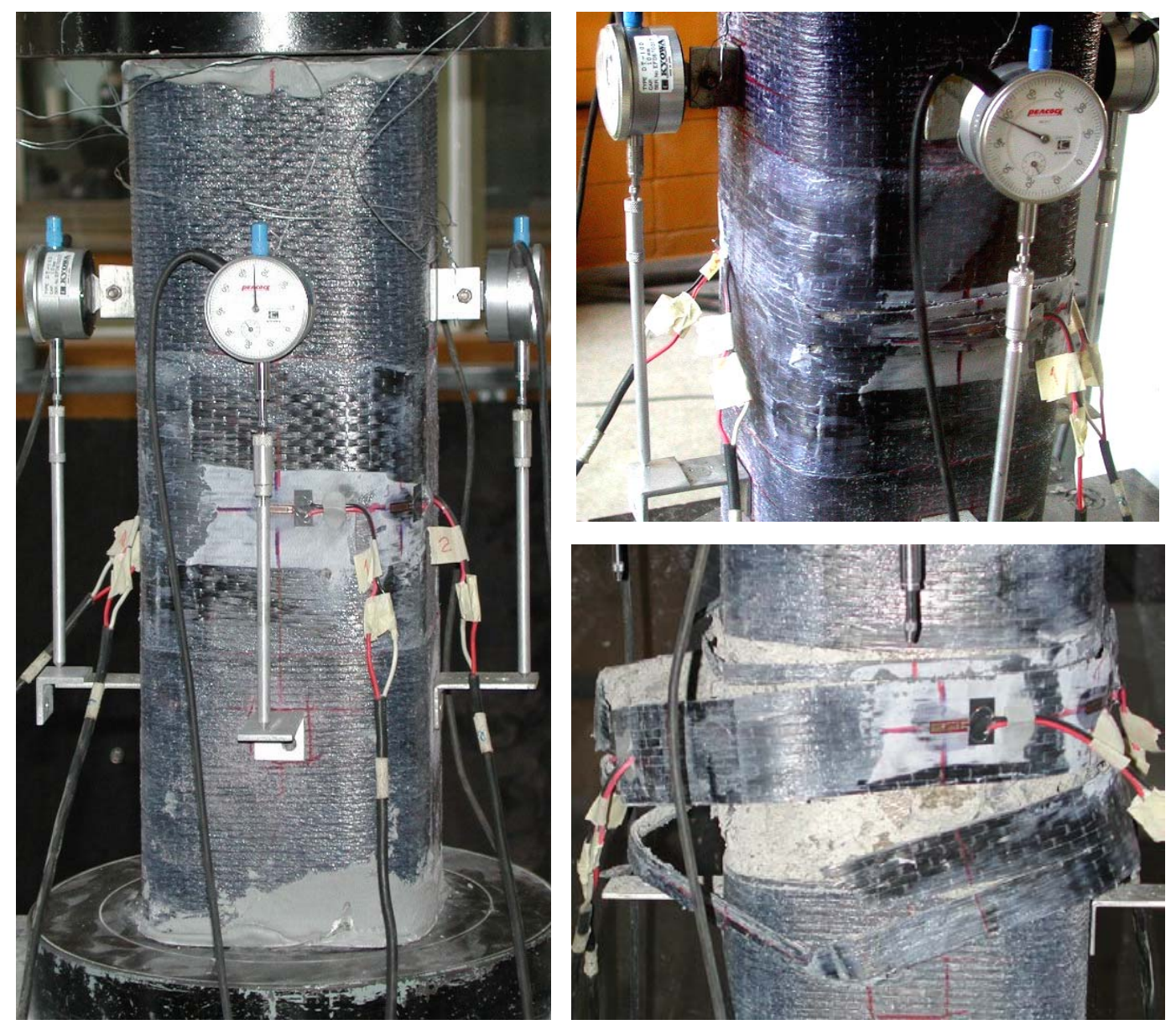

Foto 1 - Vista do modelo antes do ensaio

Fotos 2 e 3 - Ruptura da camisa de reforço 